San Jose State University

SJSU ScholarWorks

Mineta Transportation Institute Publications

$10-2020$

\title{
Promoting Transit-Oriented Developments by Addressing Barriers Related to Land Use, Zoning, and Value Capture
}

Shishir Mathur

San Jose State University

Aaron Gatdula

Mineta Transportation Institute

Follow this and additional works at: https://scholarworks.sjsu.edu/mti_publications

Part of the Infrastructure Commons, Public Policy Commons, and the Transportation Commons

\section{Recommended Citation}

Shishir Mathur and Aaron Gatdula. "Promoting Transit-Oriented Developments by Addressing Barriers Related to Land Use, Zoning, and Value Capture" Mineta Transportation Institute Publications (2020). https://doi.org/10.31979/mti.2020.1819

This Report is brought to you for free and open access by SJSU ScholarWorks. It has been accepted for inclusion in Mineta Transportation Institute Publications by an authorized administrator of SJSU ScholarWorks. For more information, please contact scholarworks@sjsu.edu. 
SJSU

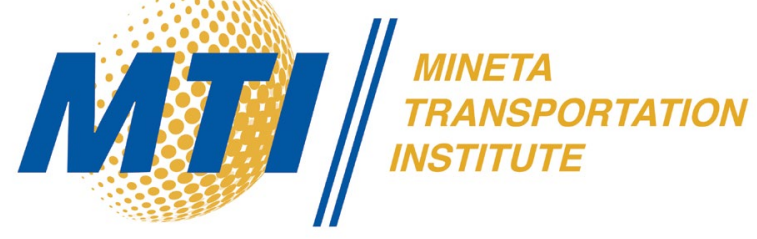

Promoting Transit-Oriented Developments by

Addressing Barriers Related to Land Use, Zoning, and Value Capture

Shishir Mathur, PhD

Aaron Gatdula, MCP
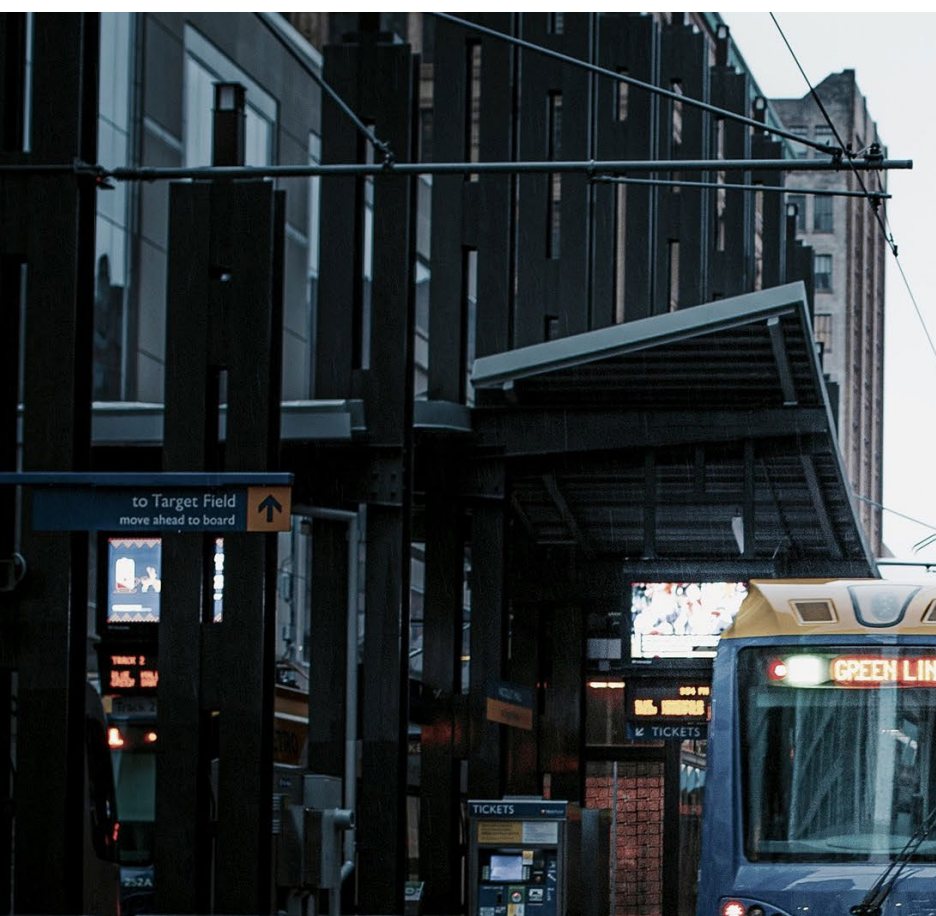

$P$




\section{MINETA TRANSPORTATION INSTITUTE \\ LEAD UNIVERSITY OF \\ Mineta Consortium for Transportation Mobility}

Founded in 1991, the Mineta Transportation Institute (MTI), an organized research and training unit in partnership with the Lucas College and Graduate School of Business at San José State University (SJSU), increases mobility for all by improving the safety, efficiency, accessibility, and convenience of our nation's transportation system. Through research, education, workforce development, and technology transfer, we help create a connected world. MTI leads the four-university Mineta Consortium for Transportation Mobility, a Tier I University Transportation Center funded by the U.S. Department of Transportation's Office of the Assistant Secretary for Research and Technology (OST-R), the California Department of Transportation (Caltrans), and by private grants and donations.

MTl's transportation policy work is centered on three primary responsibilities:

\section{Research}

MTI works to provide policy-oriented research for all levels of government and the $P$ rivate sector to foster the development of optimum surface transportation systems. Research areas include: bicycle and pedestrian issues; financing public and private sector transportation improvements; intermodal connectivity and integration; safety and security of transportation systems; sustainability of transportation systems; transportation / land use / environment; and transportation planning and policy development. Certified Research Associates conduct the research. Certification requires an advanced degree, generally a Ph.D., a record of academic publications, and professional references. Research projects culminate in a peer-reviewed publication, available on TransWeb, the MTI website (http://transweb.sjsu.edu).

\section{Education}

The Institute supports education programs for students seeking a career in the development and operation of surface transportation systems. MTI, through San José State University, offers an AACSBaccredited Master of Science in Transportation Management and graduate certificates in Transportation Management,Transportation Security, and High-Speed Rail Management that serve to prepare the nation's transportation managers for the 2 I st century. With the active assistance of the California Department of Transportation (Caltrans), MTI delivers its classes over a state-of-the-art videoconference network throughout the state of California and via webcasting beyond, allowing working transportation professionals to pursue an advanced degree regardless of their location. To meet the needs of employers seeking a diverse workforce, MTl's education program promotes enrollment to under-represented groups.

\section{Information and Technology Transfer}

MTI utilizes a diverse array of dissemination methods and media to ensure research results reach those responsible for managing change. These methods include publication, seminars, workshops, websites, social media, webinars, and other technology transfer mechanisms. Additionally, MTI promotes the availability of completed research to professional organizations and journals and works to integrate the research findings into the graduate education program.MTI's extensive collection of transportation- related publications is integrated into San José State University's world-class Martin Luther King, Jr. Library.

\section{Disclaimer}

The contents of this report reflect the views of the authors, who are responsible for the facts and accuracy of the information presented herein. This document is disseminated in the interest of information exchange. The report is funded, partially or entirely, by a grant from the U.S. Department of Transportation's University Transportation Centers Program. This report does not necessarily reflect the official views or policies of the U.S. government, State of California, or the Mineta Transportation Institute, who assume no liability for the contents or use thereof. This report does not constitute a standard specification, design standard, or regulation. 
REPORT 20-35

\section{PROMOTING TRANSIT-ORIENTED DEVELOPMENTS BY ADDRESSING BARRIERS RELATED TO LAND USE, ZONING, AND VALUE CAPTURE}

Shishir Mathur, $\mathrm{PhD}$

Aaron Gatdula, MCP

October 2020

A publication of

Mineta Transportation Institute

Created by Congress in 1991

College of Business

San José State University

San José, CA 95192-0219 


\section{TECHNICAL REPORT DOCUMENTATION PAGE}

1. Report No. 20-35

4. Title and Subtitle

Promoting Transit-Oriented Developments by Addressing Barriers Related to Land Use, Zoning, and Value Capture

2. Government Accession No.
3. Recipient's Catalog No.

5. Report Date

October 2020

6. Performing Organization Code

8. Performing Organization Report CA-MTI-1819

Shishir Mathur, PhD, https://orcid.org/0000-0003-4601-7636

Aaron Gatdula, MCP https://orcid.org/0000-0002-9739-7299

9. Performing Organization Name and Address

Mineta Transportation Institute

College of Business

San José State University

San José, CA 95192-0219

12. Sponsoring Agency Name and Address

U.S. Department of Transportation

Office of the Assistant Secretary for

Research and Technology

University Transportation Centers Program

1200 New Jersey Avenue, SE

Washington, DC 20590
10. Work Unit No.

11. Contract or Grant No.

69A3551747127

13. Type of Report and Period Covered Final Report

14. Sponsoring Agency Code

15. Supplemental Notes

DOI: 10.31979/mti.2020.1819

\section{Abstract}

This study advances land use, transportation planning, and public finance research by identifying: a) the various land use, zoning, and value capture-related barriers to the construction of transit-oriented developments (TODs); and b) the major strategies that are commonly used or could be used to address these barriers. The value capture (VC) tools include joint development projects, tax increment financing, special assessments, lease/sale of land or air rights, and impact fees. The research finds that while a large proportion of jurisdictions across the US have TODs, land use, zoning, and VC-related barriers often impede their construction. Most transit agencies are not allowed to purchase land for constructing TODs, nor do they have land use and zoning powers over the station-area land. In the absence of legally enforceable inter-agency agreements between city governments and transit agencies, a large proportion of these public agencies rely on looser, collaborative agreements. Finally, while the use of eminent domain to assemble land parcels is critical for constructing TODs in already-developed areas, local governments rarely use this power to enable TODs.

\section{Key Words}

Transit-oriented development, land use, zoning, value capture, public transit

\section{Distribution Statement}

No restrictions. This document is available to the public through The National Technical Information Service, Springfield, VA 22161
19. Security Classif. (of this report) Unclassified
20. Security Classif. (of this page) Unclassified

\section{No. of Pages 169}

22. Price 


\title{
Copyright $\odot 2020$ \\ by Mineta Transportation Institute \\ All rights reserved
}

DOI: 10.31979/mti.2020.1819

\author{
Mineta Transportation Institute \\ College of Business \\ San José State University \\ San José, CA 95192-0219 \\ Tel: (408) 924-7560 \\ Fax: (408) 924-7565 \\ Email: mineta-institute@sjsu.edu
}

transweb.sjsu.edu 


\section{ACKNOWLEDGMENTS}

The authors thank Editing Press, for editorial services, as well as MTI staff, including Executive Director Karen Philbrick, PhD; Deputy Executive Director Hilary Nixon, PhD; Graphic Designer Alverina Eka Weinardy; and Communications and Operations Manager Irma Garcia. 


\section{TABLE OF CONTENTS}

Executive Summary

Overview 1

Study Objectives $\quad 2$

Methodology 2

Findings and Policy Implications $\quad 2$

$\begin{array}{lr}\text { I. Introduction } & \mathbf{8}\end{array}$

Research Objectives and Questions $\quad 9$

$\begin{array}{ll}\text { Methodology } & 10\end{array}$

$\begin{array}{ll}\text { Report Organization } & 10\end{array}$

II. Land Use, Zoning, and VC-Related Barriers to TODs 11

Land Use and Zoning-related Barriers to TODs 11

Strategies to Address Land Use and Zoning-related Barriers to TOD 11

VC-related Barriers to Funding TODs 15

III. National Surveys $\quad 22$

Survey Methodology $\quad 22$

Survey Findings $\quad 25$

Key Insights from Surveys $\quad 55$

IV. TOD Case Studies $\quad 59$

Othello Plaza TOD $\quad 59$

$\begin{array}{ll}\text { EcoVillage TOD } & 67\end{array}$

$\begin{array}{ll}\text { Evans Station Lofts TOD } & 71\end{array}$

$\begin{array}{ll}\text { Twinbrook TOD } & 75\end{array}$

$\begin{array}{ll}\text { MacArthur Transit Village TOD } & 79\end{array}$

Waterside Place TOD $\quad 83$

$\begin{array}{ll}\text { Key Insights } & 87\end{array}$

V. Conclusions and Policy Implications 93

Recommendations and Policy Implications 93

$\begin{array}{ll}\text { Concluding Remarks } & 98\end{array}$

Appendix A: Transit Agency Survey Questionnaire $\quad 99$

Appendix B: Local Government Survey Questionnaire 114 
$\begin{array}{lr}\text { Abbreviations and Acronyms } & 129\end{array}$

$\begin{array}{lr}\text { Endnotes } & 132\end{array}$

$\begin{array}{ll}\text { Bibliography } & 151\end{array}$

$\begin{array}{ll}\text { About the Authors } & 168\end{array}$

$\begin{array}{lr}\text { Peer Review } & 169\end{array}$ 


\section{LIST OF FIGURES}

1. Distribution of Transit Surveys by the Size of Transit Systems 24

2. Distribution of Local Government Surveys by the Size of Transit Systems 24

3. Over $80 \%$ of Survey Jurisdictions Have at Least One TOD 25

4. Formal Programs to Implement TODs Vary Among Local Governments and Transit Agencies

5. Local Governments Have More Opportunities to Encourage TODs Than Transit Agencies

6. Top Three Options Chosen by Transit Agencies to Address Land Use and Zoning-Related Barriers

7. Top Three Options Chosen by Local Governments to Address Land Use and Zoning-Related Barriers

8. Mixed Use Zoning is Widely Used to Promote TODs

9. Least Used Land Use and Zoning Tools by Transit Agencies to Promote TODs

10. Least Used Land Use and Zoning Tools by Local Governments to Promote TODs

11. One in Two Survey Respondents Indicate Existence of a Statewide TOD Plan 37

12. State or Regional Growth Management Policies or Tools are Not Widely Used

13. Two in Three Transit Agencies Do Not Enter into Cooperative Agreements for TODs

14. Local Governments Most Commonly Enter into Cooperative TOD Agreements With Transit Agencies

15. Some Public Agencies Enter into TOD-Supportive Collaborative Arrangements

16. Land Use and Zoning Barriers Are Viewed as Highly or Somewhat Impedimentary

17. Public Agencies' Opinions on Zoning Restrictions, with Non-Responses Included

18. Land Use and Zoning Barriers are Somewhat Navigable 
19. Transit Agencies Typically Use Joint Development, PPPs, and TIF to Implement TODs

20. Local Governments Typically Use PPPs and Community Benefits to Implement TODs

21. Cooperative Agreements for VC are Largely Unused Among Transit Agencies

22. Very Few Local Governments Enter into Cooperative Agreements with Transit Agencies to Promote VC

23. Few Collaborative Arrangements Exist to Promote VC

24. VC Restrictions Are Somewhat Impedimentary to the Implementation of TODs

25. Public Agencies' Opinions on Barriers to the Use of VC as Impediments: Non-Responses Included

26. VC Barriers Might Be Somewhat Navigable

27. Location of Othello Plaza TOD

28. Station Map of Sound Transit's Link Light Rail

29. Service Map of King County Metro Route 106

30. Location of Othello Plaza Station

32. Rendering of Othello Plaza TOD

33. RTA System Map

34. The EcoVillage Master Plan Surrounds W.65th-Lorain Avenue Station

35. RTD System Map:

36. Evans Station Lofts

37. WMATA System Map

38. BART Route Map

39. The T's Silver Line Services Logan Airport and Other Areas North and South of The City 


\section{LIST OF TABLES}

1. Strategies/Tools to Address Land Use and Zoning-Related Barriers to TODs 14

2. Details of Othello Plaza TOD 64

3. Summary of Case Study TODs 88 


\section{EXECUTIVE SUMMARY}

\section{OVERVIEW}

Transit-Oriented Developments (TODs)_often a single building or a group of buildings built within one-quarter to one-half mile of a transit station-are being constructed across the US as a tool to increase transit ridership, provide mode choice, reduce vehicle miles traveled (VMT), ${ }^{1,2,3,4}$ and meet other policy objectives-such as, in California, the greenhouse gas (GHG) emissions reduction targets. ${ }^{5,6}$ The federal government, too, through acts such as the Intermodal Surface Transportation Efficiency Act (ISTEA), the Transportation Equity Act for the $21^{\text {st }}$ Century (TEA-21), and more recently, the Safe, Accountable, Flexible, Efficient Transportation Equity Act: A Legacy for Users (SAFETEA-LU), the Moving Ahead for Progress in the $21^{\text {st }}$ Century Act (MAP-21), and Fixing America's Surface Transportation Act (FAST), is promoting TODs by reinforcing the need to integrate land use and transportation planning and promote public transit.

Furthermore, since governments at all levels-from federal to local-possess limited financial capacity to provide/upgrade infrastructure around transit stations and to provide incentives to real estate developers to build TODs, any new funding mechanism, such as land value capture (LVC), is welcome.

In the context of public transit, provision of or enhancements to public transit systems lead to accessibility-related benefits to the neighboring properties. These benefits are positively capitalized into higher land values. It is argued that since the neighboring properties benefit from public transit systems, their owners should also help fund these systems. ${ }^{7}$ This land value increment can be captured through various means. These include increased property tax revenues, sale or joint development of land in or around the transit stations, lease or sale of air rights above the transit stations, levy of special assessments, imposition of public transportation impact fees, land value taxation, and capture of property tax increments through a tax increment financing (TIF) district. ${ }^{8}$

While several empirical studies find that public transit and TODs (especially TODs with joint development projects) are positively associated with increases in surrounding land values, LVC tools have been used very little to fund TODs. The limited use of LVC tools likely arises

due to several factors. These factors range from a lack of inter-jurisdictional and inter-agency coordination, to the inability of transit agencies and local jurisdictions to see themselves as developers and partners in building TODs, to their difficulty to affect the 180-degree turnaround in their role from one where they are constantly trying to address property owners' opposition to public transit and TODs to one where they ask property owners to share the transit- and TOD-generated land value increases.

In summary, while TODs remain a desirable goal, several barriers hinder the development and financing of TODs. These include, among others:

(a) An absence of supportive zoning and land use in and around transit stations that is often due to (i) a lack of inter-agency coordination; (ii) transit agencies' limited zoning and land use powers over land in and around the stations; (iii) a lack of will among various public agencies, 
including transit agencies, to develop TODs; and (iv) a lack of enabling legal framework; and (b) Limited will, focus, capacity, and enabling legislation to leverage transit- and TODgenerated land value increment. Financing tools to capture such increments fall beneath the umbrella of value capture (VC) tools.

\section{STUDY OBJECTIVES}

This study provides an updated review of the barriers related to land use, zoning, and VC encountered while constructing TODs. Furthermore, through in-depth case studies and national surveys of transit agencies and of the major cities in these transit agencies' service area, the study identifies the steps that are being undertaken and that still need to be taken to remove these barriers.

Posed as research questions, this study answers the following research questions:

(a) What are the various land use, zoning, and VC-related barriers to the construction of TODs?

(b) What major strategies are being or could be used to address these barriers?

\section{METHODOLOGY}

First, academic and professional literature was reviewed to identify: a) the various types of land use, zoning, and VC-related barriers to TODs and b) the strategies most commonly employed or those that could be employed to address these barriers. Second, the Federal Transit Administration's (FTA) National Transit Database (NTD) was used to survey the top 101 transit agencies in the USA (see the section titled "National Surveys" for the detailed methodology), and US Census data were used to survey the largest cities in each of these transit agencies' service area. The surveys identify the land use, zoning, and VC-related barriers faced by the public agencies in implementing TODs, and the ways in which these agencies have (are or planning to) overcome these barriers. The survey findings support and supplement those from the literature review by (a) providing an account of the current, on-the-ground barriers faced by the public agencies, and (b) by seeking the public agencies' opinion on how the barriers are, will, or can be overcome. Third, six in-depth case studies of recently-developed TODs were conducted to identify the barriers related to land use zoning, or VC, faced and overcome while constructing the TODs (see the section titled "TOD Case Studies" for the case study selection methodology). Finally, information obtained from all the three sources-literature review, surveys, and case studies-was synthesized to identify the major findings with respect to the types of barriers faced and the strategies that might be used to overcome them.

\section{FINDINGS AND POLICY IMPLICATIONS}

The major recommendations from the synthesis of the literature review, case studies, and surveys are described below, along with policy implications for the state-, regional-, and 
local-level planners and policy makers. The recommendations are divided into three groups: (a) overarching recommendations are applicable for mitigating barriers to both land use and zoning and to the use of VC, (b) land use and zoning-related recommendations are primarily applicable for mitigating land use and zoning-related barriers, and (c) VC-related recommendations are primarily applicable for mitigating barriers related to the use of VC.

\section{Overarching Recommendations}

a) Consider land use, zoning, and VC in an integrated manner: Many of the barriers to land use and zoning are similar to those affecting VC. For example, requiring a certain amount of parking and ground-floor retail, or requiring very specific uses in the TODs, are not only land use and zoning hurdles, but they could diminish the value of the TOD as well, thereby reducing the potential for VC. Integration is also needed to meet objectives such as enhanced transit ridership, adequate infrastructure provision, and good urban design. Furthermore, since the stationarea property values can increase right from the transit-anticipation period to the time the transit system matures, an integrated framework can help capture property value increases along all these time periods through tools such as long-term land banking and neighborhood-level planning ahead of TOD implementation. Transit agencies and the local governments can partner in such land banking and planning efforts. Such integrated thinking gains importance because the survey data suggest that using VC to implement TODs is likely not on the radar of most transit agencies and local governments.

b) Inter-agency coordination is important: Survey responses highlight the need for inter-agency coordination for addressing land use-, zoning-, and VC-related barriers. In the absence of strong, enforceable, cooperative agreements, transit agencies and local governments are relying on weak, collaborative arrangements such as TOD working groups. However, an integrated approach to TODs requires much closer coordination between these two public agencies. Therefore, strong state and regional leadership is required to provide incentives and an enabling environment for such coordination. Although some federal, state, or regional TOD planning or infrastructure grants require such coordination, they are piecemeal approaches at best.

c) More powers to the transit agencies over station-area land, in close consultation with these agencies: The transit agency surveys have noted the lack of control over station-area land use and zoning as a significant barrier. However, overly prescriptive legislation such as AB 2923 of California may not be very effective either. On the one hand, AB 2923 requires TODs to meet minimum FAR requirements that are almost impossible to achieve in most cases; on the other hand, it restricts San Francisco Bay Area Rapid Transit District's (BART's) zoning authority to the land parcels it owns, not extending it over all station-area parcels.

Actions are needed on many fronts. More flexible, outcome-focused requirements can be devised, such as ensuring that station-area land use and zoning lead to 
specific transit ridership and station access mode share outcomes. For example, in California, a planning commission is required to certify consistency between a city's general plan and its capital improvement plan. In the case of station-area land use and zoning, a state- or regional-level agency or a joint local committee between the local government and transit agency could be formed for such certification purposes, or an existing agency could be assigned this role. Federal, state, and regional governments could make the formation of such committees or the assignment of this role a pre-requisite for awarding grants.

Going a step further, enabling legislation may be enacted to provide transit agencies the ability to acquire land for constructing TODs. Currently, most of the transit agencies can purchase land for transit-related purposes, but not for TODs. However, some exceptions exist. For example, land bought using Federal Transit Administration (FTA) funds can be sold for constructing TODs. Similarly, California's state legislation allows some San Francisco Bay Area transit agencies to acquire properties for constructing TODs. A survey respondent from the Denver, $\mathrm{CO}$ area noted the ability of transit agencies to use the excess land acquired for transitrelated purposes for TODs. Therefore, states should consider designating TODs a transit-serving infrastructure/facility and allow transit agencies to acquire land for TODs at the time they acquire land to build or expand transit systems.

d) State- and regional-level leadership and enabling framework: The review of the literature and a large number of transit agency surveys identified a lack of state- and regional-level leadership as well as a lack of state and regional growth management (GM) tools as barriers to implementing TODs. On the other hand, survey respondents from states with state-level GM programs (for example, Washington and Oregon) frequently note the existence of state and regional laws, programs, or plans to encourage TODs, especially noting their emphasis on closer land use transportation coordination. In these states, TODs are viewed as key to achieving the GM objectives.

e) Reduce developer risk: Reducing developer risk is key to promoting TODs and can be achieved through various means identified in the literature review, surveys, and case studies, including (a) streamlining zoning and permitting processes, (b) reducing uncertainty in the environmental approval process, (c) land banking by the public sector that allows developers to do site-level due diligence and obtain approvals before purchasing land, and (d) flexibility in changing the joint development agreements due to changes in real estate market conditions.

\section{Land Use and Zoning-Related Recommendations}

a) Many zoning barriers remain: Zoning barriers such as minimum parking requirements; minimum lot sizes; minimum house sizes; and low-density, sprawling uses are addressed in many cities around the country through tools such as overlay zones, specific plans, mixed-use transit district (MXDT) zoning, and TOD zoning. However, the survey findings show that these barriers are often being removed around a few stations in a city, or by only one or two cities in a region. This lack of 
uniformity also highlights the need for the above-noted state- and regional-level leadership and enabling framework.

b) Need to get the parking right: Parking in a TOD should be based on the characteristics of the transit system, the station, and the surrounding area. Survey responses and the literature review suggest that parking maximums, not minimums, should be prescribed. However, a case study interviewee pointed out that parking maximums may not work in all cases. For example, limiting parking in TODs around transit stations that provide low-quality transit service may lower such TODs' market success. Furthermore, since many TODs are built on erstwhile surface parking lots on station land, transit agencies, such as BART, have often required oneto-one parking replacement. This requirement translated into the construction of very expensive parking garages-a bottleneck for developing TODs. Therefore, transit agencies need a shift in policy focus, like BART recently accomplished, from replacing lost parking to serving transit users. For example, if a larger proportion of transit users are now likely to bike/walk to the station and fewer are likely to use cars due to up-/re-zoning around the station area, a smaller number of parking spaces may be required at the station than before the up-/re-zoning.

c) Shift focus from ground-floor retail to active ground floor: Planners often require ground-floor retail in TODs as a way to create a lively urban area. However, retail is suffering in multiple case study TODs reviewed in this report. Several reasons are suggested, including a glut of retail in the area around TODs and an inadequate customer base. Therefore, transit agencies and local governments should consider shifting the focus from requiring ground-floor retail to the larger objective: an active ground floor.

Additionally, a survey respondent from the City of San José, CA points to a larger issue pertaining to the fiscalization of land use. To balance their budgets, cities are often compelled to require larger amounts of non-residential uses, such as ground-floor retail, than possible to construct financially viable TODs. This fiscal bind highlights the need for state- or regional-level financial assistance to cities for constructing TODs, perhaps ongoing grants large enough to offset the TODinduced fiscal imbalance.

d) Prescriptive uses for TODs may not work: For the same reason that parking requirements should be determined on a case-by-case basis, the type and amount of other uses such as affordable housing and retail should be, too. Highly prescriptive uses may not work due to a lack of market demand. Therefore, transit agencies and local governments need to be flexible, perhaps requiring developers to choose from a menu of uses. For example, live-work spaces are currently in demand in many parts of the country. Therefore, developers could be provided an option to choose between (or choose a mix of) retail, office, and live-work spaces. Alternatively, they could be allowed to convert one use to another, for example, converting retail spaces into live-work spaces.

e) Use land assembly and eminent domain: Extant literature notes that for TODs to 
be located in areas with fragmented land ownership, the land has to be assembled and then re-parceled into a single parcel-a process that could require the use of eminent domain and land assembly. Indeed, before they were dissolved in 2011, California's redevelopment agencies used eminent domain to assemble land to facilitate real estate projects in redevelopment areas. However, the survey findings show that the use of eminent domain and land assembly for facilitating TODs are among the least used tools. Furthermore, the ad-hoc use of these tools can be controversial. Therefore, they should be employed to meet well-defined objectives derived from sound planning processes: for example, to facilitate the development of affordable housing in TODs, if the provision of affordable housing has been identified as a planning objective.

\section{VC-Related Recommendations}

a) Encourage transit agencies and local governments to use VC to implement TODs: Survey responses indicate that the use of VC tools to implement TODs is likely not on the radar of most of the transit agencies and local governments. This finding is supported by other evidence as well. For example, Santa Clara Valley Transportation Authority's (VTA's) BART Silicon Valley Phase 2 Extension Project's preliminary budget does not include VC. One project document merely calls for "supporting value creation through increased development, and identification of strategies for value capture to fund station area improvements" statement considering that a much smaller project, the Warm Springs BART Extension Project, led to an approximately $\$ 4$ billion increase in the value of singlefamily houses alone, five times the amount needed to fund the entire project. ${ }^{10}$ These missed opportunities highlight the need for a well-coordinated use of tools such as eminent domain, site assembly, land banking, TIF, and special assessment districts (SADs). Even capturing some of the value increase might be adequate to fund the transit infrastructure as well as TODs (for example, public agencies can use the VC revenue to subsidize TODs, require affordable housing, and make infrastructure improvements around the transit station and TODs).

b) Enhance public agencies' ability to use TIF and other VC tools: Extant literature as well as the case studies note the inability of public agencies to use TIF as a major inhibiting factor to the use of VC to implement TODs. Many of these restrictions arise due to state-level policies and legislation. Therefore, strong state-level leadership is required to remove the barriers to the use of TIF as well as other VC tools such as SADs. For example, California's Proposition 218 could be amended to lower the current two-thirds super-majority vote requirement to institute a SAD to perhaps $55 \%$, as is the case for approving a school bond measure in the state.

c) Need for transparent assessment of value increase: The development agreements between the public agencies and the developers to construct TODs, especially the financial analyses that constitute the basis for these agreements (e.g., revenue sharing and land lease/sale agreements), are not easily available to the public. Indeed, in one case, a public agency refused to provide information about the amount of lease revenues received unless a request for information was 
filed under their state's public records law. In the absence of such freely available information, the community is likely to be concerned that the public agencies are not capturing value adequately. For example, in the case of MacArthur Station TOD, some community members felt that the City of Oakland, CA did not negotiate enough community benefits when relaxing the height of a residential project from six to 24 stories. To build public trust in the use of VC, such documents must be publicly available on agencies' websites. Public trust will be critical to scale up the use of VC.

d) Need for systematic and comprehensive assessment of value increase: While the MacArthur Station TOD and Waterside Place TOD case studies indicate that the public agencies are using sophisticated means to capture value (for example, they receive various kinds of lease revenues and a portion of sale proceeds), the use of $\mathrm{VC}$ is disjointed. For example, VC occurs at various times and in various ways during the construction of the MacArthur Station TOD project's multiple components, and it is mediated through muddled and non-transparent negotiation processes. We recommend a systematic and comprehensive analysis of the total VC potential of a TOD, and then divvying up of this potential into major buckets, such as requirements to build affordable housing, undertake infrastructure improvements, and share lease revenues.

e) Need for flexibility: Flexibility in policy and program design is needed to use VC tools. For example, Sound Transit requires that the sale of its land parcels (where TODs are to be developed) can only close after building permits are secured for the TOD projects. However, they waived this requirement for the Othello Plaza TOD. Similarly, in the case of Twinbrook Station TOD, the joint development agreement was amended multiple times, including in 2007 when the agreement was restructured to sell one-third of the station area land to the developer to construct condominium units (earlier this land was leased for 99 years). 


\section{INTRODUCTION}

Transit-Oriented Developments (TODs) — a single building, or a group of buildings built close to a transit station to promote transit ridership-are being constructed across the US as a tool to increase transit ridership, provide mode choice, reduce VMT,11,12,13,14 and meet other policy objectives (such as, in California, the GHG emissions reduction targets). ${ }^{15}, 16$ The federal government, too, through acts such as ISTEA, TEA-21, and more recently, SAFETEA-LU, MAP-21, and FAST, is promoting TODs by reinforcing the need to integrate land use and transportation planning and to promote public transit.

The key actors in the TOD process include the following, among others: (a) the local governments, which influence the process through land use, zoning, building regulations, and infrastructure planning and investment choices; (b) the real estate developers, who construct the TODs independently or in partnership with local governments and/or transit agencies; (c) the transit agencies that plan and manage the construction and operation of transit systems, and typically own the station land and the air rights above the station-locations well-suited for TOD construction; and (d) the regional, state, and federal governments that influence the process through enabling legislation, policies, and funding.

Furthermore, since governments at all levels—-from federal to local-have limited financial capacity to provide or upgrade infrastructure around transit stations and to provide incentives to real estate developers to build TODs, any new funding mechanism, such as LVC, is welcome.

In the context of public transit, provision of or enhancements to public transit systems lead to accessibility-related benefits to the neighboring properties. These benefits are positively capitalized into higher land values. Researchers argue that since the neighboring properties benefit from public transit systems, they should also help fund these systems. ${ }^{17}$ This land value increment can be captured through various means. These include increased property tax revenues, sale or joint development of land in or around the transit stations, lease or sale of air rights above the transit stations, levy of special assessments, imposition of public transportation impact fees, land value taxation, and capture of property tax increments through a TIF district. ${ }^{18}$

While several empirical studies find that public transit and TODs (especially TODs with joint development projects) are positively associated with increases in the surrounding land values, ${ }^{19,20,21,22,23}$ LVC tools have been used very little to fund TODs. Only a few examples exist, such as the use of TIF to develop Contra Costa Center in California. ${ }^{24}$ The limited use of LVC tools likely results due to several factors. These range from a lack of inter-jurisdiction and inter-agency coordination, to the inability of transit agencies and local jurisdictions to see themselves as developers and partners in building TODs, to their difficulty to affect the 180-degree-turn-around in their role from one where they are constantly trying to address property owners' opposition to public transit and TODs to where they ask property owners to share the transit- and TOD-generated land value increases.

In summary, while TODs remain a desirable goal, several barriers hinder their development and finance. These include, among others: (a) An absence of supportive zoning and land 
use in and around transit stations that is often due to (i) a lack of inter-agency coordination; (ii) transit agencies' limited zoning and land use powers over land in and around the stations; (iii) a lack of will among various public agencies, including transit agencies, to develop TODs; and (iv) a lack of enabling legal framework; and (b) Limited will, focus, capacity, and enabling legislation to leverage transit- and TOD-generated land value increment. Financing tools to capture such increments broadly fall under the umbrella of LVC tools. For example, many transit agencies may not consider TOD planning and development to be their legitimate duty; ${ }^{25,26}$ therefore, they are not likely to advocate for land use and zoning powers required to construct TODs, nor to proactively coordinate TOD planning with the city governments.

Robust state-level enabling legislation can significantly help to remove many of these barriers. ${ }^{27}$ The legislation can facilitate joint development agreements between public agencies and/or between public agencies and private developers; grant land use and zoning powers to transit agencies; and promote inter-agency coordination, for example, by requiring local government to coordinate the planning and construction of TODs with transit agencies. Such legislation can also provide a clear signal to the governing boards of transit agencies that TOD planning and construction are within their realm of duties.

The extant literature has surveyed the barriers to TODs. However, the literature either needs an update, with the last comprehensive review undertaken more than 15 years ago, ${ }^{28,29}$ or it focuses on one type of TOD-for example, Hess and Lombardi's literature review of innercity $\mathrm{TODs}^{30}$ —or it derives policy recommendations from a single case study TOD. ${ }^{31}$

Finally, the more recent studies primarily focus on the legal and land use-related issues surrounding the construction of TODs, ${ }^{32}$ offering little insight into using the transit and TODgenerated land value increase to fund TODs. Furthermore, while the literature emphasizes the need for state-level enabling legislation, ${ }^{33,34}$ no recent peer-reviewed research exists on this topic. For example, Cervero et al. (2004) reviews enabling legislation of the four states that had TOD-related legislation at the time the report was prepared. Subsequently, a 2012 report provides selected TOD-related legislation of 21 states ${ }^{35}$ However, this report does not analyze how these pieces of legislation address TOD-related barriers. Finally, a 2017 report describes how 25 states provide state-level support for TODs through planning, zoning, and financial incentives and grants. ${ }^{36}$ However, this report does not focus on state enabling legislation. Furthermore, similar to the 2012 report, ${ }^{37}$ it does not conduct a fine-grained analysis of how the support provided by the states mitigates the TOD-related barriers.

\section{RESEARCH OBJECTIVES AND QUESTIONS}

This study advances the body of knowledge by providing an updated review of land use-, zoning-, and VC-related barriers to TODs. Furthermore, through in-depth case studies and national surveys of transit agencies and of the major cities in these transit agencies' service area, the study identifies the steps that are being undertaken and that still need to be taken to remove these barriers. 
This study poses the following research questions:

(a) What are the various land use, zoning, and VC-related barriers to the construction of TODs?

(b) What major strategies are being or could be used to address these barriers?

\section{METHODOLOGY}

First, academic and professional literature was reviewed to identify the various types of land use, zoning, and VC-related barriers to TODs and the strategies most commonly employed, or those that could be employed, to address these barriers. Second, the FTA's NTD was used to survey the top 101 transit agencies in the USA (see the section titled "National Surveys" for the detailed methodology), and US Census data were used to survey the largest cities in each of these transit agencies' service area. The surveys identify the land use, zoning, and VC-related barriers faced by the public agencies while implementing TODs, and the ways in which these agencies have, are, or planning to overcome these barriers. The survey findings support and supplement those from the literature review by (a) providing an account of the current, on-the-ground barriers faced by the public agencies, and (b) seeking the public agencies' opinion on how the barriers can be overcome. Third, six in-depth case studies of recently developed TODs were conducted to identify the land use, zoning, or VC-related barriers faced and overcome while constructing the TODs considered (see the section titled "TOD Case Studies" for the case study selection methodology). Finally, information obtained from all the three sources - literature review, surveys, and case studies-was synthesized to identify the major findings with respect to the major types of barriers faced and the strategies that might be used to overcome them.

\section{REPORT ORGANIZATION}

The rest of the report is organized as follows. The next section discusses the land use, zoning, and VC-related barriers to TODs and the strategies used to remove those barriers. The subsequent section, National Surveys, describes the objectives for conducting the two surveys (the transit agency and local government surveys), the survey methodology, and the major findings. The subsequent section describes the methodology used for selecting case study TODs; provides in-depth descriptions of each case study TOD, including the barriers faced and overcome; and the major findings. The last section synthesizes the findings from the literature review, the surveys, and the case studies. 


\section{LAND USE, ZONING, AND VC-RELATED BARRIERS TO TODS}

\section{LAND USE AND ZONING-RELATED BARRIERS TO TODS}

Euclidean zoning and restrictive land use polices promote sprawl by separating uses; allowing largely single-family housing; restricting development of multi-family housing; restricting height and floor area ratios (FARs); and requiring large minimum setbacks and parking, among others. ${ }^{38}$ Such zoning regulations create an auto-oriented urban form that is not conducive to walking and biking, the two key desirable features of TODs.

Complicated zoning and building permitting processes and other regulations such as the California Environmental Quality Act (CEQA) hinder TODs by making the permit approval process long (often several years), thereby increasing project risk and development cost. ${ }^{39,40,41}$ Additionally, the community participation processes are often repetitive and timeconsuming-hence the call to streamline them and the zoning itself. ${ }^{42}$

While a lack of TOD-supportive zoning is a significant barrier, there are other, institutionallevel factors that create land use and zoning-related barriers. For example, transit agencies often have limited or no land use or zoning powers over land in and around transit stations. ${ }^{43,44}$ Indeed, in some cases, transit agencies are even prohibited from engaging in real estate development. ${ }^{45,46}$ Furthermore, public agencies such as city governments or redevelopment agencies might oppose granting land use or zoning powers to transit agencies. ${ }^{47}$ These barriers are difficult to surmount in the absence of incentives for inter-agency coordination, ${ }^{48,49}$ or clear legal authority, such as state-level enabling legislation that grants to transit agencies zoning power and the authority to undertake real estate development.

\section{STRATEGIES TO ADDRESS LAND USE AND ZONING-RELATED BARRIERS TO TOD}

The extant literature has identified several strategies to address land use and zoning-related barriers to TODs, which can be broadly grouped into three categories:

(1) Growth management (GM) or smart growth strategies at the municipal, regional, and state levels: Such strategies are called "ancillary" strategies ${ }^{50}$ and include tools that direct urban growth. For example, an urban growth boundary (UGB) discourages growth outside the UGB and focuses it inside. ${ }^{51}$ Similarly, urban areas can be divided into tiers/zones: for example, "growth areas" and "limited growth areas," ${ }^{2}$ with regulations, policies, and incentives in place to encourage development within the growth areas. States with state-level GM programs, such as Florida and Washington, have other tools such as concurrency to direct growth. Under the concurrency requirement, building permit approval can only be provided if infrastructure such as transportation, sewers, and the water supply system can be provided concurrently with growth. Therefore, TODs can be encouraged by using concurrency to direct development toward areas with high-quality public transportation or by providing concurrency exemptions for developments proposed in areas around transit. ${ }^{53}$ 
(2) Land use and zoning tools:

- Incentives for higher-density development: for example, prescribing maximum, not minimum, lot sizes; density bonuses; higher FARs; building height relaxation; and zoning for compact housing types such as apartments, condominiums, and townhouses; ${ }^{54}$

- Mixed-use zoning that allows mixing of residential, commercial, and office uses and clearly identifies permitted, accessory, and conditional uses, ${ }^{55}$

- Regulations and incentives that facilitate adaptive reuse of properties that would otherwise not meet the current zoning and building codes. ${ }^{56}$ For example, historical buildings in inner-city areas constructed in the pre-automobile era are often left unused because they cannot meet the current requirements for parking ${ }^{57,58,59,60}$ or zoning; for example, when zoning does not allow historical industrial buildings to be reused for commercial or residential uses; $; 1$

- Requiring housing at various affordability levels through programs such as inclusionary housing; ${ }^{62}$

- Parking regulations that limit the amount of parking and promote parking that aids walking and biking. For example, parking regulations can prescribe maximum, not minimum, parking standards; relax parking requirements for TODs; restrict off-street parking; and incentivize shared and paid parking; ${ }^{63,64}$

- Regulations that promote walking and biking by allowing reduced street widths and building setbacks, requiring garages in back alleys, and requiring street furniture and wide sidewalks; ${ }^{65}$

- Regulations that allow joint development projects by, for example, providing transit agencies with the power to enter into joint development agreements with private developers, and by unambiguously specifying the kinds of actions permissible under such agreements; for example, whether transit agencies can grant development and easement rights to private entities; ${ }^{66}$ and

- Other developer incentives such as no-/reduced-impact fees, reduced permit fees, and streamlined/expedited environmental review and building permit approval. TODs can also be designated "receiving zones" for development rights under a transfer of development rights (TDR) program with areas outside the TODs designated "sending areas." 67

- Several of these land use and zoning tools can be employed through techniques such as TOD overlay zoning, TOD specific plans, transit/urban village plans, developer agreements, and planned unit development (PUD) processes. . $^{68,69,70,71}$

(3) Financial incentives:

Federal, state, regional, and local agencies can promote TOD-supportive land use and 
zoning through financial incentives. For example, infrastructure development or planning assistance (grants, loans, etc.) can be made contingent upon zoning reforms and/or require that the funds be expended in areas around transit for station area planning and/or capital improvements. ${ }^{72}$ Similarly, affordable housing assistance can be directed toward areas around transit by making proximity to transit an important assistance criterion. All three sets of strategies/tools are summarized in Table 1. 
Table 1. Strategies/Tools to Address Land Use and Zoning-Related Barriers to TODs

\begin{tabular}{|c|c|c|c|c|c|c|c|c|c|}
\hline $\begin{array}{l}\text { Growth } \\
\text { Management/ } \\
\text { Smart } \\
\text { Growth }\end{array}$ & UGB & Concurrency & $\begin{array}{l}\text { Growth } \\
\text { Areas/Zones }\end{array}$ & $\begin{array}{l}\text { Farmland } \\
\text { Preservation }\end{array}$ & $\begin{array}{l}\text { Land Use- } \\
\text { Transportation } \\
\text { Integration }\end{array}$ & & & & \\
\hline $\begin{array}{l}\text { Land Use } \\
\text { and Zoning }\end{array}$ & $\begin{array}{l}\text { Higher } \\
\text { density } \\
\text { development }\end{array}$ & $\begin{array}{l}\text { Mixed-Use } \\
\text { Zoning }\end{array}$ & $\begin{array}{l}\text { Adaptive } \\
\text { Reuse }\end{array}$ & $\begin{array}{l}\text { Affordable } \\
\text { Housing }\end{array}$ & $\begin{array}{l}\text { Parking } \\
\text { Regulations }\end{array}$ & Walk/Bike & $\begin{array}{l}\text { Joint } \\
\text { Development }\end{array}$ & $\begin{array}{l}\text { Developed } \\
\text { Incentives } \\
\text { (e.g., no/ } \\
\text { reduced } \\
\text { impact fee, } \\
\text { expedited } \\
\text { permit } \\
\text { approval }\end{array}$ & $\begin{array}{l}\text { Others } \\
\text { (e.g., land } \\
\text { acquisition } \\
\text { by transit } \\
\text { agencies for } \\
\text { non-transit } \\
\text { purposes) }\end{array}$ \\
\hline $\begin{array}{l}\text { Financial } \\
\text { Incentives }\end{array}$ & $\begin{array}{l}\text { Infrastructure } \\
\text { Development } \\
\text { Assistance }\end{array}$ & $\begin{array}{l}\text { Planning } \\
\text { Grants }\end{array}$ & $\begin{array}{l}\text { TOD } \\
\text { Planning } \\
\text { Grants }\end{array}$ & $\begin{array}{l}\text { Housing } \\
\text { Assistance }\end{array}$ & $\begin{array}{l}\text { Others (e.g., } \\
\text { transit passes) }\end{array}$ & & & & \\
\hline
\end{tabular}




\section{VC-RELATED BARRIERS TO FUNDING TODS}

Many of the barriers to the use of VC to fund TODs are the same as (a) the barriers to the use of VC tools to fund public transportation and (b) the barriers to the construction of TODs. Some barriers are unique to the use of VC to fund TODs, however.

On a broader note, value creation is a prerequisite for the use of VC. In the TOD context, value creation could occur due to (a) the value of the transit system and (b) the value of the TOD. Value can be enhanced if both exist: a high-value transit system and a high-value TOD. Therefore, to understand the barriers to using VC to fund TODs, it is important to understand the factors that reduce the value of transit systems and TODs.

\section{Factors Impacting the Value of a Transit System}

The value of a transit system can be low if:

- The transit system provides poor accessibility, for example, due to limited geographical coverage (very few rail or bus lines or transit stops) and low quality service (infrequent service, long trip times, low-quality buses and trains, unsafe stations or unsafe buses/trains);

- The transit system does not enhance overall transportation accessibility: for example, if auto travel is a lower-cost and faster option because there is no traffic congestion; gas is inexpensive; the road network is extensive; and parking is convenient, ample, and free;

- Access to transit stops is difficult; for example, due to barriers such as industrial uses around transit stations, a lack of walk/bike connectivity, and a lack of station-area parking (especially for commuter rail stations); and design barriers such as only one access point to the transit station, and the need to cross expansive parking lots to access the station.

- Overall demand for transportation infrastructure is low, for example, due to small population size or slow population growth rate, high unemployment, and a weak job market.

\section{Factors Impacting the Value of a TOD}

The value of a TOD can be low due to:

- Poor architecture and urban design of the TODs that lead to low market demand;

- Non-conducive land use and zoning for the TODs. For example, high minimum parking requirements; segregation of uses; and density maximums, not minimums;

- Real estate development risk. TODs can often be high-risk, especially if (i) they are a new real estate product type for the region, or the specific type of TOD 
proposed is new for the region; therefore, such TODs have low or uncertain market demand; (ii) they have higher design complexity, for example, due to the need to provide various uses in close proximity to each other while maintaining visual and audio privacy and high aesthetic appeal; (iii) they need complex, multi-layered financing, such as a mix of several different public grants/loans/credits and private financing; (iv) they are located in brownfields requiring environmental remediation; or (v) they have to undergo lengthier permitting processes, for example, due to increased community participation for inner-city in-fill TODs and multiple public agencies' approval;

- Risks associated with the transit system. Examples of such risks include (i) the construction of the transit system is stalled or postponed; (ii) the transit system is of low quality to begin with and/or its quality deteriorates over time; or (iii) the transit system becomes non-operational, for example, a bus rapid transit (BRT) system or a commuter train is discontinued;

- Legal or programmatic restrictions: for example, city policies requiring TODs to provide ground-floor retail. Similarly, funding programs might be restricted to a certain project size or type. For example, the Transportation Infrastructure Finance and Innovation Act (TIFIA) provides fixed-rate, long-term loans for "qualified transportation projects of regional and national significance." When this program began in 1998, the minimum project size was $\$ 50$ million and the funds could be used for transportation projects only. However, the FAST Act of 2015 removed many restrictions by lowering the eligibility limit to $\$ 10$ million and increased the scope of eligible projects to include TODs and projects that enhance bike and pedestrian connectivity. The FAST Act also allowed the use of local street design guidelines rather than the state's road design standards, thereby increasing design flexibility and local control. Finally, some restrictions might come from the transit agencies themselves: for example, in the form of parking replacement policies, where in lieu of developing a TOD on surface parking lots, a transit agency might require an equal number of parking spaces in a parking garage. For example, BART used to have such a parking policy, which it has relaxed recently.

- Lack of federal funding: Although the federal government started advocating for TODs in the 1970s, it did not have a TOD-specific funding program until the passage of the federal transportation bill, MAP-21, in 2012. MAP-21 established FTA's Pilot Program for TOD Planning. This program, amended by the FAST Act of 2015, is authorized until FY 2020. The program provides "funds to local communities to integrate land use and transportation planning with a new fixed guideway or core capacity transit capital investment. Comprehensive planning funded through the program must examine ways to improve economic development and ridership, foster multimodal connectivity and accessibility, improve transit access for pedestrian and bicycle traffic, engage the private sector, identify infrastructure needs, and enable mixed-use development near transit stations." The program also encourages the use of VC tools for TOD implementation. 
- Lending practices. Often, lenders are reluctant to fund a vertical mix of uses or charge higher interest rates if the land for the TODs is leased, not owned, which can occur when transit agencies lease their land rather than selling it. For example, BART favors leasing land for up to 66 years rather than a longer-term lease or sale of land. However, it keeps the option for longer-term leases or land sales when it notes the "except in cases where alternative approaches are required to achieve specific development objectives or where other strategies would generate greater financial return to the District." Indeed, BART used an alternative approach in the case of Fruitvale Station TOD, where BART owned the TOD site but was reluctant to sell it to the developer outright. Therefore, a land swap deal was made. The developer was awarded a 96-year lease for the BART land in exchange of a developer-owned land parcel behind the station and a few Oakland-owned land parcels that had been vacant nearby. Since the land parcels exchanged were equal in value to the land BART leased to the developer, BART was able to maintain the value of the land parcels owned by the agency;

- Lack of institutional coordination. For example, if a local government does not amend zoning around transit stations to make it more transit-supportive; or widens major, competing roads, thereby reducing the value of transit; or zones for offices/ jobs in areas not served by transit;

- Poor site location. Often, TODs are not constructed at locations most suited for such developments, but at locations where it is easy to assemble or acquire land. For example, redevelopment agencies typically use TIF funds to acquire land and/ or to provide assembled land to developers. However, many state laws restrict these agencies to blighted areas. Hence, transit stations and TODs often end up in areas that may be brownfields, lack a robust real estate market, or have insufficient infrastructure to support transit stations and TODs. On the other hand, TOD sites in sprawling suburbs (away from neighborhood-level amenities such as grocery stores, restaurants, and daycare centers) are also examples of poorly located sites.

- The high cost of developing TODs. Several transit agencies allow TODs on station parking lots if the surface parking is replaced one-to-one, often by parking garages. Since such garages are very costly to construct, they are a barrier to the construction of TODs. For example, Contra Costa Center, a joint development TOD project in Contra Costa County, CA, could only be built after the county's redevelopment agency funded the construction of the parking garage. To remove this parking-related barrier, many transit agencies are adopting more flexible parking approaches based on the characteristics of the transit riders (for example, commuters versus neighborhood patrons), the transit system (for example, commuter rail versus light rail), and the type of transit station (for example, innercity mixed-use versus suburban). Furthermore, public assistance for TODs, such as city, state, and federal grants and loans, often require prevailing wages for construction workers and fulfilling certain policy objectives. Often, prevailing wages are higher than the local market-rate wages. Therefore, TODs that receive public assistance may cost more than the neighboring privately-funded developments. 
Similarly, the cost of meeting policy objectives could be higher than the subsidies or incentives received or the expected financial returns. For example, a policy requiring the inclusion of affordable housing units in a TOD could grant additional building height as an incentive. However, if the real estate market demand is low, the height relaxation might yield fewer benefits compared to the cost of providing affordable housing units. Finally, many TODs are located in urban areas with fragmented land ownership. Therefore, land might need to be assembled and then re-parceled into a single large parcel-a challenge for private developers, especially even if one land owner refuses to sell or asks for compensation at a rate much higher than the market rate. In such situations, transit agencies are often unable to help because many do not have the authority to acquire land for nontransit purposes. However, local governments, such as redevelopment agencies, or city or county governments, can use their eminent domain power to assemble land. This power also grants them leverage in influencing TOD characteristics such as use-mix, density, and design.

Even if transit and TOD are of high value, other VC hurdles might exist, such as:

a) State-level restrictions on the use of VC tools. While several VC tools are used across the country, the eligible uses may differ based on state laws. For example, TIF is extensively used in Illinois; however, it can be used only to fund capital expenditures, not to meet operations and maintenance (O\&M) expenses. Similarly, impact fees can often fund capital expenditures only. Such restrictions can hamper the use of VC tools to fund TODs, e.g., if a TOD project does not receive local government approval due to a lack of funds to meet O\&M expenses. Furthermore, even though Washington State allows the use of TIF, the use is severely restricted. Due to the state Supreme Court ruling, TIF cannot be imposed on the state's portion of property tax. The local governments are limited in their ability to increase their portion of tax rate. Property taxes cannot exceed more than $1 \%$ of assessed value and cannot increase more than $1 \%$ per year. Furthermore, the entire property value increment cannot be captured: only the amount equal to the expenditures. Similarly, in California, the Enhanced Infrastructure Financing Districts (EIFDs) can raise revenues, albeit with some limitations, such as (i) all taxing entities (e.g., county governments) must agree to divert their tax increments to the EIFD, (ii) school districts' and non-consenting taxing entities' tax increment cannot be used, and (iii) $55 \%$ voter approval is required to issue TIF-backed bonds. On a positive note, EIFDs can use 10 revenue sources other than TIF and the funds can be expended in both blighted and non-blighted areas. Furthermore, under Proposition 218, SADs in California are subject to voter approval, while business improvement districts (BIDs) are not, because BIDs levy assessments based on business characteristics (size, type, and location), not based on property value. On the other hand, some states allow very liberal use of SADs. In Minnesota, city councils can initiate SADs, and no voter approval is required. Connecticut grants very expansive powers to SADs-they can be used for functions that are generally a local government's duty, such as street cleaning. Furthermore, SAD revenues can be used to meet O\&M expenses. On a broader note, state laws largely determine the kinds of $\mathrm{VC}$ tools local agencies have at 
their disposal and how they can be used.

b) Federal-level restrictions. The federal government does not bar the use of VC tools: in fact, it has recently advocated for their use. However, certain federal rules and procedures can indirectly hamper the use of VC tools. For example, if transit projects use federal funds, then public agencies might be barred from certain activities, such as land acquisition, before the completion of the National Environmental Policy Act (NEPA) process; this, in turn, may reduce land banking opportunities if land values rise significantly by the time the NEPA process is complete.

c) Costs of implementing the VC tools are higher than the revenue generated. Such a situation could arise if very little value is created or if the value is politically or administratively difficult to capture. For example, SADs might face opposition from home owners or businesses.

d) Pre-development speculation. Land prices can increase significantly in the time soon after a public transportation project is announced. This increase occurs in anticipation of the enhanced transportation accessibility and mobility arising from the new transit service. However, the increases in land prices make it expensive for the developers to buy land to build TODs. On the other hand, since the construction of the transit system may take several years (often decades), developers trying to build TODs concurrently or soon after the commencement of the transit service usually do not have the holding capacity to buy land immediately following project announcement. Therefore, they often look to public agencies, such as transit agencies and local governments, for land. However, public agencies may face legislative, policy, and financial barriers. For example, many transit agencies are only allowed to acquire land to provide transit, not TODs. Legislative action is often needed. For example, before the Assembly Bill (AB) 670 of 1999 allowed three transit agencies in the San Francisco Bay Area to "acquire and receive property for the purposes of establishing transit-oriented joint developments," these agencies were unable to do so. Many other transit agencies in California and across the country are still unable to acquire land for TODs. Even when public agencies are allowed to acquire land, funding is often limited. Therefore, many cities are considering or have employed land acquisition/ banking funds to enable the early purchase of land. The funds often come from impact fees, transportation and housing funds, corporate philanthropy, family foundations, and federal/state assistance. For example, the Twin Cities Land Bank serves the seven-county Twin Cities region in Minnesota. It has spent over $\$ 100$ million acquiring land that has enabled the construction of more than 1,400 real estate projects and 3,500 housing units. The South Corridor Land Acquisition Fund helped to make a land purchase along Charlotte, NC's South Corridor light rail line. More recently, in 2013, a non-profit, the Urban Land Conservancy, purchased 9.4 acres of land along a commuter rail line-the East Rail Line-in Denver, CO. It sold 2.5 acres of this land to an affordable housing developer. However, the site was acquired only three years before the service on the rail line commenced because Urban Land Conservancy does not function like a typical 
land bank. It looks for short-term development potential when it purchases land, instead of the medium- to long-term horizon of land banks.

e) Risks and transaction costs associated with the use of VC tools. For example, property owners might oppose SADs, and public agencies might expend significant time and resources addressing this opposition. Therefore, SADs might be appropriate if the expected revenues are large enough to justify the risk and the high transaction cost. Similarly, taxing jurisdictions might oppose the use of TIF. Furthermore, revenues from joint development projects, impact fees, and TIF are often susceptible to downturns in the real estate market.

f) Lack of institutional capacity to implement VC mechanisms or create suitable conditions to maximize value creation. This point includes a lack of capacity to negotiate with developers for jointly developing a TOD; a lack of capacity to go through the entire joint development process, from issuing request for proposals (RFPs) to asset management/disposition; or a lack of expertise to use TIF. The lack of institutional capacity becomes even more problematic if transit agencies are restricted from outsourcing such tasks. For example, the Regional Transit Agency (RTA) that serves the Chicago, IL region cannot outsource the management of its real estate assets.

g) Land acquisition barriers. Often, transit agencies are prohibited from acquiring land for TODs. Furthermore, local governments and transit agencies may not have the funds to acquire such land. Some progress has been made, however. For example, Dallas Area Rapid Transit (DART) has a very progressive TOD policy that allows "strategic acquisition of property to capture potential TOD opportunities."

h) Lack of institutional focus. Transit agencies need to proactively engage with developers and local governments to create real estate value and to use VC tools to capture that value. However, internal and external barriers often exist. For example, governing boards of many transit agencies do not feel that the use of VC tools is their agency's job; or, the transit agencies do not have staff dedicated for this purpose. One the other hand, some transit agencies lead the way. For example, Washington Metropolitan Area Transit Authority (WMATA) and BART work with the local governments to enable transit-supportive zoning around their stations and actively seek developers to build TODs. Both WMATA and BART have departments focused on developing TODs through a joint development process. The need for such in-house capability has been highlighted by extant literature.

i) Inequities created by the use of VC tools. For example, TIF-led redevelopment could lead to a property value increase, which, in turn, could increase apartment rents. Such rent increases can make housing unaffordable for low-income renters, thereby displacing them. Such displacements could lead to community opposition to the use of TIF. Therefore, some states include policy features to mitigate displacement. In Illinois, redevelopment plans often budget funds for mitigating impacts of displacement on community members. Similarly, when localities in California undertook TIF-backed redevelopment through the redevelopment 
agencies, such agencies were required to allocate at least $20 \%$ of the tax increment to affordable housing. Finally, the use of $\mathrm{VC}$ to fund TODs could lead to real estate development where the increases in land values are high, not necessarily where such development is needed (often the low-income neighborhoods where a high proportion of community members is likely to use transit). 


\section{NATIONAL SURVEYS}

\section{SURVEY METHODOLOGY}

Two nation-wide surveys were conducted-the transit agency survey and the local government survey. Both the surveys sought to fill two research, policy, and practice gaps in promoting TODs: (a) how to facilitate TOD-supportive land use and zoning; and (b) how to use the transit and TOD-generated land value increase to fund TODs through VC tools.

Each survey was divided into two sections:

Section 1: Land use and zoning-related barriers to the implementation of TODs, and the ways in which these barriers have been, are being, or can be overcome in the survey respondent's service area;

Section 2: Barriers to the use of VC to fund TODs, and the ways these barriers have been, are being, or can be overcome in the survey respondent's service area. The survey instruments for the transit agency survey and the local government survey are in Appendices A and B, respectively.

The transit agency survey was sent to top 101 transit agencies that operate in the 50 states of the US. Ridership, as measured by the unlinked passenger trips (transit industry's standard measure for ridership) was used to identify the top transit agencies. Annual Data Tables for 2017 were downloaded from the FTA's NTD website. The data tables were downloaded as an Excel spreadsheet that contained four worksheets. The data in the worksheet titled "Metrics" contained details for 3,711 transit agencies.

\section{Selection of Transit Agencies and Cities to Survey}

The transit agencies were chosen using the step-wise process noted below.

a) Agencies marked "Rural Reporter" and "Reduced Reporter" were deleted. This led to the omission of transit agencies operating in rural areas (rural reporter) and those "operat[ing] 30 vehicles or less across all modes and types of service and do not operate fixed guideway and/or high intensity busway operate" (reduced reporter).

b) Under the "Organization Type" column, all agencies identified as "Tribe," "University," and "Private-for-Profit" were omitted. These led to the omission of (i) transit agencies such as those that operate in Indian reservations such as the transit agency titled "Chemehuevi Indian Tribe" that operates two ferry boats and (ii) transit agencies that serve universities, such as the University of Michigan Parking and Transportation Services, which operates 43 buses to serve the University of Michigan campus.

c) Under the column titled "State," 50 US states were selected. This led to the omission of one transit agency in Puerto Rico (a US territory).

d) Duplicates in the transit agencies' name were deleted. For example, "MTA New 
York City Transit" occurs five times and "New Jersey Transit Corporation" occurs eight times. Some duplicates were not that obvious. For example, Phoenix, AZbased Regional Public Transportation Authority is the same as Valley Metro Rail, Inc.

e) Transit agencies that are subsidiaries of other transit agencies or are affiliated with another transit agency were omitted. For example, MTA Bus Company was omitted. Suburban Mobility Authority for Regional Transportation was omitted because it is affiliated with the City of Detroit Department of Transportation. A total of 524 transit agencies remained in the dataset after this step.

f) Average and median values were calculated for unlinked passenger trips for the dataset. The average was $18,009,449$ and the median 1,570,977. The wide difference between the average and the median indicated that few transit agencies had a very large number of unlinked passenger trips.

g) The data were sorted by the decreasing number of unlinked passenger trips to investigate data distribution. It was noted that 14 transit agencies had more than 100 million unlinked passenger trips. Average and median were calculated for unlinked passenger trips after excluding these 14 large transit agencies. The average was $5,983,670$ and the median $1,539,360$.

h) A threshold of 6 million unlinked transit trips was used to select transit agencies for the survey. This resulted in a list of 107 transit agencies.

i) In many cases, the transit systems are run by city/county departments. In these cases, either the transit survey or the local government survey was sent to the appropriate city/county government.

j) Online searches were conducted to identify the appropriate person to whom the survey should be sent; an ideal respondent was the person managing the planning and implementation of TODs for a transit agency. A combination of keywords such as "name of the transit agency," "property division," "real estate," "TOD," "TOD manager," "transportation planner," "executive staff," "executive team," was used to identify the appropriate staff member(s). Next, searches were conducted to find their email addresses. In a couple of cases, email addresses could not be found, and in two other cases, the email sent bounced back. Hence, in all, 101 transit surveys were successfully sent out.

The local governments were chosen using the following steps:

a) The biggest city (by population) served by each of the above-selected 107 transit agencies were identified, assuming that big cities served by a large transit agency are more likely to support TODs than smaller cities.

b) Overall, 82 local government surveys were sent, lower than the 107 transit agencies, because in many cases, a city was served by more than one transit agency, or the 
transit survey was already sent, or the email addresses were not found.

\section{Survey Responses}

Thirty transit agency surveys and 25 local government completed surveys were received for response rates of $29.7 \%$ (30 out of 101 ) and $30.5 \%$ ( 25 out of 82 ), respectively. The responses are fairly well distributed by transit system size. For the transit agency surveys, $19 \%$ of the surveys are from transit agencies in the first quartile (bottom $25 \%$ of agencies) by size, $23 \%$ by those in the second quartile ( $26 \%$ to $50 \%$ percentile), $26 \%$ by those in the third quartile (51\% to $75 \%$ percentile), and $32 \%$ by those in the fourth quartile (top $25 \%$ of agencies); see Figure 1. The one-sample chi-square test for this distribution is statistically insignificant $(p=0.307)$, indicating that the distribution of the transit agency surveys by the transit system size is not statistically significantly different from an even distribution, that is, an equal number of surveys from each quartile.

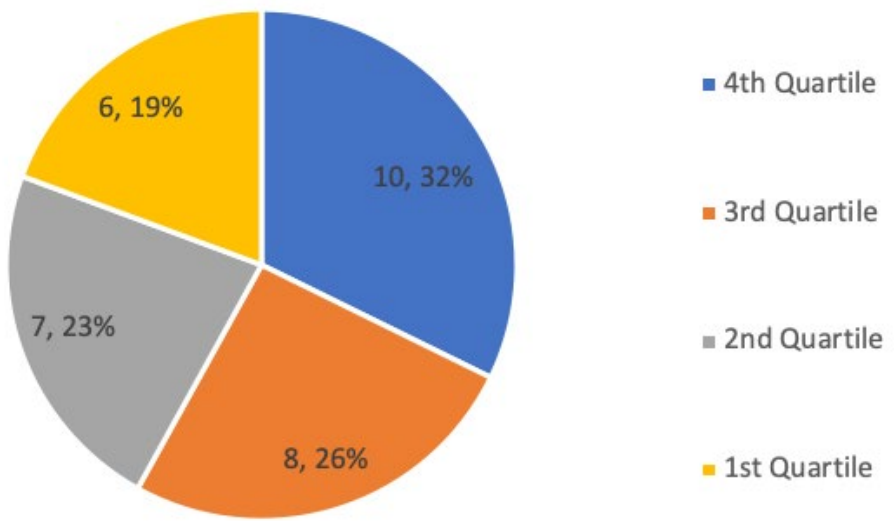

Figure 1. Distribution of Transit Surveys by the Size of Transit Systems

Five local governments in the service area with the smallest transit agencies (first quartile) responded, compared to 7, 7, and 6 in the second, third, and fourth quartiles, respectively. With a p-value of 0.93 on the one-sample chi-square test, the distribution of the local government surveys by the transit system size is also not statistically significantly different from an even distribution (see Figure 2), that is, $25 \%$ surveys in each quartile.

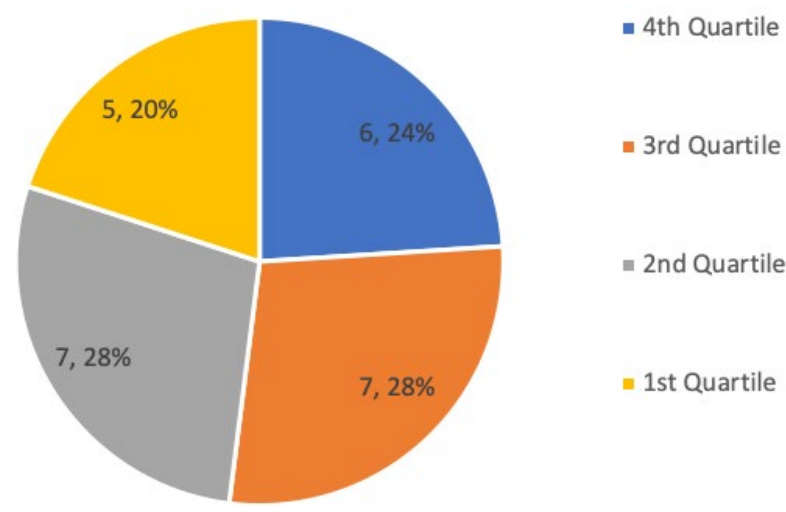


Figure 2. Distribution of Local Government Surveys by the Size of Transit Systems SURVEY FINDINGS

The surveys had both open-ended and close-ended questions. The section below provides key insights gleaned from both the qualitative and quantitative survey data.

\section{Prevalence of TODs}

The surveys show a strong prevalence of TODs across the nation and among various-sized public agencies, with over $80 \%$ of survey respondents indicating at least one TOD in their service areas (Figure 3). Of the respondents who indicated having no TODs, $10 \%$ of transit agencies had no TOD in the planning or entitlement phase, while fewer than $5 \%$ of local government agencies did not have a TOD in the planning or entitlement phase at the time of survey.

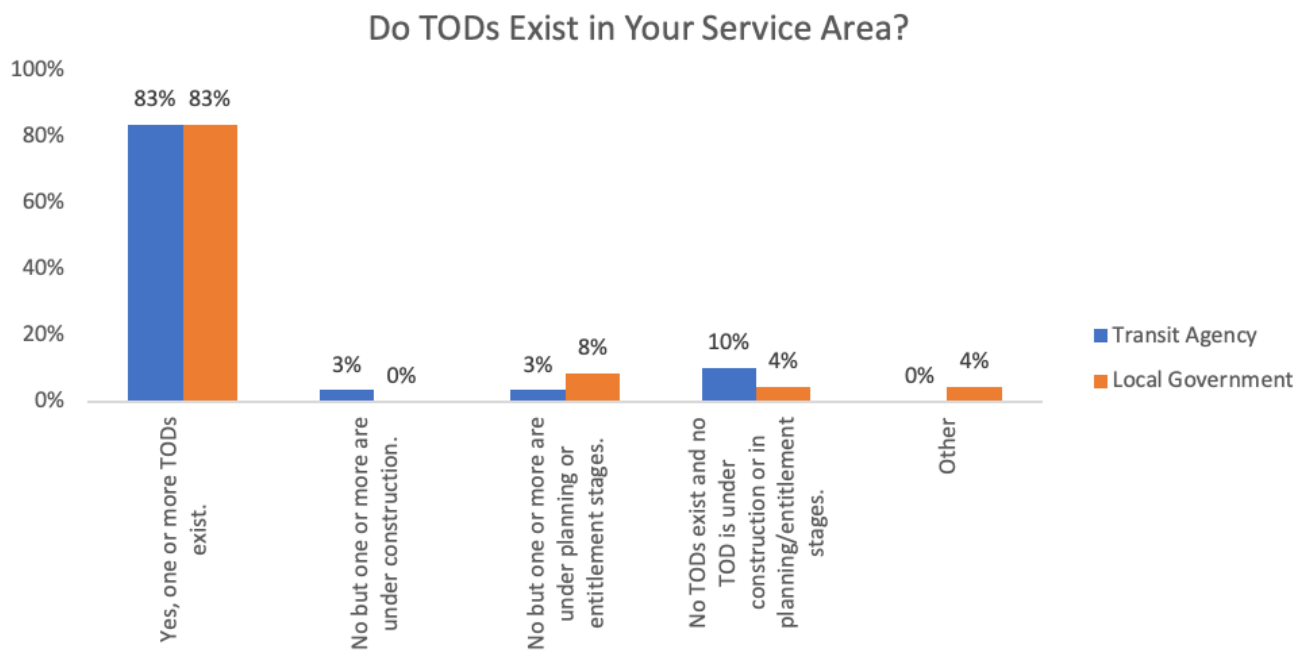

Figure 3. Over $\mathbf{8 0} \%$ of Survey Jurisdictions Have at Least One TOD

Note: 30 transit agency surveys received (1 non-response); 25 local government surveys received (1 non-response). 


\section{Formal and Informal TOD Programs}

While the prevalence of TODs in transit service areas is high, under half of the transit agency respondents indicated having a formal program encouraging the implementation of TODs (Figure 4). This number increases to almost $75 \%$ for local government respondents, perhaps explained by their influence over land use and zoning.

\section{Is There a Formal Program to Encourage TODs?}

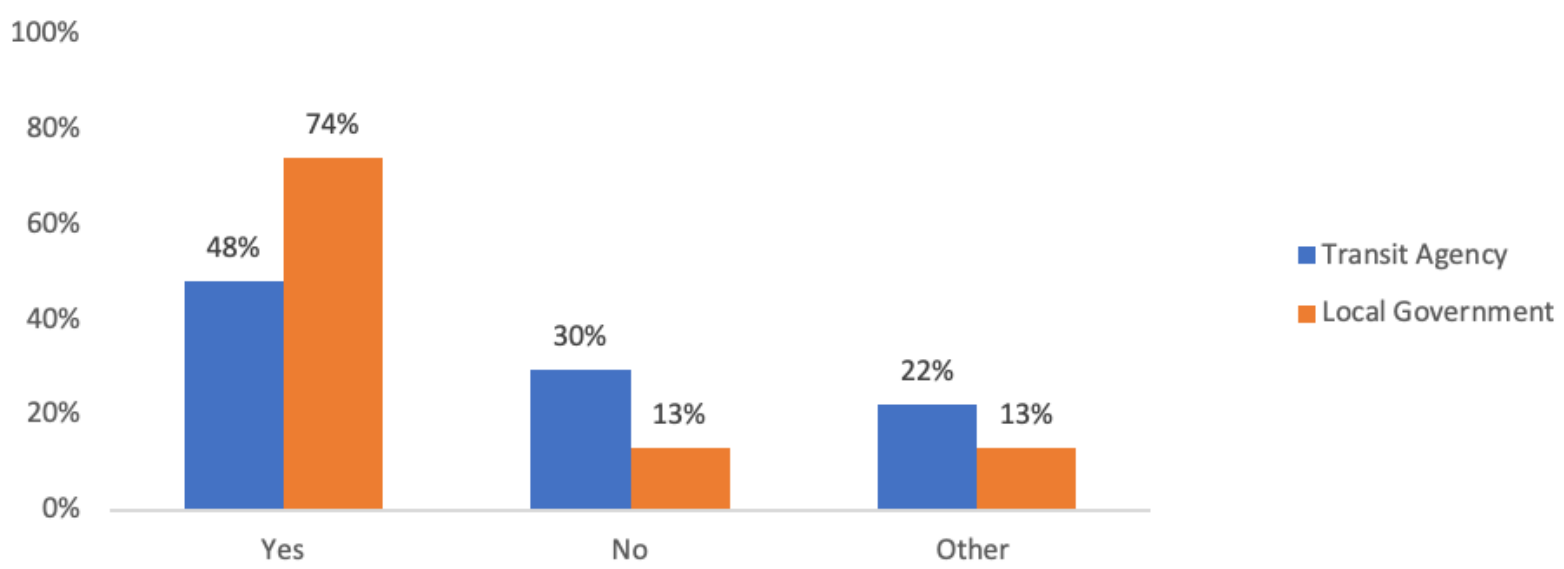

\section{Figure 4. Formal Programs to Implement TODs Vary Among Local Governments and Transit Agencies}

Note: 30 transit agency surveys received (3 non-responses); 25 local government surveys received (2 non-responses)

While a large majority of local governments and transit agencies noted the existence of a formal TOD program, in most cases, TOD-related policies/programs are embedded in various initiatives, planning documents, and zoning codes, not existing in the form of a stand-alone program. For example, among the local governments, Everett, WA pointed to their plans and policies for "Metro Everett," an area of over one square mile that includes, among others, their downtown business district, Everett station area, and surrounding commercial and residential areas. Long Beach, CA, pointed to their downtown plan, the midtown specific plan, and the land use element of their general plan. In Louisville, KY, the land development code provides a framework and approval process for creating Planned Transit Development (PTD) Districts. Similarly, Charlotte, NC, allows TOD Districts under their Unified Development Ordinance. In Reno, NV, the zoning code allows for increased density, flexibility in design regulations, and fast-tracking processes when development meets TOD zoning. In Chicago, TOD project development benefits are embedded within various sections of the city's zoning code that address development density, FAR, height, and parking limits. Each section of the code on those topics includes a clause for parcels in transit-served areas and lists the more permissive guidelines for those site-specific developments.

In San Carlos, CA, TOD-supportive goals, policies, and zoning are noted in the housing element of the city's general plan. Milwaukee, WI, has the Moving Milwaukee Forward initiative which provides a framework for attracting investment, enhancing connectivity, and reinforcing neighborhood identity through the future expansion of the Milwaukee streetcar 
system to nearby historic neighborhoods by means of equitable growth through TOD. Finally, Salt Lake City, UT pointed to the existence of TOD-supportive zoning around the major transit system such as the commuter rail, the light rail, and the streetcar systems.

Among the transit agencies, North County Transit District of North San Diego County, CA has board policies related to joint development and the use of the transit district property. Connecticut Department of Transportation observed that even though they did not have a formal program with dedicated funding, they supported TOD through an informal program in the following ways: (1) acting as a participating member of an inter-agency TOD working group that coordinates funding and support for different TOD projects; (2) assisting the CT Office of Policy \& Management with the administration of TOD grants to municipalities; (3) offering technical assistance for TOD planning to municipalities; (4) conducting TOD plans/studies; and (5) participating in joint development agreements per the agency's statutory authority.

Spokane Transit Authority, WA, noted TOD-related goals, principles, and policies in their comprehensive plan, but the agency has not created a formal program to implement them. Westchester County Public Works and Transportation, PA noted that TODs are encouraged as part of the Westchester County's land use review process. San Francisco Municipal Transportation Agency (SFMTA) pointed to the two components of their TOD program. First is working with the planning department for the City of San Francisco, CA, to facilitate greater density along high-capacity transit routes. The second component is actually pursuing development on SFMTA-owned property.

Some cities and transit agencies have formal, stand-alone TOD programs. For example, among the cities, San José, CA, has an Urban Villages Program, and San Mateo, CA, has a comprehensive Corridor Transit Oriented Development Plan for creating TOD within a half-mile radius of two commuter rail stations located within city limits. In Arizona, Phoenix's TOD program contains materials to educate the public and developers on how to build TOD projects. The city also has a TOD Strategic Policy Framework to "improve the investment environment around key nodes in the Phoenix transit network and guide sustainable urban development to benefit all residents." Similarly, Honolulu, Hawaii's TOD program provides an overview of Oahu island's TODs; the TOD-related legislation and planning documents, including the eight TOD plans adopted so far; and a description of other resources such as opportunities for constructing TODs on public lands.

A Port Authority of Allegheny County, PA program includes a station improvement program under which the agency evaluated all 69 unique station locations. The program seeks to identify and prioritize investment into existing fixed-guideway assets to encourage more transit ridership and investment. Other program components include TOD Guidelines and TOD Zoning Best Practices documents.

A Utah Transit Authority program includes the policy and procedures, the standard operating procedures (for example, those related to planning, implementing, and managing the agency's involvement in transit-oriented development), the design guidelines, and the station area plans. In Georgia, the Metropolitan Atlanta Rapid Transit Authority (MARTA) has a TOD group that actively seeks to develop TODs around MARTA stations. Toward that goal, the agency 
has developed TOD guidelines and implementation policies. These include policies related to joint development on MARTA's property and those related to station area development in which MARTA is a stakeholder but not a direct participant. BART's TOD program includes the TOD Policy, TOD performance targets, and the Affordable Housing Policy. Additionally, the agency's strategic plan and the station access policy inform their TOD program.

In Phoenix, AZ, Valley Metro's TOD program includes the agency's vison, mission, goal, and policies for TOD implementation. Additionally, the agency has developed TOD station profiles, a TOD strategy, and other related resources such as station area plans. Each TOD station profile sheet describes the station characteristics, such as the location, station-area demographics, ridership details, the type of transit service provided by the station, and potential TOD sites. This profile sheet is available to developers and other stakeholders to identify sites for future TODs.

Finally, RTD Denver has a very comprehensive TOD program that, apart from describing the advantages of TODs, also includes TOD Evaluation Guidelines, TOD Status Report, Design Criteria, and the Strategic Plan for TOD. Furthermore, the agency's "TOD group manages and conducts research to support transit-oriented development, shares information with both public and private sector partners, and provides planning assistance to help local jurisdictions connect constituents to transit service. Examples of their research include catalog of development around rail and BRT stations, which includes TOD property database, TOD station area master plans, GIS map of TODs, and an illustrated summary of TODs in the transit district. 


\section{Other Ways to Encourage TODs}

When asked if their agency encourages TODs in other ways such as through financial incentives and relaxed parking standards, a small proportion (one-third) of the transit agency participants - but an overwhelming majority (around 90\%) of the local government participants-responded yes (Figure 5). Therefore, the survey responses show that a significant proportion of transit agencies do not encourage TODs in ways other than a formal TOD program.

\section{Are There Other Ways to Encourage TODs?}

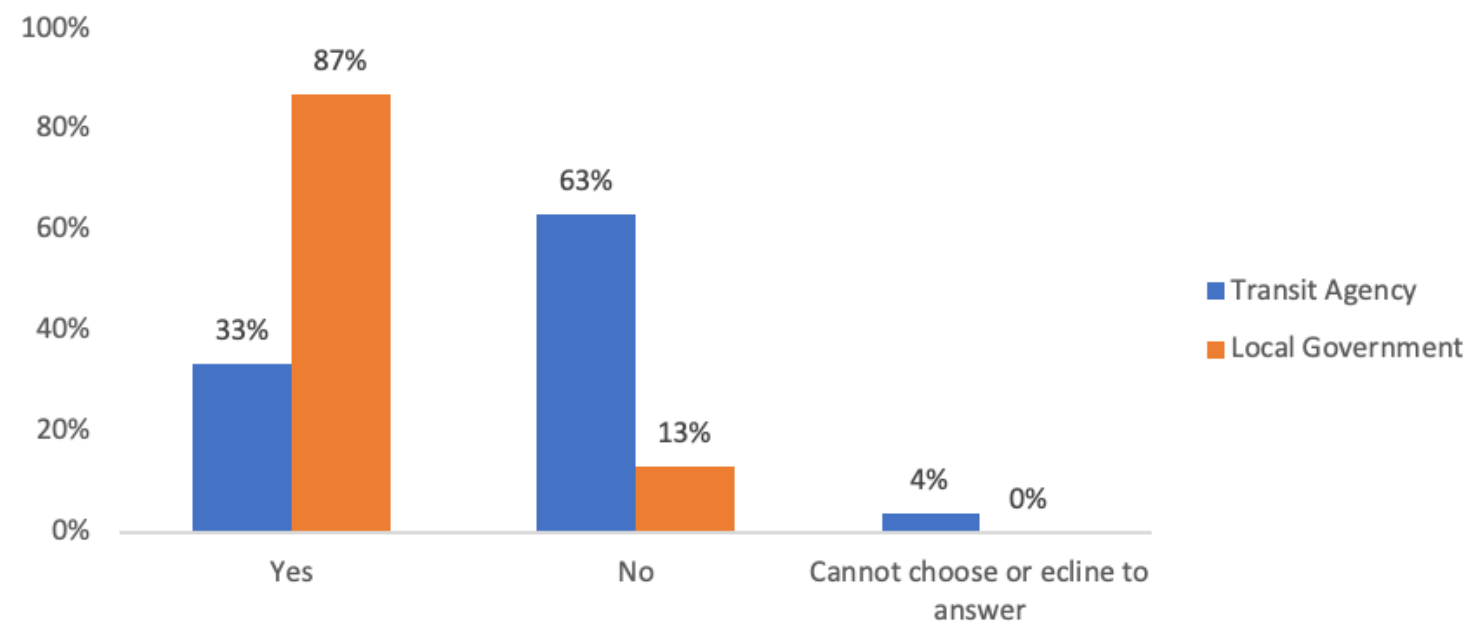

Figure 5. Local Governments Have More Opportunities to Encourage TODs Than Transit Agencies

Note: 30 transit agency surveys received (3 non-responses); 25 local government surveys received (2 non-responses)

\section{Ways to Address Land Use and Zoning-Related Barriers to TOD Implementation}

The survey also asked respondents how their agencies address land use and zoningrelated barriers to TOD implementation (see page 4 of Appendices A and B for the list of options). Results show that transit agencies have very little control over the land use and zoning-related issues that impact implementation, meaning that transit agencies play a role secondary to local governments (Figure 6). This secondary role is perhaps why slightly more than half of the transit agencies note that they jointly address these issues in partnership with the local jurisdictions and other public agencies (Figure 6). 
Transit Agencies' Response to Addressing Land Use- and Zoning-Related Issues that

Impact Implementation of TODs

$100 \%$

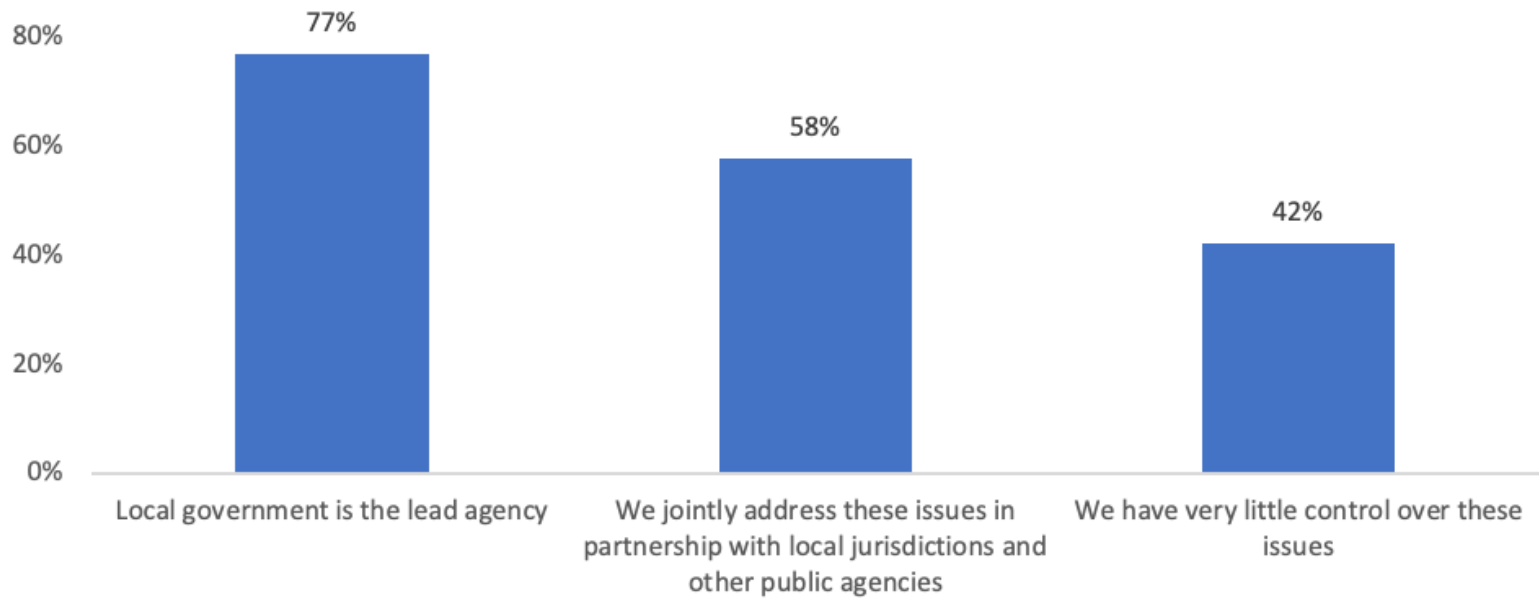

Figure 6. Top Three Options Chosen by Transit Agencies to Address Land Use and Zoning-Related Barriers

Note: 30 transit agency surveys received (4 non-responses)

Local Governments' Response to Addressing Land Use- and Zoning-Related Issues that Impact Implementation of TODs

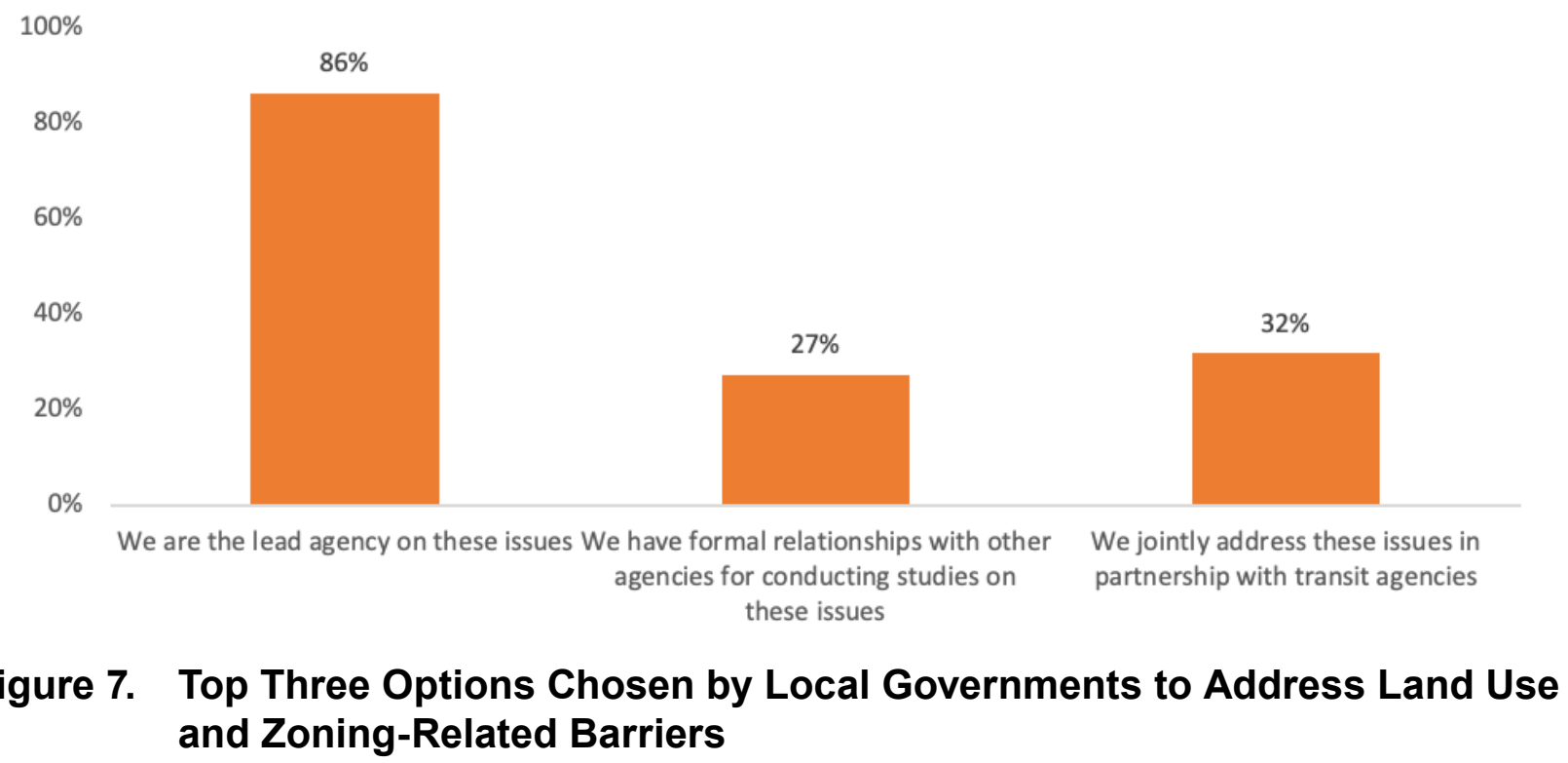

Note: 25 local government surveys received (2 non-responses) 


\section{Most Frequently Used Land Use and Zoning Tools to Promote TODs}

Survey respondents were asked to indicate their most frequently used land use and zoning tools which aid the construction of TODs. The top-three tools are consistent across both surveys. They occur as follows in decreasing order of use frequency: (1) mixed-use zoning, (2) relaxed parking standards, and (3) zoning for compact housing types such as apartments, condominiums, and townhouses (Figure 8).

\section{Most Frequently Used Land Use and Zoning Tools to Promote TODs}

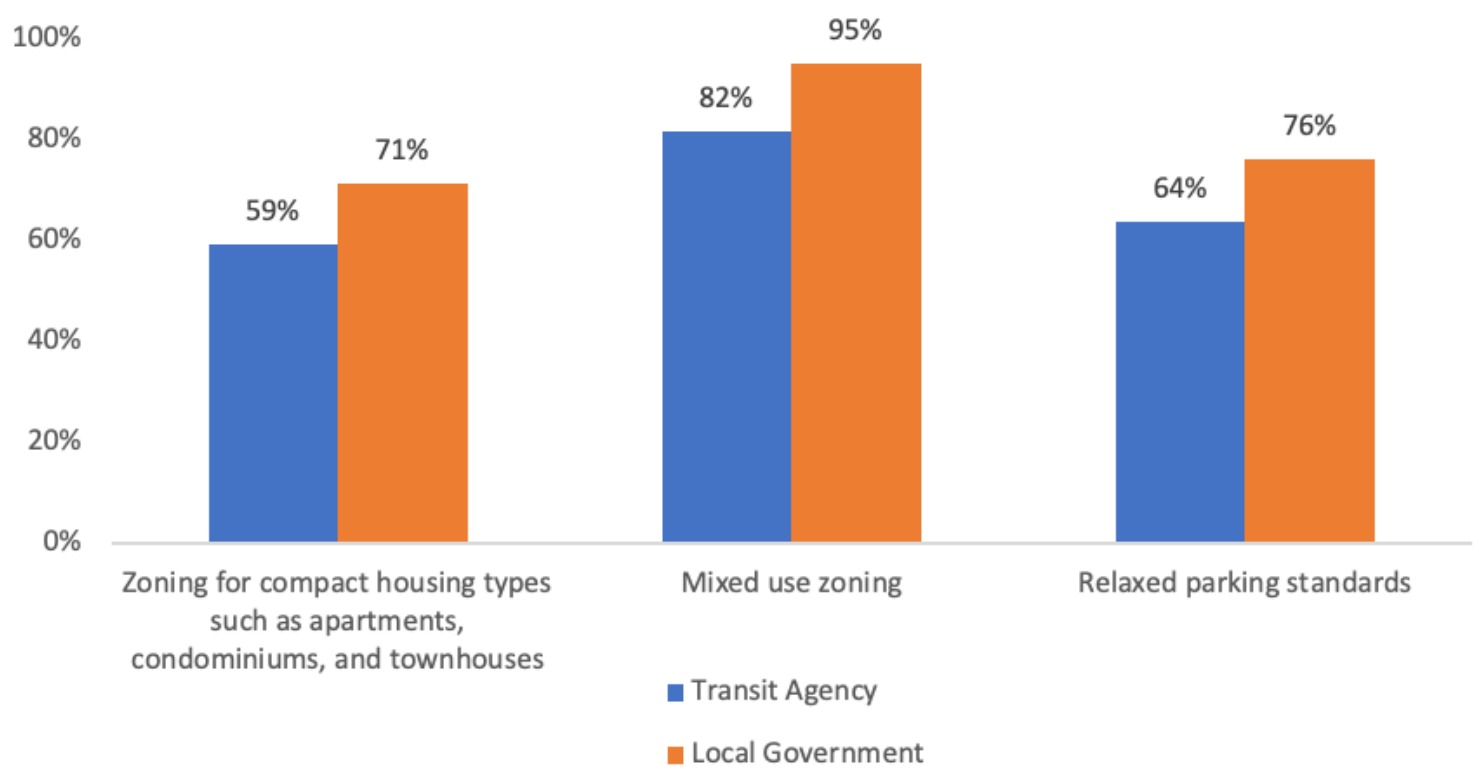

Figure 8. Mixed Use Zoning is Widely Used to Promote TODs

Note: 30 transit agency surveys received ( 8 non-responses); 25 local government surveys received (3 non-responses)

\section{Least Used Land Use and Zoning Tools to Promote TODs}

Survey results show some consistency in the least used land use tools. For example, the use of eminent domain (other than for right-of-way acquisition) was noted as the least used tool by both transit agencies and local governments. Its use was reported by only $23 \%$ of transit agencies and $10 \%$ of local governments. The use of TDR is also among the least popular in both local government and transit agency surveys. However, while assistance with land assembly is among the least used tools noted by the transit agencies (Figure 9), the local governments noted reduced permit fees (Figure 10). 
$100 \%$

$80 \%$

$60 \%$

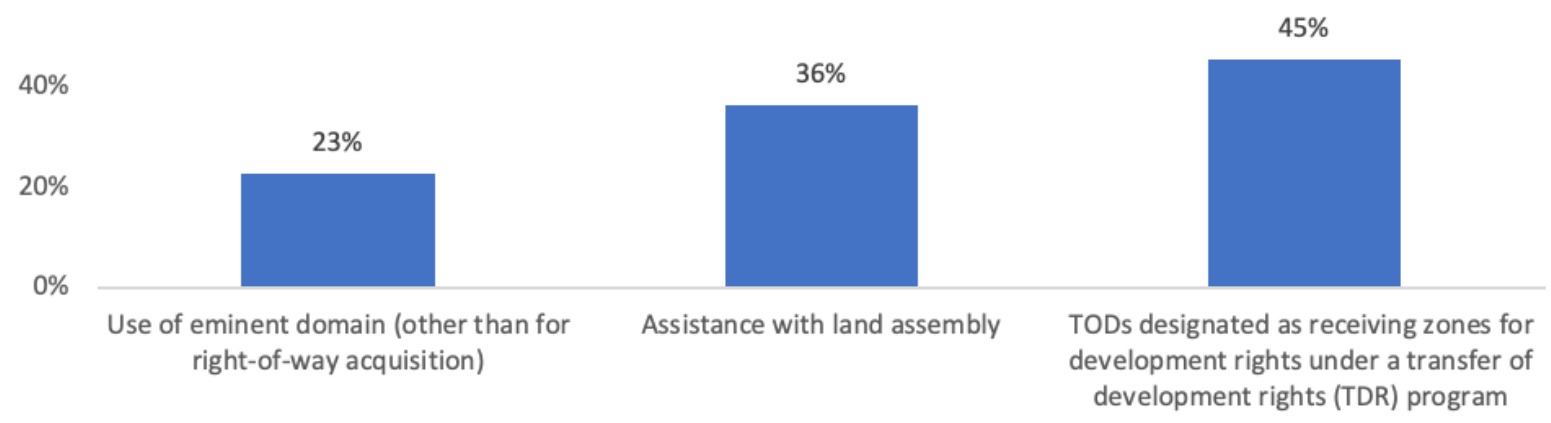

Figure 9. Least Used Land Use and Zoning Tools by Transit Agencies to Promote TODs

Note: 30 transit agency surveys received (8 non-responses)

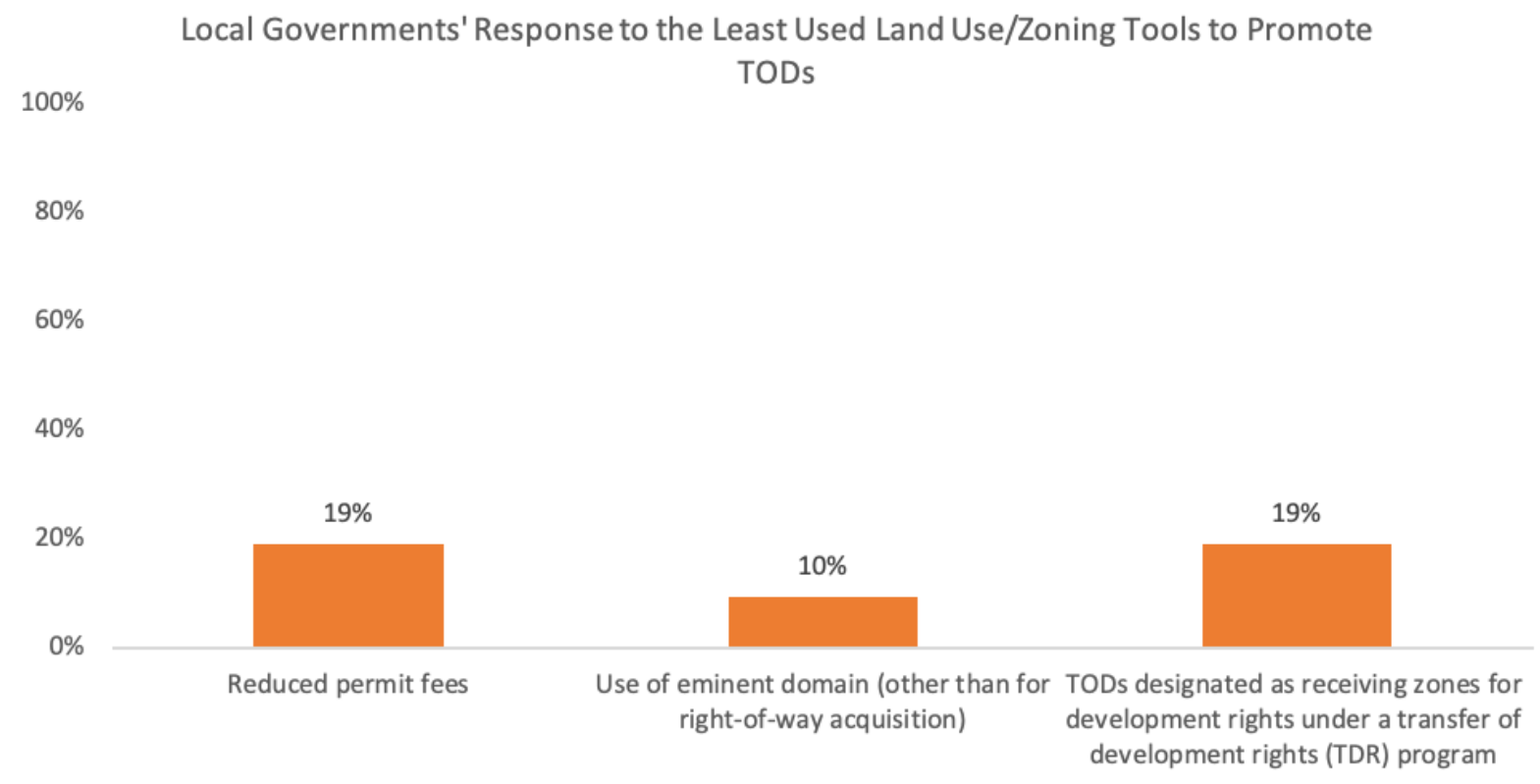

Figure 10. Least Used Land Use and Zoning Tools by Local Governments to Promote TODs

Note: 25 local government surveys received (3 non-responses)

Impact of Federal, State, Regional, or Local Laws, Policies, Plans, Funding Programs, or Financial Incentives on How Agencies Approach Land Use or Zoning

The survey responses show that transit agencies commonly identify their lack of land use and zoning powers when asked which federal, state, regional or local laws (including the 
statutory regulations governing their agency), policies, plans, funding programs, or financial incentives negatively impact how they approach land use or zoning.

Among other factors, SFMTA noted that CEQA results in a permitting process that is often lengthy, confusing, and expensive. It creates a constant threat of lawsuits that can derail projects. CEQA was noted as an obstacle by the City of Long Beach, CA, as well. Furthermore, despite the emphasis on expedited permitting for housing developments, the planning and zoning processes are lengthy, complicated, and subject to many discretionary approvals. Finally, constantly changing state laws (for example, $A B$ 1486) introduce complications into the development process. Passed in 2019, AB 1486 amends the state's Surplus Land Act, to, among others, include a larger group of public agencies (for example, cities, counties, and special districts, including school districts) under its ambit. It requires public agencies to notify housing sponsors about their intention to dispose of surplus lands. ${ }^{73}$ Through these amendments, the state hopes that more public surplus land can be used to develop housing.

MARTA noted the lack of state laws that encourage TOD-supportive land use. BART highlighted affordable housing funding programs, such as LIHTC, that do not allow parking reductions, nor unbundled or separate pricing for parking. RTD Denver noted that state statutes prohibit RTD from charging market rates for parking, and Spokane Transit Authority, WA noted the cities' minimum parking requirements as a hurdle.

Among the cities, Salt Lake City, UT pointed to a lack of TOD-supportive zoning around high-frequency bus lines, specifically, low building heights, parking requirements, and singlefamily zoning. The city also noted a lack of "teeth" or incentives provided by the state to encourage local government to adopt TOD-supportive policies. The city further observed that while regional plans include such policies, following them is optional. For example, recently, the state started requiring more housing, which they loosely tied to transportation funding. However, the requirement is very loose. Finally, the city noted that while state law allows transit agencies to partner with private developers to implement TODs, there is currently a cap of eight projects.

Continuing the focus on the states' role, San José noted that state laws could reduce discretion and public engagement. For example, local laws can facilitate development by allowing developers to pay fees in lieu of developing affordable housing units. However, state laws might prohibit such a waiver. Reno, NV, observed that the Southern Nevada Public Land Management Act emphasizes market investment in the suburbs at the expense of redevelopment and infill. The city further noted that none of their local agencies (Truckee Meadows Water Authority, NV Energy, District Health, Regional Transportation Commission, etc.) provide incentives to develop near transit. Boston, MA, highlighted that FAA height restrictions limit the ability to achieve higher densities.

Transit agencies commonly identified their work with the local governments when asked which federal, state, regional or local laws (including the statutory regulations governing the agency), policies, plans, funding programs, or financial incentives positively impact how they approach land use or zoning. For example, Spokane Transit Authority and Utah Transit Authority noted that they partner with local governments in developing plans. BART works with local governments to increase densities and reduce parking requirements near stations. 
San Diego Metropolitan Transit System's planning department provides input on local land use updates and policies. Indianapolis Public Transportation Corporation (Indygo) mentioned working with the City of Indianapolis to update the zoning code to enable TODs. The agency also noted that the city currently allows reduced parking minimums for developments located close to transit. VTA has created TOD "playbooks" that show how cities can maximize TODs around stations. They also review and comment on proposed projects near transit and act as informal TOD advocates with cities.

SFMTA works with the local government to craft land use regulations such as transportation demand management (TDM) ordinances that encourage developers to reduce or eliminate parking. Emphasizing a deeper role for their agency, Port Authority of Allegheny County noted that aside from a few overlay zoning districts that are largely ineffective, TOD-aware planning or policy is absent at the municipal level. In such a situation, the transit agency has led most planning and policy conversation on this topic and completed nearly all TODrelated planning.

A few transit agencies noted specific enabling laws/legislation. For example, BART mentioned AB 2923 (San Francisco Bay Area Rapid Transit District: transit-oriented development). This act (a) allows BART to be the lead agency for CEQA, (b) allows BART to set minimum height, density, parking, and FAR requirements to develop TODs on land parcels it owns within one half-mile of its stations, and (c) mandates that if the city's zoning is inconsistent with BART's, then the latter's will prevail. ${ }^{74}$ Additionally, both BART and OCTA noted that recent California state laws that encourage denser, mixed-use housing and infill developments aid TOD implementation. For example, SB 167 (Housing Accountability Act) passed in 2017 "prohibits a local agency from disapproving, or conditioning approval in a manner than renders infeasible, a housing development project for very low, low-, or moderate-income households or an emergency shelter unless the local agency makes specified written findings based upon substantial evidence in the record." ${ }^{75}$ SB 35 (Planning and Zoning: Affordable Housing: Streamlined Approval Process), passed in 2017, among others, requires California cities and counties that do not provide their share of housing to streamline the approval process for affordable multi-family housing and free it from being subject to a conditional use permit. The local governments either need to approve such housing projects within 60 days (for projects containing 150 housing units or less) or within 90 days (150+ housing unit projects), or they must explain reasons for permit denial. ${ }^{76}$

The Utah Transit Authority provides another example. SB 34 (Affordable Housing Modifications), which passed in 2019 in Utah, promotes planning for housing for households of all income levels and encourages coordination of this housing plan with transportation. Furthermore, local governments need to prepare "a moderate-income housing (MIH) plan" as a section of their general plan. A local government that is required to annually report on the implementation of its $\mathrm{MIH}$ plan should satisfy these requirements to remain eligible for state transportation funds. ${ }^{77}$

Connecticut DOT noted that it has the authority to participate in TOD projects pursuant to Connecticut General Statute 13b-79kk. VTA pointed to the authority to undertake joint development TOD projects under California Public Utility Code 100130.5, including the authority for eminent domain granted under California Public Utility Code 100131. WeGO 
Transit noted the SB 783 (and the corresponding HB 1384) that allows housing agencies in the state to carry out TOD redevelopment projects in transit-deficient areas and toward that end to acquire, clear, sell/lease land/property; borrow money; and receive federal grants. These housing agencies can also use (a) eminent domain power to acquire land for constructing public infrastructure/facilities such as transit lines, and (b) TIF to fund redevelopment projects. ${ }^{78}$ Other positive factors include conducive zoning and expedited permitting for affordable housing (noted by SFMTA).

The local governments often noted no/reduced parking requirements in their responses. For example, Louisville Metro Government, KY, indicated that parking minimums do not exist for their downtown area and that they are reviewing parking regulations to relax parking requirements in other urban corridors further. San José, CA, noted that their municipal code allows up to a $20 \%$ reduction in parking for projects within urban villages (these are often areas around or along transit lines) and up to a 50\% reduction if the projects have a TDM plan. Albany, NY, and San Carlos, CA, allow a $20 \%$ reduction in parking as well. In Illinois, Chicago's zoning code allows a 50\% reduction in parking by-right in transit-served locations and up to a $100 \%$ reduction with zoning approval. The city also allows 1:1 replacement of parking spaces with bicycle parking for buildings located within 250 feet of Chicago Transit Authority (CTA) rail stations. ${ }^{79}$ Milwaukee allows mixed-use with minimal parking requirements in many commercial corridors along transit routes. San Mateo and Boston allow reduced parking as well. Additionally, Boston provides density bonuses for affordable housing units in TODs. Density increases and bonuses are other popular tools that were noted by Las Vegas, NV and Reno, NV. Boston and Chicago pointed to their existing zoning code that allows for compact development around transit stations.

Several cities noted planning and zoning efforts tied to transit provision. Charlotte, NC, recently (in 2019) adopted a program to re-zone properties along its LYNX Blue Line light rail corridor to one of the four new TOD zoning districts to enable moderate to high intensity, mixed-use developments along the transit corridor. ${ }^{80}$ Everett, too, is making good use of a planned extension of a light rail line from a city to its south (Lynwood) by re-zoning around the planned light rail transit. EI Paso, TX, pointed to its smart code re-zoning policy, based on new urbanist principles that strives to create a walkable, transit-friendly, well-designed urban environment as the city is developing streetcar and BRT systems.

Several cities cite specific statutes, acts, measures, or programs that support TOD. Las Vegas, NV, pointed to NRS 287.250, which allows the creation of zoning districts; NRS 278.235 , which provides various tools to promote affordable housing, including donating/ leasing/selling city or county land for affordable housing, and establishing a process to expedite the approval of plans and specifications that help maintain and develop affordable housing; and NRS 278.160, which specifies the various elements (sections) of a general plan.

San José pointed to three recent state-level acts. AB 3194 (Housing Accountability Act: Project Approval), passed in 2018, promotes TODs by allowing development to occur even if zoning does not support it, but the general plan does; SB 1333 (Planning and Zoning: General Plan: Zoning Regulations: Charter Cities) also passed in 2018, requires zoning to be consistent with the city's general plan; and SB 330 (Housing Crisis Act of 2019) requires that if an 
applicant submits a development permit within a specific time period after the preliminary application stage, the project parameters that existed at the preliminary development stage should apply to the later stages. These project parameters include land use, zoning, fees, and design standards. Furthermore, this Act limits the number of public hearings and requires the local government to maintain a completeness checklist and hold applicants accountable to only those requirements that are in the checklist.

Los Angeles, CA, pointed to a city-wide measure JJJ which, among others, requires (a) provision of affordable housing units (or payment of in-lieu fees) for projects that include ten or more housing units and require changes to the general plan or zoning, and (b) development of an incentive program for including affordable housing in projects within one half-mile of major transit stops. The resulting Transit Oriented Communities Incentive Program incentivizes affordable housing development through reduced requirements for parking spaces and square footage of ground-floor commercial, and increased density and FAR. ${ }^{81,82,83}$ San Mateo, CA, mentioned SB 375 (The Sustainable Communities and Climate Protection Act of 2008) and Plan Bay Area. SB 375 is a statewide act that aims to meet the state's GHG emissions target by requiring regions to develop a Sustainable Communities Strategy to demonstrate how each region will achieve its GHG reduction targets. Among other aims, the Act creates CEQA streamlining incentives for projects that are consistent with the region's Sustainable Communities Strategy. ${ }^{84}$ The Plan Bay Area is a San Francisco Bay Area region-wide plan that seeks VMT reduction through a closer connection between transportation and land use to meet SB 375-related goals for the region. It encourages compact development around transit corridors and stations..$^{85}$

Reno, NV, notes that the Truckee Meadows Regional Plan directs growth for the greater region and provides direction for the densities with the TOD areas; Tacoma, WA, observed that the Washington State Growth Management Act promotes TODs.

\section{Statewide Vision, Policy, or Plan for Promoting TODs}

Answers are consistent across the two surveys when respondents are asked about the existence of a statewide vision, policy, or plan for TODs. Only about half of the survey respondents confirmed the presence of a statewide vision, policy, or plan which calls for compact development or TODs around transit stations (Figure 11). This finding highlights the need for states' leadership in promoting TODs through legislation, policy, or designated funding. 


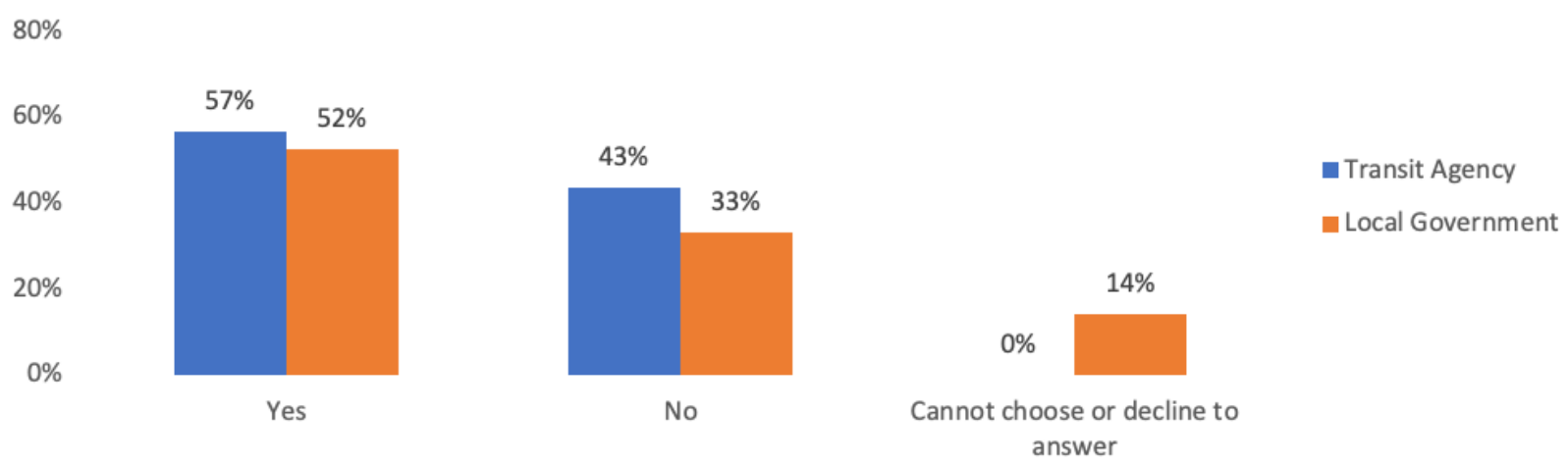

Figure 11. One in Two Survey Respondents Indicate Existence of a Statewide TOD Plan

Note: 30 transit agency surveys received (8 non-responses); 25 local government surveys received ( 3 non-responses)

\section{Regional or Statewide Growth Management Policies or Tools}

Only a little less than half of the respondents noted the existence of regional or statewide growth management policies or tools. This observation was consistent across both surveys (Figure 12). Examples of such growth management policies or tools include urban growth boundaries, concurrency and consistency requirements, and identification of growth areas with TODs promoted inside these growth areas. Results from Figure 11 and Figure 12 highlight a gap in state and regional leadership for implementing TODs.

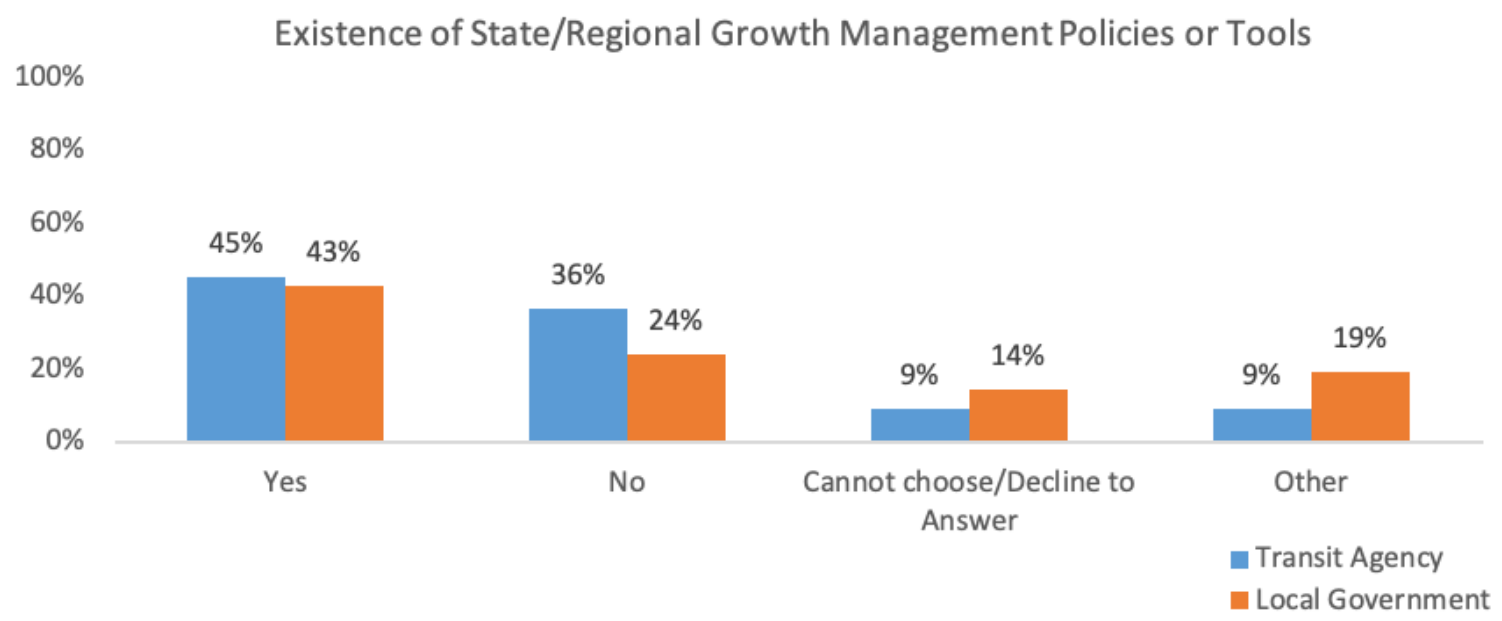

\section{Figure 12. State or Regional Growth Management Policies or Tools are Not} Widely Used

Note: 30 transit agency surveys received (9 non-responses); 25 total local government surveys received ( 3 non-responses)When asked to elaborate on the statewide vision, policy, or plan that calls for compact development or TODs around transit stations, and the stateand/or regional-level growth management/smart growth policies/tools, Everett noted that 
Washington State's Growth Management Act requires comprehensive planning for most jurisdictions in the state of Washington and encourages local jurisdictions to develop TODs near transit stations through the land use and transportation elements of local comprehensive plans. Tacoma, WA, pointed to the regional policy as articulated in Puget Sound Regional Council (PSRC) Vision 2050 and the Regional Transportation Plan, with the former calling for the concentration of growth near transit and in urban centers ${ }^{86}$ and the latter calling for the development of neighborhoods around transit stations.$^{87}$ California cities (Long Beach, Los Angeles, San Mateo, and San José), noted: (a) the climate protection acts (AB 32 and SB 375), as well as the CARB Scoping Plan that outlines the strategy for achieving the state's 2030 GHG reduction targets, which include promoting high-density transit-oriented housing; ${ }^{88}$ (b) SB 743, which shifts the metric for measuring the transportation impacts of projects for CEQA review from LOS to VMT reduction; (c) SB 330 (see above for description); and (d) the sustainable community strategy, which in the San Francisco Bay Area calls for focusing development in priority development areas.

The City of Niagara Falls, NY, pointed to the New York State Smart Growth Public Infrastructure Policy Act (SGPIPA) that was signed into law in August 2010. The Act intends to "minimize the unnecessary cost of sprawl development and requires State infrastructure agencies, including NYSDOT, to ensure public infrastructure projects undergo a consistency evaluation and attestation using the eleven Smart Growth criteria specified in the Act." ${ }^{89}$ Among others, these criteria seek to encourage development in municipal centers and in developed areas or areas designated for concentrated infill development. ${ }^{90}$

Other cities highlighted the existence of regional policies/programs. Chicago noted that the Regional Transportation Authority advocates for TODs in the Chicago metropolitan area, and Las Vegas, NV, pointed to the Southern Nevada Strong Regional Plan.

Finally, Salt Lake City, UT, observed that the state provides no "teeth" or incentives to encourage local governments to adopt TOD policies. Regional plans address TODs, but there is no requirement to follow them.

The transit agencies' responses are similar to the local governments'. For example, SFMTA mentioned AB 32, and WeGo Transit, Tennessee noted SB 783 and HB 1384. Additionally, the latter also pointed to other TOD-supportive documents such as the City of Nashville general plan and the MPO's regional transportation plan, as well as the strategic plan, nMotion, jointly prepared by the Nashville Metropolitan Transportation Authority and the Regional Transportation Authority of Middle Tennessee.

In responses similar to the municipal agencies', the transit agencies located in states with state-level growth management programs noted the existence of TOD-supportive growth management programs and tools. These included agencies include Lane Transit District, OR; Spokane Transit Authority, WA; and Community Transit, Snohomish County, WA. For example, Lane Transit District observed that Oregon's Department of Land Conservation and Development (DLCD) administers numerous programs oriented to growth management and that the state's land use laws generally call for the integration of land use and transportation. Spokane Transit District noted the state's concurrency laws, and Community Transit pointed to the mandated growth management and commute trip reduction requirements. 
The transit agencies noted the role of the state- and regional-level agencies and documents as well. Central Florida Regional Transportation Authority pointed to the TOD Guidebook prepared by the Florida State DOT. Spokane Transit Authority noted the 2016 Washington State Public Transportation Plan prepared by Washington State DOT. Utah Transit Authority highlighted Wasatch Choice 2050, a blueprint for the growth of the Wasatch Front region of Utah. OCTA noted the California Transportation Plan, the Southern California Association of Governments Regional Transportation Plan/Sustainable Communities Plan, and its own Congestion Management Program; MARTA observed that the MPO produces a Unified Growth Policy Map and provides funding for projects that conform to the recommendations of the policy map. BART and SFMTA noted the Plan Bay Area and the One Bay Area Grants that are offered under this plan for the planning and development of TODs. Finally, RTD Denver highlighted that Denver Region Council of Governments (DRCOG) promotes smart growth but has few tools to affect change in local land use regulations (i.e., zoning). DRCOG could reward communities that take steps to revise regulations to achieve its goals, but does not do so.

\section{Use of Cooperative Agreements to Promote TOD-Supportive Land Use and Zoning}

To get a better sense of how agencies implement TODs, the survey inquired about the use of cooperative TOD agreements. About half of survey respondents (for both surveys) noted an absence of cooperative agreements. For the transit agencies that use cooperative agreements, almost $30 \%$ indicated entering into agreements with city governments, and $11 \%$ indicated entering into agreements with redevelopment agencies. Transit agencies are less likely to enter cooperative agreements with state, regional, and county governments (Figure 13).

Local governments have cooperative agreements with transit agencies the most (23\%), and with MPOs and the other city governments the second most (18\%); however, over $40 \%$ of local government agencies indicated not using cooperative agreements at all (Figure 14). In summary, the survey results highlight that agreements between city governments and transit agencies are most popular for TOD development. The lack of agreements in almost two-thirds of cases indicates the need to promote inter-agency cooperation. 
Transit Agencies' Response to Types of Cooperative Agreements to Promote TOD-Supportive Land Use and Zoning

$100 \%$

$80 \%$

$60 \%$

$56 \%$

$40 \%$

$20 \%$

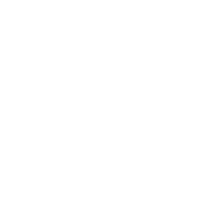

Figure 13. Two in Three Transit Agencies Do Not Enter into Cooperative Agreements for TODs

Note: 30 transit agency surveys received (12 non-responses)

When asked to describe the cooperative agreements, only a few local governments responded. Among those who responded, Everett noted a regional compact among a number of local and regional governments around "Growing Transit Communities," a planning document produced by their MPO, Puget Sound Regional Council, in which local agencies agree to promote TODs in appropriate locations to further regional and local plans. Salt Lake City, UT mentioned that the agreements are unique to each agency and include those around operating in ROWs, funding, and TIF. Finally, EI Paso, TX observed that the agreements are a work in progress and are not yet well defined.

Transit agencies noted a few cooperative agreements as well. For example, BART pointed to a former partnership with redevelopment agencies for many TOD projects (such partnerships were dissolved in California in 2011). Additionally, BART staff are currently actively participating with one successor agency, Pleasant Hill JPA. BART has an MOU with the City of El Cerrito and is negotiating one with the City of Berkeley.

Capital Area Transportation Authority (located in Michigan) noted the existence of agreements to share costs of infrastructure, facilities, and maintenance. VTA notes the presence of cooperative agreements for planning future development around transit stations.

Finally, Valley Metro (located in Phoenix, AZ) pointed to the existence of a TOD strategy that provides "a framework in the Phoenix metropolitan region to implement TOD strategies by 
leveraging collaborative partnerships between the Maricopa Association of Governments (MAG), Valley Metro, member cities and others including the development community."91 This strategy also assigns roles and responsibilities to the major partners: MAG, Valley Metro, and local jurisdictions. ${ }^{92}$

\section{Local governments' response to the types of cooperative greements to promote TOD-supporitve land use and zoning}

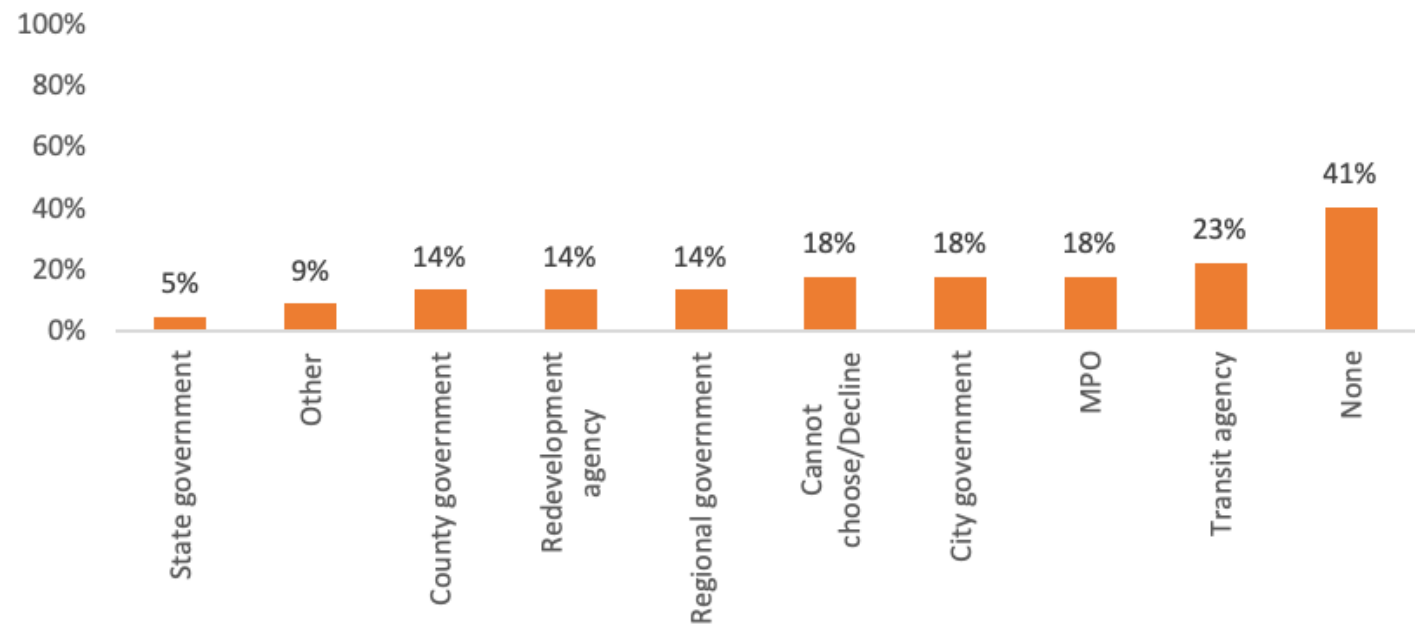

Figure 14. Local Governments Most Commonly Enter into Cooperative TOD Agreements With Transit Agencies

Note: 25 local government surveys received (4 non-responses)

\section{Use of Collaborative Arrangements to Promote TOD-Supportive Land Use and Zoning}

In addition to cooperative agreements, the survey asked respondents to identify whether their agency has entered into collaborative arrangements to promote TOD-supportive land use and zoning (Figure 15). Public-sector inter-agency committees or working groups are the most prevalent collaborative arrangement for transit agencies, with $55 \%$ of respondents indicating this arrangement exists. The most frequent arrangements for local government agencies are a) public-private organizations and committees and b) public-sector interagency committees or working groups, with a response rate of $41 \%$ each; followed by private sector committees or working groups at $23 \%$. 


\section{Types of collaborative arrangements to promote TOD-supportive land use and zoning}

$100 \%$

$80 \%$

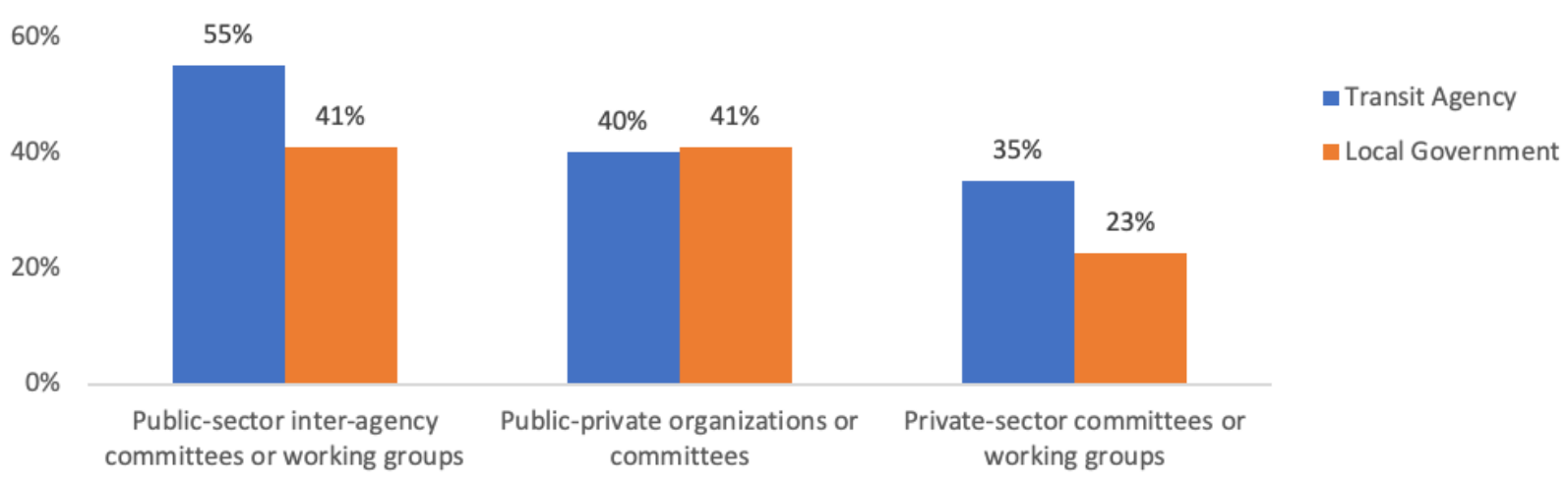

\section{Figure 15. Some Public Agencies Enter into TOD-Supportive Collaborative Arrangements}

Note: 30 transit agency surveys received (10 non-responses); 25 local government surveys received ( 3 non-responses)

When asked to describe the collaborative arrangements, Boston and Salt Lake City noted their councils of governments. The Salt Lake County Council of Governments has set up working groups to encourage cities to adopt TOD-supportive zoning. San Mateo pointed to the Rail Corridor Transportation Management Association (TMA), which is composed of developers or their representatives that have or are planning significant development within a one-half-mile area around two commuter stations located in the city, called the Corridor Plan Area. The Corridor Plan aims to reduce new vehicle trips by at least $25 \%$ corridor-wide. The TMA measures the number of vehicle trips generated by each development annually. The city is a non-voting member of the TMA. ${ }^{93}$

Everett noted a fledgling public-private partnership that promotes TOD near a transit station (Everett Station). Long Beach, CA, pointed to its downtown business improvement district in which the city participates. San José, CA, and Tacoma, WA, noted technical advisory committees. Chicago pointed to: (a) its equitable TOD Steering Committee that is evaluating the existing TOD program and will make recommendations in the third quarter of 2020; and (b) Elevated Chicago, a local non-profit focused on promoting public policy that facilitates equitable TOD projects.

Salt Lake City noted the working groups composed of local business groups and housing advocates to promote TODs. Los Angeles highlighted their collaboration with Metro (Los Angeles County Metropolitan Transit Agency) on joint development sites involving publicly owned sites adjacent to rail infrastructure. Milwaukee, WI, pointed to MKE United, a comprehensive planning process for developing a shared and inclusive vision for Downtown Milwaukee headed by community leaders from downtown Milwaukee and the adjoining 
neighborhoods ${ }^{94}$ and the collaborative efforts of the City of Milwaukee, the Historic King Drive Business Improvement District, Harbor District Inc., and the Walker's Point Association to promote equitable growth by creating the Transit Oriented Development Plan as a roadmap for development along the proposed streetcar extension from Downtown Milwaukee to adjoining historic neighborhoods. ${ }^{95}$

Honolulu noted a variety of collaborative arrangements, such as the Mayor's TOD subcabinet. The TOD subcabinet staff meets twice a month with the relevant city agencies to coordinate efforts. Furthermore, there is a state TOD Council which is a joint state/counties interagency working group focused on the development of state lands and prioritizing state investments and policies. Finally, several developer organizations and non-profit groups are active in supporting TOD and related programs, such as Urban Land Institute (ULI), Move Oahu Forward, AARP, and Ulupono Initiative.

Like local governments, transit agencies also noted various collaborative arrangements such as public-sector inter-agency committees or working groups, private-sector committees or working groups, and public-private organizations or committees. Non-profit and advocacy organizations were cited most frequently. For example, Utah Transit Authority pointed to the Congress for New Urbanism's Utah Chapter, ULI Utah, and Downtown Salt Lake City Alliance. RTC of Southern Nevada highlighted ULI Nevada; SFMTA and VTA noted the San Francisco Bay Area Planning and Urban Research Association (SPUR); additionally, VTA pointed to TransForm and SV@Home.

Among other collaborative arrangements, BART pointed to the TOD Implementation Working group hosted by the Great Communities Collaborative (GCC), which includes BART, VTA, Metropolitan Transportation Commission (MTC), and non-profit organizations such as NonProfit Housing (NPH) and TransForm. Port Authority of Allegheny County, PA, noted that it participates in neighborhood plan steering committees and institutional master plan review committees convened by the City of Pittsburgh. PAAC recently partnered with a non-profit organization, CONNECT, to provide TOD zoning technical assistance to small municipalities with transit assets. It also has a seat at the table with some land use regulators to influence their policies and planning, although this is not done with an explicit goal of promoting TOD.

RTD Denver mentioned that it meets monthly with City of Denver staff and occasionally with staff of other municipalities. In addition, RTD staff regularly attend committees convened by private-sector leaders, like the ULI.

\section{The Extent to which Land Use and Zoning Restrictions have been an Impediment to the Implementation of TODs}

More than three-quarters $(79 \%)$ of the transit agencies and around half $(45 \%)$ of the local governments note that land use and zoning restrictions are highly impedimentary or somewhat impedimentary. The larger percentage for the transit agencies could be due to the minimal control these agencies usually have over land use and zoning around station areas. However, many survey respondents did not answer this question. The non-response rate is $33 \%$ for transit agencies and $20 \%$ for local governments. Figure 17 displays the data when the non-responses are included. 
Extent to which land use and zoning restrictions have been an impediment

$100 \%$

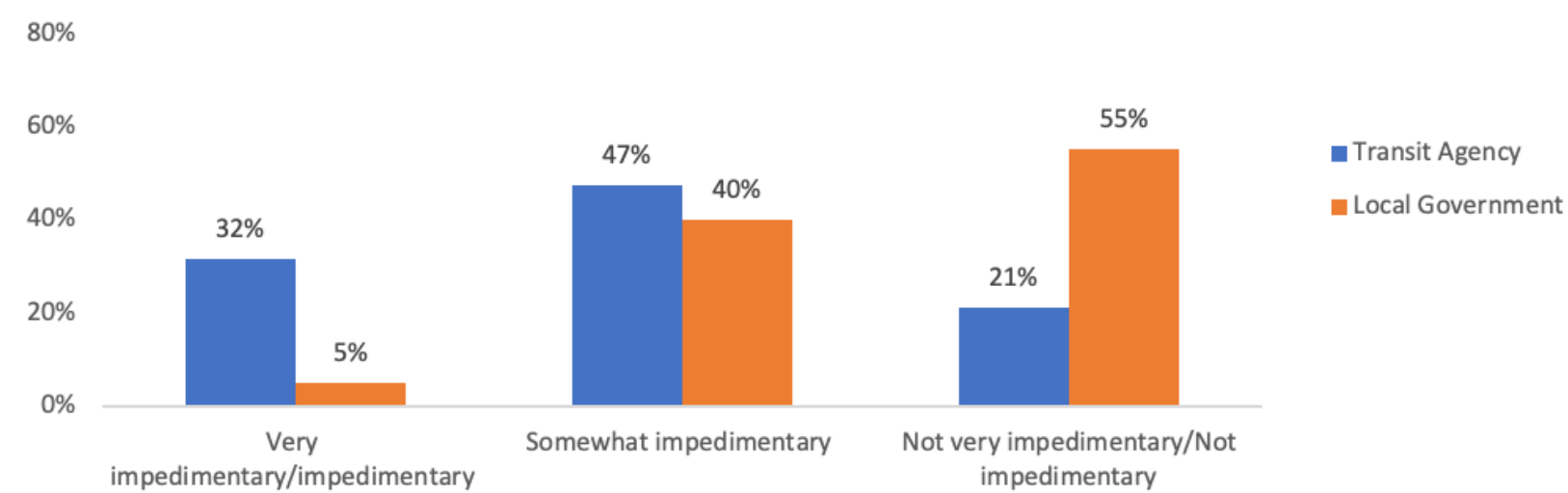

Figure 16. Land Use and Zoning Barriers Are Viewed as Highly or Somewhat Impedimentary

Note: 30 transit agency surveys received (10 non-responses); 25 local government surveys received ( 5 non-responses)

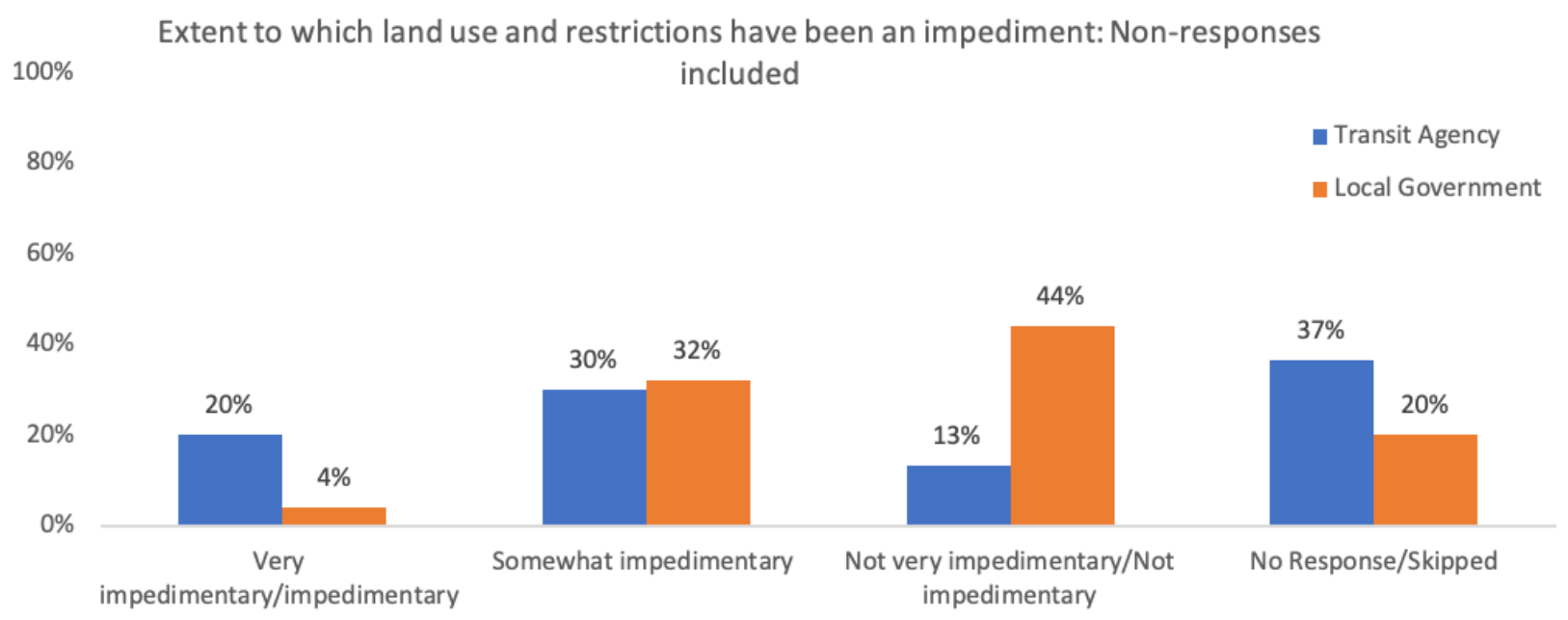

Figure 17. Public Agencies' Opinions on Zoning Restrictions, with NonResponses Included

Note: 30 transit agency surveys received (10 non-responses); 25 local government surveys received (5 non-responses)

\section{Whether Land Use and Zoning-Related Barriers Have Been Overcome, Are Being Overcome, or Are Planned to be Overcome}

Only about half of the transit agencies and local governments note that these impediments have been overcome, are being overcome, or are planned to be overcome (Figure 18). 
Have land use and zoning barriers been overcome, are bring overcome, or are planned to be overcome?

$100 \%$

$80 \%$

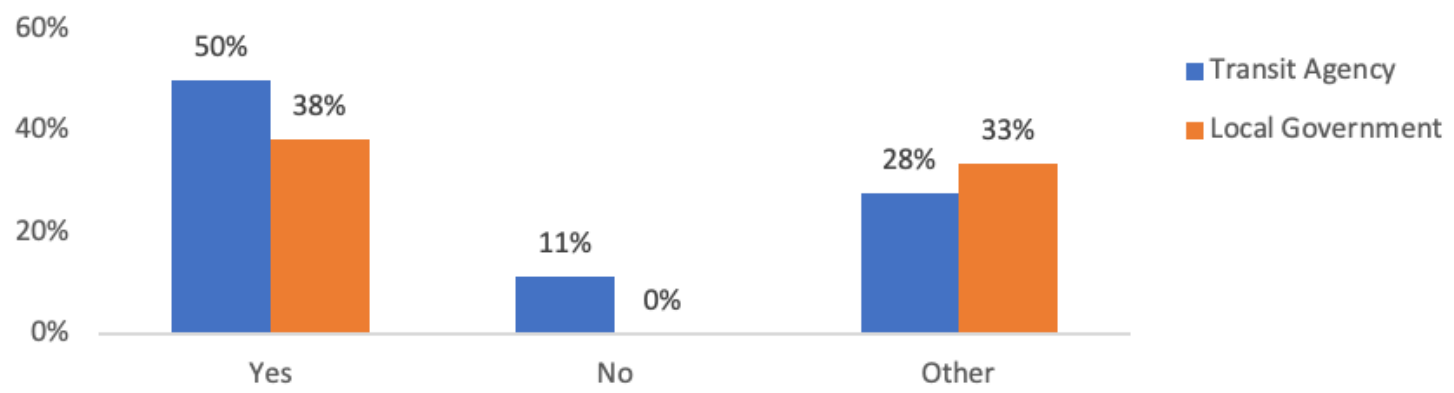

Figure 18. Land Use and Zoning Barriers are Somewhat Navigable

Note: 30 transit agency surveys received (14 non-responses); 25 local government surveys received (10 non-responses

Among the open-ended responses, the respondents provided a glimpse of the barriers. For example, San Mateo noted height- and density-related voter-imposed initiatives as key barriers; Los Angeles pointed to state-level environmental study requirements as the biggest barrier; and Chicago mentioned that TODs are not currently permitted in lower-scale residential zoning districts.

Salt Lake City, UT noted that within the transit stop walking sheds they are increasing density, expanding transit service, and looking to zone for TOD. But barriers remain outside of the main corridors and involve density limitations, parking minimums, minimum lot sizes, minimum lot widths, etc. These barriers are more frequently located in single-family neighborhoods and are controversial.

Utah Transit Authority and RTD Denver lamented the selective embrace of TODs. The former noted that some cities have fully embraced the idea of TOD and have put appropriate zoning in place. RTD Denver observed that developers would appeal for higher density allowances and lower parking requirements where local politics support such appeals. In only a few cases, and always in Denver, has the city proactively revised zoning to support TOD.

Among the steps taken, in progress, or planned, Los Angeles noted the CEQA streamlining efforts through various state bills. BART highlighted the passage of AB 2923. San José noted that the state law has removed some barriers. But the city also highlighted a nuanced fiscal issue. The city has large obligations for housing but is also fiscally imbalanced. The city needs job growth to continue to provide housing services as well as improved transit services to support the mode shift. As a result of these needs, the city often requires large amounts of commercial or job-creating uses that could be a burden for a mixed-use housing project.

SFMTA noted a mixed bag. While the overall capacity to undertake TOD has increased by eliminating parking minimums, allowing for denser development through the density bonus 
program, area planning initiatives, and trying to expedite approvals for housing, the barriers still very much exist in the form of CEQA and the potential for CEQA-related lawsuits, as well as the planning process, which is filled with discretionary decisions and innumerable process obstacles.

Many respondents highlighted the revisions that have been (or will be) made to the local zoning codes. For example, Reno, NV, noted that TODs have been in their zoning codes for the past 15-20 years. Though they are a work in progress, EI Paso, TX, pointed to actively working to overcome the barriers by rewriting current codes and polices. San José mentioned that the city is creating new zoning districts to promote housing and job development in the growth areas. Also, the city is exploring parking maximums and mandatory TDM requirements. Albany, NY, adopted new comprehensive zoning regulations. Milwaukee is in the process of updating the zoning code to reflect the recommendations of a recently completed TOD study to permit greater density in certain transit corridors.

Honolulu is adopting new plans, policies, zoning, and other ordinances to overcome the barriers. For example, interim TOD zoning permits are available for large projects in areas where permanent TOD zoning has yet to be adopted, and six larger (up to 400') towers have already been approved. TOD zoning has been adopted for two rail station areas. Furthermore, a complete streets guide has been adopted.

Indianapolis Public Transportation Corporation is currently working on updating the City of Indianapolis' zoning ordinance to zone for TOD, which includes socializing the idea with local policy and decision-makers, developers, lenders, employers, and the general public.

WeGo, TN, noted that specific areas of growth have been identified in the City of Nashville's general plan with higher densities tied to high transit usage corridors.

Port Authority of Allegheny County, PA, pointed to the incremental changes made, such as a TOD zoning technical assistance project and some small zoning changes in the City of Pittsburgh. The technical assistance project was realized when in 2017, using grant funds, Port Authority partnered with the Congress of Neighboring Communities (CONNECT) at the University of Pittsburgh to bring TOD expertise to ten municipalities deemed to have the greatest opportunities for TOD in their region. ${ }^{96}$ However, the agency highlighted the need for broader policies across municipalities to overcome these barriers effectively.

Finally, Boston pointed to the zoning relief that is often provided through the Zoning Board of Appeal or the Planned Development Area designation.

\section{Most Frequently Used VC tools to Fund TODs}

Transit agencies noted joint development, public-private partnerships (PPPs), and TIF as the most frequently used VC tools used to implement TOD projects (Figure 19), while local governments noted PPPs and community benefits, developer agreements, and impact fees as the most used (Figure 20). While PPPs are the common VC tool across the two surveys, other tools vary. This variation is perhaps because local governments and redevelopment agencies typically levy and benefit from tools like community benefits and impact fees. Only 
$15 \%$ of transit agencies and around one in four of the local governments chose 'none' or declined to respond.

Transit agencies' response to the use of VC tools to implement TODs

$100 \%$

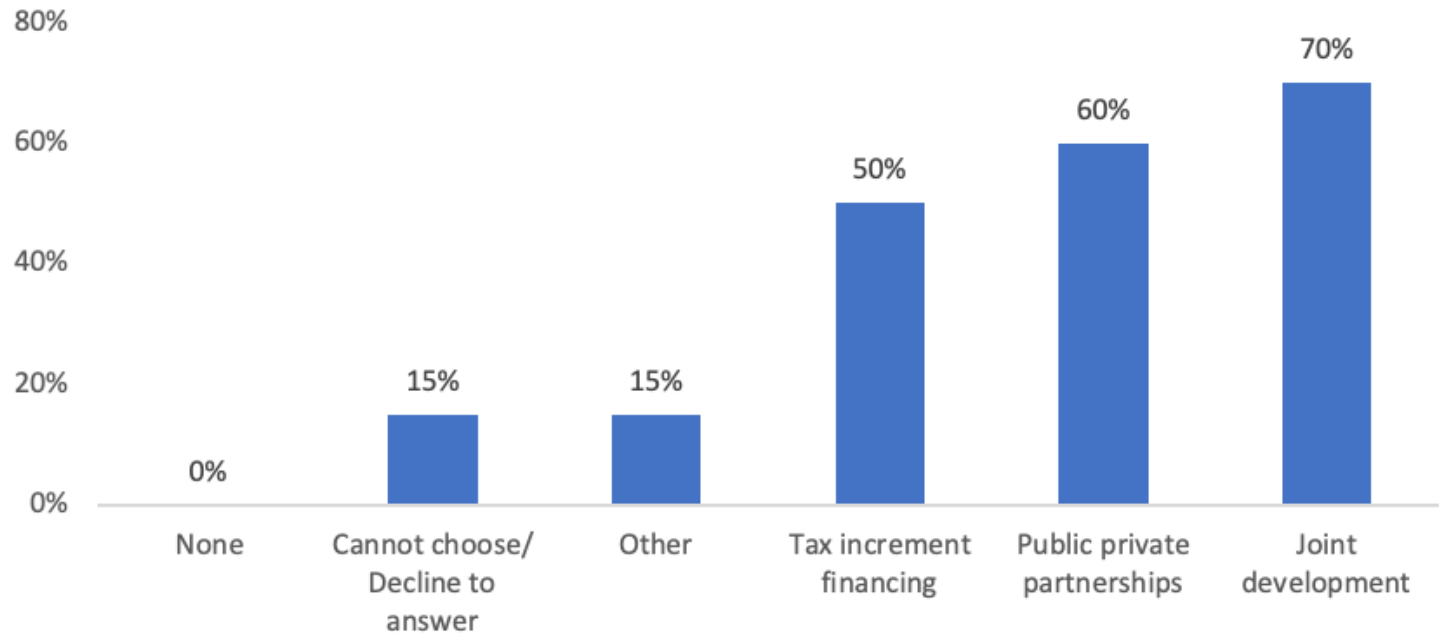

Figure 19. Transit Agencies Typically Use Joint Development, PPPs, and TIF to Implement TODs

Note: 30 transit agency surveys received (10 non-responses)

Local governments' response to the use of VC tools to implementTODs

$100 \%$

$80 \%$

$60 \%$

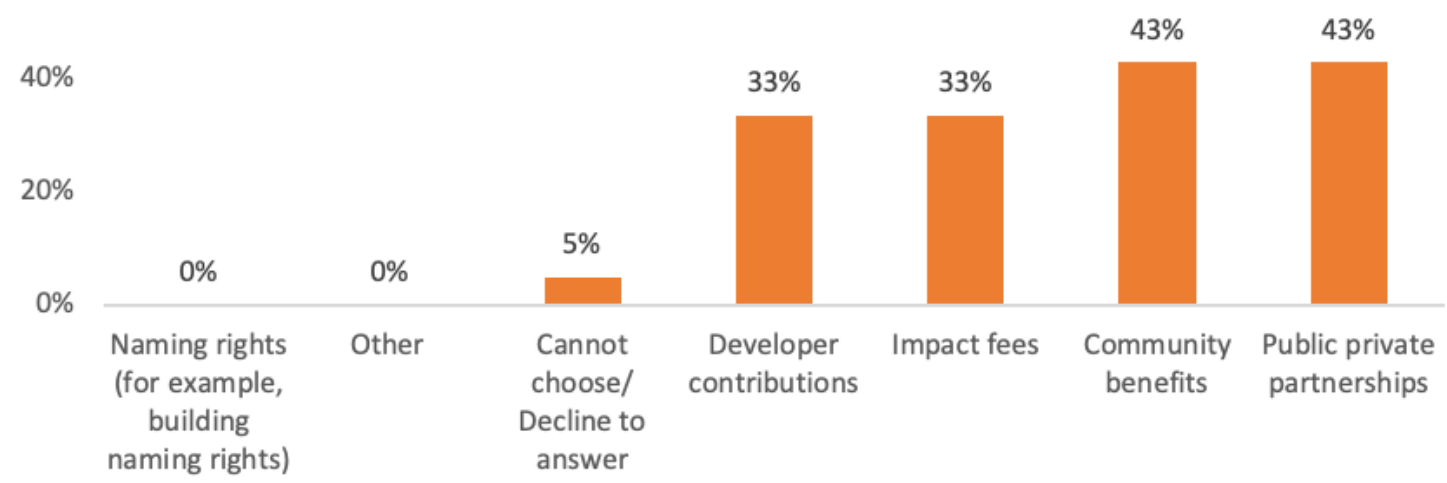

Figure 20. Local Governments Typically Use PPPs and Community Benefits to Implement TODs

Note: 25 local government surveys received (4 non-responses) 


\section{Impact of Federal, State, Regional, or Local Laws, Policies, Plans, Funding Programs, or Financial Incentives on How Agencies Approach Use of VC to Implement TODs}

The lack of ability to use TIF is highlighted as the most common inhibiting factor when agencies were asked which federal, state, regional or local laws (local laws include the statutory regulations governing the agency), policies, plans, funding programs, or financial incentives negatively impact their ability to use VC tools to implement TODs. For example, Valley Metro (Phoenix, AZ) noted that TIF is not allowed in Arizona. The City of Honolulu highlighted the inability to use TIF due to a perceived quirk in the state constitution that (to some) appears not to allow TIF revenues to pay off bonds. The City of Everett mentioned that Washington State does not allow typical TIF. A convoluted program called the Landscape Conservation and Local Infrastructure Program ${ }^{97}$ allows cities in the state's Puget Sound Region to receive a portion of the property tax revenues resulting from new development the cities attract in their local infrastructure project areas using a regional TDR program. ${ }^{98}$ However, cities usually allow generous density near transit; therefore, there is little need for developers to buy TDR credits to develop near transit.

BART noted several inhibiting factors. First, the dissolution of redevelopment agencies in California (which occurred in 2011) was a "major blow." Nearly all of BART's pre-2012 TOD projects received redevelopment funding. Second, while the state-wide infill infrastructure grants program, authorized under AB 101 in 2019, ${ }^{99}$ has helped somewhat, funding was lost for several years and is only just coming back. Third, another recent state-wide funding program that can be used to construct TODs, the Affordable Housing and Sustainable Communities Program, ${ }^{100}$ which began in 2014 , is very prescriptive and is driven heavily by the location of the affordable housing units. Finally, while SB 142, passed in 2013, provides California's transit agencies the ability to form special benefit districts and to use special assessments generated from such districts to repay bonds, another state law, Proposition 218, limits the use of special assessments because it requires approval of two-thirds of the property owners to levy assessments. ${ }^{101}$ This Proposition 218-related limitation was also pointed out by VTA.

SFMTA lamented that a well-understood and popular tool (the use of TIF through redevelopment agencies) has been supplanted by a new TIF-based tool, EIFD, which is poorly understood and sparingly used.

San José mentioned that in 2018 the city developed an urban village implementation and amenities framework under which developers would have provided additional community benefits to rezone land from employment use to residential (based on the assumption that rezoning to a more desirable use, residential, would lead to land value increase). However, before even one project was fully approved, the state of California passed AB 3194 (the Housing Accountability Act), which requires cities to allow low- and moderate-income housing projects that are "consistent with the objective general plan standards and criteria but the zoning for the project site is inconsistent with the general plan." 102 So now the city is exploring other ways in which re/zoning can be used to capture community benefits.

Milwaukee noted that the state of Wisconsin has limited cities' ability to use non-property- 
tax-related VC tools. Therefore, cities primarily use BIDs and TIF. The use of other VC tools requires state approval, and the state is anti-transit. Moreover, Milwaukee is a slow-growth city that does not want to hinder development through additional fees; therefore, it does not levy impact fees.

Other inhibiting factors include California state procurement laws that make PPPs difficult (Long Beach, CA), state highway funds restricted to road improvements and a constitutional ban on the use of impact fee (noted by Louisville, KY), a lack of ability to use impact fee for transit operations (noted by Port Authority of Allegheny County), the inability of transit agencies to condemn properties for non-transit purposes, such as expressly for TODs (RTD Denver), the inability of transit agencies to develop properties (Valley Metro), lack of tiered impact fee systems (Reno, NV), and local elected officials (City of Niagara Falls, NY).

When asked which federal, state, regional, or local laws (including statutory regulations governing their agency), policies, plans, funding programs, or financial incentives positively impact the ability to use VC tools to implement TODs, Reno, NV, noted that phased payment of impact fees and sewer connection fees help developers. Boston highlighted supportive zoning, including the use of overlay zoning districts, called planned development areas (PDAs), for large or complex projects. ${ }^{103}$

Lane Transit District (located in Oregon) pointed to the use of Multi-Unit Property Tax Exemption (MUPTE) by the City of Eugene, OR, in its downtown area. MUPTE is a stateenabled tool that exempts new multi-family development of five or more units from property taxes on the construction value for up to ten years. The property taxes continue to be levied on the land value of the project during the exemption period. ${ }^{104}$

Utah Transit Authority noted the state laws, such as the Community Reinvestment Agency Act passed in 2016 and SB 136 passed in 2018, help use VC tools. The former allows for the creation of community reinvestment agencies (CRAs) and the latter, the transportation reinvestment zones (TRZs). CRAs (also called redevelopment agencies) engage in economic development and redevelopment using TIF and require the formation of a redevelopment agency. On the other hand, a TRZ can be formed simply through an inter-local agreement between two or more public agencies. However, one of the agencies should have land use authority. TRZs can capture both property and sales tax increments generated by transportation infrastructure projects and can be used to fund transportationrelated projects. ${ }^{105}$

Port Authority of Allegheny County, PA, mentioned that Pennsylvania state legislation authorizes the creation of transit revitalization investment districts (TRIDs) that allows the use of TIF to fund public transit infrastructure and related site development improvements and maintenance. ${ }^{106}$ However, it is important to note that while the original TRID legislation ${ }^{107}$ was enacted in 2004, only one TRID has been created to date in the entire state, in a Pittsburgh suburb. ${ }^{108}$ Therefore, the legislation was amended in 2017 to remove some of the bottlenecks. One major bottleneck was removed by providing the taxing bodies the option to contribute a portion of the incremental tax revenues to the TRID. The entire amount needed to be contributed previously. ${ }^{109}$ 
Other enabling factors include a supportive comprehensive plan (City of Niagara Falls, NY); recent changes in statutes that are favorable to PPPs (Louisville, KY); the ability to use TIF to provide station-area infrastructure to support future TODs (RTD Denver); the ability to condemn property for transit-related purposes, then use the excess condemned property for non-transit purposes, such as TODs (RTD Denver); the ability of California cities to use VC tools such as community facility district (CFD), infrastructure financing district (IFD), and EIFD (SFMTA); and a Washington State law that allows the formation of public transit benefit area or PTBAs (Spokane Transit Authority). Among others, this legislation allows transit agencies to lease land and air rights. ${ }^{110}$

\section{Use of Cooperative Agreements and Collaborative Arrangements to Promote VC}

A very large majority- $85 \%$ of transit agencies and $80 \%$ of local governments-chose 'none' or declined to answer when asked whether cooperative agreements are used to promote the use of VC to implement TODs. For transit agencies, around $10 \%$ of cooperative agreements for $\mathrm{VC}$ are entered into with city governments, followed by $5 \%$ for regional and county governments (Figure 21). Alternatively, among the local governments, $16 \%$ indicated entering VC cooperative agreements with transit agencies (Figure 22). The absence of cooperative agreements for the use of VC agreements is notably similar to their absence to promote TOD-supportive land use and zoning (Figure 13, Figure 14). These two pieces of information highlight the need for encouraging inter-agency/intergovernmental cooperation for promoting both supportive land use and zoning as well as the use of $\mathrm{VC}$ tools to implement TODs.

Similarly, a very large majority chose none or declined to answer when asked whether collaborative arrangements are used to promote VC to implement TODs (Figure 23). Responses from these questions perhaps indicate a dearth in both intra-sectoral and cross-sectoral collaboration, particularly for capturing value to implement TODs. 
Transit agencies' response to the use of cooperative agreement to promote VC to implement TODs

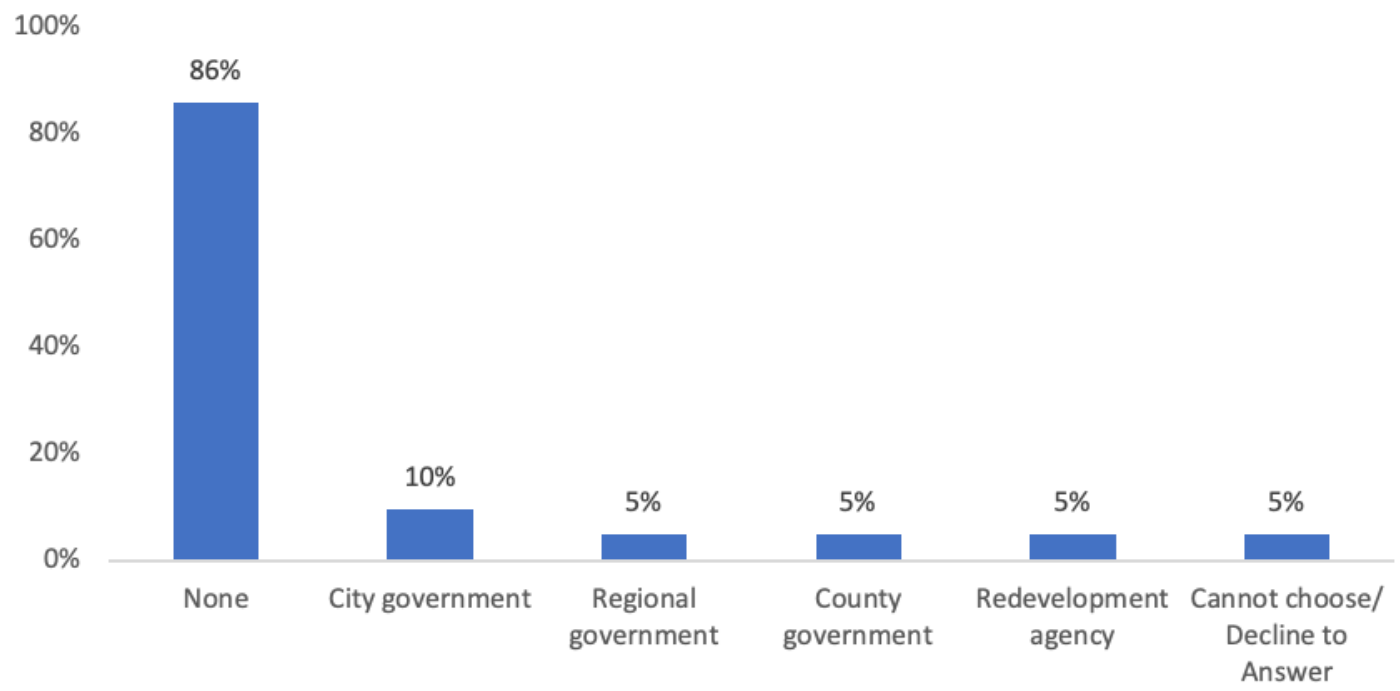

Figure 21. Cooperative Agreements for VC are Largely Unused Among Transit Agencies

Note: 30 transit agency surveys received (7 non-responses)

Local governments' response to the use of cooperative agreements to promote use of VC to implement TODs

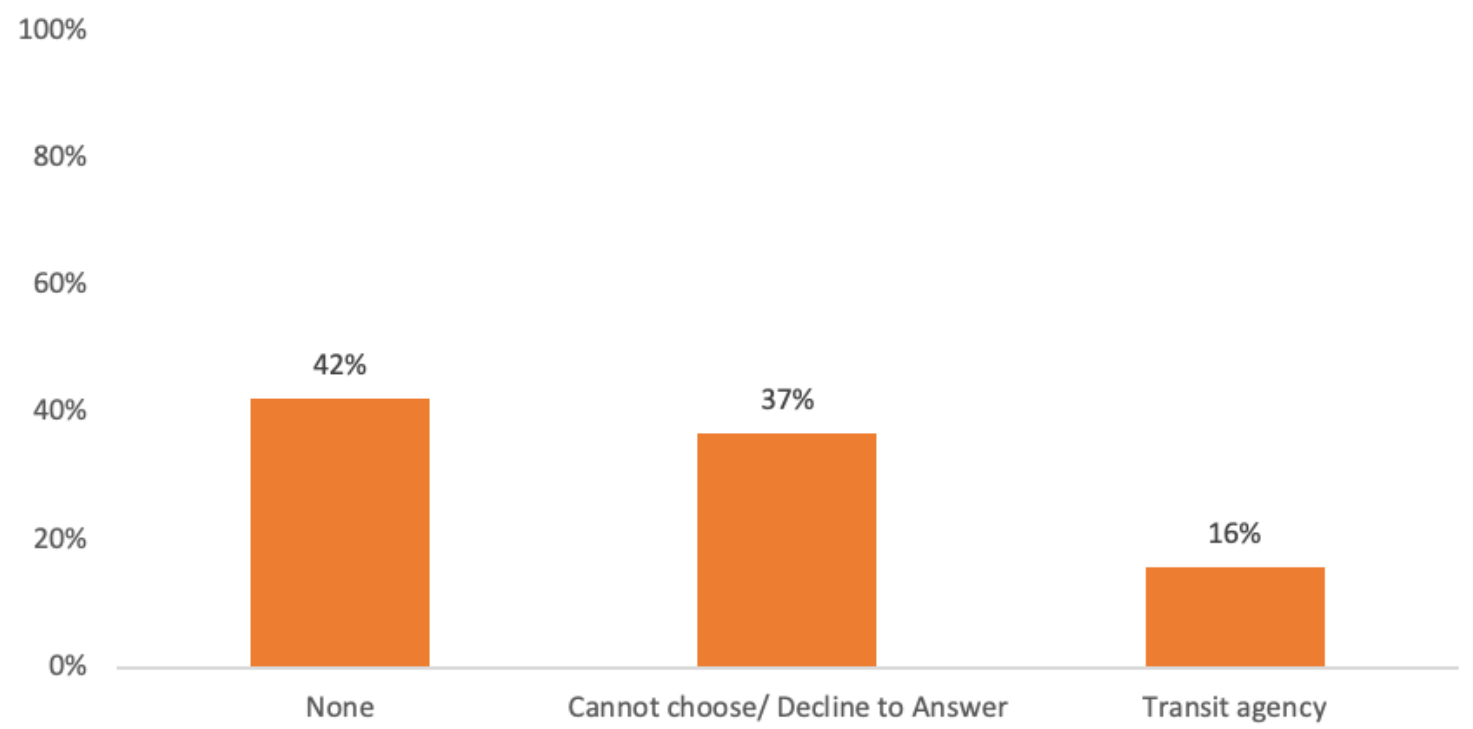

Figure 22. Very Few Local Governments Enter into Cooperative Agreements with Transit Agencies to Promote VC

Note: 25 local government surveys received (8 non-responses) 


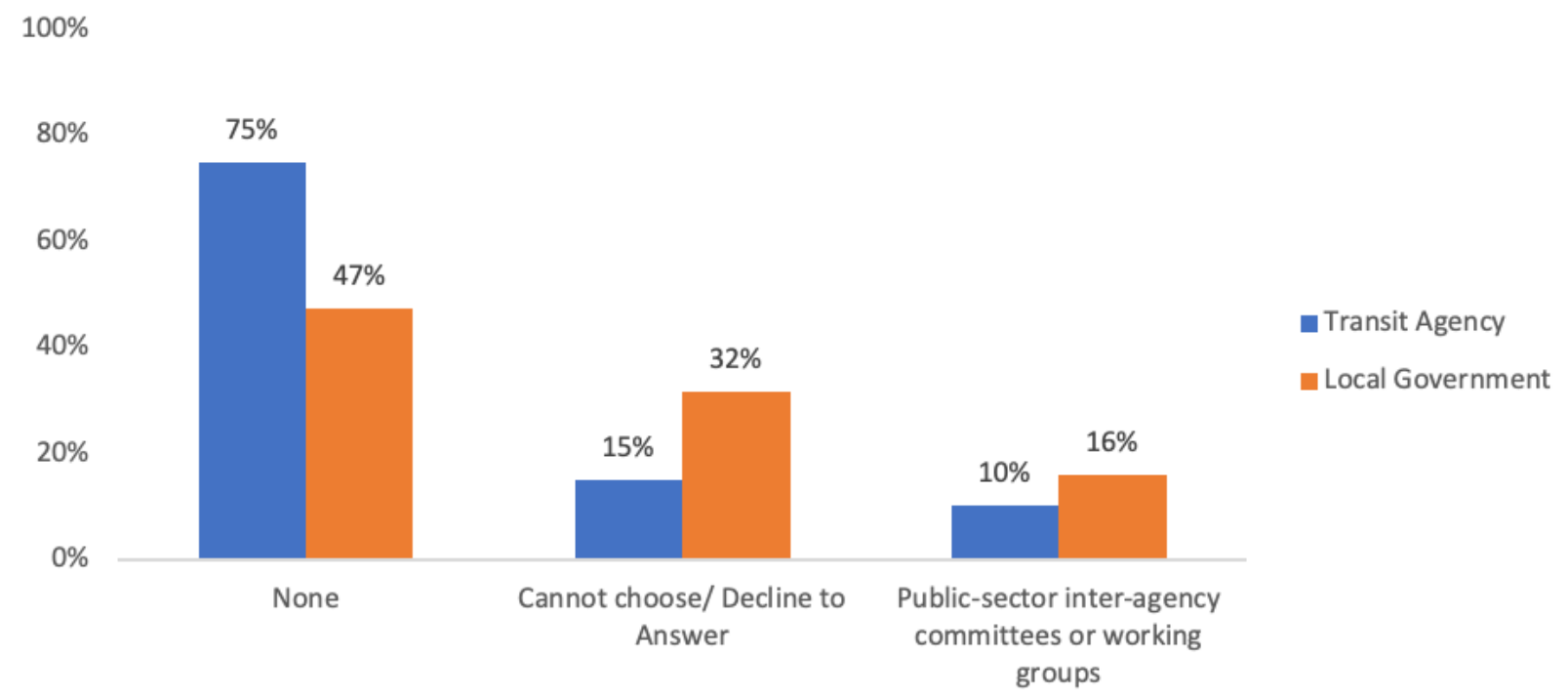

Figure 23. Few Collaborative Arrangements Exist to Promote VC

Note: 30 transit agency surveys received (9 non-responses); 25 local government surveys received ( 5 non-responses)

Very few local governments and transit agencies described the kinds of collaborative or cooperative arrangements that promote the use of VC to implement TODs. Among those who responded, Honolulu noted that their State TOD Council and the City of Honolulu are exploring the use of VC tools. VTA mentioned that informal interagency staff working groups are examining how VTA can work with cities to establish the use of VC tools. Los Angeles, $\mathrm{CA}$, highlighted that some of their TOD planning efforts are grant-funded by Metro (local transit agency), and the terms of those grants may call for $\mathrm{VC}$ strategies primarily geared toward affordable housing.

Finally, Las Vegas, NV, pointed to the Southern Nevada Strong Steering Committee, which meets quarterly, is a collaborative effort among thirteen regional partners, community groups, elected officials, and businesses to better integrate transportation, housing, and jobs in Southern Nevada. The Committee plays an important role in the implementation of the Regional Plan. ${ }^{111}$ However, the survey respondent did not note how the Committee is exploring the use of $\mathrm{VC}$ tools.

\section{The Extent to which Barriers to the Use of VC Have Been an Impediment to the Implementation of TODs}

Approximately $40 \%$ of the survey respondents note that the barriers to the use of VC tools have been somewhat to very impedimentary to the implementation of TODs in their service area; however, only $43 \%$ of transit agencies and $52 \%$ of local governments answered this question. 
Extent to which barriers to the use VC tools have been impediments

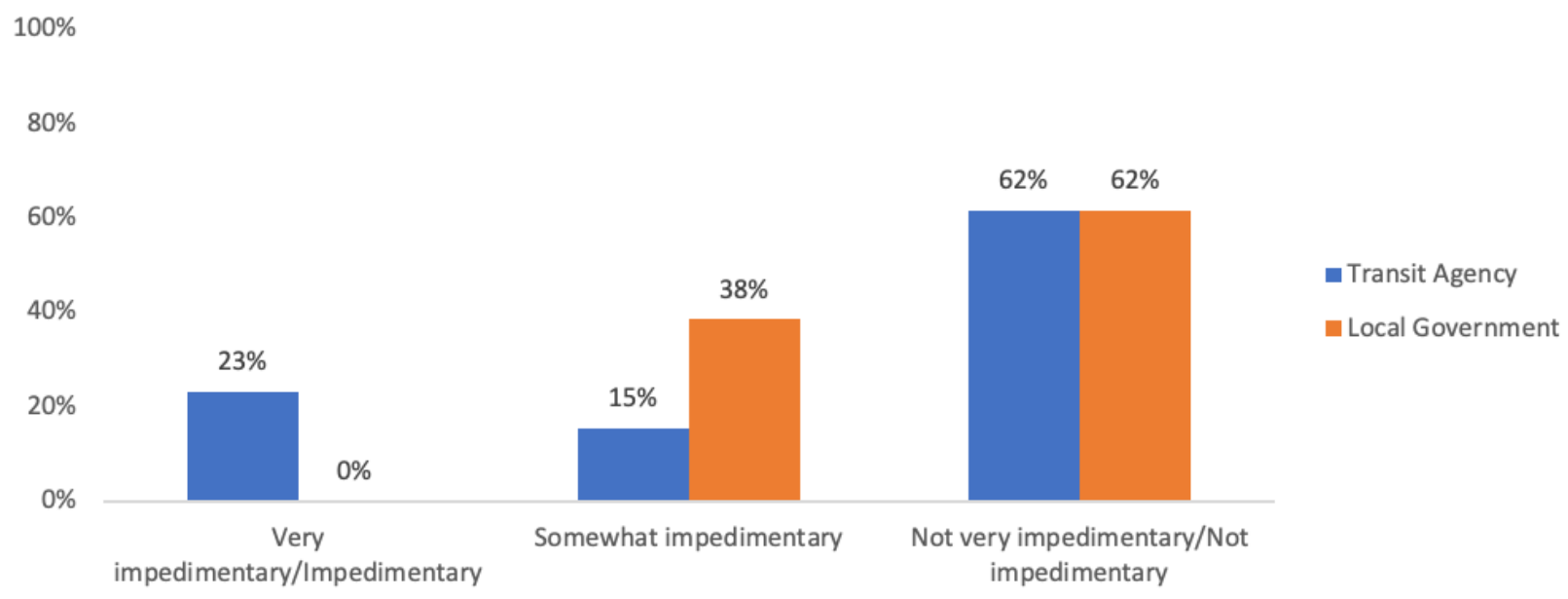

\section{Figure 24. VC Restrictions Are Somewhat Impedimentary to the Implementation of TODs}

Note: 30 transit agency surveys received (17 non-responses); 25 local government surveys received (12 non-responses)

Extent to which barriers to the use of VC have been impediments: Non-responses

included

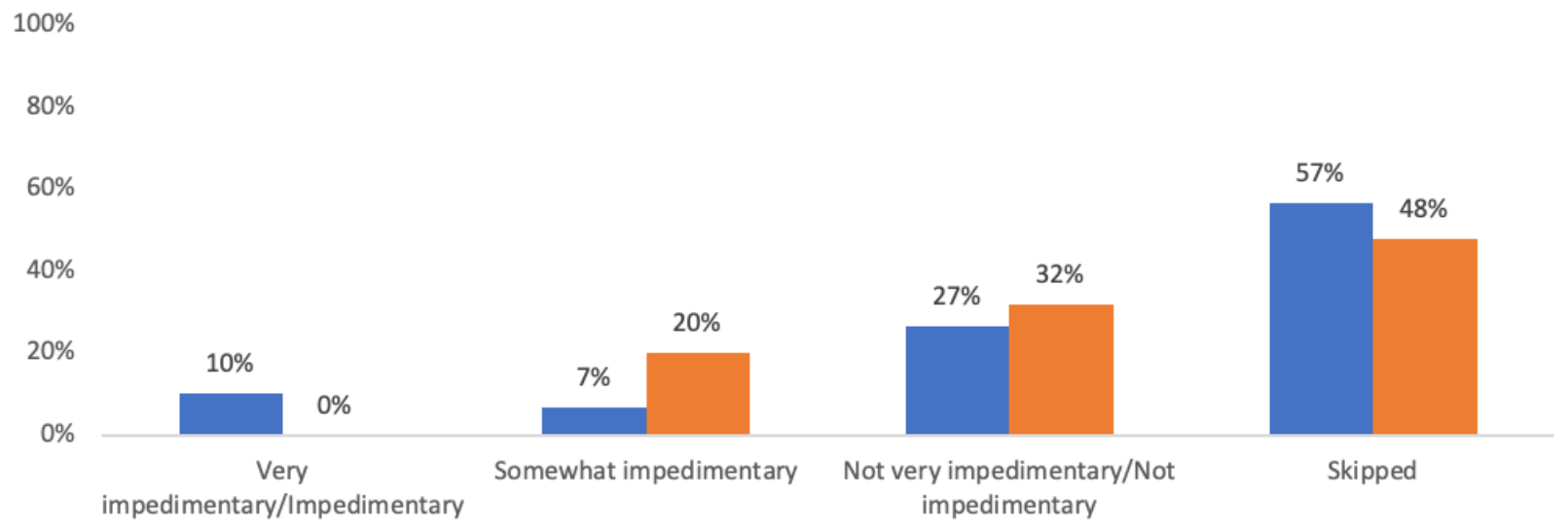

Figure 25. Public Agencies' Opinions on Barriers to the Use of VC as Impediments: Non-Responses Included

Note: 30 transit agency surveys received (17 non-responses); 25 local government surveys received (12 non-responses) 


\section{Whether the Barriers to the Use of VC Have Been Overcome, Are Being Overcome, or Are Planned to be Overcome}

Despite a low response rate, transit agencies find barriers to implementing $\mathrm{VC}$ tools to be somewhat navigable (Figure 26). Most respondents skipped this question, perhaps indicating a gap in the knowledge of how barriers to the use of $\mathrm{VC}$ tools have been, are being, or can be overcome in their service areas.

Have barriers to the use of VC tools been overcome, are being overcome, or are planned to be overcome?

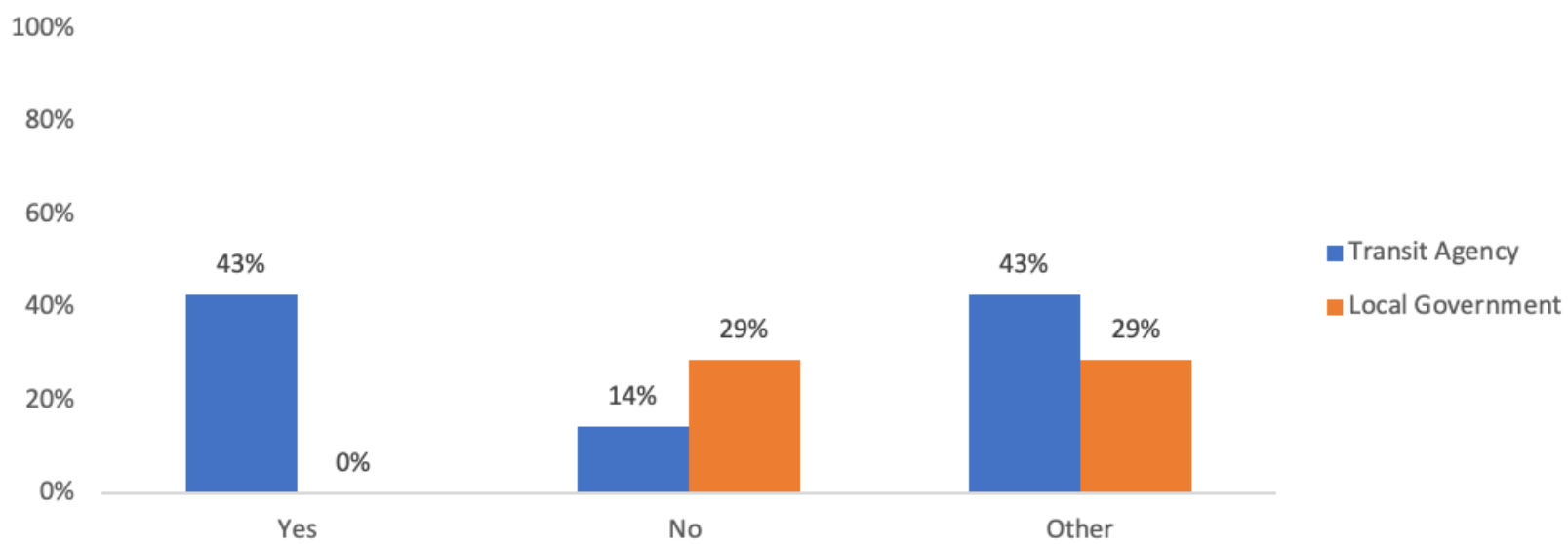

Figure 26. VC Barriers Might Be Somewhat Navigable

Note: 30 transit agency surveys received (23 non-responses); 25 local government received (18 non-responses)

Only two cities and five transit agencies responded when asked to describe how the barriers to the use of VC tools have been overcome, are being overcome, or are planned to be overcome. Everett noted that although there is talk about amending Washington's state constitution to ease the restrictive state-level TIF-enabling legislation, nothing has come out of these discussions so far. Honolulu mentioned that they are working on some options for developing a district-wide financing option.

Among the transit agencies, BART pointed to the weak attempts by the State of California to bring back redevelopment. SFMTA mentioned working with the city departments to craft development agreements and impact fee programs to engage in $\mathrm{VC}$ when new developments are pursued.

A couple of other responses are ambiguous. Port Authority of Allegheny County noted that although they do not have a plan yet, they are thinking about how to approach this problem. Without elaborating on the specifics of the barriers as well as the efforts, VTA mentioned that efforts to overcome the barriers are in progress. 


\section{KEY INSIGHTS FROM SURVEYS}

\section{Land Use and Zoning-Related Insights}

A wide range of formal TOD programs: Although close to half of the transit agencies and around three-quarters of the local governments report having a formal TOD program, the responses to the open-ended questions show that the programs range widely in their degree of formality and detail. For example, some agencies have formal stand-alone programs, but in other cases the TOD-related policies/programs are embedded in various initiatives, planning documents, and zoning codes. For example, in Chicago, TOD-related stipulations are embedded within various sections of the city's zoning code that address development density, FAR, height, and parking limits. Each section of the code on those topics includes a clause for parcels in transit-served areas and lists the more permissive guidelines for those site-specific developments. Adding to the complexity, some agencies, such as the SFMTA, may self-define their TOD programs. The agency notes two components to their TOD program. First is working with City of San Francisco's planning department to facilitate greater density along high-capacity transit routes. The second component is pursuing development on SFMTA-owned properties. Finally, Spokane Transit Authority, WA, has stated goals, principles, and policies in its comprehensive plan but has not created a formal program to implement them.

This wide variety of programs and their characteristics make it difficult to conduct a comprehensive nation-wide search for these programs, except through surveys, such as the ones conducted for this study. But the surveys typically have a response rate of only $20 \%-30 \%$.

Lack of coordination between transit agencies and local governments: Transit agencies have little control over land use- and zoning-related issues that impact the implementation of TODs. Over three-quarters of them rely on local governments to take the lead; however, only about one-quarter of the local governments noted that they address these issues in partnership with the transit agencies. This lack of partnership is further reflected in the fact that a large majority of transit agencies and local governments found that cooperative agreements to implement TODs agreements do not exist, or failed to respond to the survey question that inquired about the existence of such agreements.

Since transit agencies plan for and implement transit system extensions and service improvements, it is concerning that only a small proportion of local governments partner with transit agencies to address land use- and zoning-related issues, thus signifying a need for a robust regulatory framework and set of incentives to foster such partnerships.

In the absence of cooperative agreements, transit agencies and local governments rely on looser collaborative arrangements. Public sector inter-agency committees or working groups are the most used collaborative arrangement for the transit agencies, and publicsector organizations or committees (such as a technical advisory committee and a council of governments) prevail for the local governments. 
Sparse use of some tools is worrisome: Assistance with land assembly, use of eminent domain to acquire land for TOD construction, and reduction of permit fees for TODs are among the least used tools. Their sparse use is worrisome and indicative of a lack of political or institutional will (in the case of lack of use of eminent domain and land assembly) or constrained budgets (in the case of reduced permit fee). Furthermore, two of these tools, eminent domain and land assembly, might need to be used together to assemble land for TODs (a task that was often undertaken by redevelopment agencies in California) and are among the more effective ways in which public agencies can help developers of TODs, because a TOD project could stall if the owner of even one small land parcel refuses to sell land. Hence, the sparse use of these two tools is even more notable.

Factors negatively impacting approach to land use and zoning: Transit agencies identified a lack of land use and zoning powers as the most common negative factor. Lack of state- and regional-level leadership, visions, or plans is noted as important, too. More than half of the survey respondents also pointed to a lack of state or regional growth management tools to promote TODs. Such tools include urban growth boundaries (UGBs), concurrency and consistency requirements, and identifying growth areas with TODs promoted inside these growth areas.

MARTA pointed to the lack of state laws that encourage TOD-supportive land use. Salt Lake City, UT, noted the lack of teeth or incentives by the state to encourage local government to adopt TOD-supportive policies; the city further mentioned that while regional plans include such policies, following them is optional. For example, recently, the state started requiring more housing, which they loosely tied to transportation funding. However, the requirement is very loose.

Transit agencies and local governments located in the states with state-level growth management programs (in this survey, Oregon and Washington) noted the existence of the state- and regional-level laws, programs, or plans to encourage TODs. The emphasis of these laws, programs, and plans is on closer land use and transportation coordination. This indicates TODs are seen as a key to achieving these states' growth management objectives.

A minority noted that land use- and zoning-related restrictions do not impede the implementation of TODs: Only $15 \%$ of transit agencies and $40 \%$ of local governments felt that restrictions related to land use and zoning are not an impediment to the implementation of TODs. The remaining either did not respond to the survey question inquiring about this issue or noted that such restrictions are somewhat to very impedimentary.

Only a minority noted that these barriers have been overcome, are being overcome, or are planned to be overcome: Around $45 \%$ of local governments and a little over one-third of transit agencies mentioned that barriers have been overcome, or are being overcome, or plans are underway. These percentages are worrisome because they reveal that a majority of the agencies either did not think that plans exist to overcome the barriers or chose to not respond to the survey question related to this topic.

Some of the barriers noted by the survey respondents include a selective embrace of TODs by one or few cities in a metropolitan area, onerous environmental review processes, need 
to balance the budgets (therefore requiring more non-residential uses in a TOD then can perhaps be feasible from a real estate market perspective), parking and building requirements (minimum lot and building sizes), and building height restrictions.

Strategies to overcome the barriers: Respondents note that barriers are being overcome by undertaking station-area zoning reforms, including relaxed parking requirements; parking maximums, not minimums; zoning for TODs (allowing compact, mixed uses); and density bonus programs. These responses are consistent with the top three tools noted by the local governments and transit agencies to aid the implementation of TODs, which include (in decreasing order) mixed-use zoning, relaxed parking standards, and zoning for compact housing.

\section{VC-Related Insights}

Popular VC tools: Transit agencies note the use of joint developments, PPPs, and TIF as the most popular VC tools, while the local governments note the use of PPPs, community benefits, impact fees, and developer agreements. It is important to note that while PPPs could be different from joint developments (for example, a TOD fund created by a group of public and private sector partners is a PPP), it is possible that many respondents chose PPPs in lieu of joint development or vice versa, considering joint development to be a type of PPP.

Inability to use TIF: Several survey respondents noted that their inability to use TIF restricts the use of VC to fund TODs. This inability can arise due to various reasons. First, state legislation may not allow the use of TIF, as in Arizona. Second, a state might not have clearly laid out the eligible uses for TIF. For example, a survey respondent noted a perceived quirk in Hawaii's constitution that, to some, appears to prohibit TIF from paying off bonds. Third, TIF might be allowed on a very narrow tax base. For example, Washington State does not allow tax increment financing on the state's portion of the property tax.

Moreover, a state might have abolished an established mechanism or not created one. For example, the 2011 dissolution of redevelopment agencies has resulted in the disuse of TIF in California. Other regulatory and institutional frameworks needed to use TIF are just emerging in this state. As one survey respondent from California noted: "what was a well-known and familiar legislative tool in the past (tax increment financing through redevelopment agencies) has been supplanted with a sparingly used and poorly understood successor program." Utah only very recently enacted the state laws that created the institutions that could use TIF: CRAs and TRZs. Finally, although Pennsylvania has allowed the creation of TRIDs since 2004, the big bottleneck was that all taxing bodies within the TRID were required to dedicate the "entire" tax increment to the TRID. A 2017 amendment, hoping to encourage the use of TRIDs, allows taxing bodies to dedicate a portion of such an increment.

Other inhibiting factors: The other major factors inhibiting the use of VC tools include: (a) inability of the transit agencies to condemn properties for TODs, (b) inability to levy impact fees due to weak real estate market conditions, and (c) arduous requirements to use of VC tools, such as the super-majority (two-thirds) vote requirement to form a special assessment district in California. 
Very few survey respondents identified supporting factors: The factors identified include the following: (a) ability to use TIF; (b) supportive comprehensive plan; (c) ability of transit agencies to lease land and air rights; (d) statutes favorable to PPPs; and (e) ability of transit agencies to condemn properties for transit uses and then use the excess property for non-transit use, such as TODs. It is important to note that these supportive factors are not prevalent across the US. They are likely state- or agency-specific.

Lack of coordination between transit agencies and local governments: Only a minority of the survey respondents noted the existence of inter-agency partnerships to promote the use of VC. These partnerships include cooperative agreements and collaborative arrangements between agencies. This lack of inter-agency partnership also exists for addressing land use and zoning-related issues. Therefore, there is a need for inter-agency/inter-governmental cooperation for promoting both supportive land use and zoning and the use of VC tools to implement TODs.

Use of VC tools to implement TODs is likely not on the radar of most of the transit agencies and local governments: About half of the transit agencies and local governments did not respond when asked how impedimentary are the barriers to the use of VC tools; however, only a small proportion (close to a quarter of the survey respondents) reported thinking these barriers are not impedimentary. The non-response rate (close to threequarters of the survey respondents) was even larger when asked whether the barriers have been overcome, are being overcome, or are planned to be overcome. These three pieces of information combined indicate that the use of VC tools to implement TODs might not even be on the radar of a large number of transit agencies and local governments. 


\section{TOD CASE STUDIES}

Six TODs constructed in the last 10-15 years (or TODs that are still under construction, but of which large sections have been recently completed) around the US are studied in this section to gain a fine-grained understanding of: (a) whether the developers and agencies involved in their construction encountered barriers related to land use, zoning, or VC, and if yes, how these barriers were overcome, and (b) which/how VC tools were used to fund the TODs. To choose the case study TODs, first a large sample of around 50 potential TODs were chosen from a review of the extant literature and online searches. For example, Cervero et al. ${ }^{112}$ note several TODs that were in the planning or early construction stage at the time that the report was written. Next, the following case study selection criteria were applied:

(a) Geographical spread: TODs spread across the four regions in the US-west, midwest, northeast, and south—as classified by the US Census; ${ }^{113}$

(b) Transit type: TODs served by a variety of transit systems such as commuter rail, light rail, and BRT systems;

(c) Location within the urban area: TODs located in the inner/core cities as well as in suburban locations;

(d) TOD type: TODs ranging from individual buildings to a neighborhood;

(e) Data availability: TODs for which the data were available from secondary and primary sources (for example, where the stakeholders were willing to be interviewed); and

(f) Barriers faced: TODs that encountered at least some barriers related to land use, zoning, or VC.

Finally, the following six TODs were selected: Othello Plaza, Seattle, WA; Evans Station Lofts, Denver, CO; EcoVillage TOD, Cleveland, OH; Twinbrook Station TOD, Rockville, MD; MacArthur Station TOD, Oakland, CA; and Waterside Place TOD, Boston, MA. See Table 3 for the TODs' region, transit type, location within the urban area, and TOD type.

The remainder of this section describes the six case study TODs followed by the key insights gained.

\section{OTHELLO PLAZA TOD}

\section{Introduction}

Othello Plaza TOD (also known as Mercy Othello Plaza by its developer, Mercy Housing Northwest) is a mixed-use affordable housing TOD located in the Othello neighborhood in southeast Seattle's Rainier Valley district. ${ }^{114}$ The TOD was constructed in 2016-2017. ${ }^{115,116}$ See Figure 27 for the location map. The TOD is served by Othello Station, which falls on Sound Transit's Green Tacoma-Ballard Link light rail line (Figure 28). In addition to Link light 


\section{TOD Case Studies}

rail, the area is served by buses operated by King County Metro (Figure 29). ${ }^{117}$

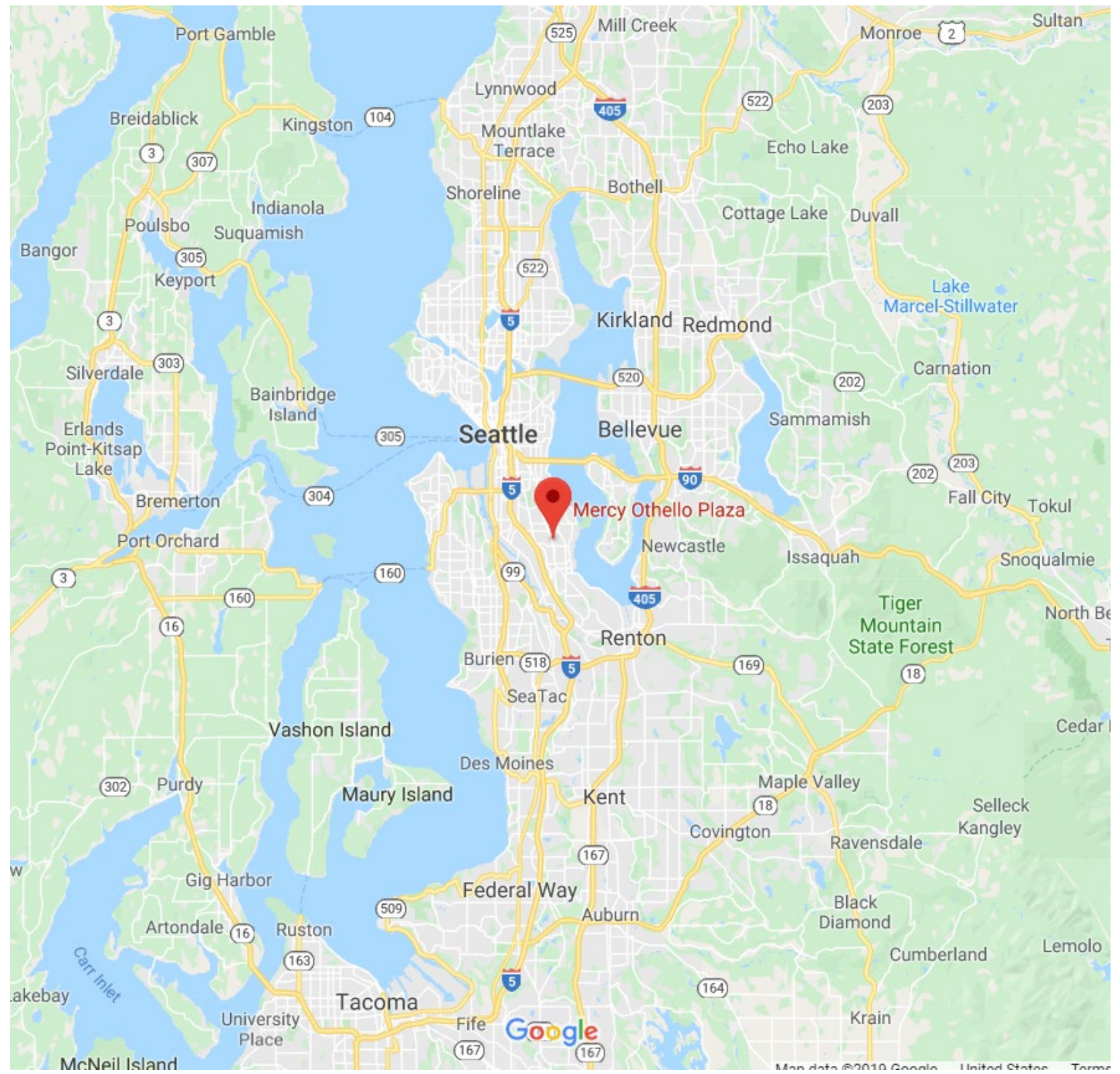

Figure 27. Location of Othello Plaza TOD

Source: Google Maps 


\section{(0) Link Light Rail Regional Map}

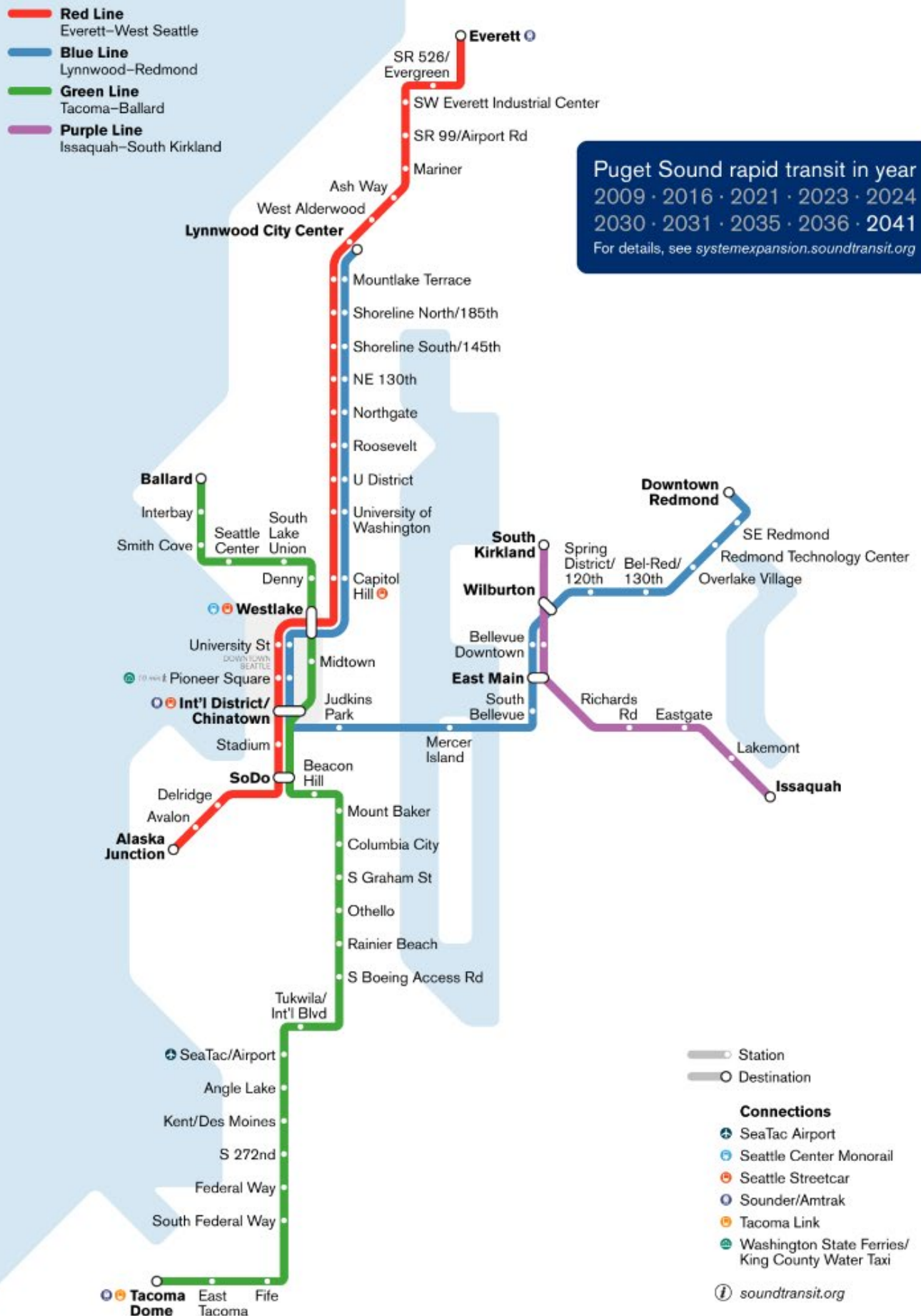

Figure 28. Station Map of Sound Transit's Link Light Rail ${ }^{118}$

Note: Othello Station is Between S. Graham St and Rainier Beach Stations 


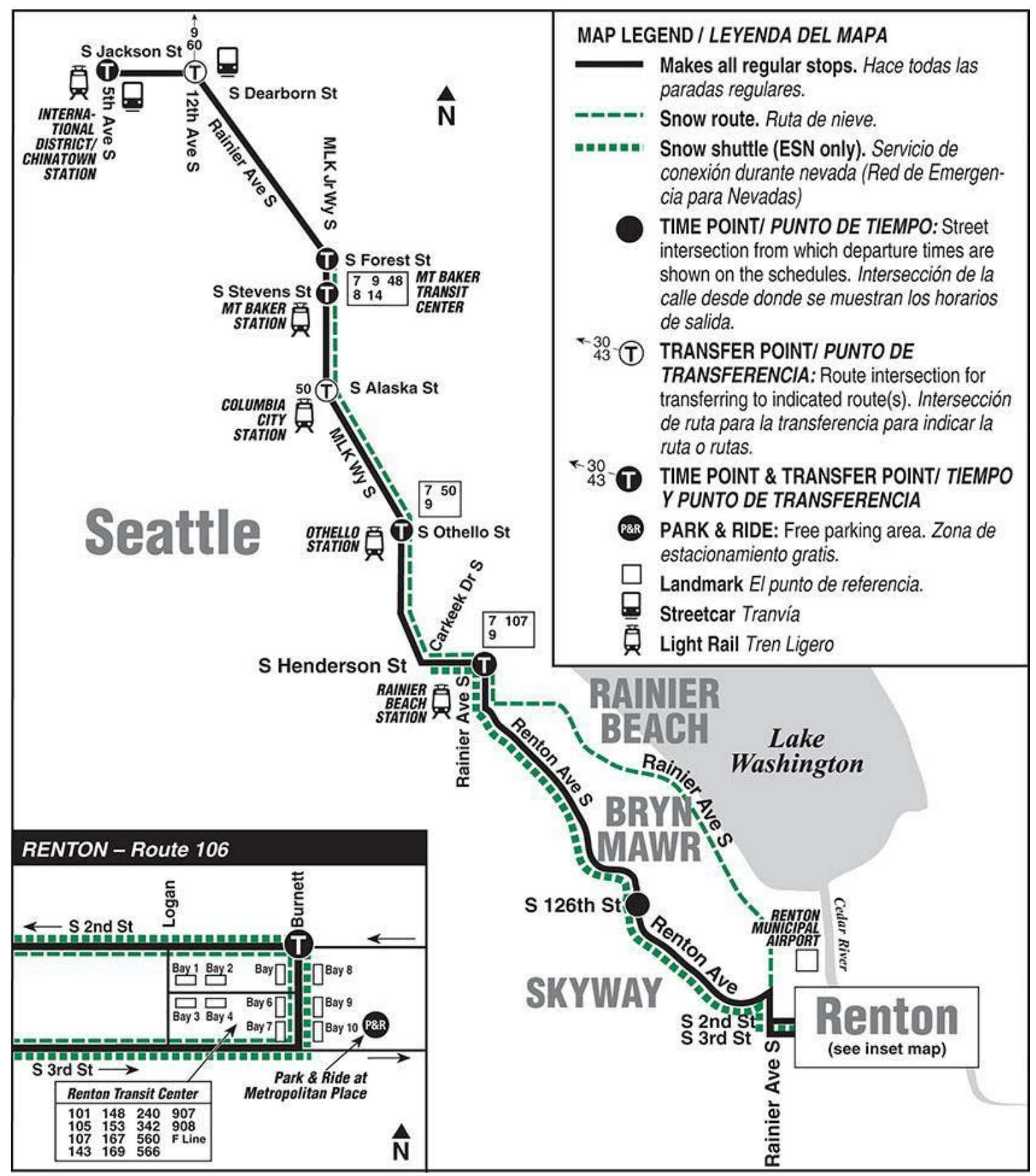

Figure 29. Service Map of King County Metro Route $106^{119}$

Note: Route 106 has a Stop at Othello Station

Sound Transit is the regional transit authority for the Central Puget Sound region of Washington State. It provides high-capacity transit services such as commuter rail, light rail, and buses. Since 2010, Sound Transit has been planning and developing TODs on surplus parcels of land as part of the TOD Program Strategic Plan. ${ }^{120}$ The purpose of this strategy is to integrate transportation and land use and promote inter-agency, intraagency, and public collaboration to transform high-capacity transit stations into livable transit communities. Othello Plaza TOD at Othello Plaza Station is one such transit community (Figure 30, Figure 31). 


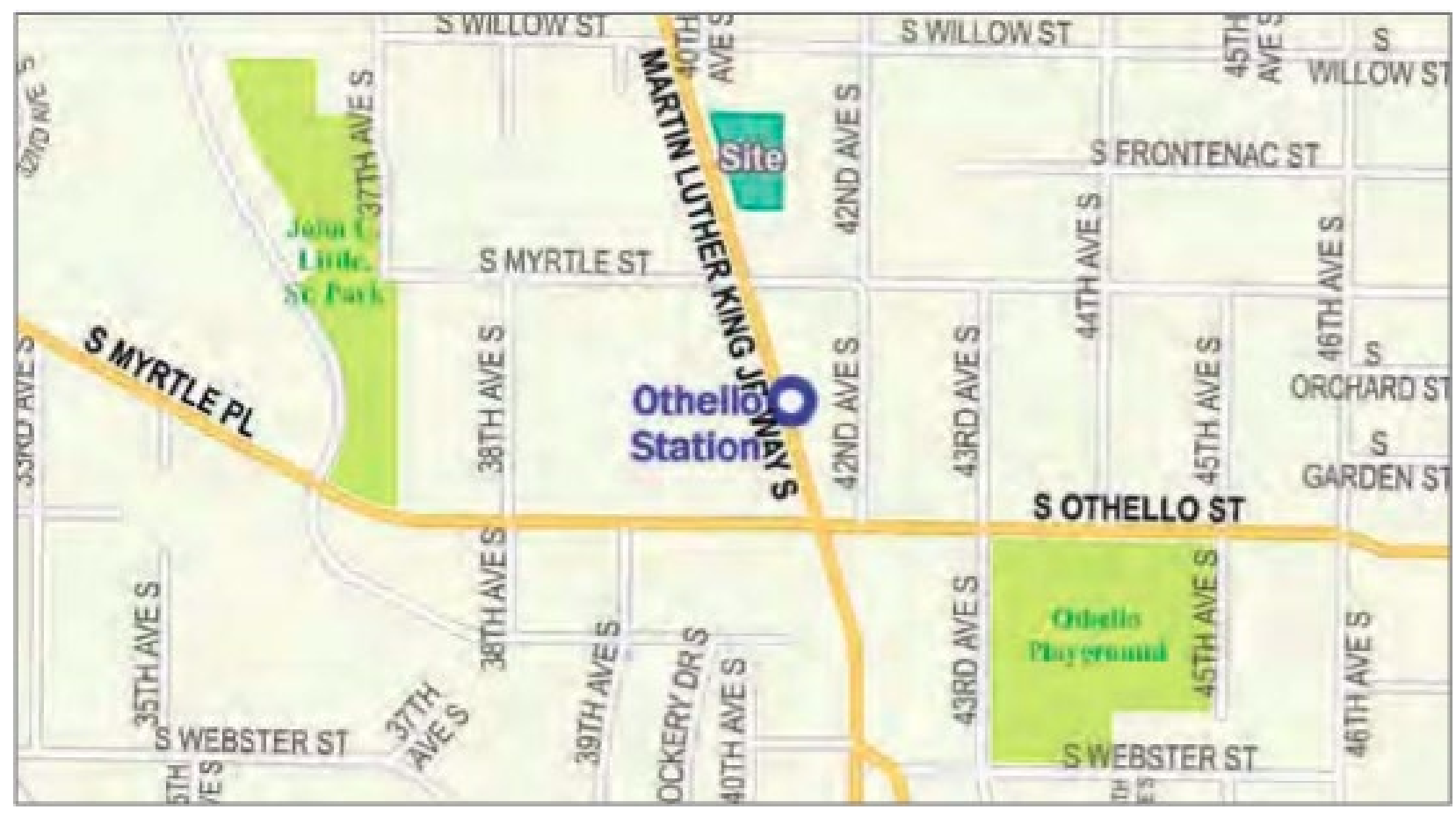

Figure 30. Location of Othello Plaza Station ${ }^{121}$

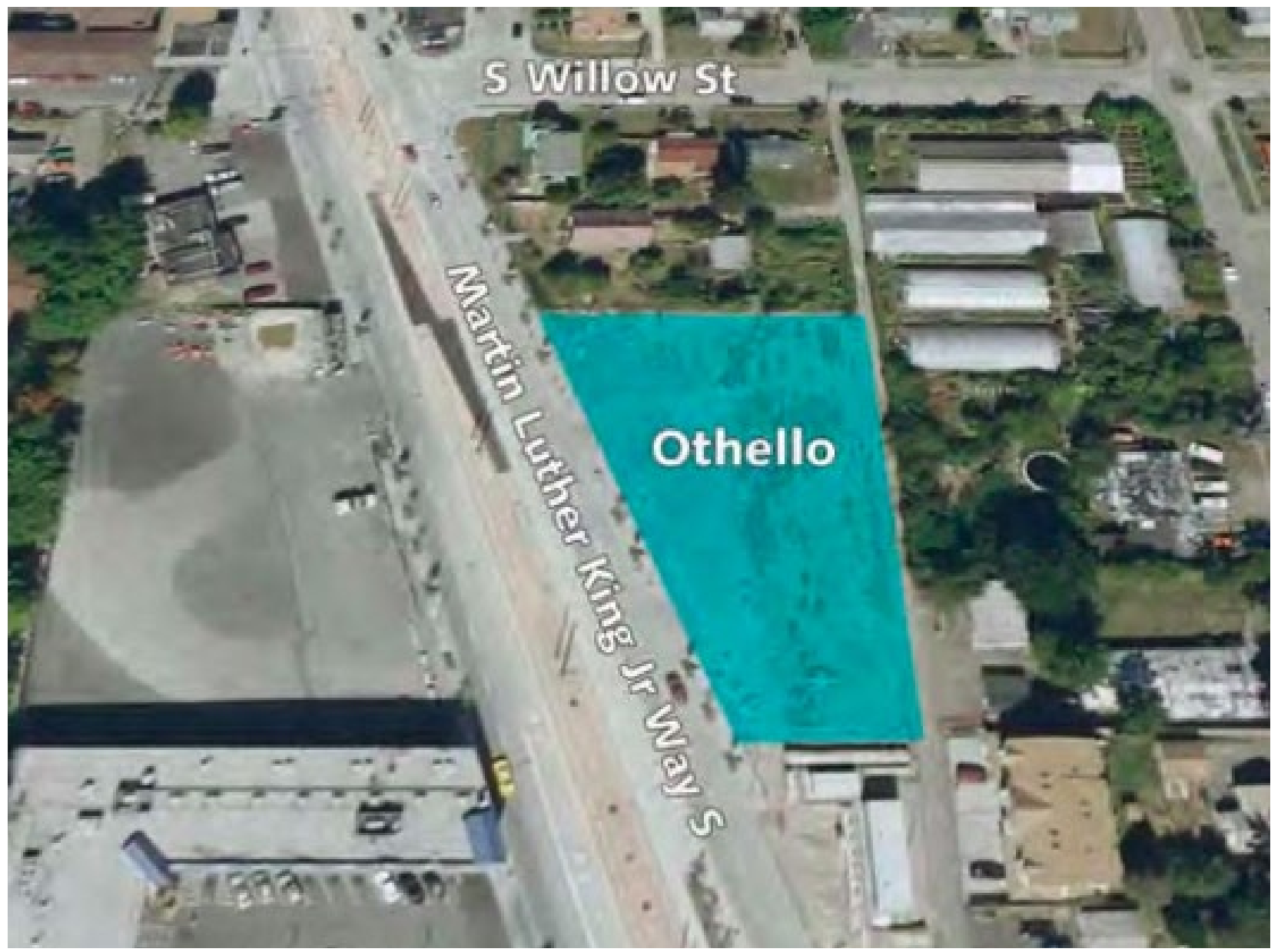

Figure 31. Development Site for Othello Plaza TOD ${ }^{122}$ 


\section{TOD Details}

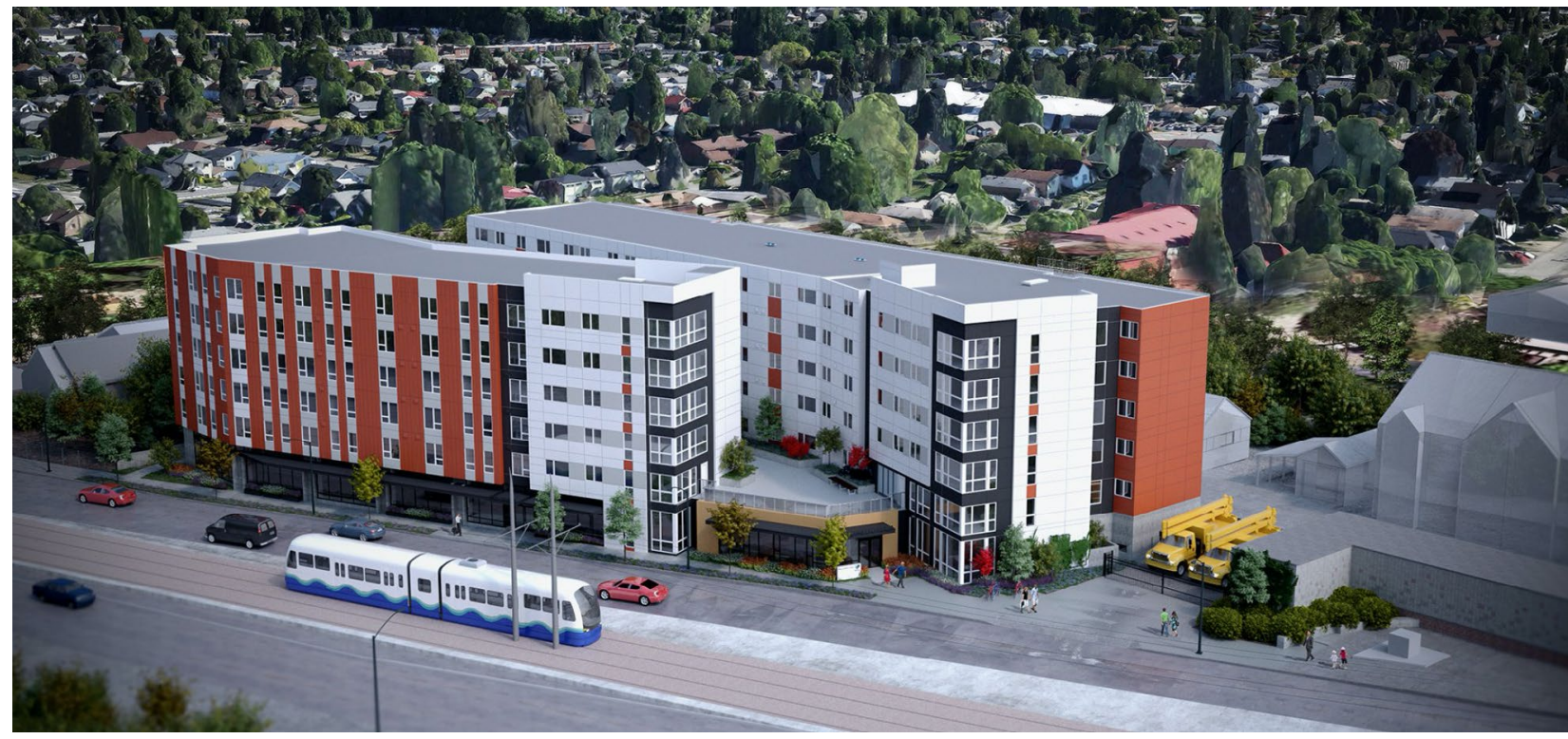

Figure 32. Rendering of Othello Plaza TOD ${ }^{123}$

Table 2. Details of Othello Plaza TOD

\begin{tabular}{ll}
\hline Programming & $\begin{array}{l}\text { Affordable mixed-use for annual incomes between } \$ 18,000 \text { and } \$ 55,000 \text { (30-80\% } \\
\text { AMI): } 108 \text { affordable units of up to three bedrooms; } 6 \text { stories; } 100,000 \text { sq. ft.; } \\
\text { Commercial ground level: } 6,500 \text { sq. ft. }\end{array}$ \\
\hline Timeline & $\begin{array}{l}\text { 2014: Sound Transit issues request for proposal for the Othello Station parcels } \\
\text { 2015: Monitor design and development process } \\
\text { 2016: Monitor construction process }\end{array}$ \\
& 2017: Official opening of Othello Plaza TOD \\
\hline Major Partners & Sound Transit; Mercy Housing; Seattle Office of Housing \\
\hline Funding Sources & $\begin{array}{l}\text { Low-Income Housing Tax Credits, The City of Seattle Office of Housing, Seattle } \\
\text { Housing Levy, JP Morgan Chase, Wells Fargo Bank, The Washington State } \\
\text { Housing Finance Commission, The Rainier Valley Community Development Fund, } \\
\text { JP Morgan Chase Foundation, Wells Fargo Housing Foundation, Longbrake Family } \\
\text { Foundation and Enterprise Community Partners }{ }^{124} \\
\text { Total cost: } \$ 29.8 \mathrm{M}\end{array}$ \\
\hline
\end{tabular}

\section{Zoning}

Prior to the construction of Othello Plaza TOD in 2017, the Othello town center featured a unique multicultural shopping district, with a mix of single-story retail along the main corridor (MLK Jr. Way South), a collection of small shops in the two-level King Plaza Mall, the Othello Public Market, and other chain stores, though urban patterns were primarily auto-oriented.

In 2009, the Othello neighborhood was chosen by then-mayor of Seattle, Greg Nickels, and the City Council as one of the three southeast Seattle neighborhoods to receive a neighborhood plan update. ${ }^{125}$ The original neighborhood plan, one of the 38 developed in the 
1990s, was adopted in 1998. It was called the MLK @ S. Holly Street Neighborhood Plan. For the updated neighborhood plan, the community decided to rename their neighborhood "Othello," so the revised plan was called the Othello Neighborhood Plan.

The plan outlined a vision for diverse housing types at various affordability levels, especially for large families, and aimed to develop a transit-oriented community with the area around Othello Station as the town center. ${ }^{126}$ Therefore, a Town Center action team convened in early 2010 to help inform the visioning, goals, and action items for the neighborhood plan. Furthermore, facilitated by the City of Seattle, the Neighborhood Plan Update reported the community-based recommendations for key zoning changes to achieve the Othello neighborhood vision. These proposed zoning changes were outlined in Othello's Urban Design Framework (UDF) and point primarily to up-zoning strategies, such as height increases for neighborhood commercial and low-rise residential parcels to 85' (up from 65') and 65', respectively. Main corridor commercial zoning was also redefined with pedestrian designations to encourage and preserve pedestrian-oriented shopping, which favors nonauto-oriented modes. Furthermore, the Othello neighborhood is located within a zoning overlay district called the Southeast Seattle Reinvestment Area (SESRA), allowing its zoning to vary from the city's underlying zoning. The zoning changes proposed in the UDF were readily adopted and implemented by the City of Seattle. Some residents, initially opposed to compact development and to locating Othello Station in their neighborhood, eventually quieted their opposition over the years as they saw the neighborhood improve and the light rail become popular among the Othello community (personal communication on December 20, 2019, with Mona Lee, community organizer and member, Othello Station Community Action Team).

\section{Enabling Environment for Sound Transit's TOD Policy}

Sound Transit's TOD policies are informed by various state, regional, and agency legislation, plans, policies, strategies, and resolutions. The state-level enabling legislation, RCW 81.104 and 81.112 (1992), guides regional transit agencies in Central Puget Sound to facilitate TODs in collaboration with public and private actors. In particular, RCW 81.104, or the High Capacity Transportation Systems bill, seeks to ameliorate roadway congestion with the implementation of "high capacity transportation system alternatives," coordinated by local jurisdictions. ${ }^{127}$ RCW 81.112, or the Regional Transit Authorities bill of 1992, enables the creation of a regional, multi-county transportation authority in the Central Puget Sound area, with recent amendments prioritizing equitable development. ${ }^{128}$

In 2010, Sound Transit adopted a TOD Program Strategic Plan. This plan provided the policy framework for developing TODs to support the development of regional high-capacity transit. Next, Sound Transit adopted a TOD Policy in December 2012. This policy outlined various goals for the TOD Program; integrated TOD planning and implementation with the planning and development of transit; allowed the implementation of TODs on agency-owned land; and directed the agency to collaborate with partners to facilitate transit-supportive policies and development in the one-half-mile distance around a transit station. The 2010 Strategic Plan was updated in 2014 to reflect the 2012 TOD Policy. Therefore, the 2012 TOD Policy and 2014 Strategic Plan provide Sound Transit the framework to integrate the development of transit infrastructure with land development. The 2012 TOD Policy also led Sound Transit 
to update its 1999 Real Property Disposition Policy, Procedures, and Guidelines. As a result, Sound Transit adopted the Real Property Excess, Surplus and Disposition Policy in 2013. Among other things, this policy directs the agency to prioritize TOD implementation on its surplus land and encourage the development of a variety of housing, including marketrate and affordable housing, on such land parcels. ${ }^{129}$ This policy of encouraging housing at various affordability levels resonates well with the objectives of the Othello Neighborhood Plan-and at the regional level with the PSRC's Growing Transit Communities Strategy (GTCS), adopted in 2013, which encourages the provision of a mix of uses and affordable housing around transit stations. ${ }^{130}$

The above-described legislation, policies, plans, and strategies existed when Sound Transit sold the surplus land near Othello Station to the developer. Hence, they formed the enabling framework for the Othello Station TOD. Sound Transit has continued to strengthen the framework further. For example, in 2018, Sound Transit updated its TOD Policy to incorporate equitable development and affordable housing construction as a specific use of Sound Transit's surplus land. This policy was adopted after the 2015 Washington legislature passed legislation (an amended RCW 81.112) aimed to guide the agency toward equitable development, specifically to use the agency's surplus land for affordable housing development. ${ }^{131}$ This legislation (RCW 81.112.350) stipulates that "when a regional transit authority disposes or transfers any surplus property, including, but not limited to, property acquired prior to July 15,2015 , a minimum of $80 \%$ of the surplus property to be disposed or transferred, including air rights, that is suitable for development as housing, must be offered for either transfer at no cost, sale, or long-term lease first to qualified entities that agree to develop affordable housing on the property, consistent with local land use and zoning laws." 132 This 2018 TOD Policy was adopted 18 months after the ballot measure for this policy (Sound Transit 3) was affirmed in 2016. ${ }^{133}$ Sound Transit 3 was a regional measure which approved the expansion of light rail by 63 miles, adding 37 new light rail transit (LRT) stations, two BRT lines, and other service increases. ${ }^{134}$

\section{Details of the Joint Development}

In November 2014, Sound Transit sold the surplus land near Othello Station for \$1.9 million to the developer. The land was sold at fair market value. The covenants on the property required it to be used for TOD for 60 years. ${ }^{135}$

Typically, Sound Transit only closes the sale of its property where a TOD is to be developed after a building permit is secured for the project. Indeed, in their RFP for the sale of the Othello Station TOD land, Sound Transit had retained the right of reversion of land if the developerbuyer did not break ground within three years of signing the purchase and sale agreement. Such stipulations ensure that Sound Transit can pursue other development opportunities if the buyer does not move forward with the project as envisaged in the purchase and sale agreement. ${ }^{136}$ The RFP also encouraged developers to consider Sound Transit's TOD principles and the community's desires as expressed in the Othello Neighborhood Plan. ${ }^{137}$

In the case of Othello Plaza TOD, Sound Transit agreed to a quick (30-day) close, however. The short close was necessary because the developer was acquiring the land using funds that needed to be spent by the end of 2014. These funds came in the form of a loan from 
the City of Seattle Office of Housing's Equitable TOD program (ETOD). The City of Seattle received funds for the ETOD program from a $\$ 3$ million Community Challenge Grant. The US Department of Housing and Urban Development (HUD) awarded the grant to the City of Seattle in November 2011 to meet the grant's objectives, which included, among others, growth of housing and commercial uses near light rail stations and the provision of housing affordable to a range of incomes and household sizes. ${ }^{138}$ Othello Station TOD met both these objectives.

The shared goal of all parties-to develop an affordable housing TOD—also contributed to Sound Transit's waiving their stipulations regarding the close of the sale. Although the RFP was not very prescriptive, in their response, the developer laid out the project details very well. The key business terms were laid out clearly in the contract (personal communication on January 07, 2020, with Sound Transit staff members Thatcher Imboden [Deputy Director, TOD, Sound Transit] and Jordan Rash [Senior Project Manager, TOD, Sound Transit]). To further safeguard its interests, Sound Transit entered into an agreement of cooperation with the City of Seattle and the developer. The agreement obliged each party to share information about the TOD openly and transparently and use good faith to communicate any permitting, construction, or design delays. ${ }^{139}$ Furthermore, under this agreement, all parties agreed to create a process for corrective action and resolve disagreements internally if the developer defaulted on the ETOD loan or if the project fell behind schedule. ${ }^{140}$ Sound Transit communicated regularly with the City of Seattle, specifically the housing department, to get the project going and the funds granted quickly (personal communication on January 7, 2020 with Sound Transit staff members Thatcher Imboden and Jordan Rash).

Furthermore, Othello Plaza was Washington State's first project that used both 4\% and 9\% Low Income Housing Tax Credits (LIHTC). Therefore, it was in Sound Transit's interest to be part of this project in order to see the developer's creativity in putting together the financing. Overall, Othello Plaza is a well-executed, high-quality TOD that provides social services such as an outpatient medical room for routine medical check-ups and a significant amount of family-size units across a range of affordability. It is an exemplar for other jurisdictions that are thinking about developing affordable housing TOD projects (personal communication on January 7, 2020 with Sound Transit staff members Thatcher Imboden and Jordan Rash).

In summary, although Othello Plaza is not a traditional joint development where the public agency is a long-term partner in the project, it provides an example of novel and nimble ways to further the development of TODs when all the parties share the same goals and are vested in ensuring project success.

\section{ECOVILLAGE TOD}

\section{Introduction}

Since its creation in 1975, the Greater Cleveland Regional Transit Authority (RTA) has provided bus, light rail, heavy rail, paratransit, and other transportation services for the Cleveland City area and surrounding suburbs of Cuyahoga County. ${ }^{141}$ In 2016, the RTA serviced 18.1 million vehicle miles with all its modes. Apart from transit, the RTA is also involved with several capital and TOD projects, including the TOD located in the Detroit 
Shoreway neighborhood in the City of Cleveland. This TOD, called EcoVillage, is centered around the W.65th-Lorain Rapid Station (also known as W.65th-Eco Village) and is serviced by the 22 Lorain Avenue bus route and the Red Line, a rapid transit rail line. ${ }^{142}$ The Red Line route runs service from 3 am to 1 am daily and connects this neighborhood to Cleveland Hopkins International Airport and the downtown Tower City shopping center, and it indirectly connects to several regional destinations such as the University Circle. ${ }^{143}$ The 22 Lorain is operational 24 hours a day. See Figure 33 for the RTA System Map, including the location of W.65th-Lorain Rapid Station.

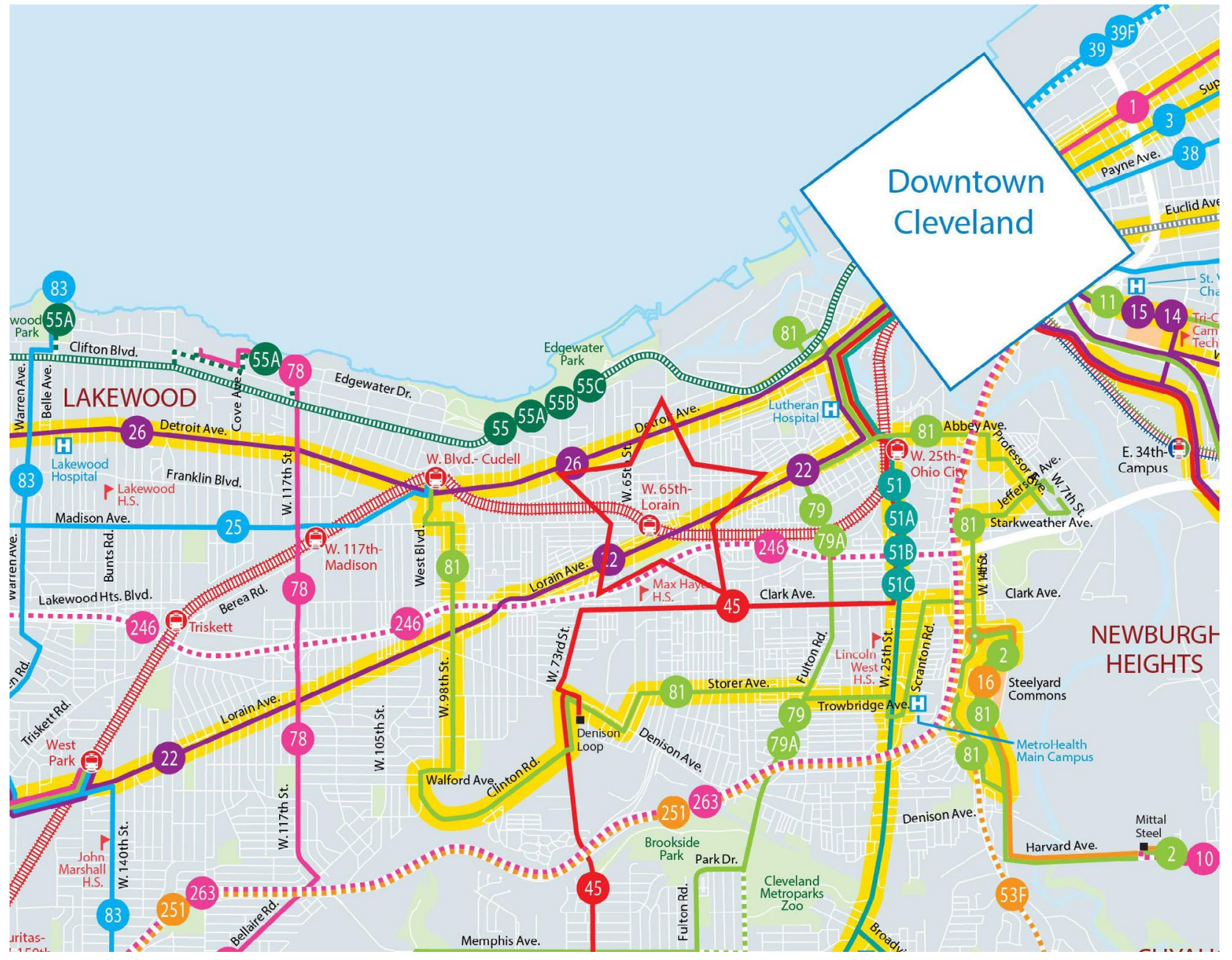

Figure 33. RTA System Map ${ }^{144}$

Note: W.65th-Lorain Avenue Station is starred

\section{Location}

The EcoVillage TOD is located in the Detroit Shoreway neighborhood situated two miles southwest of Downtown Cleveland (Figure 34). In 1998, the Detroit Shoreway Community Development Organization (DSCDO) helped establish the EcoVillage concept for the Detroit Shoreway area, partnering with the City of Cleveland, the RTA, and EcoCity Cleveland (a local environmental group), among others. ${ }^{145,146}$ By then, DSCDO was a well-established community development non-profit representing the neighborhood and 
had aided community members in blocking both the construction of a destructive highway extension and the proposed closure of the Lorain station. ${ }^{147}$ Thus, built with community support and participatory action, the EcoVillage is constructed as an antithesis to urban sprawl, community disinvestment, and environmental degradation. The City of Cleveland's partnership stems from its commitment to reduce emissions and address climate change at the local level through community engagement. To that end, the city looked toward Detroit Shoreway EcoVillage as one of the two neighborhoods to pilot actions aimed at meeting these two goals. ${ }^{148}$

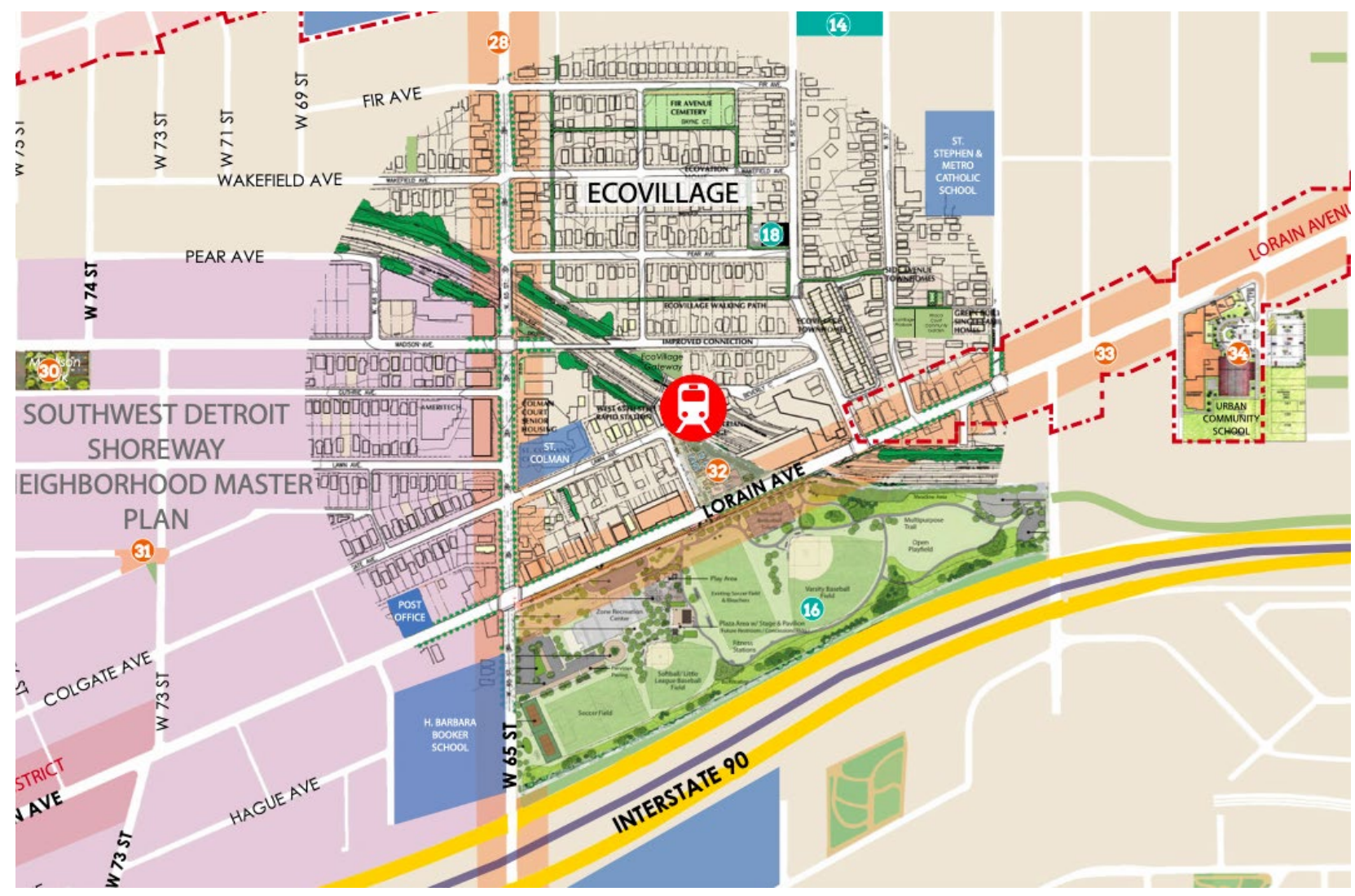

Figure 34. The EcoVillage Master Plan Surrounds W.65th-Lorain Avenue Station ${ }^{149}$

\section{EcoVillage Evolution}

EcoCity Cleveland is a local environmental advocacy and planning non-profit. ${ }^{150}$ Responding to the declining urban population, one of the goals of EcoCity Cleveland was to establish a neighborhood to demonstrate the principles of sustainable development which would attract new residents and retain current residents in the city. Thus, the EcoVillage concept was established.

DSCDO and its partners in 1998 introduced the EcoVillage concept to the Detroit Shoreway community with recommendations from an EcoCity Cleveland report which identified the W.65th-Lorain Avenue Station as the most suitable site for ecologically sound development. That same year, the RTA announced the possible closure of the station as an austerity measure due to reduced ridership. The community organized to help secure 
station preservation and, with additional funding from DSCDO and the RTA, rehabilitated the station shelter under the design principles of green building. The renovated station opened in 2004. ${ }^{151}$ DSCDO and EcoCity Cleveland continue to manage planning and development efforts in the Detroit Shoreway EcoVillage.

\section{TOD Details}

The EcoVillage hosts a variety of housing and tenure types at varying ranges of affordability. Apartments, townhomes, detached single-family homes, cottages, tiny homes, and greenrehabilitated older homes comprise the housing stock in the EcoVillage area. The first green developments of the EcoVillage were 20 townhomes priced at market rate and initially selling at a middling price point in the city. ${ }^{152}$ Two subsequently constructed townhome projects include the eight-unit Bridge Square Townhomes ${ }^{153}$ and the 22-unit Waverly Station Townhomes. ${ }^{154}$

The Green Cottages development in the EcoVillage TOD area includes five single-family, affordable, income-restricted houses built during the period 2008-2010. ${ }^{155}$ Around 1,300 square feet in size, the cottages were developed by the Cuyahoga Community Land Trust, a local land trust which preserves affordable housing stock through a shared equity model. Under this model, a homeowner leases a house for 99 years at a reduced price from a community land trust (CLT). The ownership of the land remains with the CLT. Furthermore, to maintain permanent affordability, the homeowner agrees to allow a portion of the increase in property value to remain with the house when they sell. ${ }^{15,157,158}$ The CLT model is a unique LVC tool because the land value increase is shared among the property owner and the land trust.

Tiny homes are another housing type in the EcoVillage TOD. They typically range from 80 to 800 square feet. In 2016, DSCDO helped finance the construction of two tiny homes (each approximately 500 square feet in size), though zoning challenges slowed the process. ${ }^{159}$ Cleveland's zoning code, instituted in 1929, requires a minimum house size of 950 square feet and a minimum lot size of 4,800 square feet for single-family homes. Therefore, new housing developments often need to obtain variances from the Board of Zoning Appeals. Two zoning variances were needed for tiny homes-one for house size and the other for lot size-since the homes are about 550 square feet in size and sit on approximately 3,200 square foot lots. There is growing support to change legislation through zoning overlays or zoning reforms ${ }^{160}$ (personal communication on January 6, 2020, with Adam Davenport, District Planner, City Planning Commission, City of Cleveland, $\mathrm{OH}$ ).

In 2018, DSCDO announced the opening of its latest affordable housing development in the EcoVillage: Aspen Place. This project caters to households earning $30 \%$ to $60 \%$ of the neighborhood's median income. Built on a land parcel previously owned by RTA, this project's first tenants started to move in January 2019. ${ }^{161}$ Aspen Place is a mixeduse building with ground-level retail and 40 affordable units on the first, second, and third floors. ${ }^{162}$ Situated adjacent to the W.65th-Lorain Avenue Station and within walking distance of an eighth of a mile, Aspen Place is truly transit-oriented. The project was funded by Enterprise Community Partners, the low-income housing tax credits provided 
by the Ohio Financing Agency, and the City of Cleveland, among others. Residents receive free monthly RTA transit passes as part of their amenities package.

Aspen Place was developed by the purchase of two parcels in the early 2000s from the RTA. Otherwise vacant, the lots contained a surface parking lot and sidewalks that were constructed using the FTA funds. Due to the FTA's requirements, the transit authority was not allowed to sell the land on which the parking lot and the sidewalks were constructed. This requirement was initially not known to DSCDO; however, it was met through agreements between the transit authority and DSCDO, including a parking lease agreement. The permitting process took about six months. On a positive note, the site was zoned for "local retail," which allowed a mixed-use development to be built on it. The zoning approval process included two rounds of local design review, one round of city-wide design review, and approval from the city's Board of Zoning Appeals. As the City of Cleveland partially funded Aspen Place's affordable housing units, its Community Planning Department conducted an additional design review. Furthermore, there was split zoning on these two parcels initially. Additionally, the parcels came under the Pedestrian Retail overlay zone, which was primarily for sites around street intersections. The site was then switched to Urban Form overlay zone. Another challenge in developing Aspen Place arose due to the irregularly shaped (triangular) land parcels that made it a little difficult to meet the city's frontage build-out requirement, which was eventually met with a few design modifications and zoning variances. Four zoning variances were required in total (personal communication on January 6, 2020, with Anya Kulcsar, Director of Real Estate Development, DSCDO).

\section{EVANS STATION LOFTS TOD}

\section{Overview of RTD Denver}

The Regional Transportation District (RTD) is the regional transportation agency that provides the Denver metro region with the bus, rail (including light rail and commuter rail), paratransit, and other transportation services. Formed in 1969, RTD began operating its first bus lines in 1973 and its first light rail line in 1994. ${ }^{163}$ RTD's first high-speed commuter line became operational in 2016. An expansion project of RTD's transit services, named and voter-approved in 2004 as FasTracks, aims to provide 140 miles of rapid transit extensions and improvements to the eight-county region's major transit corridors. ${ }^{164}$

An element to the FasTracks extension program includes TODs, where RTD takes the responsibility of facilitating design criteria, planning and research, and partnership-building to successfully implement TODs and other sustainable developments in the Denver region. ${ }^{165}$ RTD pursues joint development strategies where appropriate. The affordable housing project, Evans Station Lofts, was not implemented under a joint development agreement, though public and private entities were involved in its planning and construction.

\section{Evans Station and Evans Station Lofts}

Evans Station is located in south Denver, serviced by the $\mathrm{C}, \mathrm{D}, \mathrm{E}$, and $\mathrm{H}$ light rail lines on RTD's Southwest Rail corridor and the bus route $21 .{ }^{166}$ See Figure $35 .{ }^{167}$ 


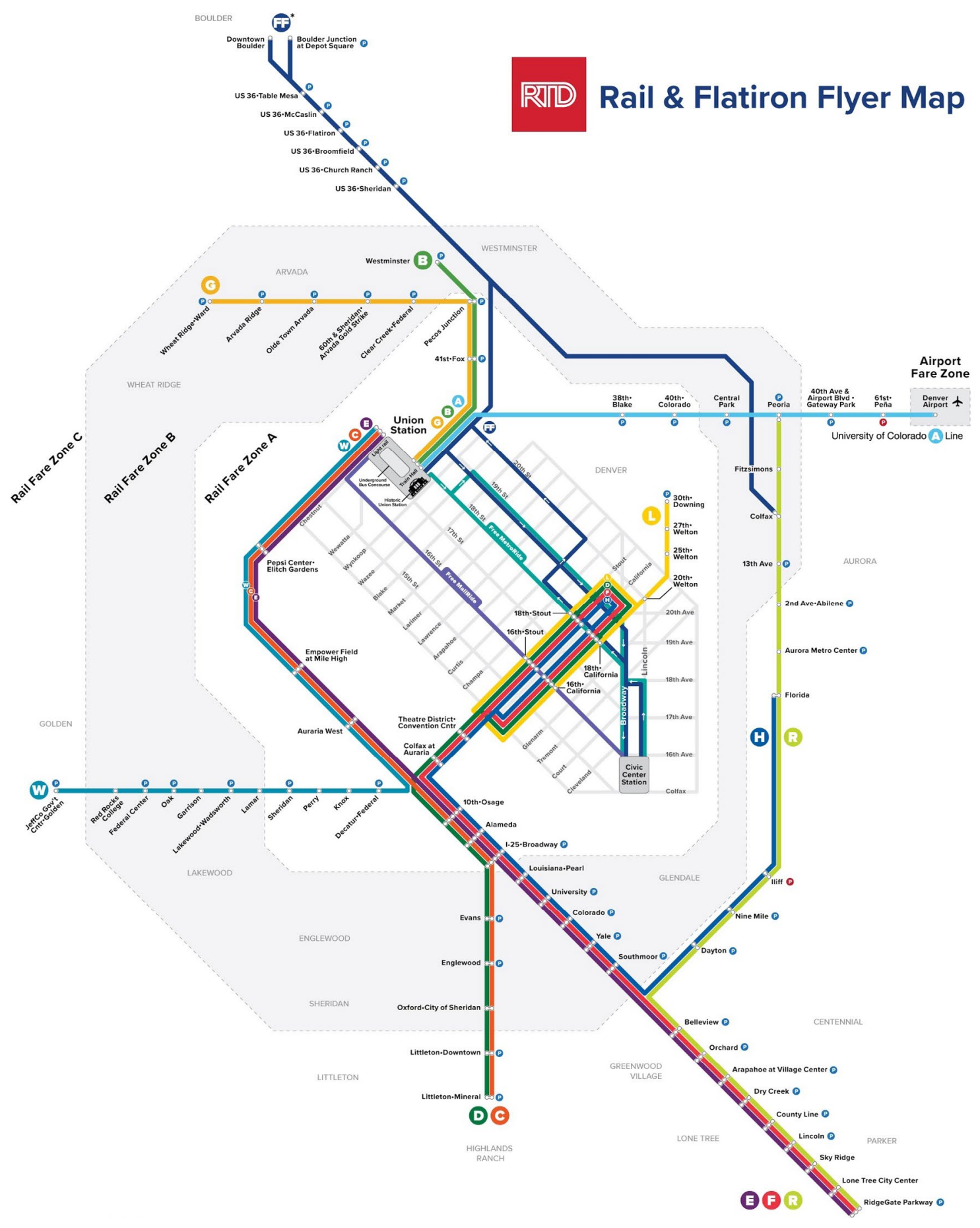

Figure 35. RTD System Map: ${ }^{168}$

Note: Evans Station is the fifth stop up from the southernmost terminus of the $D$ and $C$ rail lines

Evans Station Lofts opened in 2013. It features fifty one- and two-bedroom affordable housing units for residents at 30-60\% Area Median Income, with 10,000 square feet of commercial space on the ground floor. The complex also supports a community room with computers and wireless internet, an exercise room, and car-share available to the residents. ${ }^{169}$ The Evans Station Lofts are situated directly next to Evans Station (Figure 36). 


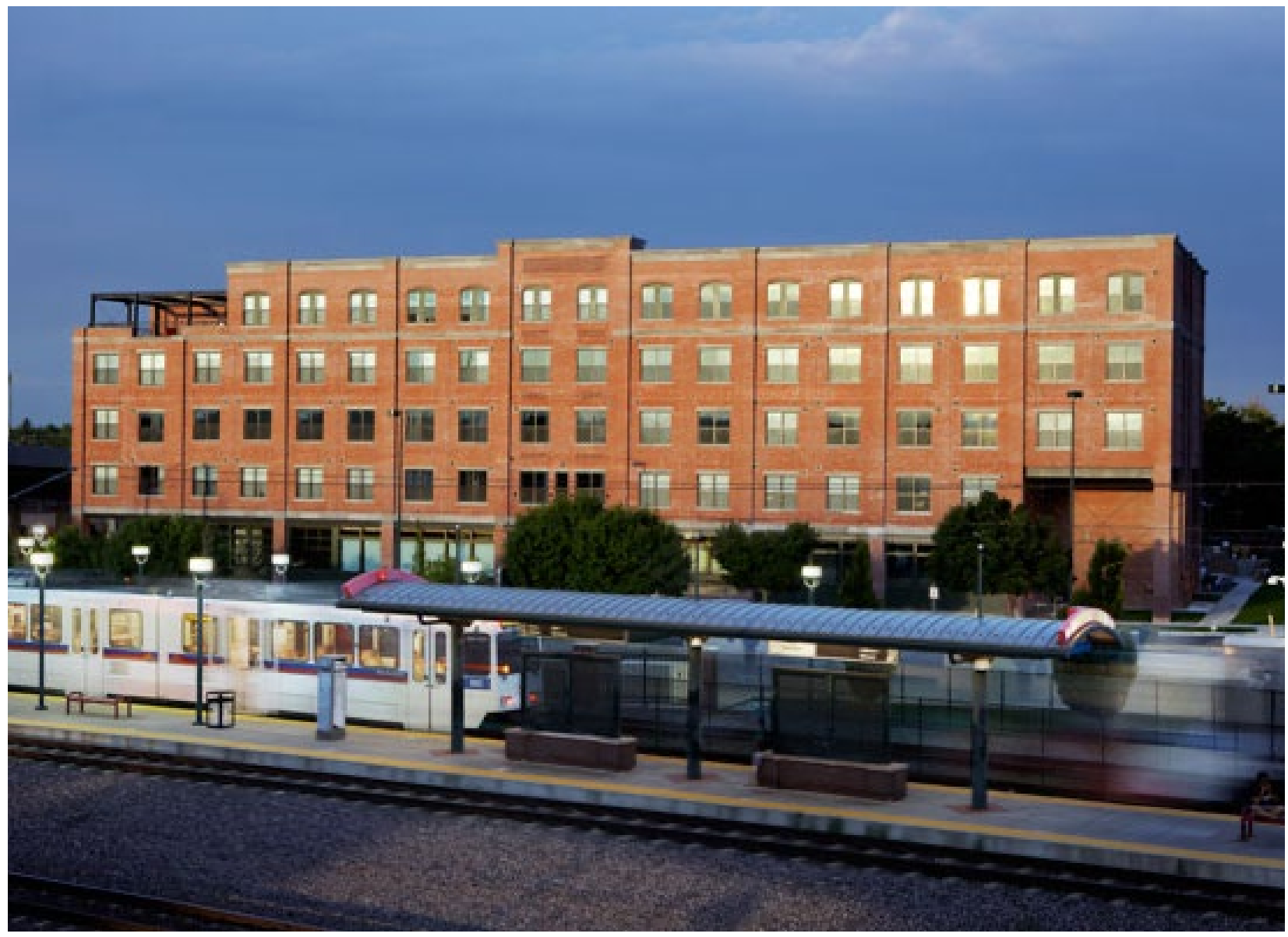

Figure 36. Evans Station Lofts ${ }^{170}$

\section{TOD Details}

The Urban Land Conservancy (ULC) was a major partner in the development of the Evans Station Lofts. In 2011, ULC purchased one acre of land adjacent to Evans Station for \$1.1 million with funding from the Denver Transit Oriented Development Fund (TOD Fund). This $\$ 30$ million fund was created in 2010 with the help of the City of Denver, ULC, and Enterprise Community Partners, among others, to develop and preserve affordable housing around transit. ${ }^{171}$ The fund guidelines allow ULC to purchase and hold properties as developers secure financing for affordable housing and TOD projects, ultimately reducing risk for developers. After its acquisition in 2011, ULC banked on the one-acre parcel for one year before selling to community and affordable housing developer Medici Consulting Group (founded as Medici Communities) for $\$ 1.2$ million to develop the Lofts, thereby recovering their original land cost and some of the holding costs (personal communication on January 31, 2020, with Troy Gladwell, CEO, Medici Consulting Group). The project was then awarded \$1 million in annual LIHTC funding from the Colorado Housing Finance Agency, which financed most of the $\$ 12$ million project. ${ }^{172}$

The Evans Station Lofts were not developed using a typical VC tool such as joint development, in that ULC was not a partner or did not buy the land for a low, pretransit station price. Because a lot of ULC's funds ( $\$ 1.1$ million) were tied up in the 
Evans Station Lofts site, they could not take a modest up-front fee (e.g., $\$ 250,000$ ) plus annual lease revenue. At the same time, due to the high cost for the Evans Station Lofts site, the developer was unable to pay ULC a large up-front fee and still have extra cash flow from the project to make annual lease payments. Hence, ULC sold the site to the developer (personal communication on January 31, 2020, with Troy Gladwell, CEO, Medici Consulting Group). Even after paying the full cost of land, the developer gained for two reasons: (a) ULC sold the land for only little more than the price they paid for it, thereby transferring any present or future land value gain to the developer, and (b) they held the land for one year for the developer without charging a holding fee. The developer arranged LIHTC funding during this risk-free, holding period. ${ }^{173}$

\section{Zoning}

The project required the city to make a few zoning changes in the station area before the developer could break ground for the Lofts. The city developed the new zoning code using recommendations from the Evans Station Area Plan, published in 2009. ${ }^{174}$ The station area was rezoned from light industrial/office use to urban-center neighborhood, mixed-use TOD in 2010, two years before the developer purchased the parcel. This rezoning expedited the entitlement process, as the newly adopted zoning codes provided a clear and specific regulatory framework that allowed the developer to implement new land uses. ${ }^{175}$

The Denver Planning Department held four public workshops and four public meetings to engage the community and help envision the Evans Station Area Plan. Additional meetings were held to discuss the proposed zoning amendments around the station. ${ }^{176}$ Apart from a few dissenting community members, the broader community supported the project. In fact, due to the rising property values that can be attributed to a large extent to the Evans Station Lofts, property owners adjacent to the TOD are selling their houses, which are being converted to triplexes (personal communication on January 31, 2020, with Troy Gladwell).

Apart from the favorable zoning amendments, the developer also benefited from relaxed parking (from two parking spots per housing unit to less than one) due to the TOD's proximity to the Evans Station, and from reduced ground-floor retail requirements (from 12,000 square feet to 8,000 square feet). The developer and its property management company occupied 3,000 of these 8,000 square feet as their offices. They share parking spaces with the residents. Per Troy Gladwell, CEO, Medici Consulting Group, reduced parking is likely to work for TODs that are close to a high-ridership transit station and have affordable housing units. TODs with market-rate housing might not benefit from reduced parking. Furthermore, limited parking reduces the desirability of TODs' retail spaces (personal communication on January 31, 2020, with Troy Gladwell).

Drawing from experience with a past project where the developer lost money underwriting retail at $\$ 10$, Medici Consulting Group underwrote the retail space at $\$ 0$ for Evans Station Lofts. According to Troy Gladwell, retail space needs to lease for around \$24-\$25 per square foot to cover the development cost in the Denver area, with $\$ 10$ per square foot adequate to cover insurance and taxes only. Therefore, although underwriting retail at $\$ 0$ was not a lender requirement, it enabled the developer to meet the city's retail requirement 
as well as address the market risk of retail space not performing well in their financial proformas. ${ }^{177}$ Furthermore, Troy Gladwell notes that it is a common misconception that a retail use such as a coffee shop in a TOD can be supported by population of 2,000 to 3,000 , with a few hundred of them buying coffee (personal communication on January 31,2020 , with Troy Gladwell). In short, local governments need to think carefully before requiring retail in TODs.

In summary, the Evan Station Lofts project shows how the cost of constructing TODs can be minimized directly through lower construction costs due to reduced parking and retail requirements, and indirectly by using TOD funds to lower entitlement and holding costs risks.

\section{TWINBROOK TOD}

\section{Overview of WMATA Transit System}

WMATA was created in 1967 to operate a regional transportation system in the nation's capital region. WMATA operated four regional bus systems in 1973, and, after almost a decade of planning and construction, the first Metrorail line became operational in 1976. Today, it operates 117 miles of track on 91 stations, deploys 1,500 buses daily, and offers paratransit services through its MetroAccess program. ${ }^{178}$

Twinbrook Station, located in Rockville, MD, is a subway station on WMATA's Red Line which runs from Shady Grove Station to Glenmont Station north of DC's Capital Beltway. Opened in December 1984, the Twinbrook Station primarily serves commuters. See Figure 37 for the WMATA system map and the station location. 

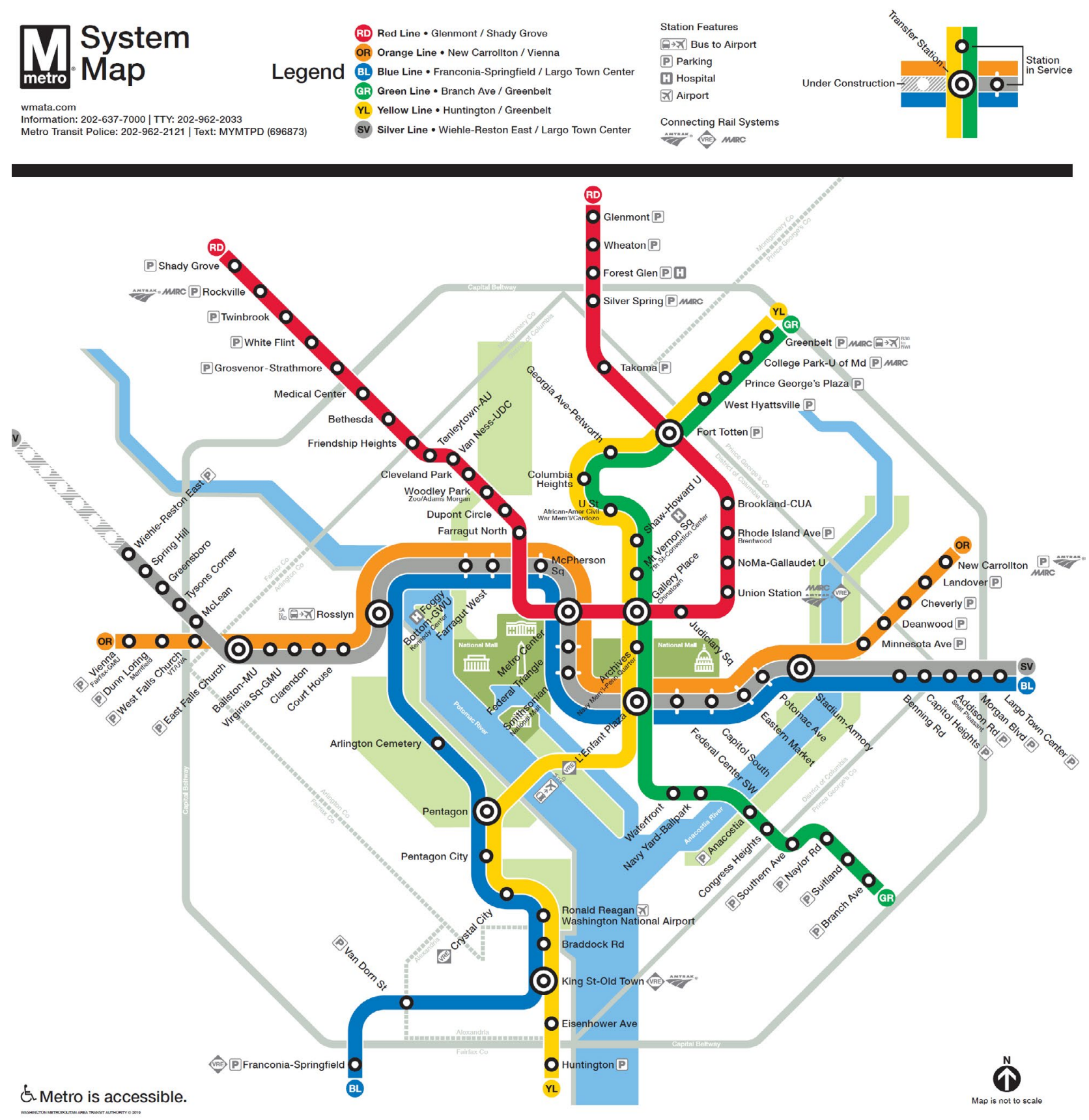

Figure 37. WMATA System Map ${ }^{179}$

Note: Twinbrook Station is starred

\section{Details of the TOD}

Two transit-oriented residential developments (parts of the Twinbrook Station TOD) are consistent with the sector plan, The Alaire and The Terano, both of which were jointly developed by WMATA and real estate firm JBG Smith. ${ }^{180}$ This joint development agreement was formed in 2002, and the first ground lease was signed in 2008 to begin construction on 26 acres of WMATA-owned land for residential development. The Alaire building was 
completed in 2010 and includes 279 residential units and 16,500 square feet of ground-floor retail. The Terano features 214 residential units with 33,000 square feet of retail and was completed in $2015 .{ }^{181}$

The project faced some initial community opposition. Two townhome communities adjacent to the TOD site were concerned about the project's building heights, including concerns that their townhomes would be under the project's shadows. However, these townhome communities supported the project once the developer addressed their concerns by (a) reducing the project's building height for sections closer to the townhomes (the heights were increased for project sections further away) and (b) increasing the buffer between the project and the townhomes (personal communication with Ricky W. Barker, Director of Community Planning and Development Services, City of Rockville, MD, and Mr. Jim Wasilak, Chief of Planning, City of Rockville, MD).

The community, led by the Twinbrook Community Association (TCA), was also concerned about the project's traffic impacts-and in general, about the large amount of development coming close to the existing residential areas. However, the project modifications undertaken by the developer and the community's desire to improve their neighborhood through new and desirable projects led the community to support the TOD project ultimately. The TCA even provided a letter of support for the project (personal communication with Ricky W. Barker and Mr. Jim Wasilak).

\section{Zoning}

At the time approvals were granted for the TOD, the Twinbrook area was largely zoned commercial, light industrial and residential, and it was composed of commercial uses of varying sizes (even single-family houses were used for commercial purposes), offices, warehouses, laboratories, and light industrial services. ${ }^{182}$ Furthermore, the TOD site falls on the eastern as well as the western side of the Twinbrook Station. At the time of project approval, the eastern side was in the unincorporated county. Therefore, it was under the Montgomery County's jurisdiction. The western side was in the City of Rockville. Therefore, the developer had to seek approvals from both the county and the city, which they obtained in the 2003-2004 period. Shortly thereafter, the Mayor of Rockville convinced the developer to initiate an annexation petition to bring the eastern side within the city's jurisdiction. Concurrently with the annexation, the City of Rockville approved text and map amendments for the TOD site. These amendments were undertaken under an "optional method of development" under which while the TOD site retained its original zoning, higher building heights were allowed compared to what the underlying zoning permitted. This development method was a two-stage process. The preliminary development plan was approved first, followed by the use permits. These approvals were obtained around mid-2005. The Twinbrook Station TOD led the City of Rockville to reimagine the station areas and to initiate a wholesale revision of the city's zoning ordinance in the 2005-2009 period that, among others, led to the creation of mixed-use transit district (MXTD) zone. MXTD zone allows higher densities that are aligned more closely with the "optional method of development." To address developers' concerns, care was taken that the parcels already entitled under the previous "optional development method" retained their entitlements (personal communication with Ricky 
W. Barker and Mr. Jim Wasilak).

For the surrounding community, after almost a decade of community meetings which included a Twinbrook Charrette held in 2000, the 2009 Twinbrook Sector Plan recommended changes for station area zoning. ${ }^{183}$ The plan included recommendations for new land uses around the Twinbrook Station area, increased opportunities for dense housing, low-impact development, and the creation of a unified community with access to residential and commercial neighborhoods. ${ }^{184}$ Most major zoning changes were proposed where light industrial, low-intensity, and single-family uses were rezoned to transit-oriented mixed-use with a higher FAR. Form-based recommendations from the sector plan were intended to create a gradient of density according to proximity to the station. ${ }^{185}$ Overall, the Twinbrook Sector Plan envisions the Twinbrook station area as a transit-oriented neighborhood, highlighting mixed-use development, high-quality urban design, and pedestrian-friendly green spaces. ${ }^{186}$ Subsequently, a larger planning effort that concluded with the 2016 passage of the Rockville Pike Neighborhood Plan also encouraged a mixeduse, transit-oriented neighborhood around Twinbrook Station. ${ }^{187}$

\section{WMATA's Joint Development Policy}

WMATA's joint development policy, enacted in the early 1970s and most recently revised in 2018, enabled the completion of the Twinbrook Station TOD. ${ }^{188}$ The goal of the joint development program is to market WMATA-owned land to real estate developers for the purpose of constructing TODs. The 2018 amendments made several changes to the policy. These included:

(a) Splitting the existing Joint Development Policy and Guidelines document ${ }^{189}$ into two, a policy document (Joint Development Polices) and a guidelines document (Joint Development Program Guidelines). This split enhanced the documents' readability because the broad policies and the specific implementation guidelines were intermixed previously. Furthermore, it obviated the need to seek the WMATA Board's approval for every minor change to the guidelines.

(b) Specifying the criteria to be considered by the staff to assess and for the Board to evaluate joint development proposals.

(c) While determining the size and extent of replacement of transit facilities impacted by the joint development (such as surface parking lots), shifting the focus from requiring replacement of a specific ratio of transit facilities impacted (such as, a certain proportion of the number of parking spaces lost) to serving the transit riders (for example, only require replacement parking needed to serve the ridership after taking into consideration any station access mode shift from auto to non-auto mode due to the joint development, TODs in the surrounding area, and the TDM policies implemented, etc.

(d) Including public policy goals such as affordable housing, sustainability (for example, green buildings), and TDM. ${ }^{190,191}$ 


\section{Twinbrook TOD Joint Development Agreement}

The initial 2002 joint development agreement (JDA) outlined a mixed-used development plan for 26.3 acres of the Twinbrook Station area, with the entire land leased for 99 years by WMATA to JBG Companies, the primary development partner in the agreement. The JDA called for the development of 1,000 housing units, 20,000 square feet of retail, 280,000 square feet of office space, and two parking garages (among others, to replace the surface parking removed to make way for the joint development). These projects were to be constructed over multiple phases (Phases 1 to 3, each with two sub-parts: for example, Phase 1a included the Alaire, and Phase 1B, The Terano). ${ }^{192,193}$ In 2007, the agreement was restructured to sell one-third of the station area land to the developer to construct 595 condominium units in addition to the rental apartments outlined in the original agreement. Furthermore, since the developer was also able to secure higher densities during the entitlement process, the restructured agreement included an increase in (a) housing units from 1,000 to 1,595 (1,000 apartments and 595 condominiums), (b) retail (from 20,000 to 200,000 square feet), and (c) office space (from 280,000 to 325,000 square feet). ${ }^{194}$ More apartments, much of the retail, and all the office space and condominiums were to be built in Phases 2 and $3 .{ }^{195}$ The Twinbrook JDA was restructured a second time in 2011 after the property values declined following the financial crisis, which led JBG to express unwillingness to continue with the project per the terms that existed at that time. These renegotiations allowed the developer to refinance the Phase $1 \mathrm{~A}$ project (The Alaire) and a parking garage structure meant to serve Alaire residents and Metroline commuters. ${ }^{196}$ In 2013, the joint development agreement was amended for a third time to extend the Phase 1B (The Terano) and Phase 3 closing dates, among other goals. ${ }^{197}$ Since then, the developer has parted ways with WMATA after completing the first two phases, specifically The Alaire and The Terano and the public streets on which these two developments are located, the parking garage, and a surface parking lot. More apartments and retail, and all of the condominiums and office space, need to be developed still (personal communication with Ricky W. Barker and Mr. Jim Wasilak).

\section{MACARTHUR TRANSIT VILLAGE TOD}

\section{BART Overview}

BART is the regional heavy rail system that connects multiple cities in Alameda, Contra Costa, San Francisco, and San Mateo counties located in the San Francisco Bay Area region of California (Figure 38). It serves an average 414,166 daily weekday trips on 122 route miles of track at 48 total stations throughout the Bay Area. ${ }^{198}$ 


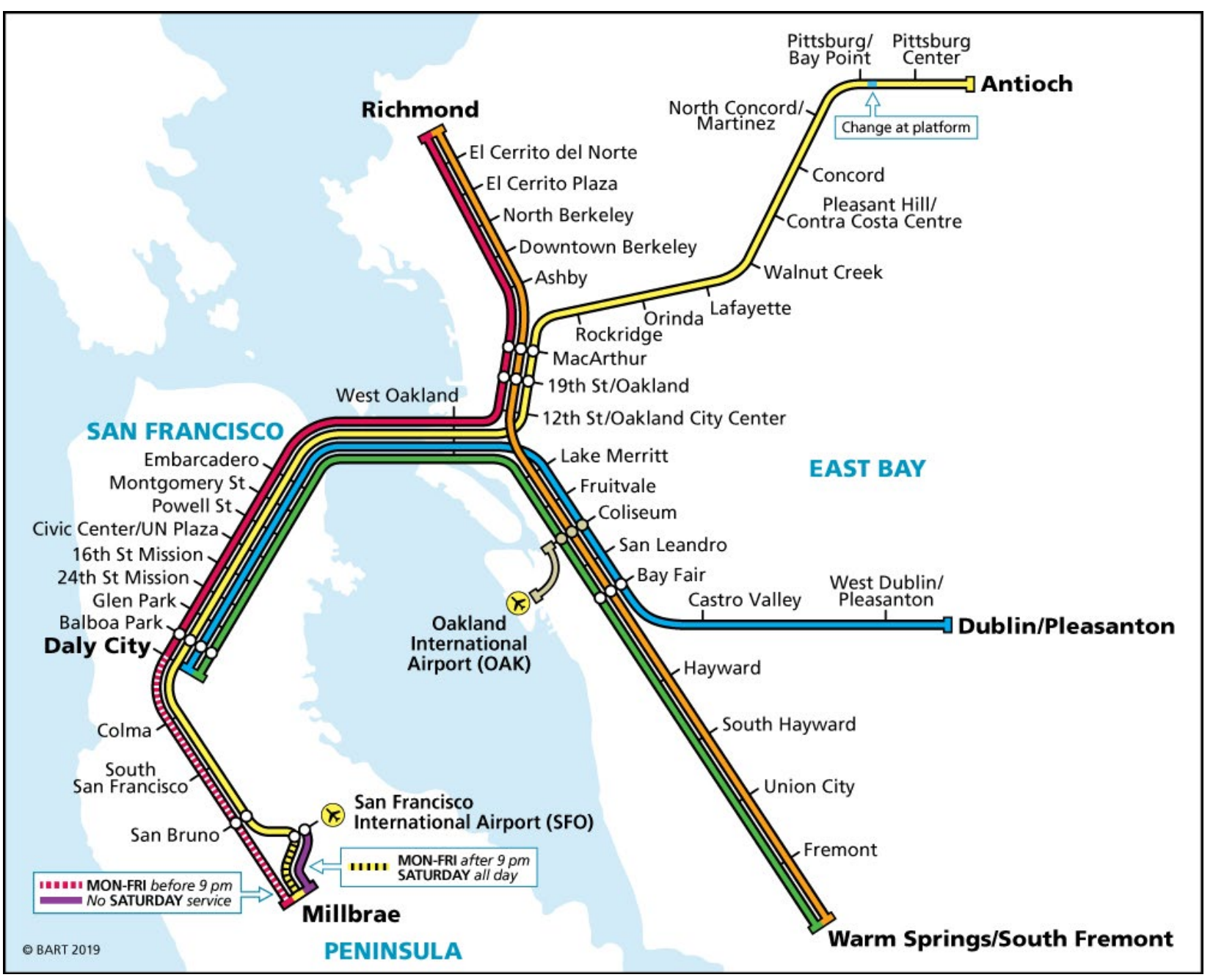

Figure 38. BART Route Map ${ }^{199}$

Note: MacArthur Station is Served by the Antioch SFO/Millbrae, Richmond-Millbrae, and Richmond-Warm Springs/South Fremont Lines

In June 2016, BART adopted its TOD Policy. It included goals for sustainable community place-making, increased ridership, VC, and affordability in an effort to further BART values and achieve regional economic development targets. ${ }^{200}$ Furthermore, new projects are not required to include structured parking to replace all the lost surface parking. ${ }^{201}$ Supported by the passing of CaliforniaAB 2923 in 2018 (AB 2923, or "BART Transit-oriented Development"), BART intends to add 18,000 residential units around its transit stops by 2040 , with $35 \%$ of these units at below-market rate (BMR). ${ }^{202}$ AB 2923 requires cities to remove restrictive zoning around BART-owned land to help facilitate the construction of higher-density housing. One of the busiest BART stations in the entire system, north Oakland's MacArthur Station is the site for the MacArthur Transit Village TOD, a series of developments aimed at achieving BART's residential density goals. ${ }^{203}$

\section{MacArthur Transit Village}

The 7.76-acre MacArthur Transit Village was approved through the PUD process. The 
preliminary development plan (PDP) was approved originally in 2008. It was revised in 2017. ${ }^{204}$ The 2008 approval set design guidelines, massing, and mixed land uses for the surface parking lots directly adjacent to the station. The same year, the City of Oakland adopted new zoning for the transit village site to be reclassified as an S-15 Transit Oriented Development Zone. ${ }^{205}$ As initially imagined, the $\$ 370$ million project would accommodateover five phases - the construction of 875 new residential units $(20 \%$ of which were mandated for affordable housing), 49,000 square feet of commercial space, and 5,000 square feet of community space, in addition to various other infrastructure improvements and a parking garage structure..$^{206}$

Phase I of the TOD began in 2011 and was completed in 2014 with the completion of the 481-space parking garage and other infrastructure improvements. The garage is meant to replace the surface parking lost to stage development. Phase II saw the construction of Mural, a 90 -unit, 100\% affordable housing complex developed by BRIDGE, Inc., completed in early 2016. ${ }^{207}$ Phases III to $\mathrm{V}$ include the construction of two market-rate, mixed-use apartment complexes - a six-story 385-unit Hines' MacArthur Commons broke ground in 2017 and will include 24,689 square feet of ground-floor retail; and a 24-story, 402-unit, mixed-income development broke ground in 2018. It will include 10,000 square feet of retail and is being developed by Boston Properties (personal communication on February 12, 2020, with Paul Voix, Principal Property Development Officer, Real Estate and Property Development, BART).

\section{Development Details}

MacArthur Transit Community Partners, a partnership between BRIDGE, Inc., and McGrath Properties, were appointed master developers of the TOD. The partnership ended a few years ago. McGrath Properties took ownership of the parcel where the 24-story Boston Properties' tower is located (Boston Properties have the ground lease for this parcel). As the master developer, BRIDGE, Inc. developed the parking garage, made improvements to the entrance plaza and adjacent city streets, and constructed the frontage road and other private streets. The parking garage sits on land initially occupied by two motels which were bought by Oakland Redevelopment Agency for $\$ 5$ million. Furthermore, per the initial agreement, the frontage road and the plaza improvements needed to be completed together. However, the plaza improvements were contingent on the availability of external funds, such as federal funds. However, two options existed when it became clear that such funds were not available: (a) downgrade the plaza improvements to fit within the existing budget, or (b) decouple the plaza improvements with the frontage road to allow plaza improvements to be undertaken when funds became available. To not compromise on the quality of the plaza, the second option was chosen and the agreement was amended to decouple the frontage road with the plaza improvements. Thus, the frontage road was completed in 2014 and the plaza improvements in 2019 (personal communication on February 12, 2020, with Paul Voix).

BRIDGE, Inc. also followed a 10-year process to plan, ready parcels, and secure funding for the Mural affordable housing development. Local redevelopment funds totaling \$30 million, in addition to $\$ 40$ million in state grants and $\$ 7$ million from BRIDGE, Inc. itself, helped the developer complete the project in early $2016 .{ }^{208}$ 


\section{Zoning Challenges}

The parcel on which the 24-story, 402-unit tower (with 41 affordable units) is being constructed was initially entitled for a 197-unit, six-story building. During the up-zoning process, the surrounding community had concerns related to shadowing and visibility of the high-rise from surrounding residences. Many local residents feared that the high-rise would be out of character in a primarily working-class single-family neighborhood, would lead to traffic congestion, and would do little to promote local retail and restaurants. ${ }^{209}$ Others thought that considering the significant density and height variances provided for the development, the city should have negotiated affordable housing at deeper levels of affordability than the proposed affordability at $80 \%$ AMI. ${ }^{210}$

The project promoter, McGrath Properties, organized several public meetings during the up-zoning process. The other promoter, Boston Properties, also participated in these meetings. Both the promoters were inclusive and welcoming of the community concerns. They also earned the support of the local businesses by financially supporting a lighting project of the local neighborhood business improvement district (BID). Moreover, since the Boston Properties tower is adjacent to a freeway, most of the shadowing occurs over the freeway or over the other parts of the TOD as opposed to the existing community (personal communication on February 12, 2020, with Paul Voix).

Finally, since the 90 affordable units in the Mural development that are affordable to households earning less than $50 \%$ AMI $^{211}$ did not meet BART's mandated $20 \%$ affordable units for the MacArthur Transit Village project, the up-zoned Boston Properties tower was approved in exchange for 41 additional affordable housing units ${ }^{212}$ and $\$ 1.3$ million in community benefits, such as upgrades to a nearby park. ${ }^{213}$

Leasing retail spaces is another challenge. When many of the TOD projects were initiated, the public agencies did not see retail shrinking. Indeed, the city governments often required retail in mixed-use projects to activate the ground floor, thereby leading to a glut of it. Furthermore, since the retail spaces rely on foot traffic, they have to be designed wellfor example, located on the way to or from the transit station. Moreover, often the retail spaces are leased without tenant improvements. For such reasons, it has been difficult to fill retail spaces. Indeed, ground-floor retail in the MacArthur parking garage is struggling, with BART looking for a lessor for the past five years, and if the retail spaces in the Hine's MacArthur Commons project do not lease within a stipulated time, they can be converted to live-work spaces. So, with difficulty filling retail and with increasing interest in uses such as shared work spaces, the focus is shifting from ground-floor retail to active ground floor with uses such as live-work spaces and shared office spaces (personal communication on February 12, 2020, with Abby Thorne-Lyman, Manager, Transit-Oriented Development Planning, Development \& Construction Department, BART).

On a larger note, BART now finds itself in a world after AB 2923. The law states that if a city has adopted conflicting zoning standards, AB 2923 standards will prevail. The height and the FAR requirements of this law are quite aggressive. For example, the law requires FAR to be 0.6 times the building height. For a six-story building, it translates into a FAR of 4.2. This high FAR will make it difficult for cities to do shadowing, step-backs, 
etc. Furthermore, the lowest FAR under AB 2923 is 3.0, double what the cities typically allow. Moreover, if a development comes under the SB 35 that was approved in 2017; for example, if the development is located within half a mile of a transit stop and is $50 \%$ residential with $20 \%$ affordable housing units, it will not be subject to design review. In this changed scenario, BART has to find new ways of interacting with the city governments and communities around the train stations so that it abides by the requirements of $A B$ 2923 and SB 35 while creating community-sensitive TODs (personal communication on February 12, 2020, with Abby Thorne-Lyman, Manager, Transit-Oriented Development Planning, Development \& Construction Department, BART).

\section{Value Capture}

Value capture happened in two important ways. First, BART contributed land worth 13 million dollars. Additional funds came from the State of California, the Oakland Redevelopment Agency, and BART's funding sources such as federal grant money and proposition funds. In return, BART received projects worth approximately $\$ 35$ million, including a parking structure worth $\$ 27$ million. Second, BART will receive long-term revenue from developers in the form of transit benefit fees. Specifically, for the marketrate apartments, BART will start receiving transit benefit fees seven years after project stabilization. Project stabilization is deemed to occur when a project reaches $90 \%$ occupancy or 18 months after a certificate of occupancy is issued. BART will receive $1 \%$ of gross revenue for 10 years post-project stabilization, and $2 \%$ of gross revenue after that. The agency is likely to receive the fee revenue from the Hines' MacArthur Commons starting in 2029 and from the Boston Properties 24-story tower starting in 2030. This fee revenue is estimated to be $\$ 383,000$ per year for the first 10 years, increasing to over $\$ 1$ million per year by 2040 . Finally, if the apartments were to convert to condominiums (when projects were entitled, the intention was for them to be condominiums, and they are built to condominiums standards), BART will receive $1.5 \%$ of the sale price (personal communication on February 12, 2020, with Paul Voix).

\section{WATERSIDE PLACE TOD}

\section{Overview of the MBTA}

The Massachusetts Bay Transportation Authority (MBTA, or "the T") operates one of the country' oldest transportation systems. It provides heavy and commuter rail, bus, ferry, and paratransit services for over a million daily riders. ${ }^{214}$ There are four major subway routes operated by the MBTA: the Red, Orange, Blue, and Green lines, which serve Boston, MA, and the surrounding cities such as Cambridge, Quincy, and Revere. ${ }^{215}$ Included in the T's rapid transit system is the Silver line (Figure 39), a BRT route which runs five different branches from Roxbury in central Boston to Chelsea and includes service to Boston's Logan Airport. ${ }^{216}$ After completing its second phase of construction in 2004, the Silver Line BRT connected South Station to Boston's World Trade Center on the seaport. Silver Lines 1, 2, and 3 share a terminus point in the Seaport District where the Waterside Place TOD is located between the World Trade Center and Silverline Way stations of the Sliver Line BRT (near Airport Terminals in Figure 39). 


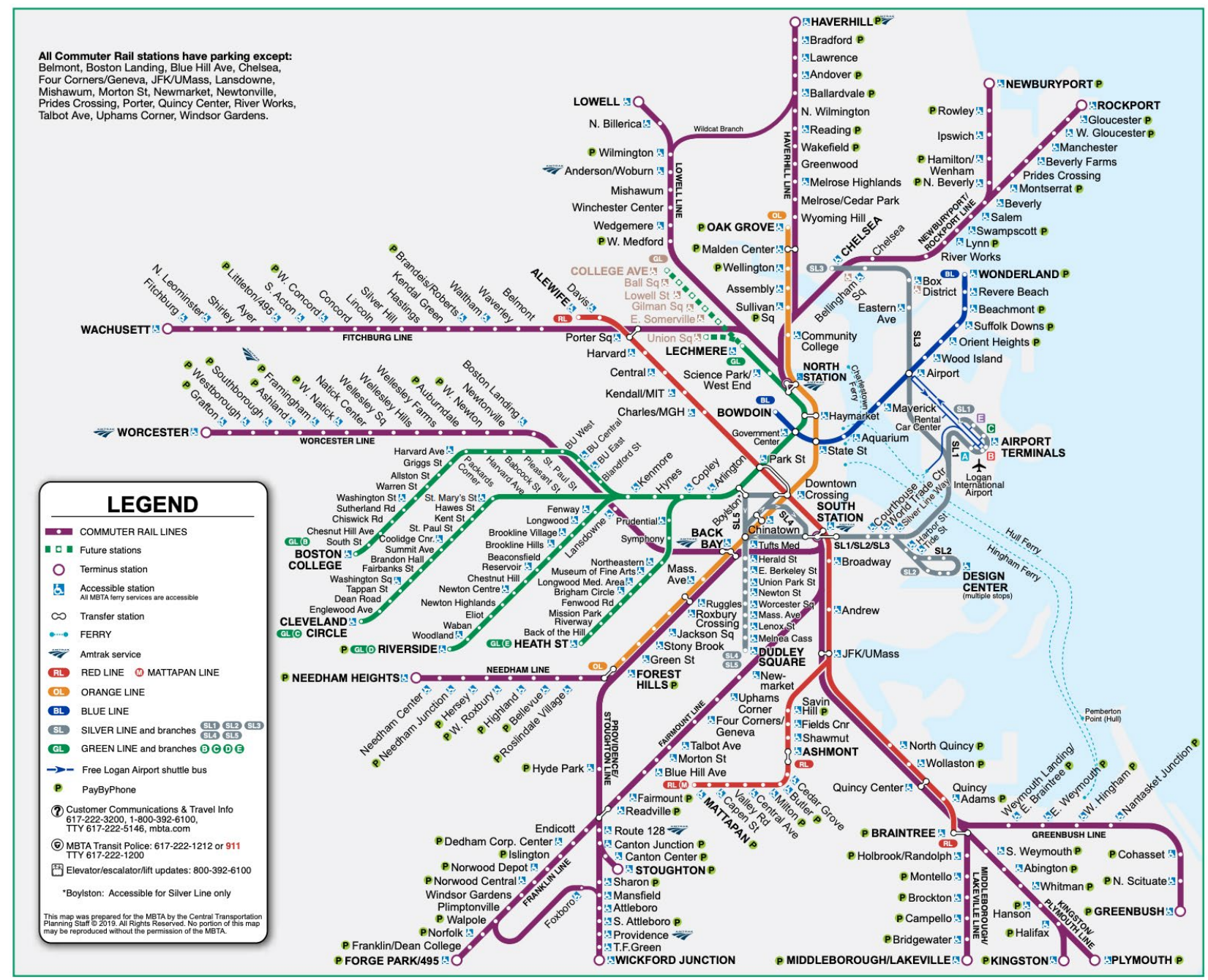

Figure 39. The T's Silver Line Services Logan Airport and Other Areas North and South of The City ${ }^{217}$

\section{Details of the TOD}

Planning for the waterfront area began with the Boston Redevelopment Authority's Seaport Public Realm Plan of 1999, which provided recommendations for Planned Development Areas (PDAs) and residential, open space, and affordable housing zoning amendments. ${ }^{218}$ Later-approved plans of this area (such as Massport's Commonwealth Flats Strategic Plan and the Final Northern Avenue Waterfront Development Plan) offer further recommendations for economic development strategies and design guidelines. These various waterfront planning efforts were scrutinized by neighborhood groups, which opposed Massport's desire to build luxury housing on the formerly industrialized site. ${ }^{219}$

In 2005, the Massachusetts Port Authority, Massport, and the developer, Core Development Group LLC (CDG), entered into an agreement under which the developer was granted an option to enter into separate, 95-year ground leases for five land parcels totaling 8.3 acres and located in the Seaport section of South Boston. These five parcels are known as Core Block. The entire Core Block development, to be called the Waterside Place Project, was 
envisaged to include a variety of uses such as 640,000-square-feet retail space, including retail shops, restaurants, and a grocery store; a 300-room hotel; 209 condominiums; a 20,000-square-feet visitor center; and a 2,350-space multi-level shared parking garage for the entire Waterside Place Project. ${ }^{220,221}$ It was part of Massport's 30-acre Commonwealth Flats Development Area (CDFA), the port's planning area set for mixed-use development on South Boston's waterfront and historic Seaport District. 222

The Waterside Place Project did not materialize as envisaged due to various reasons, mainly the economic downturn due to the 2008 recession. Furthermore, the project was envisaged as a large, integrated, enclosed urban mall with residential units and a hotel above. The enclosed mall was not feasible because of the changed landscape of retail wherein attracting anchor stores proved challenging (personal communication on February 27, 2020, with Andrew Hargens, Chief Development Officer, Massachusetts Port Authority).

Therefore, a number of Notices of Project Change (NPCs) were submitted to the Boston Planning and Development Agency. Under the first NPC requested in 2010, CDG proposed to develop the project in phases, starting with Phase 1 that was to include 234 rental apartments (the original project called for 209 condominiums); 72,000 square feet of retail space, including a grocery store and a pharmacy; 185 parking spaces; and 14,000 square feet of innovation space. 223 The innovation space requirement emanated from the location of the project in Boston's Innovation District (an approximately 1,000-acre area comprising five sub-districts, including Seaport). ${ }^{224}$ The second NPC was requested in 2011. Under it, the Phase 1 was divided into two sub-phases: $1 \mathrm{a}$ and 1b. Phase 1a was to include 236 rental apartments (Waterside by Windsor), 140 parking spaces, and 17,000 square feet of ground-floor commercial space that would include 7,000 square feet of innovation space. The Phase $1 \mathrm{~b}$ was to have 55,000 square feet of retail space, including a grocery store and 7,000 square feet of innovation space, and 115 parking spaces. ${ }^{225}$ The third NPC, in 2015, sought permission to lease 2,600 square feet of the approximately 7,000-square-feet innovation space of Phase 1a to a non-profit health center (it was leased to the Boston Veterinary Clinic). The fourth NPC was requested in 2016 to change the grocery component of the retail portion of Phase $1 \mathrm{~b}$ to rental housing (including affordable housing). This NPC enabled the construction of Waterside Place Phase 1B (known as Gables Seaport), which will open in March 2020. 226,227

Waterside Place by Windsor (apartments under Waterside Place Phase 1a) sits on a three-acre eastern portion of Core Block. This \$120 million project broke ground in 2011 and opened in 2014 (see Figure 40). The project includes 236 one-, two-, and threebedroom luxury units (including five housing units affordable to households making less than $80 \% \mathrm{AMI}$ ) on 18 floors with 12,000 square feet of restaurant and retail space on the ground floor. ${ }^{228}$ The development offers luxury amenities such as 24/7 concierge service, community garden space, residential club space, and innovation space for start-up companies, among others. ${ }^{229}$ In addition to the five affordable housing units, the developer also paid approximately $\$ 2.8$ million to the Boston Redevelopment Agency to subsidize affordable housing off-site. ${ }^{230}$

This project's ground leases are expected to generate $\$ 300,000$ a year in rent for 
Massport after closing. ${ }^{231}$ The project was developed in conjunction with the South Boston Waterfront Transportation Center (SBWTC). ${ }^{232,233}$ The SBWTC is a parking structure and multimodal transportation hub meant to consolidate parking requirements for Waterside Place and the previously planned Air Rights Garage. The structure also houses infrastructure for bikeshare, carshare, and connections to the Silver Line. ${ }^{234}$

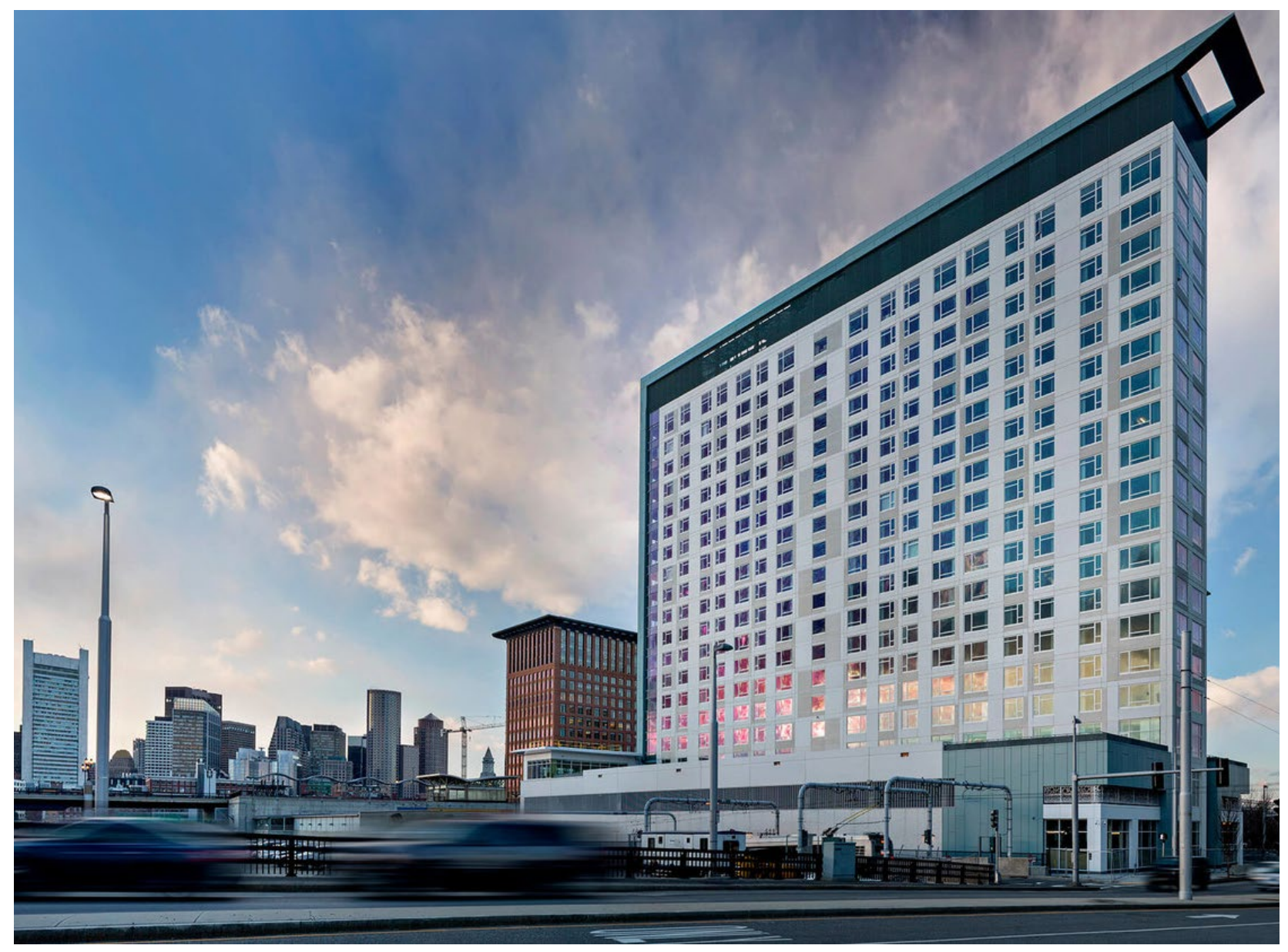

Figure 40. Waterside Place by Windsor ${ }^{235}$

This case study provides three takeaways. First, the number of NPCs issued for the Waterside Place Project underlines the need for flexible zoning to facilitate project implementation. Second, each NPC likely also led to amendments to the joint development agreement. Therefore, the joint development partners need to be flexible as well. Third, concerted planning efforts and the resultant zoning changes can create an enabling environment for value capture.

Massport proactively plans for the land parcels it owns and has the long-term vision of generating value from them. In general, Massport enters into 95- or 99-year leases and does not sell land parcels because all sale proceeds go to the state government. Massport typically receives three types of revenues from its joint development projects: fixed rent in the form of annual lease revenue; participation rent that varies depending upon a project's success; and transaction rent, which accrues when the property is sold 
or refinanced (personal communication on February 27, 2020 with Andrew Hargens, Chief Development Officer, Massachusetts Port Authority). These three lease types ensure that Massport receives a guaranteed revenue stream (fixed rent), can capture any upswing due to the project's success (participation rent), and receives its due share as a joint development partner at the asset disposition stage (transaction rent).

\section{KEY INSIGHTS}

The major case study details, including challenges related to land use, zoning, and VC, are noted in Table 3: Summary of Case Study TODs. The key insights from the case studies are noted next. 
Table 3. Summary of Case Study TODs

\begin{tabular}{|c|c|c|c|c|c|c|c|c|c|}
\hline TOD Name & City, State & Region & $\begin{array}{l}\text { Location } \\
\text { Within } \\
\text { Urban } \\
\text { Area }\end{array}$ & $\begin{array}{l}\text { Transit } \\
\text { Type }\end{array}$ & Transit Agency & $\begin{array}{l}\text { TOD Type: Single } \\
\text { Building; Group } \\
\text { of Buildings; or } \\
\text { Area }\end{array}$ & VC Tool Used & VC Challenges & $\begin{array}{l}\text { Zoning and Land } \\
\text { Use Challenges }\end{array}$ \\
\hline $\begin{array}{l}\text { Othello } \\
\text { Plaza }\end{array}$ & $\begin{array}{l}\text { Seattle, } \\
\text { WA }\end{array}$ & West & Sub-urban & Light rail & Sound Transit & Single Building & Land sale & $\begin{array}{l}\text { Transit agency had to } \\
\text { give up control of land } \\
\text { very early }\end{array}$ & \\
\hline EcoVillage & $\begin{array}{l}\text { Cleveland, } \\
\mathrm{OH}\end{array}$ & $\begin{array}{l}\text { Mid- } \\
\text { West }\end{array}$ & Sub-urban & Light rail & $\begin{array}{l}\text { Greater Cleveland } \\
\text { Regional Transit } \\
\text { Authority }\end{array}$ & Neighborhood & Community land trust & & $\begin{array}{l}\text { Old underlying zoning; } \\
\text { need for zoning } \\
\text { variances; need for } \\
\text { change in zoning } \\
\text { overlay }\end{array}$ \\
\hline $\begin{array}{l}\text { MacArthur } \\
\text { Transit } \\
\text { Village }\end{array}$ & $\begin{array}{l}\text { Oakland, } \\
\text { CA }\end{array}$ & West & City Core & $\begin{array}{l}\text { Heavy } \\
\text { rail rapid } \\
\text { transit }\end{array}$ & $\begin{array}{l}\text { San Francisco Bay } \\
\text { Area Rapid Transit } \\
\text { District (BART) }\end{array}$ & Group of Buildings & $\begin{array}{l}\text { Joint development } \\
\text { (long-term lease); } \\
\text { Parking garage and } \\
\text { other infrastructure } \\
\text { improvements in lieu } \\
\text { of land; building height } \\
\text { relaxation in-lieu of } \\
44 \text { affordable housing } \\
\text { units and } \$ 1.3 \text { million } \\
\text { community benefits; } \\
\text { transit benefit fee; } \\
\text { share in sale price }\end{array}$ & $\begin{array}{l}\text { Series of amendments } \\
\text { due to change in } \\
\text { developer and in } \\
\text { project parameters }\end{array}$ & $\begin{array}{l}\text { Underlying zoning } \\
\text { not TOD-friendly, } \\
\text { hence the PUD } \\
\text { process; contentious } \\
\text { community } \\
\text { engagement process }\end{array}$ \\
\hline $\begin{array}{l}\text { Evans } \\
\text { Station Lofts }\end{array}$ & $\begin{array}{l}\text { Denver, } \\
\text { CO }\end{array}$ & $\begin{array}{l}\text { Mid- } \\
\text { West }\end{array}$ & Sub-urban & Light rail & $\begin{array}{l}\text { Regional } \\
\text { Transportation } \\
\text { District (RTD) }\end{array}$ & Single Building & $\begin{array}{l}\text { TOD fund enabled } \\
\text { reduced risk and } \\
\text { holding costs for the } \\
\text { developer. }\end{array}$ & & $\begin{array}{l}\text { Site already zoned for } \\
\text { TOD with low parking } \\
\text { requirements. Retail } \\
\text { requirement reduced } \\
\text { during negotiations. } \\
\text { Retail underwritten } \\
\text { at } \$ 0 \text {. }\end{array}$ \\
\hline $\begin{array}{l}\text { Twinbrook } \\
\text { Station }\end{array}$ & $\begin{array}{l}\text { Rockville, } \\
\text { MD }\end{array}$ & $\begin{array}{l}\text { North- } \\
\text { East }\end{array}$ & Sub-urban & $\begin{array}{l}\text { Heavy } \\
\text { rail rapid } \\
\text { transit }\end{array}$ & $\begin{array}{l}\text { Washington } \\
\text { Metropolitan Area } \\
\text { Transit Authority } \\
\text { (WMATA) }\end{array}$ & Group of Buildings & $\begin{array}{l}\text { Joint development } \\
\text { (long-term lease, sale } \\
\text { of a part of land) }\end{array}$ & $\begin{array}{l}\text { Series of amendments } \\
\text { due to changes } \\
\text { in real estate } \\
\text { market conditions, } \\
\text { developer's ability to } \\
\text { secure higher density } \\
\text { in the entitlement } \\
\text { process, and uses }\end{array}$ & $\begin{array}{l}\text { Underlying zoning not } \\
\text { TOD-friendly, hence } \\
\text { the PUD process. Site } \\
\text { partly in the city and } \\
\text { partly in the county } \\
\text { area, so need for two } \\
\text { sets of approvals. }\end{array}$ \\
\hline $\begin{array}{l}\text { Waterside } \\
\text { Place }\end{array}$ & Boston, MA & $\begin{array}{l}\text { North- } \\
\text { East }\end{array}$ & Sub-urban & $\begin{array}{l}\text { Bus } \\
\text { Rapid } \\
\text { Transit } \\
\text { (BRT) }\end{array}$ & $\begin{array}{l}\text { Massachusetts } \\
\text { Bay Transportation } \\
\text { Authority (MBTA) }\end{array}$ & Group of Buildings & $\begin{array}{l}\text { Joint development } \\
\text { (long-term lease) }\end{array}$ & $\begin{array}{l}\text { Series of amendments } \\
\text { due to changes in } \\
\text { real estate market } \\
\text { conditions and uses }\end{array}$ & $\begin{array}{l}\text { Need for flexibility in } \\
\text { zoning and permit } \\
\text { approvals }\end{array}$ \\
\hline
\end{tabular}




\section{Land Use and Zoning-Related Insights}

Active ground floor instead of ground-floor retail; on a larger note, very prescriptive building uses may not work: Evans Station Lofts, MacArthur Station, and Waterside Place TODs show that requiring ground-floor retail can be a significant barrier. For example, the developer for the Evans Station Loft TOD had to underwrite retail at \$0 to secure project financing. In the case of MacArthur Station TOD, the retail space in the parking garage is empty even after five years. Finally, the Waterside Place TOD did not materialize as envisaged because, among others, attracting anchor retail stores proved challenging. Indeed, the BART staff noted the shift from requiring ground-floor retail in mixed-use TODs to requiring active ground floor. For example, live-work spaces are becoming popular. In fact, if the retail spaces in the Hine's MacArthur Commons project in the MacArthur Station TOD do not lease within a stipulated time, they can be converted to live-work spaces. Similarly, prescribing other uses, such as innovation spaces in Waterside TOD, may not work either. For this TOD, the developer requested permission to lease a part of the innovation space to a non-profit health center (it was eventually leased to the Boston Veterinary Clinic).

Neighborhood-level land use planning ahead of TOD implementation is helpful: Othello Plaza, Evans Station Lofts, and Waterside Place TODs underscore that good land use and physical planning, and zoning help facilitate the implementation of TODs.

In the case of Othello Plaza TOD, the City of Seattle-initiated neighborhood plan update led to a vision of a transit-oriented community with pedestrian-serving retail, and the related up- and re-zoning. Similarly, in the case of Evans Station Lofts TOD, a new zoning code was developed using recommendations from the Evans Station Area Plan. This zoning code led to the re-zoning of the station area from light industrial/office use to urban-center neighborhood, mixed-use TOD two years before the developer purchased the parcel. This re-zoning expedited the entitlement process as the newly adopted zoning codes provided a clear and specific regulatory framework to the developer. Similarly, the City of Oakland reclassified the MacArthur Station TOD site as a TOD Zone. ${ }^{236}$

In the case of Waterside Place TOD, planning for the waterfront area (the locations of the TOD) began with the Boston Redevelopment Authority's Seaport Public Realm Plan of 1999, which provided recommendations for PDAs and residential, open space, and affordable housing zoning amendments. Later-approved plans for this area offered further recommendations for economic development strategies and design guidelines.

Need for multiple zoning approvals, variances, overlay zoning, or other such techniques in the absence of supportive land use and zoning: TOD implementation often requires multiple zoning approvals or variances in the absence of supportive land use and zoning. For example, Cleveland's zoning code, instituted in 1929, is antiquated. Therefore, zoning variances are often required from the Board of Zoning Appeals. Four such variances were needed for EcoVillage TOD, two for the tiny homes, and two for the Aspen Place project. 
In the case of Twinbrook TOD, the TOD site was split between the city and the county, requiring the developer to obtain two sets of approvals. Furthermore, the City of Rockville, MD, approved text and map amendments for the TOD site. These amendments were undertaken under an "optional method of development" under which while the TOD site retained its original zoning, higher building heights were allowed compared to what the underlying zoning permitted. Finally, the Othello neighborhood is located within a zoning overlay district called the Southeast Seattle Reinvestment Area (SESRA), allowing its zoning to vary from the city's underlying zoning and facilitating easy adoption and implementation of the required zoning changes by the City of Seattle.

While transit agencies need to be provided more land use and zoning control over station area land, very aggressive legislation may not be helpful: In none of the case study TODs was the transit agency allowed land use and zoning powers over land parcels in the station area (for example, land parcels within one half-mile from the station). The most control is provided to BART through a recent piece of state legislation, whereby BART has the authority to specify zoning over the land parcels it owns. Even this legislation does not provide BART the authority over the entire station-area land parcels; nor does it require the city governments to coordinate planning and zoning with the transit agency for the cityowned land parcels. Moreover, the BART staff notes that this legislation's FAR requirements are too aggressive, highlighting that although on the one hand such a piece of legislation is welcome, on the other hand, it should be crafted with a more nuanced understanding of the context under which TODs are developed and in close coordination with the transit agency's planning staff.

TODs can be harbingers for larger land use and zoning changes in the neighborhood: The Twinbrook Station TOD led the City of Rockville to reimagine the station area and initiate a wholesale revision of the city's zoning ordinance which, among others, led to the creation of the MXTD zone. At the station-area level, the community helped create the Twinbrook Sector Plan that recommended changes to station area zoning and land use ${ }^{237}$ such as the change from light industrial, low-intensity and single-family uses to transit-oriented mixeduse with a higher FAR. Finally, at the neighborhood level, a planning effort concluded with the 2016 passage of the Rockville Pike Neighborhood Plan. This plan also encourages a mixed-use, transit-oriented neighborhood around Twinbrook Station. ${ }^{238}$

\section{VC-Related Insights}

Flexibility helps: Several case studies highlight the need for flexibility in implementing VC strategies. For example, in the case of Othello Plaza TOD, Sound Transit deviated from its policy of selling land after the developer has obtained all the approvals. A win-win situation was found in the form of an agreement of cooperation with the City of Seattle and the developer, under which each party shared information about the TOD openly and transparently and agreed to use good faith to communicate any permitting, construction, or design delays. ${ }^{239}$ Furthermore, under this agreement, all parties agreed to create a process for corrective action and resolve disagreements internally if the developer defaulted on the ETOD loan or if the project fell behind schedule. ${ }^{240}$ Sound Transit communicated regularly with the City of Seattle, specifically the housing department, to get the project going and the funds granted quickly (personal communication on January 7, 2020, with Sound Transit 
staff members Thatcher Imboden [Deputy Director, TOD Sound Transit] and Jordan Rash [Senior Project Manager, TOD Sound Transit]).

Similarly, in the case of Twinbrook Station TOD, the JDA between WMATA and the developer was restructured to sell one-third of WMATA-owned land to the developer (it was originally leased for 99 years) to enable the development of condominiums (earlier apartments were to be built). Finally, the project parameters changed several times in the case of Waterside Place TOD due to the changing economic conditions and real estate market trends.

Well-developed TOD policies help: Many of the transit agencies involved in the case study TODs have well-developed TOD policies. Such polices provide a clear direction to these transit agencies. For example, Sound Transit's Real Property Excess, Surplus and Disposition Policy directs the agency to prioritize TOD implementation on its surplus land and encourage developing a variety of housing on such land parcels, including marketrate and affordable housing. ${ }^{241}$ Similarly, WMATA's joint development policy, enacted in the early 1970s and most recently revised in 2018, enabled the completion of the Twinbrook Station TOD. ${ }^{242}$ The goal of the joint development program is to market WMATA-owned land to real estate developers to construct TODs.

Innovative ways to capture value: In the case of Evans Station Lofts TOD, although the land owner, UDC, sold the land to the developer at the market rate, still the developer gained for several reasons, including reduced risk and partial offset of the holding costs. This case highlights that risk translates into the cost of financing for the developer; hence, innovative techniques to reduce developers' risk can be found in even simple $V C$ tools such as the sale or lease of land. Finally, EcoVillage TOD uses an innovative VC tool, CLT, to develop cottage housing.

Need for transparent, publicly available analysis of the total value increase: For almost all the case study TODs, the development agreements and especially the financial analysis that constitute the basis for various agreements such as the revenue sharing agreements and the lease/sale of land agreements are not easily publicly available. Indeed, in one case, a public agency even refused to provide information about the amount of lease revenues received unless a request for information was filed under their state's public records law. In the absence of such freely available information, the community is likely to be concerned that the public agencies are not capturing value adequately. For example, in the case of MacArthur Station TOD, some community members felt that the City of Oakland did not negotiate enough community benefits when relaxing the height of a residential project from six to 24 stories.

Various types of leases: Two case studies-MacArthur Station and Waterside TODsshow that public agencies are sharing the value increase through sophisticated means. For example, in the case of MacArthur Station TOD, the value capture happened through the provision of affordable housing, through the developer-provided parking garage and other improvements, and the transit benefit fees. As noted earlier, BART will start receiving transit benefit fees 7 years after project stabilization for the market-rate apartments. BART will receive $1 \%$ of gross revenue for 10 years post-project stabilization and $2 \%$ of gross 
revenue after that. Finally, if the apartments were to convert to condominiums, BART would receive $1.5 \%$ of the sale price (personal communication on February 12, 2020, with Paul Voix, Principal Property Development Officer, Real Estate and Property Development, BART). Similarly, Massport receive three types of lease revenues: fixed rent in the form of annual lease revenue, participation rent that varies depending upon a project's success, and transaction rent, which accrues when the property is sold or refinanced (personal communication on February 27, 2020, with Andrew Hargens, Chief Development Officer, Massachusetts Port Authority).

Need for thoughtful integration of planning, zoning, and VC: Since a land parcel's value is likely to increase through supportive surrounding development, changes in use within the TOD, and re- and up-zoning of the TOD, transit agencies and local governments need to coordinate planning, zoning, and VC closely. For example, if a developer receives permission to up-zone after entering into a joint development agreement with a transit agency, the latter and the local government could renegotiate the lease and other terms such as the number of affordable housing units and/or the levels of affordability. Similarly, requiring specific uses in a TOD, such as large amounts of ground-floor retail and minimum or maximum parking requirements, could depress its value. Therefore, the local government and the transit agency should better coordinate such requirements. Such close coordination was not found for the case study TODs. For example, in one instance, the city government staff did not even have access to the joint development agreement between the transit agency and the developer. 


\section{CONCLUSIONS AND POLICY IMPLICATIONS}

Through a literature review of land use, zoning, and VC-related barriers to TODs, in-depth case studies, and national surveys of transit agencies and the major cities in these transit agencies' service area, this study identifies the major land use, zoning, and VC-related barriers to the implementation of TODs and the steps that are being undertaken or need to be taken to remove these barriers.

\section{RECOMMENDATIONS AND POLICY IMPLICATIONS}

Overall, many of the literature review findings are supported by the surveys and the case studies, and vice versa. The surveys and case studies also provide nuances to some of the literature review findings.

The major recommendations from the synthesis of the literature review, case studies, and surveys are described below, along with policy implications for state-, regional-, and locallevel planners and policy makers. The recommendations are divided into three groups: (a) overarching recommendations that are applicable for mitigating barriers to both land use (zoning) and the use of VC, (b) recommendations that are primarily applicable for mitigating land use and zoning-related barriers, and (c) recommendations that are primarily applicable for mitigating barriers related to the use of VC.

\section{Overarching Recommendations}

a) Consider land use, zoning, and VC in an integrated manner: Many of the barriers to land use and zoning are similar to those affecting VC. For example, requiring a certain amount of parking and ground-floor retail, or requiring very specific uses in the TODs (such as innovation uses in the case of Waterside Place TOD), are not only land use and zoning hurdles, but they could diminish the value of the TOD as well, thereby reducing the potential for VC. Integration is also needed to enhance transit ridership, provide adequate infrastructure, and enable good urban design. Furthermore, since the station-area property values can increase right from the transit-anticipation period to the time the transit system matures, an integrated framework can help capture property value increases along all these time periods through tools such as long-term land banking and neighborhood-level planning ahead of TOD implementation. One of the interviewees for the Evan Station Lofts noted that transit service provision or expansion provides an opportunity to rethink station-area land use and zoning. Transit agencies and the local governments can partner in such land banking and planning efforts. Such integrated thinking gains importance because the survey data suggest that using VC to implement TODs is likely not on the radar of most transit agencies and local governments.

b) Inter-agency coordination is important: Survey responses highlighted the need for inter-agency coordination for addressing both land use (zoning) and VC-related barriers. In the absence of strong, enforceable, cooperative agreements, transit agencies and local governments are relying on weak, collaborative arrangements such as TOD working groups. However, an integrated approach to the TODs requires 
much closer coordination between these two public agencies. Therefore, strong state and regional leadership is required to provide incentives and foster the right environment for such coordination. Although some federal, state, and regional TOD planning and infrastructure grants promote such coordination, they are piecemeal efforts at best.

c) More powers to the transit agencies over station-area land, in close consultation with these agencies: Respondents to the transit agency survey pointed to the lack of control over station-area land use and zoning as a big barrier. However, overly prescriptive legislation such as AB 2923 (California) may not be very effective, either. On the one hand, AB 2923 requires TODs to meet minimum FAR requirements that are almost impossible to achieve in most cases; on the other hand, this piece of legislation restricts BART's zoning authority to the land parcels it owns, instead of including all station-area parcels.

Actions are needed on many fronts. More flexible, outcome-focused requirements can be devised, such as ensuring that station-area land use and zoning lead to specific transit ridership and station access mode share outcomes. For example, in California, a city's planning commission is required to certify consistency between a city's general plan and capital improvement plan. In the case of station-area land use and zoning, a state- or regional-level agency or a joint local committee between the government and transit agency could be formed for such certification purposes, or an existing agency could be assigned this role. Federal, state, and regional governments could make the formation of such committees, or the assignment of this role, a pre-requisite for receiving grants.

Going a step further, enabling legislation may be enacted to provide transit agencies the ability to acquire land for constructing TODs. Currently, most of the transit agencies can purchase land for transit-related purposes, but not for TODs. However, some exceptions exist. For example, land bought using FTA funds can be sold for constructing TODs. Similarly, California's state legislation allows some San Francisco Bay Area transit agencies to acquire properties for constructing TODs. A survey respondent from the Denver, $\mathrm{CO}$ area noted the ability of transit agencies to use the excess land acquired for transit-related purposes for TODs. Therefore, states should consider designating TODs a transit-serving infrastructure/facility and allow transit agencies to acquire land for TODs at the time when they acquire land to build or expand transit systems.

d) State- and regional-level leadership and enabling framework to implement TODs: The review of the literature and a large number of transit agency surveys identified a lack of state- and regional-level leadership and a lack of state and regional growth management $(\mathrm{GM})$ tools as barriers to implementing TODs. On the other hand, survey respondents from states with state-level GM programsfor example, Washington and Oregon-frequently noted the existence of state and regional laws, programs, or plans to encourage TODs, especially their emphasis on closer land use transportation coordination. In these states, TODs are viewed as key to achieving the GM objectives. 
e) Reduce developer risk: Reducing developer risk is key to promoting TODs and can be achieved through various means identified in the literature review, surveys, and case studies, including (a) streamlining zoning and permitting processes; (b) reducing uncertainty in the environmental approval process; (c) public-sector land banking that allows developers to conduct site-level due diligence and obtain approvals before purchasing land, as was done in the case of Evans Station Lofts; and (d) flexibility in changing the joint development agreements due to changes in real estate market conditions, as was done for many case study TODs such as MacArthur Station, Twinbrook, and Waterside TODs.

\section{Land Use and Zoning-Related Recommendations}

a) Many zoning barriers remain: Zoning barriers such as minimum parking requirements; minimum lot sizes; minimum house sizes; and low-density, sprawling uses are addressed in many cities around the country through tools such as overlay zones, specific plans, MXDT zoning, and TOD zoning. However, the survey findings show that these barriers are often removed around only a few stations in a city, or by only one or two cities in a region. This lack of uniformity also highlights the need for the state- and regional-level leadership noted above.

b) Need to get the parking right: Parking in a TOD should be based on the characteristics of the transit system, the station, and the surrounding area. Surveys and the literature review suggest that parking maximums, not minimums, should be prescribed. However, a case study interviewee pointed out that parking maximums may not work in all cases. For example, limiting parking in TODs around transit stations that provide low-quality transit service may lower such TODs' market success. Furthermore, since many TODs are built on erstwhile surface parking lots on station land, transit agencies, such as BART, often required one-to-one parking replacement. This translated into the construction of very expensive parking garages - a bottleneck for developing TODs. Therefore, transit agencies need a shift in policy focus, following BART's example, from replacing lost parking to serving transit users. For example, suppose a larger proportion of transit users are now likely to bike/walk to the station and fewer are likely to use cars due to up-/re-zoning around the station area. In that case, a smaller number of parking spaces may be required at the station compared to before the up-/re-zoning.

c) Shift focus from ground-floor retail to active ground floor: Planners often require ground-floor retail in TODs as a way to create a lively urban area. However, retail is suffering in multiple case study TODs. Several reasons are suggested, including a glut of retail in the area around TODs and an inadequate customer base. Therefore, transit agencies and local governments should consider shifting the focus from requiring ground-floor retail to the larger objective-active ground floor.

Additionally, a survey respondent from the City of San José, CA, pointed to a larger issue: the fiscalization of land use. To balance their budgets, cities might be compelled to require larger amounts of non-residential uses than possible to construct financially viable TODs. This fiscal bind highlights the need for state- or 
regional-level financial assistance to cities for constructing TODs, perhaps in the form of an on-going grant large enough to offset the TOD-induced fiscal imbalance.

d) Prescriptive uses for TODs may not work: For the same reason that parking requirements should be determined on a case-by-case basis, so should the type and the amount of other uses such as affordable housing and retail be determined by each TOD's particular context. Highly prescriptive uses, such as innovation spaces provided in Waterside Place TOD, may not work due to a lack of market demand. Therefore, transit agencies and local governments need to be flexible; perhaps developers could be required to choose from a menu of uses. For example, live-work spaces are currently in demand in many parts of the country. Therefore, developers could be provided an option to choose between (or choose a mix of) retail, office, and live-work spaces. Alternatively, they could be allowed to convert one use to another, for example, retail spaces into live-work spaces, as is the case for one building project in the MacArthur Station TOD.

e) Use land assembly and eminent domain: Extant literature notes that for TODs to be located in areas with fragmented land ownership, the land has to be assembled and then re-parceled into a single parcel. This often requires the use of eminent domain and land assembly. Indeed, before they were dissolved in 2011, California's redevelopment agencies used eminent domain to assemble land to facilitate real estate projects in redevelopment areas. However, the survey findings show that the use of eminent domain and land assembly for facilitating TODs are among the least used tools. Furthermore, the ad-hoc use of these tools can be controversial. Therefore, they should be employed to meet well-defined objectives derived from a sound planning process: for example, to facilitate the development of affordable housing in TODs, if the provision of affordable housing has been identified as a planning objective.

\section{VC-Related Recommendations}

a) Encourage transit agencies and local governments to use VC to implement TODs: Survey responses indicate that using VC tools to implement TODs is likely not on the radar of most transit agencies and local governments. Other evidence support this finding, too. For example, the preliminary budget of the VTA's BART Silicon Valley Phase 2 Extension Project does not include VC. One project document merely calls for "supporting value creation through increased development, and identification of strategies for value capture to fund station area improvements"243 -a very weak statement, considering that a much smaller project, the Warm Springs BART Extension Project, led to an approximately $\$ 4$ billion increase in the value of single-family houses alone-five times the amount needed to fund the entire project. ${ }^{244}$ These missed opportunities highlight the need for well-coordinated use of tools such as eminent domain, site assembly, land banking, TIF, and SADs. Even capturing some of the value increase might be adequate to fund the transit infrastructure as well as TODs (for example, public agencies can use the VC revenue to subsidize TODs, require affordable housing, and make infrastructure improvements around transit stations and TODs). 
b) Enhance public agencies' ability to use TIF and other VC tools: Extant literature and surveys indicate that not being able to use TIF is a major factor inhibiting the use of VC to implement TODs. Many of these restrictions are due to statelevel policies and legislation. Therefore, strong state-level leadership is required to remove the barriers to the use of TIF and to other VC tools such as SADs. For example, California's Proposition 218 could be amended to lower the current twothirds super-majority vote requirement to institute a SAD to perhaps $55 \%$, as is the case for approving a school bond measure in the state.

c) Need for transparent assessment of value increase: The development agreements, especially the financial analyses that constitute the basis for various agreements (e.g., revenue sharing and land lease/sale agreements), are not easily available to the public. Indeed, in one case, a public agency even refused to provide information about the amount of lease revenues received unless a request for information was filed under their state's public records law. In the absence of such freely available information, the community is likely to be concerned that the public agencies are not capturing value adequately. For example, in the case of MacArthur Station TOD, some community members felt that the City of Oakland did not negotiate enough community benefits when relaxing the height of a residential project from six to 24 stories. To build public trust in the use of VC, such documents must be publicly available on agencies' websites. Public trust will be critical to scaleup the use of VC.

d) Need for systematic and comprehensive assessment of value increase: While the MacArthur Station TOD and Waterside Place TOD case studies indicate that the public agencies are using sophisticated means to capture value (for example, they receive various kinds of lease revenues and a portion of sale proceeds), the use of $\mathrm{VC}$ is disjointed. For example, $\mathrm{VC}$ occurred at various times and in multiple ways during the construction of the MacArthur Station TOD project's numerous components and was mediated through muddled and non-transparent negotiation processes. Based on the present investigation, recommended is a systematic and comprehensive analysis of the total VC potential of a TOD, and then divvying up of this potential into major buckets, such as requirements to build affordable housing, undertake infrastructure improvements, and share lease revenues.

e) Need for flexibility: Flexibility in policy and program design is needed to use VC tools. For example, Sound Transit requires that the sale of its land parcels (where TODs are to be developed) can only close after building permits are secured for the TOD projects. However, they waived this requirement for the Othello Plaza TOD. Similarly, in the case of Twinbrook Station TOD, the joint development agreement was amended multiple times, including in 2007, when the agreement was restructured to sell one-third of the station area land to the developer to construct condominium units (earlier, this land was leased for 99 years).

\section{CONCLUDING REMARKS}

In conclusion, this study advances land use, transportation planning, and public finance 
research by identifying: a) the various land use, zoning, and VC-related barriers to the construction of TODs; b) the major strategies that are or could be used to address these barriers. The VC tools include joint development projects, TIF, special assessments, lease/ sale of land or air rights, and impact fees.

The major research findings reveal that while a large proportion of jurisdictions across the US have TODs, much is needed to remove land use, zoning, and VC-related barriers to their construction. Most of the transit agencies are not allowed to purchase land for constructing TODs, nor do they have land use and zoning powers over the station-area land. In the absence of legally enforceable inter-agency agreements between city governments and transit agencies, a large proportion of these public agencies rely on looser, collaborative agreements. Finally, while the use of eminent domain to assemble land parcels is critical for constructing TODs in already developed areas, local governments rarely use this power to enable TODs.

Finally, the major recommendations to address land use, zoning, and VC-related barriers include the need for a) thoughtful integration of land use, zoning, and VC; b) flexible land use and zoning, especially flexible parking requirements and uses within TODs; c) flexibility in using VC tools, d) providing more power to transit agencies over station-area land use and zoning, e) reducing developer risk, f) use of land assembly and eminent domain to assemble land parcels, g) systematic and comprehensive assessment of value increase, h) encouraging transit agencies and local governments to use VC to construct TODs, i) enhancing public agencies' ability to use TIF and other VC tools, j) strong state and regionallevel leadership and robust enabling framework; and $k$ ) moving away from requiring groundfloor retail in TODs to facilitating an active ground floor. 


\section{APPENDIX A: TRANSIT AGENCY SURVEY QUESTIONNAIRE}

\section{TOD Survey: Transit Agency}

This survey is part of a nationwide study sponsored by the Mineta Transportation Institute. The study seeks to fill two research, policy and practice gaps in promoting transit-oriented developments (TODs): a) how to facilitate TOD-supportive land use and zoning; and b) how to use the transit- and TOD-generated land value increase to fund TODs through value capture tools.

The survey is divided into two sections:

Section 1: Land-use- and zoning-related barriers to the implementation of TODs, and the ways in which these barriers have been, are being, or can be overcome in your service area;

Section 2: Barriers to the use of value capture (VC) to fund TODs, and the ways in which these barriers have been, are being, or can be overcome in your service area.

For the purposes of this study, a TOD is broadly defined as urban development (for example, a single building or a group of buildings) that: a) is located close to a transit station; b) is easily accessible from that station through a walk/bike way; and c) generates transit ridership for that station.

Contact information provided in this survey will not be included in any publication. Please contact Dr. Shishir Mathur (shishir.mathur@sjsu.edu) for questions about the study or the survey.

Finally, it should take approximately $\mathbf{3 0}$ minutes to complete this survey. Many thanks for taking time out of your busy schedule.

\section{TOD Survey: Transit Agency}

* Please provide the following information for the person completing the survey:

Name:

Email address:

Name of the agency:

\section{TOD Survey: Transit Agency}


Are there one or more TODs in your agency's service area?

For the purposes of this study, a TOD is broadly defined as urban development (for example, a single building or a group of buildings) that: a) is located close to a transit station; b) is easily accessible from that station through a walk/bike way; and c) generates transit ridership for that station.

Yes, one or more TODs exist.

No TODs currently exist but one or more are under construction.

No TODs currently exist but one or more are under planning/entitlement stages.

Other (please specify)
No TODs exist and no TOD is under construction or in planning/entitlement stages. (selecting this option will end the survey)

Cannot choose/Decline to Answer

\section{TOD Survey: Transit Agency}

Does your agency have a formal program to encourage TODs?
Yes
No
Cannot choose/Decline to Answer
Other (please specify)

\section{TOD Survey: Transit Agency}

Please elaborate on the program and/or provide a web address (URL). Please email any supporting files at shishir.mathur@sjsu.edu. Click on the "Next" button to skip the question.

\section{TOD Survey: Transit Agency}


Does your organization encourage TODs in other ways; for example, through financial incentives and relaxed parking standards?
Yes
No
Cannot choose/Decline to Answer

\section{TOD Survey: Transit Agency}

Please elaborate on how your organization encourages TODs in other ways. Click on the "Next" button to skip the question.

\section{TOD Survey: Transit Agency}

* Who is the contact person for TOD-related programs or assistance that your organization provides?

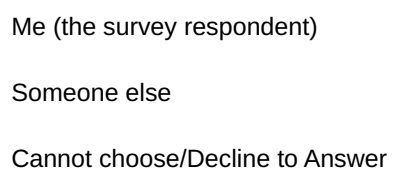

\section{TOD Survey: Transit Agency}

* If someone other than you is the contact person for TOD-related programs or assistance, please provide that person's contact information.

Name
Email Address

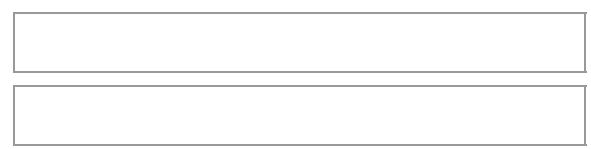

TOD Survey: Transit Agency

The next set of questions will request your input on a) land-use- and zoning-related barriers to the implementation of TODs in your agency's service area; and b) the ways in which these barriers have been, are being, or can be overcome in your service area. 
How does your transit agency address land-use- and zoning-related issues that impact implementation of TODs? Please check all that apply.

\footnotetext{
We are the lead agency on these issues

MPO is the lead agency

Local government is the lead agency

We provide funds to leverage land use and zoning decisions made by local jurisdictions

We have formal relationships with other agencies for conducting studies on these issues

We jointly address these issues in partnership with local jurisdictions and other public agencies

We have very little control over these issues

Cannot choose/Decline to Answer

Other (please specify)
}

\section{TOD Survey: Transit Agency}

Are any of the following land use and zoning tools used to incentivize TODs in your agency's service area? Please note that these tools may be used by your agency or by one or more of the following agencies: a city government, a county government, or some other public agency such as a redevelopment agency. Please check all that apply. Click on the "Next" button to skip the question.

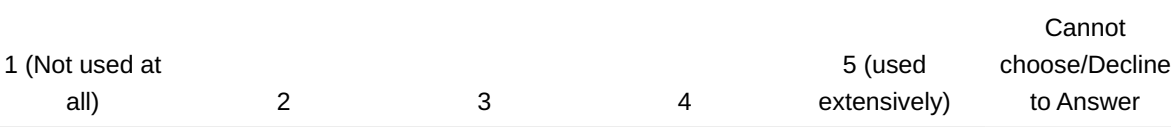

Maximum, not minimum,

lot sizes for single-family

residences

Density bonuses

Higher floor area ratios

(FARs)

Relaxation of limitations on building height

Zoning for compact housing types such as apartments,

condominiums, and

townhouses

Mixed use zoning 
1 (Not used at

all)

Regulations and

incentives that facilitate

adaptive reuse of

properties that would

otherwise not meet the

current zoning and/or

building codes

Requiring housing at

various affordability

levels through programs

such as inclusionary

housing

Parking regulations that prescribe maximum, not minimum, parking

requirements

Relaxed parking

standards

Restricted off-street

parking

Incentives for shared

and paid parking

Transit agencies have

the power to enter into

joint development

agreements with private

developers

Unambiguously

specifying the kinds of

actions permissible

under joint development

agreements; for

example, whether transit

agencies can grant

development and

easement rights to

private entities

Other developer

incentives such as

no/reduced impact fees

Reduced permit fees

Streamlined/expedited

environmental review

Streamlined/expedited

building permit approval
5 (used

extensively)

Cannot

choose/Decline

to Answer 


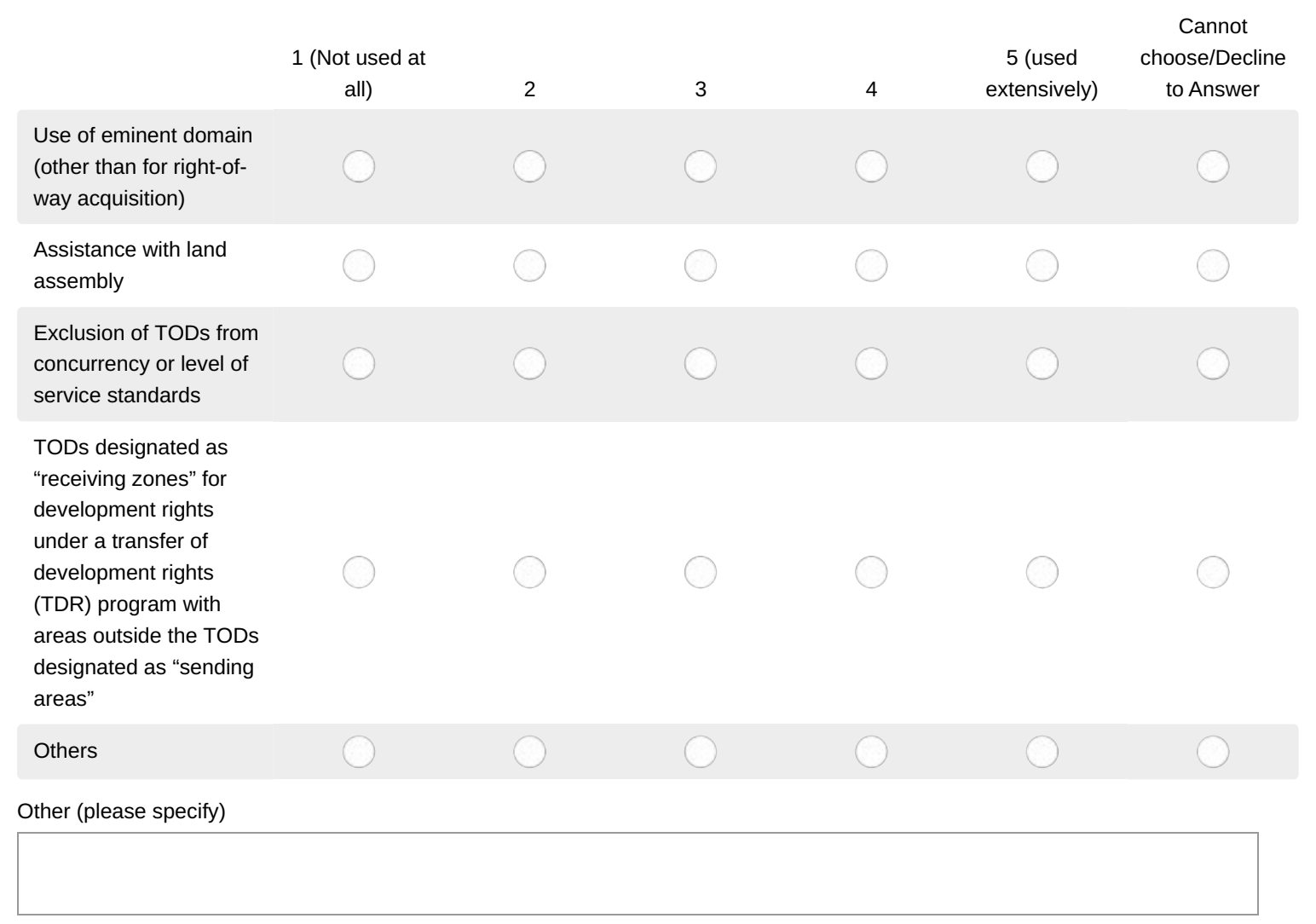

\section{TOD Survey: Transit Agency}

Which of the following planning techniques are used in your agency's service area to promote TODs? Please check all that apply. For the planning technique/s selected below, please email relevant plan/policy documents at shishir.mathur@sjsu.edu.

TOD overlay zoning

TOD specific plans

Transit/urban village plans

Developer agreements

Other (please specify)
Planned unit development (PUD) process

None of these

Cannot choose/Decline to Answer

TOD Survey: Transit Agency 
Do any federal, state, regional or local laws, policies, plans, funding programs or financial incentives positively or negatively impact how your agency approaches land use or zoning in the implementation of TODs?

Some impact positively, some negatively

All impact positively

All impact negatively

Other (please specify)
No impact, either positive or negative

Cannot choose/Decline to Answer

\section{TOD Survey: Transit Agency}

Please elaborate on the specific laws, policies, plans, funding programs or financial incentives and their impacts. Please email any supporting files at shishir.mathur@sjsu.edu. Click on the "Next" button to skip the question.

TOD Survey: Transit Agency

Which statutory regulations governing your agency aid the agency's ability to promote TOD-supportive land use and zoning? Provide the name and number code of the statutes and note how they promote TODsupportive land use and zoning. Please email any supporting files at shishir.mathur@sjsu.edu. Click on the "Next" button to skip the question.

\section{TOD Survey: Transit Agency}


Which statutory regulations governing your agency inhibit the agency's ability to promote TOD-supportive land use and zoning? Provide the name and number code to the statutes and note how they inhibit TODsupportive land use and zoning. Please email any supporting files at shishir.mathur@sjsu.edu. Click on the "Next" button to skip the question.

\section{TOD Survey: Transit Agency}

In the state your agency is located, is there a statewide vision, policy, or plan that calls for compact development or TODs around transit stations?
Yes
No
Cannot choose/Decline to Answer

\section{TOD Survey: Transit Agency}

Please elaborate on the vision, policy, or plan and indicate who is promoting it. Email any supporting files at shishir.mathur@sjsu.edu. Click on the "Next" button to skip the question.

\section{TOD Survey: Transit Agency}


In the state your agency is located, do state- and/or regional-level growth management/smart growth policies/tools promote TODs? Examples of such policies/tools include urban growth boundary, concurrency and consistency requirements, and identification of growth areas with TODs promoted inside these growth areas.

\section{Yes}

No

Cannot choose/Decline to Answer

Other (please specify)

\section{TOD Survey: Transit Agency}

Please list the growth management/smart growth policies/tools. Email any supporting files at shishir.mathur@sjsu.edu. Click on the "Next" button to skip the question.

\section{TOD Survey: Transit Agency}

Are any of the following collaborative arrangements in your agency's service area explicitly devoted to promoting TOD-supportive land use and zoning? Please check all that apply.

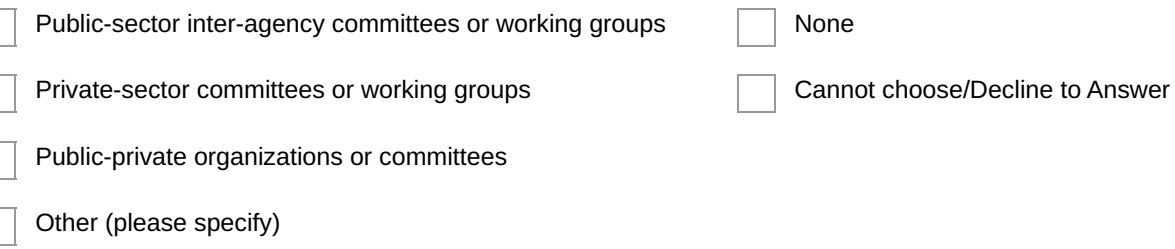

TOD Survey: Transit Agency 
Please describe the committees, organizations, and working groups. Email any supporting files at shishir.mathur@sjsu.edu. Click on the "Next" button to skip the question.

\section{TOD Survey: Transit Agency}

Does your agency have cooperative agreements with any of the following public agencies to promote TODsupportive land use and zoning? Check all that apply.

\begin{tabular}{l}
$\square$ State government \\
$\square$ Regional government \\
$\square$ County government \\
$\square$ City government \\
$\square$ Other (please specify) \\
$\square$ Cannot choose/Decline to Answer \\
\hline$\quad \square$ None
\end{tabular}

\section{TOD Survey: Transit Agency}

Please describe the nature of these cooperative agreements; for example, what duties and functions are shared between the partner agencies? Email any supporting files at shishir.mathur@sjsu.edu. Click on the "Next" button to skip the question.

\section{TOD Survey: Transit Agency}

Overall, to what extent land use and zoning restrictions have been an impediment to the implementation of TODs in your service area?
Very large extent
Large extent
Some extent
Very little extent
None at all
Cannot choose/Decline to Answer




\section{TOD Survey: Transit Agency}

Have these land-use- and zoning-related barriers been overcome, or are they being overcome, or are they planned to be overcome?

Yes

No

Cannot choose/Decline to Answer

Other (please specify)

\section{TOD Survey: Transit Agency}

Please provide examples of how these barriers were either overcome for some of the TODs in your service area, or are being overcome, or are planned to be overcome. Please provide specific examples and contact information of people who can provide further information and insights. Email any supporting files at shishir.mathur@sjsu.edu. Click on the "Next" button to skip the question.

\section{TOD Survey: Transit Agency}

The last set of questions will seek your input on a) barriers to the use of VC tools to implement TODs in your agency's service area; and b) the ways in which these barriers have been, are being, or can be overcome in your service area. 
Have any of the following VC tools been or are being used, or are being considered, to implement TODs in your agency's service area? Please note that these tools may be used by your agency or by one or more of the following agencies: a city government, a county government, or some other public agency such as a redevelopment agency. Please check all that apply.

Community benefits
$\square$ Impact fees
$\quad$ Joint development
$\square$ Naming rights (for example, building naming rights)
$\square$ Public private partnerships

Sale or lease of air rights

ecial assessments

Cannot choose/ Decline to answer

None

\section{TOD Survey: Transit Agency}

Do any federal, state, regional or local laws, policies, plans, funding programs or financial incentives positively or negatively impact how your agency approaches the use of VC tools to implement TODs?

Some impact positively, some negatively

All impact positively

All impact negatively

Other (please specify)
No impact, either positive or negative

Cannot choose / Decline to Answer

TOD Survey: Transit Agency

Please elaborate on the specific laws, policies, plans, funding programs or financial incentives and their impacts. Email any supporting files at shishir.mathur@sjsu.edu. Click on the "Next" button to skip the question. 


\section{TOD Survey: Transit Agency}

Which statutory regulations governing your agency aid the agency's ability to promote or use VC tools to implement TODs? Provide the name and number code of the statutes and note how they aid the use of VC tools to fund TODs. Email any supporting files at shishir.mathur@sjsu.edu. Click on the "Next" button to skip the question.

\section{TOD Survey: Transit Agency}

Which statutory regulations governing your agency inhibit the agency's ability to promote or use VC tools to implement TODs? Provide the name and number code of the statutes and note how they inhibit the use of VC tools to fund TODs. Email any supporting files at shishir.mathur@sjsu.edu. Click on the "Next" button to skip the question.

\section{TOD Survey: Transit Agency}

Are any of the following collaborative arrangements in your agency's service area explicitly devoted to promoting use of VC tools to implement TODs? Please check all that apply.

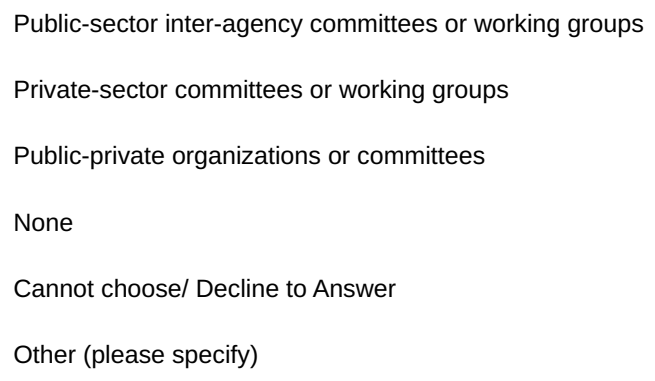

TOD Survey: Transit Agency 
Please describe the committees, organizations, and working groups. Email any supporting files at shishir.mathur@sjsu.edu. Click on the "Next" button to skip the question.

\section{TOD Survey: Transit Agency}

Does your agency have cooperative agreements with any of the following public agencies to promote use of VC tools to implement TODs? Check all that apply.

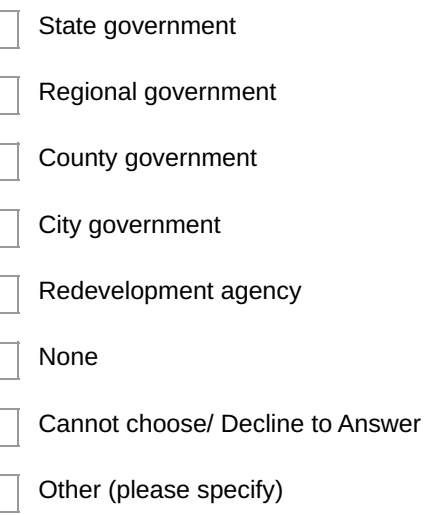

\section{TOD Survey: Transit Agency}

Please describe the nature of these cooperative agreements; for example, what duties and functions are shared between the partner agencies? Email any supporting files (such as copies of the agreements) at shishir.mathur@sjsu.edu. Click on the "Next" button to skip the question.

\section{TOD Survey: Transit Agency}


Overall, to what extent barriers to the use of VC tools have been an impediment to the implementation of TODs in your service area?
Very large extent
Large extent
Some extent
Very little extent
None at all (selecting this option will end the survey)
Cannot choose/Decline to Answer (selecting this option will end the survey)

\section{TOD Survey: Transit Agency}

Have these barriers to the use of $\mathrm{VC}$ tools been overcome, or are they being come, or are they planned to be overcome?

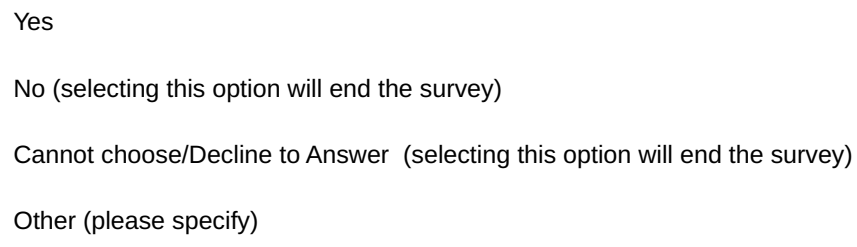

TOD Survey: Transit Agency

Please provide examples of how these barriers were either overcome for some of the TODs in your service area, or are being overcome, or are planned to be overcome. Please provide specific examples and contact information of people who can provide further information and insights. Email any supporting at shishir.mathur@sjsu.edu. Click on the "Next" button to skip the question. 


\section{APPENDIX B: LOCAL GOVERNMENT SURVEY QUESTIONNAIRE}

\section{TOD Survey: Local Government}

This survey is a part of a nationwide study sponsored by the Mineta Transportation Institute. The study seeks to fill two research, policy and practice gaps in promoting transit-oriented developments (TODs): a) how to facilitate TOD-supportive land use and zoning; and b) how to use the transit- and TOD-generated land value increase to fund TODs through value capture tools.

The survey is divided into two sections:

Section 1: Land-use- and zoning-related barriers to the implementation of TODs, and the ways in which these barriers have been, are being, or can be overcome in your local government's service area; and

Section 2: Barriers to the use of value capture (VC) to fund TODs, and the ways in which these barriers have been, are being, or can be overcome in your local government's service area.

For the purposes of this study:

a) a TOD is broadly defined as urban development (for example, a single building or a group of buildings) that: a) is located close to a transit station; b) is easily accessible from that station through a walk/bike way; and c) generates transit ridership for that station; and

b) a local government includes a city, a county, a township, a borough, or a village government.

Contact information provided in this survey will not be included in any publication. Please contact Dr. Shishir Mathur (shishir.mathur@sjsu.edu) for questions about the study or the survey.

Finally, it should take approximately $\mathbf{3 0}$ minutes to complete this survey. Many thanks for taking time out of your busy schedule.

\section{TOD Survey: Local Government}

* Please provide the following information for the person completing the survey:

Name:

Email address:

Name of the local

government:

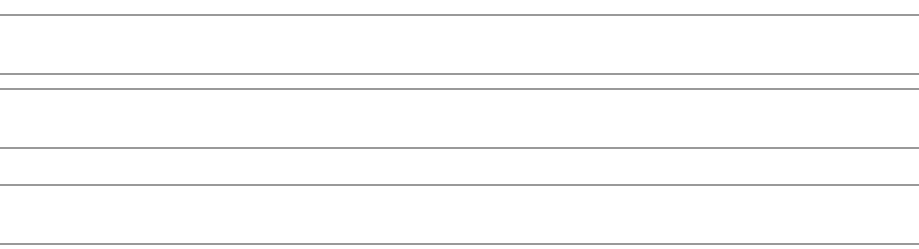

\section{TOD Survey: Local Government}


Are there one or more TODs in your local government's service area?

For the purposes of this study, a TOD is broadly defined as urban development (for example, a single building or a group of buildings) that: a) is located close to a transit station; b) is easily accessible from that station through a walk/bike way; and c) generates transit ridership for that station.

Yes, one or more TODs exist.

No TODs currently exist but one or more are under construction.

No TODs currently exist but one or more are under planning/entitlement stages.

Other (please specify)
No TODs exist and no TOD is under construction or in planning/entitlement stages. (selecting this option will end the survey)

Cannot choose/Decline to Answer

\section{TOD Survey: Local Government}

Does your local government have a formal program to encourage TODs?
Yes
No
Cannot choose/Decline to Answer
Other (please specify)

\section{TOD Survey: Local Government}

Please elaborate on the program and/or provide a web address (URL). Please email any supporting files at shishir.mathur@sjsu.edu. Click on the "Next" button to skip the question.

\section{TOD Survey: Local Government}


Does your local government encourage TODs in other ways; for example, through financial incentives and relaxed parking standards?

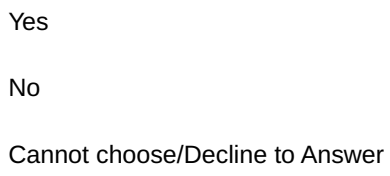

\section{TOD Survey: Local Government}

Please elaborate on how your local government encourages TODs in other ways. Click on the "Next" button to skip the question.

\section{TOD Survey: Local Government}

* Who is the contact person for TOD-related programs or assistance provided by your local government?

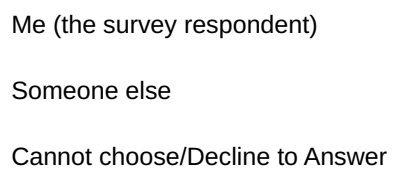

\section{TOD Survey: Local Government}

* If someone other than you is the contact person for TOD-related programs or assistance, please provide that person's contact information.

Name
Email Address

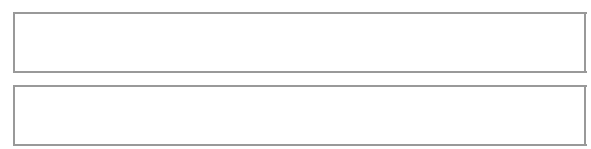

TOD Survey: Local Government

The next set of questions will request your input on a) land-use- and zoning-related barriers to the implementation of TODs in your local government's service area; and b) the ways in which these barriers have been, are being, or can be overcome in your service area. 
How does your local government address land-use- and zoning-related issues that impact implementation of TODs? Please check all that apply.

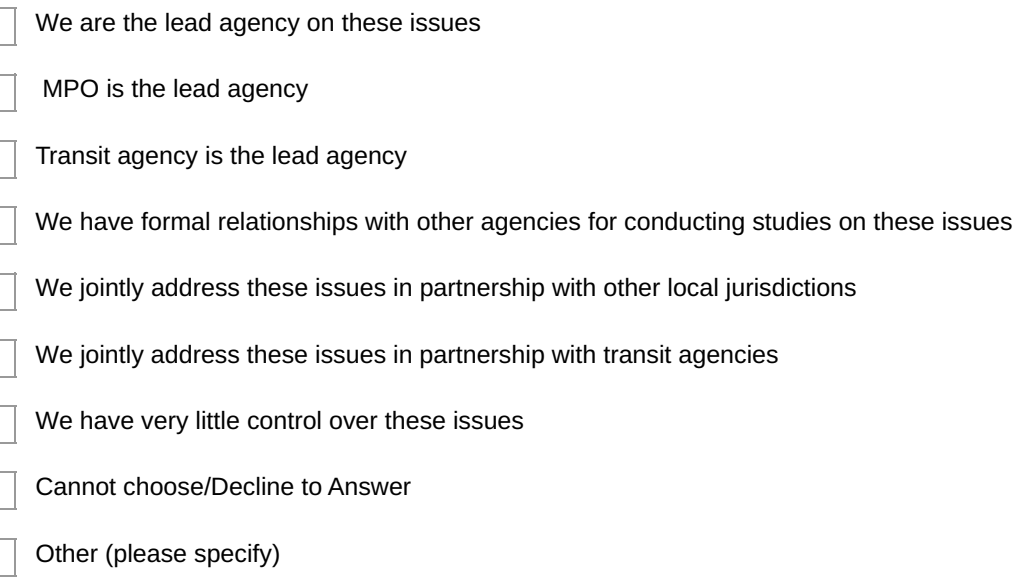

\section{TOD Survey: Local Government}

Are any of the following land use and zoning tools used to incentivize TODs in your local government's service area? Please note that these tools may be used by your local government or by one or more of the following agencies: a city government (if you are a county government), a county government (if you are a city government), or some other public agency such as a redevelopment agency. Please check all that apply. Click on the "Next" button to skip the question.

\begin{tabular}{|c|c|c|c|c|c|}
\hline $\begin{array}{c}1 \text { (Not used at } \\
\text { all) }\end{array}$ & 2 & 3 & 4 & $\begin{array}{c}5 \text { (used } \\
\text { extensively) }\end{array}$ & $\begin{array}{c}\text { Cannot } \\
\text { choose/Decline } \\
\text { to Answer }\end{array}$ \\
\hline
\end{tabular}

Maximum, not minimum,
lot sizes for single-family
residences
Density bonuses
Higher floor area ratios
(FARs)
Relaxation of limitations
on building height
Zoning for compact
housing types such as
condominiums, and
townhouses
Mixed use zoning


1 (Not used at

all)

Regulations and

incentives that facilitate

adaptive reuse of

properties that would

otherwise not meet the

current zoning and/or

building codes

Requiring housing at

various affordability

levels through programs

such as inclusionary

housing

Parking regulations that prescribe maximum, not minimum, parking

requirements

Relaxed parking

standards

Restricted off-street

parking

Incentives for shared

and paid parking

Transit agencies have

the power to enter into

joint development

agreements with private

developers

Unambiguously

specifying the kinds of

actions permissible

under joint development

agreements; for

example, whether transit

agencies can grant

development and

easement rights to

private entities

Other developer

incentives such as

no/reduced impact fees

Reduced permit fees

Streamlined/expedited

environmental review

Streamlined/expedited

building permit approval
Cannot

5 (used

choose/Decline

to Answer extensively) 


\begin{tabular}{|c|c|c|c|c|c|c|}
\hline & $\begin{array}{c}1 \text { (Not used at } \\
\text { all) }\end{array}$ & 2 & 3 & 4 & $\begin{array}{c}5 \text { (used } \\
\text { extensively) }\end{array}$ & $\begin{array}{c}\text { Cannot } \\
\text { choose/Decline } \\
\text { to Answer }\end{array}$ \\
\hline $\begin{array}{l}\text { Use of eminent domain } \\
\text { (other than for right-of- } \\
\text { way acquisition) }\end{array}$ & O & 0 & 0 & O & O & 0 \\
\hline $\begin{array}{l}\text { Assistance with land } \\
\text { assembly }\end{array}$ & $\bigcirc$ & O & 0 & O & O & O \\
\hline $\begin{array}{l}\text { Exclusion of TODs from } \\
\text { concurrency or level of } \\
\text { service standards }\end{array}$ & O & O & 0 & O & O & 0 \\
\hline $\begin{array}{l}\text { TODs designated as } \\
\text { "receiving zones" for } \\
\text { development rights } \\
\text { under a transfer of } \\
\text { development rights } \\
\text { (TDR) program with } \\
\text { areas outside the TODs } \\
\text { designated as "sending } \\
\text { areas" }\end{array}$ & O & O & O & O & O & O \\
\hline Others & O & O & O & O & O & O \\
\hline ther (please specify) & & & & & & \\
\hline
\end{tabular}

\section{TOD Survey: Local Government}

Which of the following planning techniques are used by your local government to promote TODs? Please check all that apply. For the planning technique/s selected below, please email relevant plan/policy documents at shishir.mathur@sjsu.edu.

TOD overlay zoning

TOD specific plans

Transit/urban village plans

Developer agreements

Other (please specify)
Planned unit development (PUD) process

None of these

Cannot choose/Decline to Answer 


\section{TOD Survey: Local Government}

Do any federal, state, regional or local laws, policies, plans, funding programs or financial incentives positively or negatively impact how your local government approaches land use or zoning in the implementation of TODs?

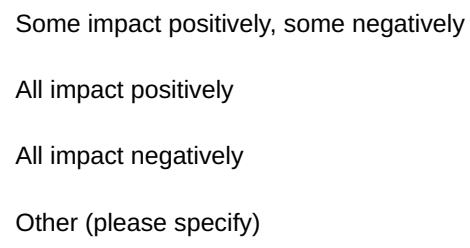

No impact, either positive or negative

Cannot choose/Decline to Answer

\section{TOD Survey: Local Government}

Please elaborate on the specific laws, policies, plans, funding programs or financial incentives and their impacts. Please email any supporting files at shishir.mathur@sjsu.edu. Click on the "Next" button to skip the question.

\section{TOD Survey: Local Government}

Which statutory regulations governing your local government aid it's ability to promote TOD-supportive land use and zoning? Provide the name and number code of the statutes and note how they promote TODsupportive land use and zoning. Please email any supporting files at shishir.mathur@sjsu.edu. Click on the "Next" button to skip the question.

\section{TOD Survey: Local Government}


Which statutory regulations governing your local government inhibit it's ability to promote TOD-supportive land use and zoning? Provide the name and number code to the statutes and note how they inhibit TODsupportive land use and zoning. Please email any supporting files at shishir.mathur@sjsu.edu. Click on the "Next" button to skip the question.

\section{TOD Survey: Local Government}

In the state your local government is located, is there a statewide vision, policy, or plan that calls for compact development or TODs around transit stations?

\section{Yes}

No

Cannot choose/Decline to Answer

\section{TOD Survey: Local Government}

Please elaborate on the vision, policy, or plan and indicate who is promoting it. Email any supporting files at shishir.mathur@sjsu.edu. Click on the "Next" button to skip the question. 
In the state your local government is located, do state- and/or regional-level growth management/smart growth policies/tools promote TODs? Examples of such policies/tools include urban growth boundary, concurrency and consistency requirements, and identification of growth areas with TODs promoted inside these growth areas.

\section{Yes}

No

Cannot choose/Decline to Answer

Other (please specify)

\section{TOD Survey: Local Government}

Please list the growth management/smart growth policies/tools. Email any supporting files at shishir.mathur@sjsu.edu. Click on the "Next" button to skip the question.

\section{TOD Survey: Local Government}

Are any of the following collaborative arrangements in your local government's service area explicitly devoted to promoting TOD-supportive land use and zoning? Please check all that apply.

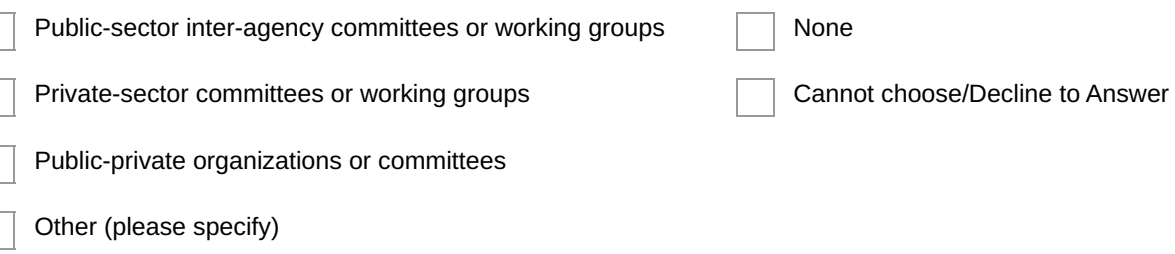


Please describe the committees, organizations, and working groups. Email any supporting files at shishir.mathur@sjsu.edu. Click on the "Next" button to skip the question.

\section{TOD Survey: Local Government}

Does your local government have cooperative agreements with any of the following public agencies to promote TOD-supportive land use and zoning? Check all that apply.
State government
Regional government
County government
City government
Redevelopment agency
Other (please specify)

$\square$ MPO

Transit agency

None

\section{TOD Survey: Local Government}

Please describe the nature of these cooperative agreements; for example, what duties and functions are shared between the partner agencies? Email any supporting files at shishir.mathur@sjsu.edu. Click on the "Next" button to skip the question.

\section{TOD Survey: Local Government}


Overall, to what extent land use and zoning restrictions have been an impediment to the implementation of TODs in your service area?
Very large extent
Very little extent
Large extent
None at all
Some extent
Cannot choose/Decline to Answer

\section{TOD Survey: Local Government}

Have these land-use- and zoning-related barriers been overcome, or are they being overcome, or are they planned to be overcome?

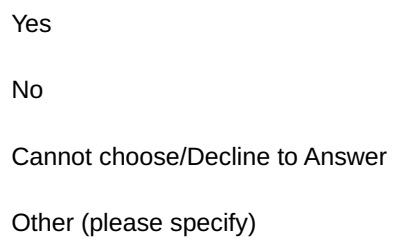

\section{TOD Survey: Local Government}

Please provide examples of how these barriers were either overcome for some of the TODs in your local government's service area, or are being overcome, or are planned to be overcome. Please provide specific examples and contact information of people who can provide further information and insights. Email any supporting files at shishir.mathur@sjsu.edu. Click on the "Next" button to skip the question.

\section{TOD Survey: Local Government}

The last set of questions will seek your input on a) barriers to the use of VC tools to implement TODs in your local government's service area; and b) the ways in which these barriers have been, are being, or can be overcome in your service area. 
Have any of the following VC tools been or are being used, or are being considered, to implement TODs in your local government's service area? Please note that these tools may be used by your local government or by one or more of the following agencies: a city, a county, a township, or a borough government; or some other public agency such as a redevelopment agency. Please check all that apply.

Community benefits
$\square$ Impact fees
$\quad$ Joint development
$\square$ Naming rights (for example, building naming rights)
$\square$ Public private partnerships

Other (please specify)

\section{TOD Survey: Local Government}

Do any federal, state, regional or local laws, policies, plans, funding programs or financial incentives positively or negatively impact how your local government approaches the use of VC tools to implement TODs?

Some impact positively, some negatively

All impact positively

All impact negatively

Other (please specify)
No impact, either positive or negative

Cannot choose / Decline to Answer

\section{TOD Survey: Local Government}

Please elaborate on the specific laws, policies, plans, funding programs or financial incentives and their impacts. Email any supporting files at shishir.mathur@sjsu.edu. Click on the "Next" button to skip the question. 


\section{TOD Survey: Local Government}

Which statutory regulations governing your local government aid it's ability to promote or use VC tools to implement TODs? Provide the name and number code of the statutes and note how they aid the use of VC tools to fund TODs. Email any supporting files at shishir.mathur@sjsu.edu. Click on the "Next" button to skip the question.

\section{TOD Survey: Local Government}

Which statutory regulations governing your local government inhibit it's ability to promote or use VC tools to implement TODs? Provide the name and number code of the statutes and note how they inhibit the use of VC tools to fund TODs. Email any supporting files at shishir.mathur@sjsu.edu. Click on the "Next" button to skip the question.

\section{TOD Survey: Local Government}

Are any of the following collaborative arrangements in your local government's service area explicitly devoted to promoting use of VC tools to implement TODs? Please check all that apply.

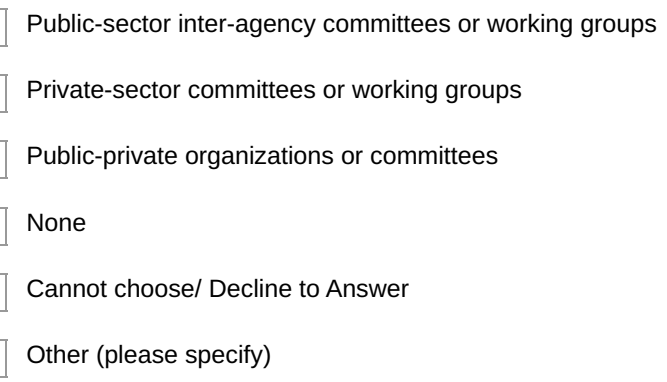

TOD Survey: Local Government 
Please describe the committees, organizations, and working groups. Email any supporting files at shishir.mathur@sjsu.edu. Click on the "Next" button to skip the question.

\section{TOD Survey: Local Government}

Does your local government have cooperative agreements with any of the following public agencies to promote use of VC tools to implement TODs? Check all that apply.

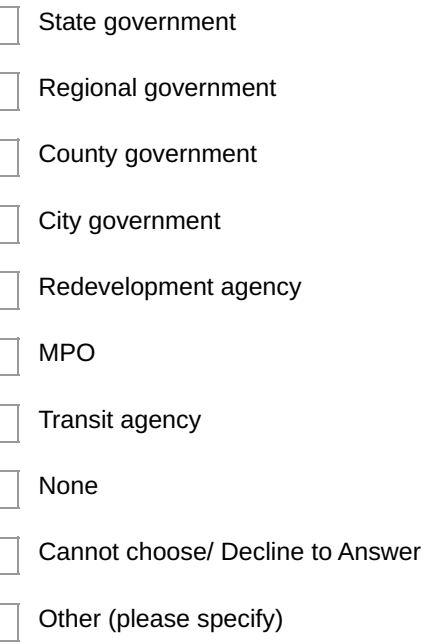

\section{TOD Survey: Local Government}

Please describe the nature of these cooperative agreements; for example, what duties and functions are shared between the partner agencies? Email any supporting files (such as copies of the agreements) at shishir.mathur@sjsu.edu. Click on the "Next" button to skip the question. 


\section{TOD Survey: Local Government}

Overall, to what extent barriers to the use of VC tools have been an impediment to the implementation of TODs in your service area?
Very large extent
Large extent
Some extent
Very little extent
None at all (selecting this option will end the survey)
Cannot choose/Decline to Answer (selecting this option will end the survey)

\section{TOD Survey: Local Government}

Have these barriers to the use of VC tools been overcome, or are they being come, or are they planned to be overcome?

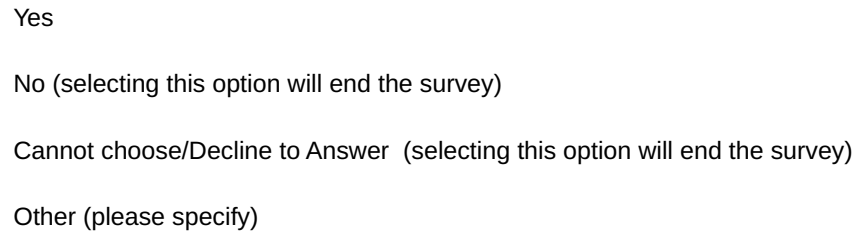

\section{TOD Survey: Local Government}

Please provide examples of how these barriers were either overcome for some of the TODs in your service area, or are being overcome, or are planned to be overcome. Please provide specific examples and contact information of people who can provide further information and insights. Email any supporting files at shishir.mathur@sjsu.edu. Click on the "Next" button to skip the question. 


\section{ABBREVIATIONS AND ACRONYMS}

AARP

$A B$

AMI

BART

BID

BMR

BRT

CARB

CDFA

CDG

CEQA

CFD

CLT

CONNECT

CRA

CTA

DART

DLCD

DRCOG

DSCDO

EIFD

ETOD

FAA

FAR

FAST

FBC

FTA

GCC

GHG
Association of American Retired Persons

Assembly Bill

Area Median Income

San Francisco Bay Area Rapid Transit District

Business Improvement District

Below Market Rate

Bus Rapid Transit

California Air Resource Board

Commonwealth Flats Development Area

Core Development Group

California Environmental Quality Act

Community Facility District

Community Land Trust

Congress of Neighboring Communities

Community Reinvestment Agency

Chicago Transit Authority

Dallas Area Rapid Transit

Department of Land Conservation and Development

Denver Regional Council of Governments

Detroit Shoreway Community Development Organization

Enhanced Infrastructure Financing District

Equitable TOD

Federal Aviation Administration

Floor Area Ratio

Fixing America's Surface Transportation Act

Form-Based Code

Federal Transit Administration

Great Communities Collaborative

Green House Gas 
GM

HUD

IFD

ISTEA

JPA

LIHTC

LOS

LRT

LVC

MAG

MAP-21

MARTA

MBTA

MOU

MPO

MTC

MUPTE

MXDT

NEPA

NPC

$\mathrm{NPH}$

NRS

NTD

NYSDOT

OCTA

O\&M

PDA

PDP

PPP

PSRC

PTBA
Growth Management

US Department of Housing and Urban Development Infrastructure Financing District Intermodal Surface Transportation Efficiency Act Joint Powers Authority

Low Income Housing Tax Credit

Level of Service

Light Rail Transit

Land Value Capture

Maricopa Association of Governments

Moving Ahead for Progress in the 21st Century Act

Metropolitan Atlanta Rapid Transit Authority

Massachusetts Bay Transportation Authority

Memorandum of Understanding

Metropolitan Planning Organization

Metropolitan Transportation Commission

Multi-Unit Property Tax Exemption

Mixed Used Transit District

National Environmental Policy Act

Notice of Project Change

Non Profit Housing

Nevada Revised Statutes

National Transit Database

New York State Department of Transportation

Orange County Transportation Authority

Operations and Maintenance

Planned Development Area

Preliminary Development Plan

Public Private Partnership

Puget Sound Regional Council

Public Transportation Benefit Area 
PUD

RFP

ROW

RTA

RTD

SAD

SAFETEA-LU

SB

SBWTC

SESRA

SFMTA

SGPIPA

TDM

TDR

TEA-21

TIF

TIFIA

TMA

TOD

TRID

TRZ

UGB

ULC

ULI

VC

VMT

VTA

WMATA
Planned Unit Development

Request for Proposal

Right Of Way

Greater Cleveland Regional Transit Authority

Regional Transportation District

Special Assessment District

The Safe, Accountable, Flexible, Efficient Transportation Equity Act: A Legacy for Users

Senate Bill

South Boston Waterfront Transportation Center

Southeast Seattle Reinvestment Area

San Francisco Municipal Transportation Agency

Smart Growth Public Infrastructure Policy Act

Transportation Demand Management

Transfer of Development Rights

Transportation Equity Act for the 21st Century

Tax Increment Financing

Transportation Infrastructure Finance and Innovation Act

Transportation Management Association

Transit Oriented Development

Transit Revitalization Investment District

Transit Reinvestment Zone

Urban Growth Boundary

Urban Land Conservancy

Urban Land Institute

Value Capture

Vehicles Miles Travelled

Santa Clara Valley Transportation Authority

Washington Metropolitan Area Transit Authority 


\section{ENDNOTES}

1. "Potential State-Level Strategies to Advance Sustainable, Equitable Communities and Reduce Vehicle Miles of Travel (VMT) - for Discussion," California Air Resources Board (ARB), last updated 2016, taken from https://ww3.arb.ca.gov/cc/scopingplan/ meetings/091316/potential\%20vmt\%20measures\%20for\%20discussion_9.13.16.pdf.

2. N. Arfeh and Z. Lei, "The Analysis of transit-oriented development (TOD) in Washington, D.C. and Baltimore metropolitan areas," Transportation Policy 32 (2014): 172-79.

3. "Driving Change: Reducing Vehicle Miles Travelled in California," L. Bedsworth, Hanak, and Kolko, Public Policy Institute of California, last updated 2011, taken from http://www.ppic.org/content/pubs/report/R_211LBR.pdf.

4. "MTC Resolution 3434 Transit-Oriented Development (TOD) Policy for Regional Transit Expansion Projects," Metropolitan Transportation Commission (MTC), last updated 2005, taken from https://mtc.ca.gov/sites/default/files/Resolution\%203434\%20TOD_ policy.pdf.

5. "Transit-Oriented Development Supportive Zoning," Sustainable Jersey, last updated 2017, taken from http://www.sustainablejersey.com/actions-certification/ actions/?type $=1336777436 \& t x$ _sjcert_action $\% 5$ BactionObject $\% 5 \mathrm{D}=522 \&$ tx_sjcert_ action $\% 5$ Baction $\% 5 \mathrm{D}=$ getPDF\&tx_sjcert_action $\% 5 \mathrm{Bcontroller} \% 5 \mathrm{D}=$ Action\&cHash= 7d698135231866883a26b10b76885025.

6. "Revised Quantification Methodology for the Strategic Growth Council Affordable Housing and Sustainable Communities Program: Greenhouse Gas Reduction Fund Fiscal Year 2016-17," California Air Resources Board (ARB), last updated 2017, taken from https://ww3.arb.ca.gov/cc/capandtrade/auctionproceeds/sgc_ahsc_ finalrevisedqm_16-17.pdf.

7. "Financing Transit Systems through Value Capture: an annotated bibliography," J. Smith, T. Gihring, and T. Litman, Transport Policy, last updated 2009.

8. Shishir Mathur, Innovation in Public Transport Finance: Property Value Capture (Burlington, VT: Ashgate and Farnham, Surrey, UK, 2014).

9. "VTA's BART Silicon Valley Phase II Extension Project," Santa Clara Valley Transportation Authority, last updated September 20, 2019, taken from https://www. vta.org/sites/default/files/2019-10/2019-09-20\%20VTA\%20Board\%20Workshop\%20 Presentation_2SlidesPerPage_Reduced.pdf.

10. Shishir Mathur, "Impact of Heavy-rail-based Rapid Transit on House Prices: Evidence from the Fremont, CA, Warm Springs BART Extension Project," Journal of American Planning Education and Research (2020).

11. "Potential State-Level Strategies to Advance Sustainable, Equitable Communities 
and Reduce Vehicle Miles of Travel (VMT)—for Discussion," California Air Resources Board (ARB), last updated 2016, taken from https://ww3.arb.ca.gov/cc/scopingplan/ meetings/091316/potential\%20vmt\%20measures\%20for\%20discussion_9.13.16.pdf.

12. N. Arfeh and Z. Lei, "The Analysis of transit-oriented development (TOD) in Washington, D.C. and Baltimore metropolitan areas," Transportation Policy 32 (2014): 172-79.

13. "Driving Change: Reducing Vehicle Miles Travelled in California," L. Bedsworth, Hanak, and Kolko, Public Policy Institute of California, last updated 2011, taken from http://www.ppic.org/content/pubs/report/R_211LBR.pdf.

14. "MTC Resolution 3434 Transit-Oriented Development (TOD)Policy for Regional Transit Expansion Projects," Metropolitan Transportation Commission (MTC), last updated 2005, taken from https://mtc.ca.gov/sites/default/files/Resolution\%203434\%20TOD_ policy.pdf.

15. "Transit-Oriented Development Supportive Zoning," Sustainable Jersey, last updated 2017, taken from http://www.sustainablejersey.com/actions-certification/

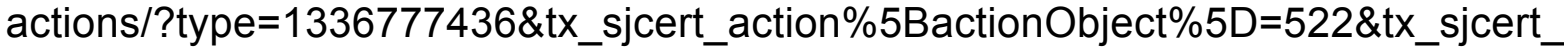
action $\% 5$ Baction $\% 5 \mathrm{D}=$ getPDF\&tx_sjcert_action\%5Bcontroller\%5D=Action\&cHash= 7d698135231866883a26b10b76885025.

16. "Revised Quantification Methodology for the Strategic Growth Council Affordable Housing and Sustainable Communities Program: Greenhouse Gas Reduction Fund Fiscal Year 2016-17," California Air Resources Board (ARB), last updated 2017, taken from https://ww3.arb.ca.gov/cc/capandtrade/auctionproceeds/sgc_ahsc finalrevisedqm_16-17.pdf.

17. "Financing Transit Systems through Value Capture: an annotated bibliography," J. Smith, T. Gihring, and T. Litman, Transport Policy, last updated 2009.

18. Shishir Mathur, Innovation in Public Transport Finance: Property Value Capture (Burlington, VT: Ashgate and Farnham, Surrey, UK, 2014).

19. Robert Cervero and Michael Duncan "Transit's value-added effects: Light and commuter rail services and commercial land values," Transportation Research Record 1805.1 (2002): 8-15.

20. Robert Cervero and John Landis, "Twenty years of the Bay Area Rapid Transit system: Land use and development impacts," Transportation Research Part A: Policy and Practice 31.4 (1997): 309-333

21. Shishir Mathur and Christopher Ferrell, "Measuring the impact of sub-urban transitoriented developments on single-family home values," Transportation Research Part A: Policy and Practice 47 (2013): 42-55

22. Sara Mohammad et al. "A meta-analysis of the impact of rail projects on land and 
property values," Transportation Research Part A: Policy and Practice 50 (2013): 158-170.

23. Haitao Yu, Hao Pang and Ming Zhang, "Value-added effects of transit-oriented development: The impact of urban rail on commercial property values with consideration of spatial heterogeneity," Regional Science 97.4 (2017): 1375-1396.

24. Shishir Mathur, "Use of Tax Increment Financing to Fund Public Transportation: Enabling Environment and Equity Impacts," Public Works Management and Policy 22.3 (2017): 201-225.

25. Robert Cervero, Transit-oriented development in the United States: Experiences, challenges, and prospects (Transportation Research Board, Vol. 102, 2004).

26. Shishir Mathur, Innovation in Public Transport Finance: Property Value Capture (Burlington, VT: Ashgate and Farnham, Surrey, UK, 2014).

27. Robert Cervero, Transit-oriented development in the United States: Experiences, challenges, and prospects (Transportation Research Board, Vol. 102, 2004).

28. Robert Cervero, Ferrell and Murphy, "Transit-Oriented Development and Joint Development in the United States: A Literature Review," Transportation Cooperative Research Program (presented at Transportation Research Board, 2002, Washington, $\mathrm{DC})$, taken from https://community-wealth.org/content/transit-oriented-developmentand-joint-development-united-states-literature-review.

29. Robert Cervero, Transit-oriented development in the United States: Experiences, challenges, and prospects (Transportation Research Board, Vol. 102, 2004).

30. D. Hess and P. Lombardi, "Policy Support for and Barriers to Transit-oriented development in the Inner-city: Literature Review," Transportation Research Record 1887 (2004): 26-33.

31. E. Dumbaugh, "Overcoming Financial and Institutional Barriers to TOD: Lindbergh Station Case Study" Journal of Public Transportation 7.3 (2004): 43-68.

32. J. Renne et al., "Transit-Oriented and Joint Development: Case Studies and Legal Issues," Transit Cooperative Research Program's Legal Research Digest 36 (2011).

33. Robert Cervero, Transit-oriented development in the United States: Experiences, challenges, and prospects (Transportation Research Board, Vol. 102, 2004).

34. J. Renne et al., "Transit-Oriented and Joint Development: Case Studies and Legal Issues," Transit Cooperative Research Program's Legal Research Digest 36 (2011).

35. D. Shinkle, "Transit Oriented Developments in the States," presented at the National Conference of State Legislatures, Washington, DC, 2012. Taken from http://www.ncsl. 
org/Documents/transportation/TOD_Final.pdf.

36. J. Lynott, Zimmerman and Happ, "Communities are Embracing Developments Near Transit: A Snap-shot of Transit Oriented Development Support Across the United States," AARP Public Policy Institute (2017).

37. D. Shinkle, "Transit Oriented Developments in the States," presented at the National Conference of State Legislatures, Washington, DC, 2012. Taken from http://www.ncsl. org/Documents/transportation/TOD_Final.pdf.

38. The Fourth Regional Plan, "Remove barriers to transit-oriented and mixed-use development," Regional Plan Association (RPA), n.d., taken from http://fourthplan. org/action/tod.

39. J. Schuetz, Guilliano, and Shin, "Does Zoning Help or Hinder Transit-Oriented (re) Development?" Urban Studies. 55.8 (2018): 1672-1689.

40. Glaeser et al., "Regulation and the Rise of Housing Price in Greater Boston," Pioneer Institute for Public Policy Research and Rappaport Institute for Greater Boston, Cambridge, MA (2006).

41. Robert Olshansky, "The California Environmental Quality Act and Local Planning," Journal of American Planning Association 62.3 (1996): 313-330.

42. The Fourth Regional Plan, "Remove barriers to transit-oriented and mixed-use development," Regional Plan Association (RPA), n.d., taken from http://fourthplan. org/action/tod.

43. Robert Cervero, Transit-oriented development in the United States: Experiences, challenges, and prospects (Transportation Research Board, Vol. 102, 2004).

44. J. Renne et al., "Transit-Oriented and Joint Development: Case Studies and Legal Issues," Transit Cooperative Research Program's Legal Research Digest 36 (2011).

45. Robert Cervero, Transit-oriented development in the United States: Experiences, challenges, and prospects (Transportation Research Board, Vol. 102, 2004).

46. Shishir Mathur, Innovation in Public Transport Finance: Property Value Capture (Burlington, VT: Ashgate and Farnham, Surrey, UK, 2014).

47. Robert Cervero, Transit-oriented development in the United States: Experiences, challenges, and prospects (Transportation Research Board, Vol. 102, 2004).

48. Robert Cervero, Ferrell and Murphy, "Transit-Oriented Development and Joint Development in the United States: A Literature Review," Transportation Cooperative Research Program (presented at Transportation Research Board, 2002, Washington, $\mathrm{DC})$, taken from https://community-wealth.org/content/transit-oriented-development- 
and-joint-development-united-states-literature-review.

49. E. Dumbaugh, "Overcoming Financial and Institutional Barriers to TOD: Lindbergh Station Case Study," Journal of Public Transportation 7.3 (2004): 43-68.

50. M. White, "The Zoning and Real Estate Implications of Transit-Oriented Development," Transit Cooperative Research Program's Legal Research Digest 12 (presented at Transportation Research Board, Washington, DC, 1999).

51. S. Mathur, "Impact of an Urban Growth Boundary Across the Entire House Price Spectrum: The Two-Stage Quantile Spatial Regression Approach," Land Use Policy 80 (2019): 88-94.

52. M. White, "The Zoning and Real Estate Implications of Transit-Oriented Development," Transit Cooperative Research Program's Legal Research Digest 12 (presented at Transportation Research Board, Washington, DC, 1999)

53. Ibid.

54. Robert Cervero, Transit-oriented development in the United States: Experiences, challenges, and prospects (Transportation Research Board, Vol. 102, 2004).

55. The Fourth Regional Plan, "Remove barriers to transit-oriented and mixed-use development," Regional Plan Association (RPA), n.d., taken from http://fourthplan. org/action/tod.

56. W. Riggs and F. Chamberlain, "The TOD and Smart Growth Implications of the LA Adaptive Reuse Ordinance," Sustainable Cities and Society 38 (2018): 594-606.

57. P. Frey and R. Bowdon, "Historic Preservation: Expanding the Planner's Toolbox," American Planning Association PAS Memo, APA Press (2012), Chicago, IL.

58. M. Manville, "Parking Requirements and Housing Development," Journal of the American Planning Association 79.1 (2013): 49-66.

59. Manville and Shoup 2010 M. Manville and D. Shoup, "Parking Requirements as a Barrier to Housing Development: Regulation and Reform in Los Angeles," University of California Transportation Center, Berkeley, CA, taken from http://escholarship.org/ uc/item/1qr84990.

60. The Partnership for Building Reuse, "Building on Baltimore's History," The National Trust for Historic Preservation, 2014, Washington, DC.

61. S. Cantell, "The Adaptive Reuse of Historical Industrial Buildings: Regulation Barriers, Best Practices and Case Studies," Virginia Polytechnic Institute and State University, (2005) Blacksburg, VA. 
62. "The Fourth Regional Plan," Regional Transportation Authority (RTA), last updated 2012, taken from http://fourthplan.org/action/tod.

63. "Transit-Oriented Development Supportive Zoning," Sustainable Jersey, last updated 2017, taken from http://www.sustainablejersey.com/actions-certification/ actions/?type=1336777436\&tx_sjcert_action\%5BactionObject\%5D=522\&tx_sjcert_ action $\% 5$ Baction $\% 5 \mathrm{D}=$ getPDF\&tx_sjcert_action\%5Bcontroller\%5D=Action\&cHash= 7d698135231866883a26b10b76885025.

64. M. White, "The Zoning and Real Estate Implications of Transit-Oriented Development," Transit Cooperative Research Program's Legal Research Digest 12 (presented at Transportation Research Board, Washington, DC, 1999).

65. Ibid.

66. Ibid.

67. Ibid.

68. "The Fourth Regional Plan," Regional Transportation Authority (RTA), last updated 2012, taken from http://fourthplan.org/action/tod.

69. "Streamlining the Entitlement Process for Transit-Oriented Development: Best Practices Summary," Regional TransportationAuthority (RTA), last updated 2012, taken from https://www.rtachicago.org/sites/default/files/documents/plansandprograms/ landusetod/St.

70. Robert Cervero, Transit-oriented development in the United States: Experiences, challenges, and prospects (Transportation Research Board, Vol. 102, 2004).

71. M. White, "The Zoning and Real Estate Implications of Transit-Oriented Development," Transit Cooperative Research Program's Legal Research Digest 12 (presented at Transportation Research Board, Washington, DC,

72. Robert Cervero, Transit-oriented development in the United States: Experiences, challenges, and prospects (Transportation Research Board, Vol. 102, 2004).

73. "Surplus Land Act Requirements Expand for Local Agencies," Best Best \& Krieger, last updated October 15, 2019, taken from https://www.bbklaw.com/news-events/ insights/2019/legal-alerts/10/surplus-land-act-requirements-expand-for-local-age .

74. "Assembly Bill No. 2923 - San Francisco Bay Area Rapid Transit District: transitoriented development," Chiu, last updated September 30, 2018, taken from https:// leginfo.legislature.ca.gov/faces/billTextClient.xhtml?bill_id=201720180AB2923.

75. "Senate Bill No. 167 - Housing Accountability Act," Skinner, last updated September 29, 2017, taken from https://leginfo.legislature.ca.gov/faces/billTextClient.xhtml?bill_ 
id $=201720180 S B 167$.

76. "Senate Bill No. 35 - Planning and zoning: affordable housing: streamlined approval process," Wiener, last updated September 29, 2017, taken from https://leginfo. legislature.ca.gov/faces/billTextClient.xhtml?bill_id=201720180SB35.

77. "Summary of SB 34 Affordable Housing Modifications (4 ${ }^{\text {th }}$ Substitute)," Jake Anderegg and Val Potter, last updated March 22, 2019, taken from http://www.ulct.org/wp-content/ uploads/sites/4/2019/03/Summary-of-SB-34-Affordable-Housing-Modifications-4thSubstitute.pdf.

78. "SB 0783," Dickerson, last updated May 11, 2017, taken from http://wapp.capitol. tn.gov/apps/Billinfo/default.aspx?BillNumber=SB0783\&ga=110.

79. "Chicago Code of Ordinances, Chapter 17-10-0100. General," City of Chicago, last updated 2020, taken from http://chicago-il.elaws.us/code/coor_t17_ch17-10_sec1710-0100.

80. "Transit Oriented Development Alignment Rezoning Guide," City of Charlotte, last updated May 2019, taken from https://charlotteudo.org/wp-content/uploads/2019/05/ TOD_Alignment_Rezoning_Guide.pdf.

81. "Initiative Ordinance JJJ: Affordable housing and labor standards for general plan amendments and zoning changes," City of Los Angeles, last updated November 2016, taken from http://www.allianceforcommunitytransit.org/wp-content/uploads/2017/03/ MeasureJJJ_FullText.pdf.

82. "Measure JJJ triggers new incentives to encourage affordable housing near transit," Elijah Chiland, Curbed, last updated March 14, 2017, taken from https://la.curbed. com/2017/3/14/14928306/los-angeles-incentives-affordable-housing-transit-jjj.

83. "Transit Oriented Communities Affordable Housing Incentive Program: Frequently Asked Questions and Answers," Los Angeles City Planning, last updated May 15, 2018, taken from https://planning.lacity.org/odocument/87b0f2c2-8422-4767-a104b7cd323ee26f/Transit-Oriented_Communities_-_Affordable_Housing_Incentive_ Program_(FAQ).pdf.

84. "The Basics of SB 375," Institute for Local Government, last updated 2015, taken from https://www.ca-ilg.org/post/basics-sb-375.

85. "Strategies and Performance - Plan Bay Area 2040," MTC and ABAG, last updated 2019, taken from http://2040.planbayarea.org/strategies-and-performance.

86. "HIP Focus: Urban Centers," Puget Sound Regional Council, last updated 2020, taken from http://2040. planbayarea.org/strategies-and-performance.

87. "The Regional Transportation Plan - 2018: Executive Summary," Puget Sound 
Regional Council, last updated May 2018, taken from https://indd.adobe.com/view/ df641a93-6058-4f15-b1a0-67b4e7fa7128.

88. "California's 2017 Climate Change Scoping Plan - Executive Summary," California Air Resources Board, last updated November 2017, taken from https://ww3.arb.ca.gov/ cc/scopingplan/scoping_plan_2017_es.pdf.

89. "NYSDOT Implementation of the Smart Growth Public Infrastructure Policy Act (SGPIPA)," New York DOT, last updated 2016, taken from https://www.dot.ny.gov/ programs/smart-planning/smartgrowth-law.

90. "Section 6-0107: State smart growth public infrastructure criteria," New York State Senate, taken from https://www.nysenate.gov/legislation/laws/ENV/6-0107.

91. "Transit Oriented Development Strategy - Phoenix Metropolitan Region," Maricopa Association of Governments and Valley Metro, last updated March 24, 2014, taken from https://www.valleymetro.org/sites/default/files/uploads/event-resources/ maricopa_association_of_governments_tod_strategy.pdf.

92. Ibid.

93. "Agenda Report," City of San Mateo, last updated May 20, 2019, taken from https:// sanmateo.primegov.com/meeting/document/502.pdf?name=Agenda\%20Report.

94. "MKE United," Greater Milwaukee Committee, last updated 2018, taken from https:// www.gmconline.org/mke-united.

95. "Equitable Growth Through Transit Oriented Development," City of Milwaukee, last updated 2020, taken from https://city.milwaukee.gov/Plans/MovingMKEForward\#. XoLc2S2ZNQJ.

96. "TOD Zoning Best Practices," Port Authority, last updated 2017, taken from https:// www.portauthority.org/inside-Port-Authority/projects-and-programs/transit-orientedcommunities/tod-zoning-best-practices/.

97. "Landscape Conservation and Local Infrastructure Program," Forterra, last updated 2013, taken from https://forterra.org/service/lclip-landscape-conservation-and-localinfrastructure-program.

98. "Senate Bill 5253: Tax Increment Financing - Local Infrastructure Project Areas," Washington State Senate, last updated July 22, 2011, taken from http://lawfilesext. leg.wa.gov/biennium/2011-12/Pdf/Bills/Session\%20Laws/Senate/5253-S.SL.pdf.

99. "Infill Infrastructure Grant Program (IIGP)," California Department of Housing and Community Development, last updated 2020, taken from https://www.hcd.ca.gov/ grants-funding/active-funding/iigp.shtml\#purpose. 
100. "Affordable Housing and Sustainable Communities Program (AHSC)," California Department of Housing and Community Development, last updated 2020, taken from https://www.hcd.ca.gov/grants-funding/active-funding/ahsc.shtml.

101. "Understanding Proposition 218," California Legislative Analyst's Office, last updated December 1996, taken from https://lao.ca.gov/1996/120196_prop_218/ understanding_prop218_1296.html.

102. "Assembly Bill 3194: Housing Accountability Act - ProjectApproval," Daly, last updated August 28, 2018, taken from https://leginfo.legislature.ca.gov/faces/billTextClient. xhtml?bill_id=201720180AB3194.

103. "What is Development Review?" Boston Planning \& Development Agency, last updated 2020, taken from http://www.bostonplans.org/projects/development-review/ planned-development-areas.

104. "Multi-Unit Property Tax Exemption," City of Eugene, last updated 2019, taken from https://www.eugene-or.gov/829/Multi-Unit-Property-Tax-Exemption.

105. "Senate Bill 136: Transportation Reinvestment Zones," Zions Public Finance, Inc., last updated June 2019, taken from https://wfrc.org/Publiclnvolvement/ GovernmentalAffairs/SB136/TRZWhitePaperFinal.pdf.

106. “TRID (Transit Revitalization Investment District) Planning," Delaware Valley Regional Planning Commission, last updated 2017, taken from https://www.dvrpc.org/TRID/.

107. "Act No. 2004-238: Transit Revitalization Investment District Act," Pennsylvania General Assembly, last updated 2004, taken from https://www.dvrpc.org/TRID/pdf/1TRIDAct-2004.pdf.

108. "Why aren't TRIDs working?" Anthony Campisi, last updated January 20, 2011, taken from https://whyy.org/articles/why-arent-trids-working/.

109. “TRID (Transit Revitalization Investment District) Planning," Delaware Valley Regional Planning Commission, last updated 2017, taken from https://www.dvrpc.org/TRID/.

110."RCW 36.57A.080: General Powers," Washington State Legislature, last updated 1975, taken from https://app.leg.wa.gov/RCW/default.aspx?cite=36.57A.080.

111. "Southern Nevada Strong Steering Committee," Regional Transportation Commission, last updated 2020, taken from https://www.rtcsnv.com/about/meetings-agendas/ southern-nevada-strong-steering-committee/.

112. Robert Cervero, Transit-oriented development in the United States: Experiences, challenges, and prospects (Transportation Research Board, Vol. 102, 2004).

113."Census Regions and Divisions of the United States," U.S. Census Bureau, no date, 
taken from https://www2.census.gov/geo/pdfs/maps-data/maps/reference/us_regdiv. pdf.

114."Othello East," Mercy Housing, updated 2012. https://www.mercyhousing.org/ northwest/othello-east/.

115."Mercy Housing Northwest celebrates the start of construction of Mercy Othello Plaza-108 family rental homes in Rainier Valley". Taken from https://www. mercyhousing.org/2016/02/mercy-housing-northwest-celebrates-the-start-ofconstruction-of-mercy-othello-plaza-108-family-rental-homes-in-rainier-valley/.

116.Zach Shaner, "108 Affordable Housing Apartments Come to Othello Station," Sound Transit (2017), taken from https://www.soundtransit.org/blog/platform/108-affordableapartments-come-othello-station.

117. "Othello Station," SoundTransit, updated 2019. https://www.soundtransit.org/ridewith-us/stations/link-light-rail-stations/othello-station.

118. “Link Light Rail Regional Map,” SoundTransit, updated 2019. Taken from http://benjo. parkersydnorhistoric.org/seattle-light-rail-map-airport-to-downtown/seattle-futurelight-rail-transit-maps-posters-by.html.

119."Route 106," King County Metro, updated September 20, 2019. Taken from https:// kingcounty.gov/depts/transportation/metro/schedules-maps/route/106.aspx\#routemap.

120. Strategic Plan, Sound Transit TOD Program (Seattle, WA: SoundTransit, 2012.)

121. Ibid.

122. Ibid.

123. "Mercy Othello TOD," Ankrom Moisan Architects, updated 2018, https://www. ankrommoisan.com/project/mercy-othello-tod/discipline/transit-orienteddevelopment-hit.

124. "Othello East," Mercy Housing, updated 2012. https://www.mercyhousing.org/ northwest/othello-east/.

125. Othello Town Center Urban Design Framework, (Seattle, WA: City of Seattle Department of Planning and Development, 2011).

126. Ibid

127. High Capacity Transportation Systems 1992 (WA 81.104). Taken from https://app. leg.wa.gov/rcw/default.aspx?cite=81.104\&full=true. 
128. Regional Transit Authorities 1992. (WA 81.112). Taken from https://app.leg.wa.gov/ RCW/default.aspx?cite=81.112.

129. Resolution No. R2013-30: Real Property Excess, Surplus, and Disposition Policy. Taken from https://www.soundtransit.org/st_sharepoint/download/sites/PRDA/ FinalRecords/2013/Resolution\%20R2013-30.pdf

130. Resolution No. R2018-10: Adopting an Equitable Transit Oriented Development Policy. Taken from https://www.soundtransit.org/st_sharepoint/download/sites/ PRDA/FinalRecords/2018/Resolution\%20R2018-10.pdf

131. Ibid.

132. Transit-oriented development strategy system plan-RequirementsDefinitions-Quarterly reports. Taken from https://app.leg.wa.gov/RCW/default. aspx?cite $=81.112 .350$

133. "SoundTransit 3," SoundTransit, updated 2016, http://soundtransit3.org/documentlibrary.

134. Ibid.

135. Community Cornerstones A new model for development in Southeast Seattle: A study and proposal for an Equitable Transit-Oriented Development Loan Program. Taken from http://clerk.seattle.gov/ public/meetingrecords/2013/cerrr20130416_4a.pdf.

136. Motion No. M2014-92: Agreement of Cooperation between Sound Transit, the City of Seattle, MHNW 9 Othello East LP and Mercy Housing Northwest for the development of Myrtle Street Apartments, a TOD, at Othello Station. Taken from https:// www.soundtransit.org/st_sharepoint/download/sites/PRDA/FinalRecords/2014/ Motion\%20M2014-92.pdf.

137. Motion No. M2014-89: Mercy Housing Northwest Transit-Oriented Development Purchase and Sale Agreement. Taken from https://www.soundtransit.org/st_ sharepoint/download/sites/PRDA/FinalRecords/2014/Motion\%20M2014-89.pdf.

138. Community Cornerstones A new model for development in Southeast Seattle: A study and proposal for an Equitable Transit-Oriented Development Loan Program. Taken from http://clerk.seattle.gov/ public/meetingrecords/2013/cerrr20130416_4a.pdf.

139. Motion No. M2014-92: Agreement of Cooperation between Sound Transit, the City of Seattle, MHNW 9 Othello East LP and Mercy Housing Northwest for the development of Myrtle Street Apartments, a TOD, at Othello Station. Taken from https:// www.soundtransit.org/st_sharepoint/download/sites/PRDA/FinalRecords/2014/ Motion\%20M2014-92.pdf.

140. Ibid. 
141. "Overview: Facts about the Greater Cleveland RTA," Greater Cleveland Regional Transit Authority, last modified 2019, http://www.riderta.com/overview.

142. "W. 65 - Lorain Rapid Station," Greater Cleveland Regional Transit Authority, last modified 2019, http://www.riderta.com/facilities/w65.

143. "Climate and Sustainability Action in Detroit Shoreway EcoVillage," Center for Neighborhood Technology, last modified October 23, 2013, taken from https:// d3n8a8pro7vhmx.cloudfront.net/sustainablecleveland/pages/149/attachments/ original/1462884616/EcoVillage_Climate_and_Sustainability.pdf?1462884616.

144. "RTA 2018 System Map," Greater Cleveland Regional Transit Authority, last modified 2018, http://www.riderta.com/sites/default/files/pdf/maps/System_Map_Main.pdf.

145. "Cleveland EcoVillage," Detroit Shoreway Community Development Organization, last modified 2019, https://www.dscdo.org/cleveland-ecovillage.

146. "Climate and Sustainability Action in Detroit Shoreway EcoVillage," Center for Neighborhood Technology, last modified October 23, 2013, taken from https:// d3n8a8pro7vhmx.cloudfront.net/sustainablecleveland/pages/149/attachments/ original/1462884616/EcoVillage_Climate_and_Sustainability.pdf?1462884616.

147. Ibid.

148. "Climate and Sustainability Action in Detroit Shoreway EcoVillage," Center for Neighborhood Technology, last modified October 23, 2013, taken from https:// d3n8a8pro7vhmx.cloudfront.net/sustainablecleveland/pages/149/attachments/ original/1462884616/EcoVillage_Climate_and_Sustainability.pdf?1462884616.

149. "Detroit Shoreway Master Plan Update 2016," Detroit Shoreway Community Development Organization, last modified 2016, https://static1.squarespace.com/ static/5a906218cef372c749c9dae7/t/5bbfc1fe4785d399c10691da/1539293697782/ ds_masterplan_2016_map.pdf.

150. Wendy Kellogg and W. Dennis Keating, "Cleveland's EcoVillage: Green and Affordable Housing Through a Network Alliance," Housing Policy Debate 21 (2011): 69-91.

151. Cleveland EcoVillage," Detroit Shoreway Community Development Organization, last modified 2019, https://www.dscdo.org/cleveland-ecovillage.

152. Wendy Kellogg and W. Dennis Keating, "Cleveland's EcoVillage: Green and Affordable Housing Through a Network Alliance," Housing Policy Debate 21 (2011): 69-91.

153. "Bridge Square Townhomes," Fiorilli Construction, last modified 2018, http://fio-con. $\mathrm{com} /$ project/bridge-square-townhomes/.

154. "Waverly Station," High Rises, last modified 2020, https://www.highrises.com/ 
cleveland/waverly-station-condos/.

155. "Green Cottages," The Project Group, last modified 2010, http://theprojectgroup.net/ project-manager-2/green-cottages.

156. "EcoVillage's very green, small house," Green City Blue Lake, last modified 2013, https://www.gcbl.org/files/resources/ecovillagesverygreensmallhouse.pdf.

157. Perkins, Olivera, "Homeowner happy she doesn't own land under her house: a look at community land trusts," Cleveland.com, last updated January 12, 2019, https:// www.cleveland.com/business/2014/04/homeowner_likes_happy_she_does.html.

158. Hansen, Kristin, "Can Cleveland bring itself back from the brink?" Grist.org, last modified May 16, 2008, https://grist.org/article/cleveland/.

159. "Avery, very, very small house," Lydia Coutré, Crain's Cleveland Business, last modified 2016, https://www.crainscleveland.com/article/20160918/NEWS/160919856/a-veryvery-very-small-house.

160. "Tiny-house trend builds momentum in Cleveland, with Detroit Shoreway project planned," Cleveland.com, last modified 2015, https://www.cleveland.com/ business/2015/05/tiny_house_trend_builds_moment.html.

161. Rice, Karin Connelly, "Aspen Place marks first new construction project for affordable housing in Detroit Shoreway," Fresh Water Cleveland, April 24, 2019, https://www. freshwatercleveland.com/breaking-ground/AspenPlace042419.aspx

162. "2018 Annual Report," Detroit Shoreway Community Development Organization, last updated 2018, https://static1.squarespace.com/static/5a906218cef372c749c9dae7/ t/5c94f8824192023ec16fc835/1553266825616/FINAL+2018+Annual+Report.pdf.

163. "Who We Are," Regional Transportation District, last updated 2019, https://www.rtddenver.com/who-we-are.

164. Ibid.

165. "Transit-Oriented Development," Regional Transportation District, last updated 2019, https://www.rtd-denver.com/projects/transit-oriented-development-projects.

166. "Next Ride," Regional Transportation District, last updated 2020, https://www.rtddenver.com/app/nextride/route/21?direction $=0$.

167. "Rail and Flatiron Flyer Map," Regional Transportation District, last updated 2019, https://www.rtd-denver.com/sites/default/files/image/2019-11/rail-fare-zonemap-2019.jpg.

168. "Rail and Flatiron Flyer Map," Regional Transportation District, last updated 2019, 
https://www.rtd-denver.com/sites/default/files/image/2019-11/rail-fare-zonemap-2019.jpg.

169. "Denver's Newest Transit Oriented Development Opens at Evans Rail Station," Christi Smith, Urban Land Conservancy, last updated August 30, 2013, https://www. urbanlandc.org/assets-investments/evans-station-lofts/tod-opens-at-evans-stationin-denver/.

170. "Evans Station Lofts," Echelon Property Group, last updated 2020, https://www. echelonrents.com/evans-station-lofts-denver-co/.

171. "Innovative Partnership Funds Transit-Oriented Housing in Denver," HUD.gov, last updated December 2012, https://archives.huduser.gov/scrc/sustainability/ newsletter_120612_3.html.

172. "Innovative Partnership Funds Transit-Oriented Housing in Denver," HUD.gov, last updated December 2012, https://archives.huduser.gov/scrc/sustainability/ newsletter_120612_3.html.

173. Lance Bross, "Transit Oriented Development and Affordable Housing: Analyzing the effect of economic, regulatory and advocacy factors on a developer's decision to include affordable housing in TODs in the Denver, Colorado region," University of Colorado (2014).

174. "Evans Station Area Plan," Community Planning \& Development, City of Denver, adopted October 12, 2009, https://www.denvergov.org/content/dam/denvergov/ Portals/646/documents/planning/Plans/Evans_Station_Area_Plan.pdf.

175. Lance Bross, "Transit Oriented Development and Affordable Housing: Analyzing the effect of economic, regulatory and advocacy factors on a developer's decision to include affordable housing in TODs in the Denver, Colorado region," University of Colorado (2014).

176. "Evans Station Area Plan," Community Planning \& Development, City of Denver, adopted October 12, 2009, https://www.denvergov.org/content/dam/denvergov/ Portals/646/documents/planning/Plans/Evans_Station_Area_Plan.pdf.

177. Lance Bross, "Transit Oriented Development and Affordable Housing: Analyzing the effect of economic, regulatory and advocacy factors on a developer's decision to include affordable housing in TODs in the Denver, Colorado region," University of Colorado (2014).

178. "History Washington Metropolitan Area Transit Authority," Metro, last updated 2018, https://www.wmata.com/about/history.cfm\#main-content.

179. "Metro System Map," Metro, last updated 2019, https://www.wmata.com/schedules/ maps/upload/2019-System-Map.pdf. 
180. "Twinbrook," Real Estate \& TOD, Metro, last updated 2020, https://www.wmata.com/ business/real-estate/Twinbrook-Real-Estate.cfm\#main-content.

181. "Twinbrook," Real Estate \& TOD, Metro, last updated 2020, https://www.wmata.com/ business/real-estate/Twinbrook-Real-Estate.cfm\#main-content.

182. "Twinbrook Sector Plan" Montgomery Planning, last updated June 26, 2019, https:// montgomeryplanning.org/planning/communities/area-2/twinbrook/.

183. "Twinbrook Sector Plan" Montgomery Planning, last updated June 26, 2019, https:// montgomeryplanning.org/planning/communities/area-2/twinbrook/.

184. Ibid.

185. Ibid.

186. “Twinbrook Sector Plan" Montgomery Planning, last updated June 26, 2019, https:// montgomeryplanning.org/planning/communities/area-2/twinbrook/.

187. "Rockville Pike Neighborhood Plan," City of Rockville, last updated August 1, 2016, https://www.rockvillemd.gov/DocumentCenter/View/16716/Rockville-Pike-Plan2016 ?bidld=.

188. "Joint Development," Real Estate \& TOD, Metro, last updated 2018, https://www. wmata.com/business/real-estate/about-joint-development.cfm.

189. "WMATA Joint Development Policies and Guidelines," Metro, last updated July 25, 2013, https://www.wmata.com/about/board/upload/Joint-DevelopmentPolicies-2013-07-25.pdf.

190. "Update to Metro's Joint Development Policies," Metro, last updated April 12, 2018, https://www.wmata.com/about/board/meetings/board-pdfs/upload/3A-JointDevelopment-Policies.pdf.

191. "Joint Development Policies," Metro, last updated April 2018, https://www.wmata.

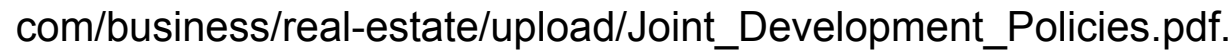

192. "Metro Electronic Action Document - 99075," Metro, last updated October 27, 2005, https://www.wmata.com/about/board/meetings/board-pdfs/upload/111705_ REBTwinbrook.pdf.

193. "Approve Amended Twinbrook JDA and Phase 1A Lease," Metro, last updated March 24, 2011, https://www.wmata.com/about/board/meetings/upload/032411_8D101059 TwinbrookUpdated.pdf.

194. Ibid. 
195. "Amendment to Twinbrook Joint Development Agreement," Metro, Planning, Program Development and Real Estate Committee, last updated April 11, 2013, https://www.wmata.com/about/board/meetings/board-pdfs/upload/041113_ TwinbrookJDApackage.pdf.

196. "Amendment to Twinbrook Joint Development Agreement," Metro, Planning, Program Development and Real Estate Committee, last updated April 11, 2013, https://www.wmata.com/about/board/meetings/board-pdfs/upload/041113_ TwinbrookJDApackage.pdf.

197. Ibid.

198. "BART: The Bay Area's Transportation Backbone," San Francisco Bay Area Rapid Transit District, last updated 2019, https://www.bart.gov/sites/default/files/ docs/2019\%20BARTFacts2019\%20FINAL.pdf.

199. "System Map," San Francisco Bay Area Rapid Transit District, last updated 2020, https://www.bart.gov/system-map.

200. "Transit-Oriented Development Policy," San Francisco Bay Area Rapid Transit District, adopted June 9, 2016, https://www.bart.gov/sites/default/files/docs/A-\%20BART\%20 TOD\%20Policy\%20Adopted\%206-9-16_0.pdf.

201. King, John, "At Home at BART," San Francisco Chronicle, last updated July 18, 2019, https://www.sfchronicle.com/bayarea/article/SF-Bay-Area-BART-stations-have-anew-draw-14100713.php.

202. Ibid.

203. King, John, "At Home at BART," San Francisco Chronicle, last updated July 18, 2019, https://www.sfchronicle.com/bayarea/article/SF-Bay-Area-BART-stations-have-anew-draw-14100713.php.

204. "MacArthur BART Transit Village Project (MacArthur Station)," City of Oakland, last updated 2019, https://www.oaklandca.gov/projects/macarthur-transit-villageproject\#page-timeline.

205. List of City Approvals for MacArthur BART Transit Village, City Council Ordinance No. 12883 C.M.S., Oakland City Council, July 2008, http://www2.oaklandnet.com/ oakca1/groups/ceda/documents/webcontent/oak036139.pdf.

206. "MacArthur BART Transit Village Project (MacArthur Station)," City of Oakland, last updated 2019, https://www.oaklandca.gov/projects/macarthur-transit-villageproject\#page-timeline.

207. "Master Plan," MacArthur Station, last updated 2019, http://macarthurstation.com/ masterplan.php. 
208. Pollack and Prater, Filling the Financing Gap for Equitable Transit-Oriented Development, Enterprise Community Partners and Low Income Investment Fund, April 2013, https://www.liifund.org/wp-content/uploads/2013/04/TOD-Report-03-2613-FINAL.pdf.

209. "At Home at BART," John King, July 18, 2019, SF Chronicle, https://www.sfchronicle. com/bayarea/article/SF-Bay-Area-BART-stations-have-a-new-draw-14100713.php.

210. Graham, Darwin Bond, "Oakland Planning Commission Approves 'Mammoth' Tower Next to MacArthur BART," East Bay Express, last updated February 2, 2017, https:// www.eastbayexpress.com/SevenDays/archives/2017/02/02/oakland-planningcommission-approves-mammoth-tower-next-to-macarthur-bart.

211. Hazheer, Yama, "90 New Affordable Housing Units Open at MacArthur BART Station," KRON4, last updated March 21, 2016, https://www.kron4.com/news/90new-affordable-housing-units-open-at-macarthur-bart-station/.

212. MacArthur Transit Village Parcel B, Oakland City Planning Commission, February 2017, https://cao-94612.s3.amazonaws.com/documents/ltem-7-1-Report.pdf.

213. King, John, "At Home at BART," San Francisco Chronicle, last updated July 18, 2019, https://www.sfchronicle.com/bayarea/article/SF-Bay-Area-BART-stations-have-anew-draw-14100713.php.

214. "The History of the T," Massachusetts Bay Transportation Authority, last updated 2019, https://www.mbta.com/history.

215. "Welcome to the MBTA," Massachusetts Bay Transportation Authority, last updated 2019, https://www.mbta.com/mbta-at-a-glance.

216. "MBTA Silver Line," NYCSubway.org, last updated 2012, https://www.nycsubway. org/wiki/MBTA_Silver_Line.

217. "2020 System Mab," Massachusetts Bay Transportation Authority, last updated 2020, https://cdn.mbta.com/sites/default/files/maps/2019-12-22-mbta-system-map-2020full.pdf.

218. Seaport Public Realm Plan 1999, (Massachusetts Port Authority, 1999), http://www. bostonplans.org/getattachment/5484e9d8-d985-4c6d-8e7f-4530845b78fc.

219. "Commonwealth Flats Takes Off: Development of S. Boston waterfront area sparks debate," Paul Restuccia, The Boston Herald, 2002, http://www.seaportalliance.org/ SAND/Archive/020706commflats.html.

220. "Maxx Private Investments, LLC. v. Drew/Core Development, LLC. et al.," Ralph Gants, J., 2008, https://cite.case.law/mass-law-rep/24/456/. 
221. "Second Notice of Project Change for Waterside Place Project, South Boston," Peter Meade, the Drew Company, 2011, http://www.bostonplans.org/getattachment/ a4d19c04-6a90-441a-ab74-f0d8910fbda7.

222. South Boston Waterfront Transportation Center, Notice of Project Change to the Air Rights Garage EEA \#8505 and Waterside Place EEA \#13367 (Massachusetts Port Authority, 2016), https://www.massport.com/media/2271/sbwtc_compiled_08152016. pdf.

223. "Second Notice of Project Change for Waterside Place Project, South Boston," Peter Meade, the Drew Company, 2011, http://www.bostonplans.org/getattachment/ a4d19c04-6a90-441a-ab74-f0d8910fbda7.

224. "The Development of Boston's Innovation District: A case study of cross-sector collaboration and public entrepreneurship," The Intersector Project, last updated 2017, http://intersector.com/wp-content/uploads/2015/10/The-Development-ofBostons-Innovation-District.pdf.

225. "Fourth Notice of Project Change for Waterside Place Project South Boston," Brian Golden, the Drew Company, 2016, http://www.bostonplans.org/getattachment/ b1b60332-a378-4c76-9c4b-523e44b8a331.

226. "Gables Residential and Drew Company will open Gables Seaport in March - To be LEED Silver certified," Green Buildings, last updated, November 1, 2019, https:// nerej.com/gables-residential-drew-company-gables-seaport.

227. "Fourth Notice of Project Change for Waterside Place Project South Boston," Brian Golden, the Drew Company, 2016, http://www.bostonplans.org/getattachment/ b1b60332-a378-4c76-9c4b-523e44b8a331.

228. "Commercial Real Estate," Massachusetts Port Authority, last updated 2020, http:// www.massport.com/massport/business/real-estate/commercial-properties/.

229. "Waterside Place," The HYM Investment Group, LLC., last updated 2020, https:// www.hyminvestments.com/watersideplace.

230. Kate Cahalane, "Affordable Housing in Boston: A closer look at the role of a transportation agency in community building," last updated August, 2013, http://www. metrohousingboston.org/wp-content/uploads/2013/06/CahalaneReport.pdf.

231. "'Pioneer' Seaport developer John Drew launches Waterside Place," Greg Turner, last updated November 17, 2018, https://www.bostonherald.com/2012/06/26/pioneerseaport-developer-john-drew-launches-waterside-place/.

232. Palmer Jr., Thomas C., "Developer picked for waterfront retail center," Boston Globe, last updated February 11, 2004, http://www.seaportalliance.org/SAND/ Archive/040211massport.html. 
233. South Boston Waterfront Transportation Center, Notice of Project Change to the Air Rights Garage EEA \#8505 and Waterside Place EEA \#13367 (Massachusetts Port Authority, 2016), https://www.massport.com/media/2271/sbwtc_compiled_08152016. pdf.

234. Ibid.

235. Image taken from Google Images, https://cdngeneral.rentcafe.com/dmslivecafe/2/70 135/1OurCommunity_P1_Waterside.jpg?width=350.

236. List of City Approvals for MacArthur BART Transit Village, City Council Ordinance No. 12883 C.M.S., Oakland City Council, July 2008, http://www2.oaklandnet.com/ oakca1/groups/ceda/documents/webcontent/oak036139.pdf.

237. "Twinbrook Sector Plan" Montgomery Planning, last updated June 26, 2019, https:// montgomeryplanning.org/planning/communities/area-2/twinbrook/.

238. "Rockville Pike Neighborhood Plan," City of Rockville, last updated August 1, 2016, https://www.rockvillemd.gov/DocumentCenter/View/16716/Rockville-Pike-Plan2016 ?bidld=.

239. Motion No. M2014-92: Agreement of Cooperation between Sound Transit, the City of Seattle, MHNW 9 Othello East LP and Mercy Housing Northwest for the development of Myrtle Street Apartments, a TOD, at Othello Station. Taken from, https:// www.soundtransit.org/st_sharepoint/download/sites/PRDA/FinalRecords/2014/ Motion\%20M2014-92.pdf

240. Ibid.

241. Resolution No. R2013-30: Real Property Excess, Surplus, and Disposition Policy. Taken from

242. https://www.soundtransit.org/st_sharepoint/download/sites/PRDA/ FinalRecords/2013/Resolution\%20R2013-30.pdf

243. "Joint Development," Real Estate \& TOD, Metro, last updated 2018, https://www. wmata.com/business/real-estate/about-joint-development.cfm.

244. "VTA's BART Silicon Valley Phase II Extension Project," Santa Clara Valley TransportationAuthority, last updated September 20, 2019, taken from https://www.vta. org/sites/default/files/2019-10/2019-09-20\%20VTA\%20Board\%20Workshop\%20 Presentation_2SlidesPerPage_Reduced.pdf.

245. Shishir Mathur, "Impact of Heavy-rail-based Rapid Transit on House Prices: Evidence from the Fremont, CA, Warm Springs BART Extension Project," Journal of American Planning Education and Research (2020). 


\section{BIBLIOGRAPHY}

Anderegg, Jake, and Val Porter. 2019. "Summary of SB 34 Affordable Housing Modifications (4th Substitute)." ULCT.org. March 22. Accessed 2020. http://www. ulct.org/wp-content/uploads/sites/4/2019/03/Summary-of-SB-34-AffordableHousing-Modifications-4th-Substitute.pdf.

Ankrom Moisan Architects. 2018. Mercy Othello TOD. Accessed 2019. https://www. ankrommoisan.com/project/mercy-othello-tod/discipline/transit-orienteddevelopment-hit.

Arfeh, N., and Z. Lei. "The Analysis of Transit-Oriented Development (TOD) in Washington, D.C. and Baltimore Metropolitan Areas." Transportation Policy 32 (2014): 172-79.

Assembly Committee of Transportation. 2000. "Summary of Legislation 1999-2000, Paper 485." California Assembly. Accessed 2020. http://digitalcommons.law.ggu. edu/caldocs_assembly/485.

BART. 2019. "BART: The Bay Area's Transportation Backbone." BART.gov. Accessed 2020. https://www.bart.gov/sites/default/files/docs/2019\%20BARTFacts2019\%20 FINAL.pdf.

BART. 2020. "System Map." BART.gov. Accessed 2020. https://www.bart.gov/systemmap.

BART. 2020. "Transit-Oriented Development (TOD)." BART.gov. March 2. Accessed 2020. https://www.bart.gov/about/business/tod.

BART. 2017. "Transit-Oriented Development Guidelines." BART.gov. May. Accessed 2020. https://www.bart.gov/sites/default/files/docs/BART_ TODGuidelinesFinal2017_compressed.pdf.

Bedsworth, L., Hanak, and Kolko. 2011. "Driving Change: Reducing Vehicle Miles Travelled in California." Public Policy Institute of California. Accessed 2020. http:// www.ppic.org/content/pubs/report/R_211LBR.pdf.

Best, Best and Krieger. 2019. "Surplus Land Act Requirements Expand for Local Agencies." BBKLaw.com. October 15. Accessed 2020. https://www.bbklaw.com/ news-events/insights/2019/legal-alerts/10/surplus-land-act-requirements-expandfor-local-age.

Boston Planning \& Development Agency. 2020. "What is Development Review? Planned Development Area (PDA) Review." BostonPlans.org. Accessed 2020. http://www. bostonplans.org/projects/development-review/planned-development-areas.

Bross, Lance. 2014. "Transit Oriented Development and Affordable Housing: Analyzing 
the effect of economic, regulatory and advocacy factors on a developer's decision to include affordable housing in TODs in the Denver, Colorado region." PhD Thesis, Public Affairs, University of Colorado, Denver.

Build America Bureau. 2020. "Transportation Infrastructure Finance and Innovation Act (TIFIA)." Transportation.gov. April 3. Accessed 2020. https://www.transportation. gov/buildamerica/financing/tifia/transportation-infrastructure-finance-andinnovation-act-tifia.

Cahalane. 2013. Affordable Housing in Boston A closer look at the role of a transportation agency in community building. Report, Boston: Massport.

California Air Resources Board (ARB). 2016. "Potential State-Level Strategies to Advance Sustainable, Equitable Communities and Reduce Vehicle Miles of Travel (VMT)—for Discussion." ARB.CA.gov. Accessed 2020. https://ww3.arb.ca.gov/ cc/scopingplan/meetings/091316/potential\%20vmt\%20measures $\% 20$ for $\% 20$ discussion_9.13.16.pdf.

California Air Resources Board. 2017. "California's 2017 Climate Change Scoping Plan: Executive Summary." ARB.CA.gov. November. Accessed 2020. https://ww3.arb. ca.gov/cc/scopingplan/scoping_plan_2017_es.pdf.

California Air Resources Board. 2017. "Revised Quantification Methodology for the Strategic Growth Council Affordable Housing and Sustainable Communities Program: Greenhouse Gas Reduction Fund Fiscal Year 2016-17." ARB.CA.gov. Accessed 2020. https://ww3.arb.ca.gov/cc/capandtrade/auctionproceeds/sgc ahsc_finalrevisedqm_16-17.pdf.

California Department of Housing and Community Development. 2020. "Affordable Housing and Sustainable Communities Program (AHSC)." hcd.ca.gov. Accessed 2020. https://www.hcd.ca.gov/grants-funding/active-funding/ahsc.shtml.

California Department of Housing and Community Development. 2020. "Infill Infrastructure Grant Program (IIG)." hcd.ca.gov. Accessed 2020. https://www.hcd. ca.gov/grants-funding/active-funding/iigp.shtml\#purpose.

California Legislative Analyst's Office. 1996. "Understanding Proposition 218." LAO. CA.gov. December. Accessed 2020. https://lao.ca.gov/1996/120196_prop_218/ understanding_prop218_1296.html.

Caltrans. 2002. "Statewide Transit-Oriented Development Study Factors for Success in California." CalTrans. Accessed 2020. https://rosap.ntl.bts.gov/view/dot/38272/ dot_38272_DS1.pdf.

Campisi, Anthony. 2011. "Why aren't TRIDs working?" WHYY.org. January 20. Accessed 2020. https://whyy.org/articles/why-arent-trids-working/. 
Cantell, S. 2005. The Adaptive Reuse of Historical Industrial Buildings: Regulation Barriers, Best Practices and Case Studies. Blacksburg, VA: Virginia Polytechnic Institute and State University.

Center for Neighborhood Technology. 2013. "Climate and Sustainability Action in the Detroit Shoreway EcoVillage." October 23. Accessed 2020. https:// d3n8a8pro7vhmx.cloudfront.net/sustainablecleveland/pages/149/attachments/ original/1462884616/EcoVillage_Climate_and_Sustainability.pdf?1462884616.

Cervero, Robert. "Transit-oriented development in the United States: Experiences, challenges, and prospects." Transportation Research Board 102 (2004). Washington, DC.

Cervero, Robert, and John Landis. "Twenty years of the Bay Area Rapid Transit system: Land use and development impacts." Transportation Research Part A: Policy and Practice 31 (1997): 309-333.

Cervero, Robert, and Michael Duncan. "Transit's Value-Added Effects: Light and Commuter Rail Services and Commercial Land Values." Transportation Research Record 1805 (2002): 8-15.

Cervero, Robert, C. Ferrell, and S. Murphy. "Transit-Oriented Development and Joint Development in the United States: A Literature Review." Transportation Cooperative Research Program, Report 52 (2002). Washington, DC: Transportation Research Board.

Charlotte City Council. 2019. "Transit Oriented Development Districts." CharlotteUDO. org. April 15. Accessed 2020. https://charlotteudo.org/transit-orienteddevelopment/.

Chiland, Elijah. 2017. "Measure JJJ triggers new incentives to encourage affordable housing near transit." Curbed Los Angeles. March 14. Accessed 2020. https:// la.curbed.com/2017/3/14/14928306/los-angeles-incentives-affordable-housingtransit-jjj.

Chiu. 2017. "Senate Bill No. 167." California Legislative Information. September 29. Accessed 2020. https://leginfo.legislature.ca.gov/faces/billTextClient.xhtml?bill_ id=201720180SB167.

"City and County of Honolulu." TOD Honolulu, 2009. Accessed 2020. http://www. honolulu.gov/tod/dpp-tod-home.html.

City of Charlotte. 2019. "TRANSIT ORIENTED DEVELOPMENT ALIGNMENT REZONING GUIDE." CharlotteUDO.org. May. Accessed 2020. https:// charlotteudo.org/wp-content/uploads/2019/05/TOD_Alignment_Rezoning_Guide. pdf. 
City of Chicago. 2020. "Code of Ordinances Chapter 17-10-0100. General." Chicago-IL. elaws.us. Accessed 2020. http://chicago-il.elaws.us/code/coor_t17_ch17-10_ sec17-10-0100.

City of Eugene. 2019. "Multi-Unit Property Tax Exemption." Eugene-OR.gov. Accessed 2020. https://www.eugene-or.gov/829/Multi-Unit-Property-Tax-Exemption.

City of Milwaukee. 2020. "Equitable Growth Through Transit Oriented Development." City.Milwaukee.gov. Accessed 2020. https://city.milwaukee.gov/Plans/ MovingMKEForward\#.Xnr05y2ZM_U.

City of Oakland. 2019. "MacArthur BART Transit Village Project (MacArthur Station)." OaklandCA.gov. Accessed 2020. https://www.oaklandca.gov/projects/macarthurtransit-village-project\#page-timeline.

City of Phoenix. 2020. "Transit Oriented Development (TOD)." Phoenix.gov. Accessed 2020. https://www.phoenix.gov/pdd/tod.

City of Rockville. 2016. "Rockville Pike Neighborhood Plan." RockvilleMD.gov. August 1. Accessed 2020. https://www.rockvillemd.gov/DocumentCenter/View/16716/ Rockville-Pike-Plan-2016?bidld=.

City of Rockville. 2016. "Rockville Pike Neighborhood Plan." RockvilleMD.gov. August 1. Accessed 2020. https://www.rockvillemd.gov/DocumentCenter/View/16716/ Rockville-Pike-Plan-2016?bidld=.

City of San Carlos. 2015. "San Carlos 2030 General Plan." CityofSanCarlos.org. May 11. Accessed 2020. https://www.cityofsancarlos.org/home/showdocument?id=32.

City of San José. 2017. "Urban Villages." SanJoseCA.gov. Accessed 2020. https:// www.sanjoseca.gov/your-government/departments/planning-building-codeenforcement/planning-division/citywide-planning/urban-villages.

City of San Leandro. 2018. "Bay Fair TOD Specific Plan." SanLeandro.org. February 20. Accessed 2020. https://www.sanleandro.org/civicax/filebank/blobdload. aspx?blobid=28339.

City of San Mateo. 2019. "Agenda Report 2018 San Mateo Rail Corridor Transportation Management Association - Update." CityofSanMateo.org. May 20. Accessed 2020. https://www.google.com/url?sa=t\&rct=j\&q=\&esrc=s\&source=web\&cd=1\&ve $\mathrm{d}=2$ ahUKEwj134frhsToAhUMIKwKHdQNAjkQFjAAegQIAhAB\&url=https $\% 3 A \% 2 F$ $\% 2 F$ sanmateo.primegov.com\%2Fmeeting\%2Fdocument\%2F502.pdf\%3Fname\%3 DAgenda\%2520Report\&usg=AOvVaw31qTiV8pRsoYh8fBex9VUY.

City of San Mateo. 2020. "Rail Corridor Transit-Oriented Development." CityofSanMateo. org. Accessed 2020. https://www.cityofsanmateo.org/1899/Rail-Corridor-TransitOriented-Developme. 
City of Seattle Office of Housing. 2013. "Community Cornerstones A new model for development in Southeast Seattle: A study and proposal for an Equitable TransitOriented Development Loan Program." Clerk.Seattle.gov. January. Accessed 2020. http://clerk.seattle.gov/ public/meetingrecords/2013/cerrr20130416_4a.pd.

Community Planning \& Development. 2009. "Evans Station Area Plan." DenverGov.org. October 12. Accessed 2020. https://www.denvergov.org/content/dam/denvergov/ Portals/646/documents/planning/Plans/Evans_Station_Area_Plan.pdf.

Coutré, Lydia. 2016. "A very, very, very small house." Crain's Cleveland Business. Accessed 2020. https://www.crainscleveland.com/article/20160918/ NEWS/160919856/a-very-very-very-small-house.

Daly. 2018. "Assembly Bill No. 3194." Housing Accountability Act: project approval. August 28. Accessed 2020. https://leginfo.legislature.ca.gov/faces/billTextClient. xhtml?bill_id=201720180AB3194.

DART. 1989. "Transit Oriented Development Policy." Dart.org. October 24. Accessed 2020. https://dart.org/economicdevelopment/DARTTODPolicy.pdf.

Day, Linda. 2016. "A New Financing Tool for California: Enhanced Infrastructure Finance Districts." Planetizen. Accessed 2020. https://www.planetizen.com/node/88347/ new-financing-tool-california-enhanced-infrastructure-finance-districts.

Delaware Valley Regional Planning Commission. 2017. "TRID (Transit Revitalization Investment District) Planning." DVRPC.org. Accessed 2020. https://www.dvrpc. org/TRID/.

Department of Planning and Development. 2011. Othello Town Center Urban Design Framework. Seattle: Planning and Development.

Detroit Shoreway Community Development Organization. 2018. "2018 Annual Report." DSCDO.org. Accessed 2020. https://static1.squarespace. com/static/5a906218cef372c749c9dae7/t/5c94f8824192023ec16 fc835/1553266825616/FINAL+2018+Annual+Report.pd.

Detroit Shoreway Community Development Organization. 2019. "Cleveland EcoVillage." DSCDO.org. Accessed 2020. https://www.dscdo.org/cleveland-ecovillage.

Detroit Shoreway Community Development Organization. 2016. "Detroit Shoreway Master Plan Update 2016." Accessed 2020. https://static1.squarespace. com/static/5a906218cef372c749c9dae7/t/5bbfc1fe4785d399c10691 da/1539293697782/ds_masterplan_2016_map.pdf.

Dickerson. 2017. "SB 0783." Tennessee General Assembly. May 11. Accessed 2020. http://wapp.capitol.tn.gov/apps/Billinfo/default.aspx?BillNumber=SB0783\&ga=110. 
Dumbaugh, E. "Overcoming Financial and Institutional Barriers to TOD: Lindbergh Station Case Study." Journal of Public Transportation 7 (2004): 43-68.

Echelon Property Group. 2020. "Evans Station Lofts." EchelonRents.com. Accessed 2020. https://www.echelonrents.com/evans-station-lofts-denver-co/.

EPA. 2013. "Infrastructure Financing Options for Transit-Oriented Development." EPA.gov. Accessed August 23, 2019. https://www.epa.gov/sites/production/ files/2014-02/documents/infrastructure_financing_options_for_transit-oriented_ development.pdf.

Federal Transit Administration. 2018. "Chemehuevi Indian Tribe - Annual Agency Profile." Transit.dot.gov. Accessed 2020. https://www.transit.dot.gov/sites/fta.dot.gov/files/ transit_agency_profile_doc/2018/99316.pdf.

Federal Transit Administration. 2018. "National Transit Database." Transit.dot. gov. Accessed 2020. https://www.transit.dot.gov/sites/fta.dot.gov/files/docs/ ntd/117161/2018-ntd-reduced-policy-manual.pdf.

Federal Transit Administration. 2020. "NTD Data." Transit.dot.gov. Accessed 2020. https://www.transit.dot.gov/ntd/ntd-data.

Federal Transit Administration. 2019. "Pilot Program for Transit-Oriented Development Planning - Section 20005(b)." Transit.DOT.gov. Accessed 2020. https://www. transit.dot.gov/TODPilot.

Fiorilli Construction. 2018. Bridge Square Townhomes. Accessed 2020. http://fio-con. $\mathrm{com} /$ project/bridge-square-townhomes/.

Forterra. 2013. "Landscape Conservation and Local Infrastructure Program." Forterra. org. Accessed 2020. https://forterra.org/service/lclip-landscape-conservation-andlocal-infrastructure-program.

Frey, P. and R. Bowdon. 2012. "Historic Preservation: Expanding the Planner's Toolbox." American Planning Association PAS Memo.

Glaeser et al. 2006. "Regulation and the Rise of Housing Price in Greater Boston." Pioneer Institute for Public Policy Research and Rappaport Institute for Greater Boston.

Golden, Brian. 2016. "Fourth Notice of Project Change for Waterside Place Project South Boston." Boston Plans - The Drew Company. Accessed 2020. http://www. bostonplans.org/getattachment/b1b60332-a378-4c76-9c4b-523e44b8a331.

Google Images. 2020. "South Boston Rentals." Rent Cafe. Accessed 2020. https:// cdngeneral.rentcafe.com/dmslivecafe/2/70135/1OurCommunity_P1_Waterside. jpg? width=350. 
Grabar, Henry. 2014. "Part Land Bank, Part Community-Focused Credit Line." CityLab. December 5. Accessed 2020. https://www.citylab.com/equity/2014/12/part-landbank-part-community-focused-credit-line/383417/\#city-maker-embed-codebottom.

Graham, Darwin Bond. 2017. "Oakland Planning Commission Approves 'Mammoth' Tower Next to MacArthur BART." East Bay Express, February 2: https://www. eastbayexpress.com/SevenDays/archives/2017/02/02/oakland-planningcommission-approves-mammoth-tower-next-to-macarthur-bart.

Grants, J. Ralph. 2008. "Maxx Private Investments, LLC. v. Drew/Core Development, LLC. et al." Cite Case Law. Accessed 2020. https://cite.case.law/mass-lawrep/24/456/.

Greater Cleveland Regional Transit Authority. 2019. "Overview: Facts about the Greater Cleveland RTA." RideRTA.com. Accessed 2020. http://www.riderta.com/overview.

Greater Cleveland Regional Transit Authority. 2018. "RTA 2018 System Map." RideRTA. com. Accessed 2020. http://www.riderta.com/sites/default/files/pdf/maps/System_ Map_Main.pdf.

Greater Cleveland Regional Transit Authority. 2019. "W. 65 - Lorain Rapid Station." RideRTA.com. Accessed 2020. http://www.riderta.com/facilities/w65.

Greater Milwaukee Committee. 2018. "MKE United." gmconline.org. Accessed 2020. https://www.gmconline.org/mke-united.

Green Buildings. 2019. "Gables Residential and Drew Company will open Gables Seaport in March - to be LEED Silver certified." Nerej.com. November 1. Accessed 2020. https://nerej.com/gables-residential-drew-company-gables-seaport.

Green City Blue Lake. 2013. EcoVillage's very green, small house. Accessed 2020. https://www.gcbl.org/files/resources/ecovillagesverygreensmallhouse.pdf.

Hansen, Kristine. 2008. "Can Cleveland bring itself back from the brink?" Grist.org. May 16. Accessed 2020. https://grist.org/article/cleveland/.

Hazheer, Yama. 2016. "90 new affordable housing units open at MacArthur BART station." KRON4, March 21: https://www.kron4.com/news/90-new-affordablehousing-units-open-at-macarthur-bart-station/.

Hess, D., and P. Lombardi. 2004. "Policy Support for and Barriers to Transit-Oriented Development in the Inner-City: Literature Review." Transportation Research Record 1887 (2004): 26-33.

High Rises. 2020. Waverly Station. Accessed 2020. https://www.highrises.com/cleveland/ waverly-station-condos/. 
Housing and Urban Development. 2012. "Innovative Partnership Funds Transit-Oriented Housing in Denver." HUD.gov. December. Accessed 2020. https://archives. huduser.gov/scrc/sustainability/newsletter_120612_3.html.

HYM Investment Group, LLC. 2020. "Waterside Place." HYM Investments. Accessed 2020. https://www.hyminvestments.com/watersideplace.

Institute for Local Government. 2015. "The Basics of SB 375." CA-ILG.org. Accessed 2020. https://www.ca-ilg.org/post/basics-sb-375.

Kellog, Wendy, and W. Dennis Keating. 2011. "Cleveland's EcoVillage: Green and Affordable Housing Through a Network Alliance." Housing Policy Debate (21): 69-91.

King County Metro. 2019. "Route 106." King County. Accessed 2020. https://kingcounty. gov/depts/transportation/metro/schedules-maps/route/106.aspx\#route-map.

King, John. 2019. "At home at BART." San Francisco Chronicle, July 18: https://www. sfchronicle.com/bayarea/article/SF-Bay-Area-BART-stations-have-a-newdraw-14100713.php.

Land Bank Twin Cities. 2020. "Why Our Work Matters." Land Bank Twin Cities. Accessed 2020. http://www.landbanktwincities.org/why-our-work-matters/.

League of Minnesota Cities. 2019. "Special Assessment Toolkit." LMC.org. December 3. Accessed 2020. https://www.Imc.org/resources/special-assessment-toolkit/.

Los Angeles City Planning. 2016. "INITIATIVE ORDINANCE JJJ AFFORDABLE HOUSING AND LABOR STANDARDS FOR GENERAL PLAN AMENDMENTS AND ZONING CHANGES. INITIATIVE ORDINANCE." AllianceForCommunityTransit.org. November. Accessed 2020. http://www. allianceforcommunitytransit.org/wp-content/uploads/2017/03/MeasureJJJ_ FullText.pdf.

Los Angeles City Planning. 2018. "Transit Oriented Communities Affordable Housing Incentive Program Frequently Asked Questions and Answers." Planning.LACity. org. May 15. Accessed 2020. https://planning.lacity.org/odocument/87b0f2c28422-4767-a104-b7cd323ee26f/Transit-Oriented_Communities_-_Affordable_ Housing_Incentive_Program_(FAQ).pdf.

Louisville-Jefferson County Metropolitan Government. 2019. "Land Development Code." LouisvilleKY.gov. June. Accessed 2020. https://louisvilleky.gov/sites/default/files/ planning_design/land_development_code/c02metroapp_june2019.pdf.

Lynott, J., Zimmerman, and Happ. 2017. "Communities are Embracing Developments Near Transit: A Snap-Shot of Transit Oriented Development Support Across the United States." AARP Public Policy Institute. 
MacArthur Station. 2019. "Master Plan." MacArthurStation.com. Accessed 2020. http:// macarthurstation.com/masterplan.php.

Manville and Shoup. n.d. "Parking Requirements as a Barrier to Housing Development: Regulation and Reform in Los Angeles." University of California Transportation Center. Accessed 2020. http://escholarship.org/uc/item/1qr84990.

Manville, M. "Parking Requirements and Housing Development." Journal of the American Planning Association 79 (2013): 49-66.

Maricopa Association of Governments. 2014. "TRANSIT ORIENTED DEVELOPMENT STRATEGY Phoenix Metropolitan Region." ValleyMetro.org. March 24. Accessed 2020. https://www.valleymetro.org/sites/default/files/uploads/event-resources/ maricopa_association_of_governments_tod_strategy.pdf.

MARTA Board of Directors. 2010. "POLICIES FOR IMPLEMENTING MARTA'S TOD GUIDELINES." ITSMARTA.com. November. Accessed 2020. https://itsmarta.com/ uploadedFiles/More/Transit_Oriented_Development/MARTA-TOD-ImplementationPolicies-Adopted-Text-November-2010.pdf.

MARTA. 2020. "TOD + Real Estate + Art." ITSMARTA.com. Accessed 2020. https:// itsmarta.com/guidelines-policies.aspx.

Massachusetts Bay Transportation Authority. 2020. "2020 System Map." MBTA.com. Accessed 2020. https://cdn.mbta.com/sites/default/files/maps/2019-12-22-mbtasystem-map-2020-full.pdf.

Massachusetts Bay Transportation Authority. 2019. "The History of the T." MBTA.com. Accessed 2020. https://www.mbta.com/history.

Massachusetts Bay Transportation Authority. 2019. "Welcome to the MBTA." MBTA.com. Accessed 2020. https://www.mbta.com/mbta-at-a-glanc.

Massachusetts Port Authority. 2016. "Notice of Project Change to the Air Rights Garage EEA \#8505 and Waterside Place EEA\#13367." South Boston Waterfront Transportation Center. Accessed 2020. https://www.massport.com/media/2271/ sbwtc_compiled_08152016.pdf.

Massachusetts Port Authority. 1999. "Seaport Public Realm Plan 1999." BostonPlans.org. Accessed 2020. http://www.bostonplans.org/getattachment/5484e9d8-d985-4c6d$8 \mathrm{e} 7 \mathrm{f}-4530845 \mathrm{~b} 78 \mathrm{fc}$.

Massachussetts Port Authority. 2020. "Commercial Real Estate." Massport.com. Accessed 2020. http://www.massport.com/massport/business/real-estate/ commercial-properties/.

Mathur, Shishir. 2019. "Impact of an Urban Growth Boundary Across the Entire House 
Price Spectrum: The Two-Stage Quantile Spatial Regression Approach." Land Use Policy 80 (2019): 88-94.

Mathur, Shishir. 2020. "Impact of Heavy-Rail-Based Rapid Transit on House Prices:

Evidence from the Fremont, CA, Warm Springs BART Extension Project." Journal of Planning Education and Research.

Mathur, Shishir. 2014. Innovation in Public Transport Finance: Property Value Capture. Burlington, VT: Routledge.

Mathur, Shishir. "Use of Tax Increment Financing to Fund Public Transportation: Enabling Environment and Equity Impacts." Public Works Management and Policy 22 (2017): 201-225.

Mathur, Shishir, and Christopher Ferrell. "Measuring the Impact of Sub-Urban TransitOriented Developments on Single-Family Home Values." Transportation Research Part A: Policy and Practice 47 (2013): 42-55.

Meade, Peter. 2011. "Second Notice of Project Change for Waterside Place Project, South Boston." Boston Plans - The Drew Company. Accessed 2020. http://www. bostonplans.org/getattachment/a4d19c04-6a90-441a-ab74-f0d8910fbda7.

Mercy Housing. 2016. Mercy Housing Northwest celebrates the start of construction of Mercy Othello Plaza-108 family rental homes in Rainier Valley. Accessed 2020. https://www.mercyhousing.org/2016/02/mercy-housing-northwest-celebrates-thestart-of-construction-of-mercy-othello-plaza-108-family-rental-homes-in-rainiervalleyl.

Mercy Housing. 2012. Othello East. Accessed 2020. https://www.mercyhousing.org/ northwest/othello-east/.

Metro - Real Estate \& TOD. 2018. “Joint Development.” WMATA.com. Accessed 2020. https://www.wmata.com/business/real-estate/about-joint-development.cfm.

Metro - Real Estate \& TOD. 2020. “Twinbrook.” WMATA.com. Accessed 2020. https:// www.wmata.com/business/real-estate/Twinbrook-Real-Estate.cfm\#main-content.

Metro. 2013. "Amendment to Twinbrook Joint Development Agreement." WMATA.com. April 11. Accessed 2020. https://www.wmata.com/about/board/meetings/boardpdfs/upload/041113_TwinbrookJDApackage.pdf.

Metro. 2011. "Approve Amended Twinbrook JDA and Phase 1A Lease." WMATA.com. March 24. Accessed 2020. https://www.wmata.com/about/board/meetings/upload/ 032411_8D101059TwinbrookUpdated.pdf.

Metro. 2018. "History Washington Metropolitan Area Transit Authority." WMATA.com. Accessed 2020. https://www.wmata.com/about/history.cfm\#main-content. 
Metro. 2018. "Joint Development - Real Estate \& TOD." WMATA.com. Accessed 2020. https://www.wmata.com/business/real-estate/about-joint-development.cfm.

Metro. 2018. "Joint Development Policies." WMATA.com. April. Accessed 2020. https:// www.wmata.com/business/real-estate/upload/Joint_Development_Policies.pdf.

Metro. 2005. "Metro Electronic Action Document - 99075." WMATA.com. October 27. Accessed 2020. https://www.wmata.com/about/board/meetings/board-pdfs/ upload/111705_REBTwinbrook.pdf.

Metro. 2019. "Metro Station Map." WMATA.com. Accessed 2020. https://www.wmata. com/about/history.cfm\#main-content.

Metro. 2018. "Update to Metro's Joint Development Policies." WMATA.com. April 12. Accessed 2020. https://www.wmata.com/about/board/meetings/board-pdfs/ upload/3A-Joint-Development-Policies.pdf.

Metro. 2013. "WMATA Joint Development Policies and Guidelines." WMATA.com. July 25. Accessed 2020. https://www.wmata.com/about/board/upload/JointDevelopment-Policies-2013-07-25.pdf.

Metropolitan Transportation Commission. 2005. "MTC Resolution 3434 Transit-Oriented Development (TOD)Policy for Regional Transit Expansion Projects." MTC.CA.gov. Accessed July 31, 2019. https://mtc.ca.gov/sites/default/files/Resolution\%20 3434\%20TOD_policy.pdf.

Mohammad, Sara, et al. "A meta-analysis of the impact of rail projects on land and property values." Transportation Research Part A: Policy and Practice 50 (2013): 158-170.

Montgomery Planning. 2019. "Twinbrook Sector Plan." MontgomeryPlanning.com. June 26. Accessed 2020. https://montgomeryplanning.org/planning/communities/area-2/ twinbrook/.

Montgomery Planning. 2019. "Twinbrook Sector Plan." Montgomery Planning. June 26. Accessed 2020. https://montgomeryplanning.org/planning/communities/area-2/ twinbrook/.

MTC/ABAG. 2019. "Strategies and Performance." 2040.PlanBayArea.org. Accessed 2020. http://2040. planbayarea.org/strategies-and-performance.

National Housing Conference. 2020. "Program Profiles." NHC.org. Accessed 2020. https://www.nhc.org/policy-guide/financing-the-early-costs-in-affordable-housingdevelopment/program-profiles-pdaif/.

New York State Department of Transportation. n.d. "NYSDOT Implementation of the Smart Growth Public Infrastructure Policy Act (SGPIPA)." Dot.ny.org. Accessed 
2020. https://www.dot.ny.gov/programs/smart-planning/smartgrowth-law.

New York State Senate. n.d. "Section 6-0107 State smart growth public infrastructure criteria." NYSenate.gov. Accessed 2020. https://www.nysenate.gov/legislation/ laws/ENV/6-0107.

NYCSubway. 2012. "MBTA Silver Line." NYCSubway.org. Accessed 2020. https://www. nycsubway.org/wiki/MBTA_Silver_Line.

Oakland City Council. 2008. "List of City Approvals for MacArthur BART Transit Village, City Council Ordinance No. 12883 C.M.S." OaklandNet.com. July. Accessed 2020. http://www2.oaklandnet.com/oakca1/groups/ceda/documents/webcontent/ oak036139.pdf.

Oakland City Council. 2008. "List of City Approvals for MacArthur BART Transit Village, No. 12883 C.M.S." Oaklandnet.com. July. Accessed 2020. http://www2. oaklandnet.com/oakca1/groups/ceda/documents/webcontent/oak036139.pdf.

Oakland City Planning Commission. 2017. "MacArthur Transit Village Parcel B." February 1. Accessed 2020. https://cao-94612.s3.amazonaws.com/documents/ltem-7-1Report.pdf.

Olshansky, Robert. 1996. "The California Environmental Quality Act and Local Planning." Journal of American Planning Association 62 (3): 313-330.

Page, Sasha, William Bishop, and Waiching Wong. "Guide to Value Capture Financing for Public Transportation Projects." Transit Cooperative Research Program Research Report 190 (2016).

Palmer, Thomas C. 2004. "Developer picked for waterfront retail center." The Boston Globe, February 11: http://www.seaportalliance.org/SAND/ Archive/040211massport.html.

Pennsylvania General Assembly. 2004. "Act 2004-238: Transit Revitalization Investment District Act." DVRPC. org. Accessed 2020. https://www.dvrpc.org/TRID/pdf/1TRIDAct-2004.pdf.

Perkins, Olivera. 2019. “Homeowner happy she doesn't own land under her house: A look at community land trusts." Cleveland.com. January 12. Accessed 2020. https:// www.cleveland.com/business/2014/04/homeowner_likes_happy_she_does.html.

Pollack, Melinda, and Brian Prater. 2013. Filling the Financing Gap for Equitable TransitOriented Development: Lessons from Atlanta, Denver, the San Francisco Bay Area and the Twin Cities. Report, Enterprise Community Partners \& Low Income Investment Fund.

Port Authority. 2017. "TOD Zoning Best Practices." PortAuthority.org. Accessed 2020. 
https://www.portauthority.org/inside-Port-Authority/projects-and-programs/transitoriented-communities/tod-zoning-best-practices/.

Port Authority. 2020. "TRANSIT-ORIENTED COMMUNITIES." PortAuthority.org. Accessed 2020. https://www.portauthority.org/inside-Port-Authority/projects-andprograms/transit-oriented-communities/.

PSRC. 2013. "Value Capture Financing in Washington." PSRC.org. Accessed 2020. https://www.psrc.org/sites/default/files/valuecapturefinancingreport113-printing. pdf.

Puget Sound Regional Council. n.d. "HIP Focus Area: Urban Centers." PSRC.org. Accessed 2020. https://www.psrc.org/focus-urban-centers.

Puget Sound Regional Council. 2018. "The Regional Transportation Plan - 2018: Executive Summary." PSRC.org. May. Accessed 2020. https://indd.adobe.com/ view/df641a93-6058-4f15-b1a0-67b4e7fa7128.

Reconnecting America. 2009. "Case Studies for Transit Oriented Development." Reconnecting America. Accessed April 8, 2020. http://www.liscphoenix.org/wpcontent/uploads/2015/10/Case-Studies-for-TOD.pdf.

Regional Plan Association. n.d. "Remove barriers to transit-oriented and mixed-use development." The Fourth Regional Plan. Accessed 2020. http://fourthplan.org/ action/tod.

Regional Transportation Authority. 2012. "Streamlining the Entitlement Process for Transit-Oriented Development: Best Practices Summary,." RTAChicago.org. Accessed 2020. https://www.rtachicago.org/sites/default/files/documents/ plansandprograms/landusetod/St.

Regional Transportation District. 2020. "Next Ride." RTD-Denver.com. Accessed 2020. https://www.rtd-denver.com/app/nextride/route/21?direction=0.

Regional Transportation District. 2019. "Rail and Flatiron Flyer Map." RTD-Denver.com. Accessed 2020. https://www.rtd-denver.com/sites/default/files/image/2019-11/railfare-zone-map-2019.jpg.

Regional Transportation District. 2019. "Transit-Oriented Development." RTD-Denver. com. Accessed 2020. https://www.rtd-denver.com/projects/transit-orienteddevelopment-projects.

Regional Transportation District. 2020. "UNIVERSITY OF COLORADO A LINE." RTD. Accessed 2020. https://www.rtd-denver.com/reports-and-policies/facts-figures/aline.

Regional Transportation District. 2019. "Who We Are." RTD-Denver.com. Accessed 2020. 
https://www.rtd-denver.com/who-we-are.

Renne, J., et al. 2011. "Transit-Oriented and Joint Development: Case Studies and Legal Issues." Transit Cooperative Research Program's Legal Research Digest 36.

Restuccia, Paul. 2002. "Commonwealth Flats Takes Off: Development of S. Boston waterfront area sparks debate." The Boston Herald, http://www.seaportalliance. org/SAND/Archive/020706commflats.html.

Rice, Karin Connelly. 2019. "Aspen Place marks first new construction project for affordable housing in Detroit Shoreway." FreshWaterCleveland.com. April 24. Accessed 2020. https://www.freshwatercleveland.com/breaking-ground/ AspenPlace042419.aspx.

Riggs, W., and F. Chamberlain. 2018. "The TOD and Smart Growth Implications of the LA Adaptive Reuse Ordinance." Sustainable Cities and Society 38: 594-606.

RTC. 2020. "Southern Nevada Strong Steering Committee." RTCSNV.com. January 30. Accessed 2020. https://www.rtcsnv.com/about/meetings-agendas/southernnevada-strong-steering-committee/.

RTD. 2020. "Transit-oriented Development." RTD-Denver.com. Accessed 2020. https:// www.rtd-denver.com/projects/transit-oriented-development-projects.

Schuetz, J., Guiliano, and Shin. "Does Zoning Help or Hinder Transit-Oriented (re) Development?" Urban Studies 55 (2018): 1672-1689.

SF BART District. 2016. "Transit-Oriented Development Policy." BART.gov. June 9. Accessed 2020. https://www.bart.gov/sites/default/files/docs/A-\%20BART\%20 TOD\%20Policy\%20Adopted\%206-9-16_0.pdf.

SF TOD Working Group. 2014. "Transit Oriented Development Roles and Responsibilities Survey Results: Technical Memorandum." SFRegionalCouncil. org. Accessed July 6, 2019. http://sfregionalcouncil.org/wp-content/ uploads/2017/01/TOD_RolesandResponsibilities_122314.pdf.

Shaner, Zach. 2017. "108 Affordable Housing Apartments Come to Othello Station." SoundTransit.org. July 7. Accessed 2020. https://www.soundtransit.org/blog/ platform/108-affordable-apartments-come-othello-station.

Shinkle, D. 2012. "Transit Oriented Developments in the States." National Conference of State Legislatures. Accessed 2020. http://www.ncsl.org/Documents/transportation/ TOD_Final.pdf.

Skinner. 2017. "Senate Bill No. 167." California Legislative Information. September 29. Accessed 2020. https://leginfo.legislature.ca.gov/faces/billTextClient.xhtml?bill_ id=201720180SB167. 
Smith, Christi. 2014. "Affordable Housing Development begins at Park Hill Village West." Urban Land Conservancy. August 22. Accessed 2020. https://www.urbanlandc. org/announcements/affordable-housing-park-hill-village-west-2/.

Smith, Christi. 2013. "Denver's Newest Transit Oriented Development Opens at Evans Rail Station.” UrbanLandC.org. August 30. Accessed 2020. Denver's Newest Transit Oriented Development Opens at Evans Rail Station.

Smith, J., T. Gihring, and T. Litman. 2009. "Financing Transit Systems through Value Capture: An annotated bibliography." Transport Policy.

Sound Transit. 2014. "Motion No. M2014-89: Mercy Housing Northwest Transit-Oriented Development Purchase and Sale Agreement." SoundTransit.org. Accessed 2020. https://www.soundtransit.org/st_sharepoint/download/sites/PRDA/ FinalRecords/2014/Motion\%20M2014-89.pdf.

Sound Transit. 2019. "Link Light Rail Regional Map." SoundTransit.org. Accessed 2020. http://benjo.parkersydnorhistoric.org/seattle-light-rail-map-airport-to-downtown/.

Sound Transit. 2014. "Motion No. M2014-92: Agreement of Cooperation between Sound Transit, the City of Seattle, MHNW 9 Othello East LP and Mercy Housing Northwest for the development of Myrtle Street Apartments, a TOD, at Othello Station." SoundTransit.org. Accessed 2020. https://www.soundtransit.org/st sharepoint/download/sites/PRDA/FinalRecords/2014/Motion\%20M2014-92.pdf.

Sound Transit. 2019. "Othello Station." SoundTransit.org. Accessed 2020. https://www. soundtransit.org/ride-with-us/stations/link-light-rail-stations/othello-station.

Sound Transit. 2013. "Resolution No. R2013-30: Real Property Excess, Surplus, and Disposition Policy." Accessed 2020. https://www.soundtransit.org/st_sharepoint/ download/sites/PRDA/FinalRecords/2013/Resolution\%20R2013-30.pdf.

Sound Transit. 2018. "Resolution No. R2018-10: Adopting an Equitable Transit Oriented Development Policy." Accessed 2020. https://www.soundtransit.org/st_sharepoint/ download/sites/PRDA/FinalRecords/2018/Resolution\%20R2018-10.pdf.

Sound Transit. 2016. "SoundTransit3." SoundTransit.org. Accessed 2020. http:// soundtransit3.org/document-library.

Sound Transit. Strategic Plan. Planning document, Seattle: Sound Transit, 2012.

Spokane Transit. 2019. "Connect Spokane: A Comprehensive Plan For Public Transportation." SpokaneTransit.com. Accessed 2020. https://www. spokanetransit.com/files/content/Connect_Spokane_Update_Final_5-22-19.pdf.

Sustainable Jersey. 2017. "Transit-Oriented Development Supportive Zoning." SustainableJersey.com. Accessed 2020. http://www.sustainablejersey. 
com/actions-certification/actions/?type $=1336777436 \&$ tx_sjcert action\%5BactionObject\%5D=522\&tx_sjcert_action\%5Baction\%5D=getPDF\&tx_ sjcert_action\%5Bcontroller\%5D=Action\&cHash=7d698135231866883a26b1 Ob76885025.

The Intersector Project. 2017. “The Development of Boston's Innovation District: A Case Study of Cross-Sector Collaboration and Public Entrepreneurship." Intersector. com. Accessed 2020. http://intersector.com/wp-content/uploads/2015/10/TheDevelopment-of-Bostons-Innovation-District.pdf.

The Partnership for Building Reuse. 2014. Building on Baltimore's History. Washington, DC: The National Trust for Historic Preservation.

The Project Group. 2010. Green Cottages. Accessed 2020. http://theprojectgroup.net/ project-manager-2/green-cottages.

Turner, Greg. 2018. "Pioneer Seaport developer John Drew launches Waterside Place." Boston Herald, November 17: https://www.bostonherald.com/2012/06/26/pioneerseaport-developer-john-drew-launches-waterside-place/.

US Census Bureau. n.d. "Census Regions and Divisions of the United States." Census. gov. Accessed 2020. https://www2.census.gov/geo/pdfs/maps-data/maps/ reference/us_regdiv.pdf.

US Department of Transportation. 2016. "The FAST Act: Increasing Transportation Choices and Opportunities." Transportation.gov. January 12. Accessed 2020. https://www.transportation.gov/fastact/opportunities-factsheet.

Utah Transit Authority. 2020. "Transit Oriented Development." RideUTA.com. Accessed 2020. https://www.rideuta.com/Doing-Business/Transit-Oriented-Development.

Valley Metro. 2019. "Station Profiles." ValleyMetro.org. Accessed 2020. https://www. valleymetro.org/station-profiles.

Valley Metro. 2019. "Transit Oriented Development." ValleyMetro.org. Accessed 2020. https://www.valleymetro.org/transit-oriented-development.

Valley Transit Authority. 2019. "VTA's BART Silicon Valley Phase II Extension Project." VTA.org. September 20. Accessed 2020. https://www.vta.org/sites/ default/files/2019-10/2019-09-20\%20VTA\%20Board\%20Workshop\%20 Presentation_2SlidesPerPage_Reduced.pdf.

Vantuono, William. 2018. "\$25.8 million for TOD: FTA." Railway Age. May 25. Accessed 2020. https://www.railwayage.com/news/25-8-million-for-tod-fta/.

Washington State Legislature. 1992. "High Capacity Transportation Systems 1992 (WA 81.104)." Accessed 2020. https://app.leg.wa.gov/rcw/default. 
aspx?cite $=81.104 \&$ full $=$ true.

Washington State Legislature. 1975. "RCW 36.57A.080: General Powers." App. Leg.WA.gov. Accessed 2020. https://app.leg.wa.gov/RCW/default. aspx?cite=36.57A.080.

Washington State Legislature. 1992. "Regional Transit Authorities." Accessed 2020. https://app.leg.wa.gov/RCW/default.aspx?cite=81.112.

Washington State Legislature. 2015. "Transit-oriented development strategy system plan-Requirements-Definitions-Quarterly reports." Accessed 2020. https://app. leg.wa.gov/RCW/default.aspx?cite=81.112.350.

Washington State Senate. 2011. "Senate Bill 5253: TAX INCREMENT FINANCING-LOCAL INFRASTRUCTURE PROJECT AREAS." LawFilesEXT.leg.wa.gov. July 22. Accessed 2020. http://lawfilesext.leg.wa.gov/biennium/2011-12/Pdf/Bills/ Session\%20Laws/Senate/5253-S.SL.pdf.

White, M. 1999. "The Zoning and Real Estate Implications of Transit-Oriented Development." Transportation Research Board. Washington, DC.

Wiener. 2017. "Senate Bill No. 35." California Legislative Information. September 29. Accessed 2020. https://leginfo.legislature.ca.gov/faces/billTextClient.xhtml?bill_ id=201720180SB35.

Yu, Haitao, Hao Pang, and Ming Zhang. 2017. "Value-Added Effects of Transit-Oriented Development: The Impact of Urban Rail on Commercial Property Values with Consideration of Spatial Heterogeneity." Regional Science 97 (2017): 1375-1396.

Zions Public Finance, Inc. 2019. "Utah State Senate Bill 136 - Transportation Reinvestment Zones." WFRC White Paper. June. Accessed 2020. https://wfrc.org/ PublicInvolvement/GovernmentalAffairs/SB136/TRZWhitePaperFinal.pdf. 


\section{ABOUT THE AUTHORS}

\section{SHISHIR MATHUR, PHD}

Dr. Shishir Mathur is a Professor of Urban and Regional Planning at San Jose State University. He served as Associate Dean of Research (College of Social Sciences) during 2016-2019. His research interests include transportation finance, urban and real estate economics, affordable housing policy, international development, infrastructure and development finance, and growth management. His research has been published in top-tier journals such as Transportation Research Part A, Transport Policy, Journal of Planning Education and Research, Urban Studies, Land Use Policy, Cities, and Habitat International. $\mathrm{He}$ is the author of two books: Understanding India's New Approach to Spatial Planning and Development: A Salient Shift? (Oxford University Press) and Innovation in Public Transport Finance: Property Value Capture (Routledge). Dr. Mathur has advised several international and national organizations. United Nations Human Settlements Programme, UN-HABITAT, sought his input on ways to encourage land based financing in Africa, Asia, and South America. He advised Federal Transit Administration on ways to encourage use of land value capture to fund transit-oriented developments and transit infrastructure.

\section{AARON GATDULA, MCP}

Aaron holds a Master's degree in City Planning from UC Berkeley's Department of City + Regional Planning. As a researcher, consultant, and advocate he is actively working towards climate resilience and justice in transportation and land use. $\mathrm{He}$ is experienced in GIS/mapping, TOD policy, community engagement, and design. Aaron is based in Chicago, IL. 


\section{PEER REVIEW}

San José State University, of the California State University system, and the Mineta Transportation Institute (MTI) Board of Trustees have agreed upon a peer review process required for all research published by MTI. The purpose of the review process is to ensure that the results presented are based upon a professionally acceptable research protocol. 


\section{MTI BOARD OF TRUSTEES}

Founder, Honorable

Norman Mineta*

Secretary (ret.),

US Department of Transportation

\section{Chair,}

Abbas Mohaddes

President \& $\mathrm{COO}$

Econolite Group Inc.

\section{Vice Chair,}

\section{Will Kempton}

Executive Director

Sacramento Transportation Authority

\section{Executive Director,}

Karen Philbrick, PhD*

Mineta Transportation Institute

San José State University

\section{Winsome Bowen}

Chief Regional Transportation

Strategy

Facebook

\section{David Castagnetti}

\section{Co-Founder}

Mehlman Castagnetti

Rosen \& Thomas

\section{Maria Cino}

Vice President

America \& U.S. Government

Relations Hewlett-Packard Enterprise

\author{
Grace Crunican** \\ Owner \\ Crunican LLC
}

\section{Donna DeMartino \\ Managing Director \\ Los Angeles-San Diego-San Luis \\ Obispo Rail Corridor Agency}

\section{Nuria Fernandez**}

General Manager \& CEO

Santa Clara Valley

Transportation Authority (VTA)

\section{John Flaherty}

Senior Fellow

Silicon Valley American

Leadership Form

\section{William Flynn * \\ President \& CEO \\ Amtrak}

\section{Rose Guilbault}

Board Member

Peninsula Corridor

Joint Powers Board

Ian Jefferies*

President \& CEO

Association of American Railroads
Diane Woodend Jones

Principal \& Chair of Board

Lea + Elliott, Inc.

David S. Kim*

Secretary

California State Transportation

Agency (CALSTA)

\section{Therese McMillan}

Executive Director

Metropolitan Transportation

Commission (MTC)

\section{Bradley Mims}

President \& CEO

Conference of Minority

Transportation Officials (COMTO)

Jeff Morales

Managing Principal

InfraStrategies, LLC

Dan Moshavi, PhD*

Dean, Lucas College and

Graduate School of Business

San José State University

Toks Omishakin*

Director

California Department of

Transportation (Caltrans)
Takayoshi Oshima

Chairman \& CEO

Allied Telesis, Inc.

Paul Skoutelas*

President \& CEO

American Public Transportation

Association (APTA)

Beverley Swaim-Staley

President

Union Station Redevelopment

Corporation

Jim Tymon*

Executive Director

American Association of

State Highway and Transportation

Officials (AASHTO)

\section{Larry Willis*}

President

Transportation Trades

Dept.,AFL-CIO

$*$ = Ex-Officio

$* *=$ Past Chair, Board of Trustees

\section{Directors}

\section{Karen Philbrick, PhD}

Executive Director

\section{Hilary Nixon, PhD}

Deputy Executive Director

\section{Asha Weinstein Agrawal, PhD}

\section{Education Director}

National Transportation Finance

Center Director

\section{Brian Michael Jenkins}

National Transportation Security

Center Director

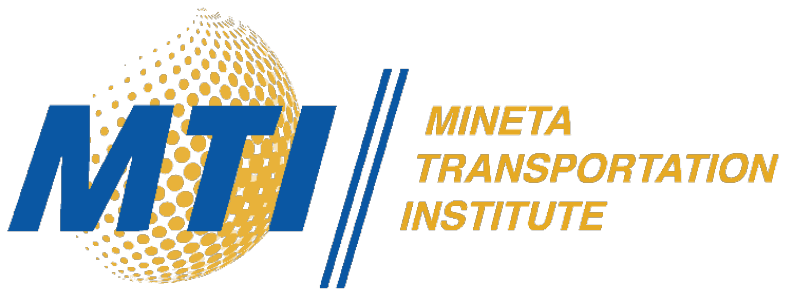

